\author{
Universidade de São Paulo \\ Instituto de Física
}

\title{
Análise FORC em Nanofios de Ni e Co e Excitação de Mágnons de Superfície em Filmes de O-Fe/W(001) via SPEELS
}

\section{Thiago Ribeiro Fonseca Peixoto}

Orientador: Prof. Dr. Daniel Reinaldo Cornejo

Tese apresentada ao Instituto de Física para a obtenção do grau de Doutor em Ciências.

Comissão Examinadora:

Prof. Dr. Daniel Reinaldo Cornejo (IFUSP)

Prof. Dr. Rafael Sá de Freitas (IFUSP)

Profa. Dra. Márcia Carvalho de Abreu Fantini (IFUSP)

Prof. Dr. Julian Geshev Penkov (UFRGS)

Prof. Dr. Antonio Azevedo da Costa (UFPE) 
FICHA CATALOGRÁFICA

Preparada pelo Serviço de Biblioteca e Informação do Instituto de Física da Universidade de São Paulo

Peixoto, Thiago Ribeiro Fonseca

Análise FORC em nanofios de $\mathrm{Ni}$ e Co e excitação de mágnons de superfície em filmes de O-Fe/w (001) via speels. São Paulo, 2010.

Tese (Doutorado) - Universidade de São Paulo. Instituto de Física - Depto. de Física Geral.

Orientador: Prof. Dr. Daniel Reinaldo Cornejo

\begin{tabular}{|l|}
\hline \multicolumn{2}{|c|}{ Área de Concentração: Física } \\
\hline Unitermos: 1. Magnetismo, 2. Fenômenos \\
3. Física do estado sólido; 4. Filmes finos. \\
USP/IF/SBI-054/2010 \\
\hline
\end{tabular}


A meus Pais

Fernando Teixeira Peixoto e

Sonia Rejane Ribeiro Fonseca Peixoto,

A meus Padrinhos

Francisco de Assis Dias Fonseca e

Maria José Peixoto,

A minha Avó

Maria Nativa Dias Fonseca (in memoriam)

Em homenagem ao

Professor Hercílio Rodolfo Rechenberg (in memoriam) 
"O tempo não é uma medida. Um ano não conta, dez anos não representam nada.

Ser artista não significa contar, é crescer como a árvore que não apressa a sua seiva e resiste, serena, aos grandes ventos da primavera, sem temer que o verão possa não vir. O verão há de vir. Mas só vem para aqueles que sabem esperar, tão sossegados como se tivessem na frente a eternidade."

Ranier Maria Rilke 


\section{Agradecimentos}

A meus pais e à minha família por todo apoio, sacrifício, incentivo, confiança e respeito às minhas escolhas.

Ao Professor Daniel Reinaldo Cornejo por sua segurança, competência e paciência no trabalho de orientação e pelo apoio, confiança, companheirismo e amizade durante todo o meu tempo em São Paulo e no LMM-IFUSP. Sou muito grato pela confiança e paciência empenhados na minha capacidade.

Aos membros da Banca Examinadora, por aceitarem o convite e se dedicarem à leitura crítica e avaliação do meu trabalho de doutorado e pelos valiosos conselhos, críticas e sugestões a este trabalho.

À Comissão de Pós-Graduação do IFUSP, em particular a Francisleine Mendes Rezina, Éber de Patto Lima, Cláudia Conde Barioni, Marina Sundfeld Pereira e Tais Cristina de Carvalho.

Aos Professores Hercílio Rechenberg (in memoriam), Antônio Domingues dos Santos (Toninho) e Carmen Partiti, pelo companheirismo e pela convivência agradável e prazerosa no LMM por todo o tempo que aqui estudei.

Aos colegas Renato Cohen, Sérgio Romero e Marcelo Lancarote, pela prestativa e dedicada colaboração em todas as dificuldades e necessidades da pesquisa no LMM e pela agradável convivência.

A Camilla Rodrigues Fossa, por todo carinho, apoio e companhia dedicados.

Franciane Azevedo e Hélio Scatena Júnior, pela sincera amizade, companheirismo e apoio nos momentos de celebração e de dificuldade.

Aos amigos do LMM: Charles Rocha da Silva, Fabiana Arantes, Leonardo Alonso, Lincoln, Gil, Gabriel, Mariana e aos "heróis" Jeconias, Jarleson e Damião Meira, com 
quem compartilhei tantos momentos célebres de discussões, incentivo e apoio, sendo, em algumas situações, motivadores do meu empenho acadêmico.

Aos amigos dos demais departamentos do IFUSP, em especial a Henrique dos Santos Guidi, Áttila Leães Rodrigues, Thomas Forster de la Fuente, o "Thominhas", Danilo Tonini, entre outros, pela amizade, apoio e companheirismo.

A todos os Professores do IFUSP que participaram direta ou indiretamente da minha formação acadêmica e me incentivaram e inspiraram à carreira científica de diferentes maneiras, em especial ao Prof. Sílvio Roberto de Azevedo Salinas e à Profa. Márcia Fantini.

A todos os Funcionários do DFMT, pela disposição e trabalho árduo dedicados diariamente ao Departamento, em especial a Rosana Gimenes, Tatiana Lacerda Costa Dejean e Iran Mamedes.

À CAPES e ao CNPq, pelo apoio financeiro.

\section{IN Deutschland:}

My most sincere thanks

To Professor Jürgen Kirschner and Professor Ulrich Gösele (in memoriam), for the unique opportunity of working in the Max Planck Institute of Microstructure Physics, in such a delightful environment and sharing a good time of new experieneces and learning good Physics.

To Prof. Marek Przybylski and Prof. Werner Keune for their so pleasant company and hospitality in the MPI-Halle.

To Dr. Monika Kaempfe and Miss Doreen Röder, for all their support and hospitality in the MPI.

To my dear colleagues Jacek Prokop, Yu Zhang, Khalil Zakeri and Wen-Xin Tang, for their constant help, collaboration and most enjoyable time at work. I learned a lot with you, guys.

To the "hard-core" gang, Nitin Shingne, Pratyush Das Kanungo, Uwe Bauer, Isabel Morgado, Vinicius Zoldan and, in special, to Katharina Tepper. 
To the funny lunchtime gang, Kuntala Bhattacharjee, Ramesh Thamankar, Fikret Yildiz, Xiao-Deng Ma and Yiqi Zhang.

To the Movie Night/No Mensa Day/Party/Fun gang, Pawel Buczek, Elke Eleczka, Guillemin Rodary, Karoline Sachse, Guntram Fischer, Nick Sedllmayr, Martyna Polok, Daniela Ivanova, Nadya Petrova, Oxana Rogova, Hossein Mirhosseini, Yeganeh Koye, Grant van Riessen, Kasia Michalak, Milton Muñoz Navia, Achiri Tange, Hirofumi and Mariko Oka, Sebastian Wedekind, Corina Etz, Fabio Donati, Somendra Parihar, Parul Singh and Orlando Pando.

To the colleagues from MPI, Chun-Lei Gao, Dahai Wei, Cheng-Tieng Chiang, Oleg Mironets, Ionela Vrejoiu, Maria Torres, Hilmar Straube, Seung Mo Lee, Balaji Birajdar, Anuj Chopra, Vijay Singh, Oussama Moutanabir, Brian and Claudia Rodriguez and many others.

Meine herzliche Danke zur Frau Violetta Neuber, unsere Deustchspracheslehrerin, und allen vom Deutschkurs.

To the Administration staff, for their hospitality and their good work in the MPI.

To all colleagues in MPI-Halle for their hospitality.

A América Cantarino e Rafael Block Veras pela hospitalidade e amizade dedicadas durante minha estadia em Halle.

Und besonders zu meinen guten Freunden aus Halle, Sandra Schäfer, Sven Gründler, Birte Rudolf, Torsten Kokot und Amadeus Aurin, die mich so gern in ihrem Freundeskreis aufgenommen haben. 


\section{Resumo}

Estudamos o comportamento estático e os mecanismos de inversão da magnetização de arranjos auto-organizados de nanofios de $\mathrm{Ni}$ e $\mathrm{Co}$ com alta anisotropia de forma. Os arranjos são obtidos a partir da anodização em dois passos de lâminas de Al e subseqüente eletrodeposição do metal magnético. Sua caracterização estrutural é realizada por microscopia eletrônica de varredura, microscopia de força atômica e magnética e difração de raios X. Seu comportamento magnético é estudado a partir da medida de curvas de inversão de primeira ordem (FORCs) a temperatura ambiente, via magnetometria SQUID ou de amostra vibrante. A análise FORC consiste na construção de uma mapa da resposta magnética do material a partir dos dados experimentais e pode ser interpretado a partir da analogia direta com o modelo de histerese de Preisach. Apresentamos resultados da influência dos diâmetros dos nanofios e do ângulo do campo externo aplicado em relação ao eixo de anisotropia sobre as principais características dos diagramas FORC.

Estudamos também a dinâmica de spins em superfícies de O-Fe/W(001) através de espectroscopia por perda de energia de elétrons spin-polarizados (SPEELS). As amostras consistem em 30 monocamadas atômicas de Fe crescidas sobre um monocristal de W(001), via epitaxia por feixe molecular a temperatura ambiente. Subseqüentemente, a amostra é exposta a 5 langmuirs de $\mathrm{O}_{2}$ e sofre um suave annealing a $500 \mathrm{~K}$. A estrutura e a pureza da amostra são analisadas por difração de elétrons de baixas energias e espectroscopia de elétrons Auger. A caracterização magnética é realizada por magnetometria por efeito Kerr magneto-óptico, resultando num filme com alta magnetização remanente no plano. Os espectros de SPEELS revelam uma rica profusão de picos inelásticos tipo spin-flip e nãospin-flip, que exibem clara dispersão ao longo de toda a zona de Brillouin de superfície. Os resultados são atribuídos a modos de superfície de fônons e mágnons (ondas de spin), de acordo com resultados da literatura e com modelos teóricos atuais. 


\section{Abstract}

We study the static behavior and the mechanisms of magnetization reversal of arrays of self-organized Ni and Co nanowires with high shape anisotropy. The arrays are obtained by two-step anodization of $\mathrm{Al}$ foils and subsequent electrodeposition of the magnetic metal. Their structural characterization is obtained by scanning electron microscopy, atomic and magnetic force microscopy and X-ray diffraction. Their magnetic behavior is studied from the measurement of first order reversal curves (FORCs) at room temperature, via SQUID or vibrating sample magnetometry. The FORC analysis method consists in building a map of the magnetic response of the material from the experimental data and it can be interpreted from the direct analogy with the Preisach model of hysteresis. We present results of the influence of the diameter of the nanowires and the angle of the applied external field in relation to the anisotropy easy-axis on the main features of the FORC diagrams.

We also study the spin dynamics of O-Fe/W(001) surfaces through spin-polarized electron energy loss spectroscopy (SPEELS). The samples consist of 30 atomic monolayers of Fe grown on a W(001) single crystal via molecular beam epitaxy at room temperature. Subsequently, the samples are exposed to 5 langmuirs of $\mathrm{O}_{2}$ and suffer a mild annealing at $500 \mathrm{~K}$. The structure and purity of the samples are analyzed by low-energy electron diffraction and Auger electron spectroscopy. The magnetic characterization is performed by magneto-optical Kerr effect magnetometry, resulting in films with high remanent in-plane magnetization. SPEEL-spectra reveal a rich profusion of inelastic spinflip and non-spin-flip peaks, which exhibit clear dispersion for wave vectors throughout the whole surface Brillouin zone. The results are attributed to surface modes of phonons and magnons (spin waves), in accordance with the literature and with current theoretical models. 


\section{Índice}

$\begin{array}{ll}\text { Agradecimentos } & \text { i }\end{array}$

Resumo iv

$\begin{array}{lll}\text { Abstract } & \text { v }\end{array}$

1 Introdução 1

1.1 Estrutura da Tese . . . . . . . . . . . . . . . . 3

2 Revisão Bibliográfica $\quad 6$

2.1 Propriedades Físicas de Arranjos de Nanofios Magnéticos . . . . . . . . 6

2.1.1 Anodização em Dois Passos . . . . . . . . . . . . . . 10

2.1.2 Eletrodeposição . . . . . . . . . . . . . . . . . 15

2.1.3 Microestrutura dos Arranjos de Nanofios de Fe, Co e Ni . . . . . . 22

2.1.4 Micromagnetismo de Nanofios Magnéticos . . . . . . . . . . . 29

2.1.5 Ciclos Internos e Curvas de Inversão de Primeira Ordem (FORCs) • 39

2.1.6 A Análise FORC e o Modelo de Preisach . . . . . . . . . . . . 43

2.2 Dinâmica de Spins em Filmes Finos Magnéticos . . . . . . . . . . 54

2.2.1 Técnicas e Métodos em Física de Superfícies . . . . . . . . . 57

2.2.2 Espectroscopia por Perda de Energia de Elétrons Spin-Polarizados

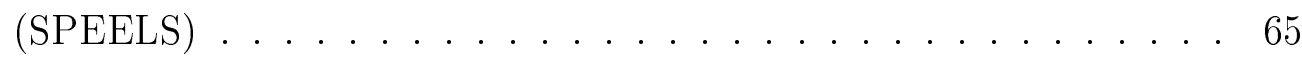

3 Arranjos Auto-Organizados de Nanofios Magnéti- 
3.1 Preparação e Caracterização Estrutural das Amostras . . . . . . . 77

3.1.1 Microscopia Eletrônica de Varredura . . . . . . . . . . . . . . 79

3.1 .2 Microscopias de Força Atômica e Força Magnética . . . . . . . . . . 93

3.1.3 Análise Morfológica do Arranjo de Poros . . . . . . . . . . . . 95

3.1.4 Difratometria de Raios X . . . . . . . . . . . . . . . . . . . 102

3.2 Caracterização Magnética . . . . . . . . . . . . . . . . 109

3.2 .1 Curvas de Magnetização . . . . . . . . . . . . . . . . . 110

3.2 .2 Análise FORC . . . . . . . . . . . . . . . . . . . . 111

3.3 Resultados e Discussão . . . . . . . . . . . . . . . . . . . . 113

4 Excitações de Superfície em Filmes Finos de O$\mathrm{Fe} / \mathrm{W}(001)$

4.1 Sistema de Ultra-Alto Vácuo (UHV) . . . . . . . . . . 138

4.2 Preparação e Caracterização de Filmes de $\mathrm{O}-\mathrm{Fe} / \mathrm{W}(001) \ldots . .140$

4.2.1 Estrutura e Morfologia . . . . . . . . . . . . . . . . . . . . 143

4.2 .2 Magnetismo . . . . . . . . . . . . . . . . 146

4.3 Resultados e Discussão . . . . . . . . . . . . . . . . . . . . . . . 149

5 Conclusões e Perspectivas 158

A Algoritmo Desenvolvido para o Cálculo da Distribuição FORC

B Lista de Publicações

165

Referências bibliográficas

168 


\section{Lista de Figuras}

2.1 Exemplo do perfil da corrente elétrica através da célula eletrolítica durante a primeira (linha sólida) e segunda (linha pontilhada) anodizações [32]. Os três diferentes regimes de corrente marcam (1) o crescimento da camada de barreira, (2) o início da formação dos poros e (3) o crescimento estacionário da camada

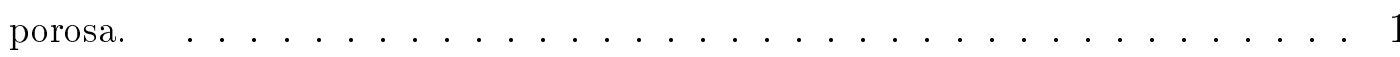

2.2 Esquema pictórico do gradiente do campo elétrico durante a anodização. Após a formação da camada de barreira (a), a rugosidade natural da superfície induz o gradiente do campo elétrico, criando núcleos de oxidação (b), que crescem e coalescem (c). Isso leva à concentração das linhas de campo em regiões muito pequenas nas interfaces (d), onde a dissolução da $\mathrm{Al}_{2} \mathrm{O}_{3}$ é favorecida. Essa dissolução ocorre a uma taxa inicial mais alta que a de formação de $\mathrm{Al}_{2} \mathrm{O}_{3}$ na interface metal/óxido, que diminui até se igualar a esta última. Daí em diante, a espessura da camada de barreira mantém-se constante e estabelece-se o crescimento estacionário da camada porosa [33]. . . . . . . . . . . . . . . . 12

2.3 Esquema pictórico da formação da camada de óxido porosa [34]. A espessura da camada de barreira $t_{B}$ depende da tensão de anodização e do eletrólito [13]. Para soluções de $(\mathrm{COOH})_{2}$ em tensões típicas de trabalho, $t_{B}$ deve variar entre

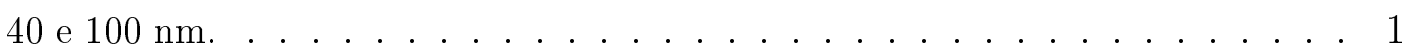

2.4 Esquema pictórico (à esquerda) e imagem de SEM (à direita) de uma lâmina de $\mathrm{Al}_{2} \mathrm{O}_{3}$ porosa auto-organizada, obtida por anodização em dois passos de uma lâmina de Al puro $(99,9995 \%)$ em meio ácido. . . . . . . . . . . . . . . . . 14 
2.5 Perfil da amostra em cada etapa de fabricação das lâminas de $\mathrm{Al}_{2} \mathrm{O}_{3}$ porosa: (a) lâmina de $\mathrm{Al}$ antes da anodização, (b) após a primeira anodização, (c) após remoção da camada de óxido, (d) após segunda anodização e (e) após eletrodeposição do metal magnético (obtido da ref. [39]). . . . . . . . . . . . . . . 1

2.6 Voltamograma de uma amostra anodizada sob as condições padrão $\left[3^{\circ} \mathrm{C}\right.$, em 0,3 $\mathrm{mol} / \mathrm{L}(\mathrm{COOH})_{2}$, a $40 \mathrm{~V}$, por 1hora $\left(1^{\mathrm{a}}\right) / 40$ minutos $\left.\left(2^{\mathrm{a}}\right)\right]$, e eletrodepositada em solução de $\mathrm{NiSO}_{4} \cdot 6 \mathrm{H}_{2} \mathrm{O}$ a $0,1 \mathrm{~mol} / \mathrm{L}+\mathrm{H}_{3} \mathrm{BO}_{3}$ a $45 \mathrm{~g} / \mathrm{L}$, à temperatura ambiente. Os círculos vermelhos indicam os picos de redução dos íons $\mathrm{Ni}^{2+} \rightarrow \mathrm{Ni}^{0}$, quando estes se depositam sobre a superfície interna dos poros. . . . . . . . . . . . 18

2.7 Perfil típico da corrente elétrica na célula eletrolítica durante uma eletrodeposição DC de nanofios de Ni numa matriz porosa de $\mathrm{Al}_{2} \mathrm{O}_{3}[22] . \ldots \ldots . . \ldots 19$

2.8 Perfil típico da corrente elétrica na célula eletrolítica durante uma eletrodeposição $\mathrm{AC}$ de nanofios de $\mathrm{Ni}$ numa matriz porosa de $\mathrm{Al}_{2} \mathrm{O}_{3}[18] . \ldots . . . . .20$

2.9 Imagens de MEV de nanofios eletrodepositados numa matriz de poros, mostrando o efeito da freqüência do sinal $\mathrm{AC}$ sobre o grau de preenchimento dos poros de uma matrix de $\mathrm{Al}_{2} \mathrm{O}_{3}$. As freqüências são (a) 100, (b) 300, (c) 500 e (d) $750 \mathrm{~Hz}$ $[18]$ para Ni. . . . . . . . . . . . . . . . . 21

2.10 Imagens de MEV de nanofios de Ni (a e b) e Bi (c e d) obtidos por eletrodeposição

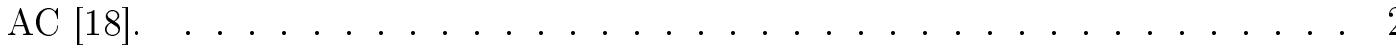

2.11 Imagens de MET de (a) nanofios de Co obtidos por eletrodeposição DC, com 40 nm de diâmetro e $22 \mu \mathrm{m}$ de comprimento e seus defeitos mais comuns: (b) indentações, (c) rugosidades, extremidades (d) planas, (e) rombudas e (f) pontiagudas

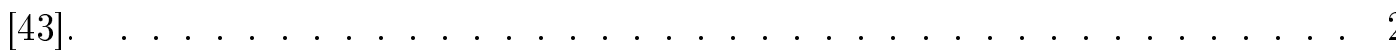

2.12 Imagens de MFM de nanofios de Co de $40 \mathrm{~nm}$ de diâmetro e $10 \mu \mathrm{m}$ de comprimento, obtidos por eletrodeposição DC. [43] . . . . . . . . . . . . . . 25

2.13 Difratogramas de raios X de amostras de nanofios de (a) Co e (b) Ni, obtidos com tubo de Co. Os nanofios de Co e Ni se encontram respectivamente nas fases $h c p$ e $f c c$, com direções preferenciais de crescimento respectivas [0001] e [110]. Vê-se também picos de $\mathrm{Cu}$ e $\mathrm{Au}$, que foram depositados na parte traseira das amostras para facilitar o contato elétrico [43]. . . . . . . . . . . . 27 
2.14 Difratograma de raios X de nanofios de Fe com $56 \pm 6 \mathrm{~nm}$ de diâmetro e 3-5 $\mu \mathrm{m}$ de comprimento, com uma clara textura [200] da fase bcc e grãos de $48 \pm 2 \mathrm{~nm}$ [29]. 28

2.15 Modos de inversão da magnetização em partículas elipsoidais: (a) rotação coerente, (b) formação de vórtices (curling), (c) dobramento (buckling) (d) "efeito sanfona" (fanning) e (e) efeito dominó [48]. . . . . . . . . . . . . . . 35

2.16 Diagrama de fases do estado remanente em função da razão de aspecto e do diâmetro dos cilindros. As curvas tracejadas foram obtidas por modelagem micromagnética. Três diferentes estados remanentes são encontrados: um uniforme paralelo ao plano (in plane flower), um uniforme fora do plano (out of plane flower) e um não-uniforme, com a formação de um vórtice no cilindro (vortex/multidomain). Os pontos experimentais foram obtidos para arranjos de nanofios policristalinos de $\mathrm{Ni}, \mathrm{Co}, \mathrm{CoNi}$ e $\mathrm{CoP}$ crescidos por eletrodeposição em matrizes de Si porosas. As curvas pontilhadas correspondem a cilindros de mesma $M_{R}[50]$

2.17 Resultados de simulações micromagnéticas do estado remanente de cilindros magnéticos. Vistas lateral (a) e da extremidade (b) de um cilindro que estabiliza num estado uniforme ao longo do eixo $\left(R=2,1\right.$ e $\left.D=2,61 l_{e x}\right)$. Vistas lateral (c) e da extremidade (d) de um cilindro que estabiliza num estado de vórtice $(R=2,1 \mathrm{e}$ $\left.D=6,10 l_{e x}\right)$. Neste último caso, percebe-se a componente longitudinal da magnetização no centro do cilindro, enquanto os momentos magnéticos mais externos formam o vórtice no plano tranversal [50]. . . . . . . . . . . . . .

2.18 Remanência normalizada calculada ao longo do cilindro em função do diâmetro. O valor crítico $D / l_{e x}=3,5$ marca a transição entre as fases remanentes uniforme e de vórtice. A remanência só apresenta dependência com a razão de aspecto na fase de vórtice. Antes da transição, a remanência é praticamente igual a 1 e decresce fortemente após a transição [50]. . . . . . . . . . . . . . . 38

2.19 Transição entre as fases remanentes uniforme e de vórtice em função do parâmetro de anisotropia uniaxial $Q$, para cilindros com razões de aspecto $R=1,5-3,0$. A anisotropia uniaxial favorece o estado de vórtice para nanofios com diâmetros maiores $[50] . \ldots \ldots \ldots \ldots \ldots \ldots \ldots \ldots \ldots$ 
2.20 Definição de uma curva de inversão de primeira ordem (FORC). Uma FORC $M\left(H_{r}, H\right)$ é determinada por um campo de retorno $H_{r}$, aplicado a partir do estado saturado, e pelo campo magnético instantâneo $H$ [30] . . . . . . . . . . . 40

2.21 Ciclos internos de histerese (a) e FORCs (b) de uma amostra de nanofios de $\mathrm{Ni}$, preparada nas condições-padrões de anodização $\left(V_{a n}=30 \mathrm{~V}\right)$ e eletrodeposição AC a $30 \mathrm{~V}, 100 \mathrm{~Hz}$, por 15 minutos. As medidas foram realizadas em SQUID, a $300 \mathrm{~K}$, com campo perpendicular à superfície. . . . . . . . . . . . . .

2.22 Curva $\Delta M \equiv M_{d}-\left[M_{R}-2 M_{r}\left(H_{r}\right)\right]$ da mesma amostra das figs. 2.21(a e b), calculada a partir das remanências isotérmica $M_{r}\left(H_{r}\right)$ e recuperada $M_{d}\left(H_{r}\right)$ obtidas das medidas de ciclos internos e FORCs, respectivamente. A predominância da curva sob o eixo $\Delta M<0$ revela o caráter desmagnetizante dos processos de magnetização no sistema. . . . . . . . . . . . . . . . . .

2.23 Resposta magnética elementar de uma partícula no modelo de Preisach, representada pelo operador $\hat{\Gamma}_{H_{c}, H_{b}}$. Os dois parâmetros $H_{c}$ e $H_{b}$ caracterizam o comportamento individual da partícula (reversível ou irreversível, bloqueada ou superparamagnética). O sistema como um todo é, então, é caracterizado por uma distribuição de campos de inversão e de interação $P\left(H_{c}, H_{b}\right)[55] . \quad$. . . . .

2.24 (a) FORCs de um arranjo de nanofios de Ni, policristalinos, com tamanho de grão de 10 a $20 \mathrm{~nm},\langle D\rangle=92 \mathrm{~nm}, d_{\text {int }}=200 \mathrm{~nm}$ e $L=250 \mathrm{~nm}$ e (b) seu diagrama FORC. O arranjo de nanofios foi fabricado por litografia e eletrodeposição [55].

2.25 Perfil vertical da distribuição FORC da fig. 2.24(b) ao longo de $H_{c}=0$, chamado de "pico reversível" $[55] . \ldots \ldots \ldots \ldots \ldots$

2.26 Resultados do modelo de Preisach com campo médio para (a) $J=0$ e (b) $J=$ 21,1 mT. A forma típica de "dois ramos" da distribuição FORC de nanofios deve-se à interação dipolar desmagnetizante entre os fios [55]. . . . . . . . . . .

2.27 Resultados do modelo de Preisach com campo médio $(J=21,1 \mathrm{mT})$ para ciclos elementares curvilíneos, em vez de retangulares, como no modelo de Preisach clássico. Com isso recupera-se o pico reversível em $H_{c}=0$ [55]. . . . . . . . . 50

2.28 Rede de pontos $\left(H_{r}, H\right)$, de tamanho $2 n_{v i z}+1 \times 2 n_{v i z}+1\left(n_{v i z}=2\right)$, em torno de um ponto $i$ (no centro), sobre a qual o polinômio 2.23 aproximará $M_{\text {exp }}\left(H_{r}, H\right)$ para calcular o valor da distribuição FORC no ponto $i[54]$. . . . . . . . . . . 51 
2.29 Domínio no qual $M\left(H_{r}, H\right)$ e, conseqüentemente, a distribuição FORC são definidas. A borda diagonal do triângulo corresponde ao eixo $H_{r}=H$. A transformação de variáveis $\left\{H_{r}, H\right\} \rightarrow\left\{H_{c}, H_{b}\right\}$ corresponde a uma rotação de $45^{\circ}$ no sentido anti-horário do triângulo da figura. Para o cálculo, os dados experimentais devem ser primeiramente interpolados numa rede discreta definida sobre o domínio, com um espaçamento $\left(\Delta H_{r}, \Delta H\right)$ regular. . . . . . . . . 51

2.30 Comparação do tempo computacional para o cálculo da distribuição FORC entre o método de Pike et al. [30] (à esquerda) e o de Heslop e Muxworthy [54] (à direita) em função do tamanho lateral da rede, para $n_{v} i z=2$ e 4 (SF, smoothing factor). Percebe-se uma redução de até 500 vezes no tempo de computação [54].

2.31 Representação pictórica dos processos atômicos individuais que determinam o modo de crescimento de um filme sobre um substrato sólido. A velocidade e a estabilidade de cada um desses processos é determinado pela interação entre adsorvatos e entre adsorvatos e substrato. (Obtido da ref. [5]) . . . . . . . . 58

2.32 Representação pictórica dos possíveis modos de crescimento de um filme sobre um substrato sólido em função da espessura $(\Theta)$ em monocamadas atômicas (ML). (a) Modo Frank-van der Merve (FM) ou crescimento por camadas, (b) modo Stransky-Krastanov (SK) ou crescimento por camadas e ilhas (misto) e (c) modo Vollmer-Weber (VW) ou crescimento por formação de ilhas. (Obtido da ref. [5]).

2.33 Representação esquemática do espalhamento inelástico de elétrons dependente em spin, em regimes de perda e ganho de energia, em geometrias especular (a) e não-especular (b) e (c), seguidos de seus respectivos espectros de SPEELS. A curva em azul, com seta para cima (vermelho, com seta para baixo) representa o espectro para incidência de elétrons majoritários (minoritários). Em (a) e (b), os eventos inelásticos são tipo não-spin-flip, pois ocorrem nos dois canais de spin. Em (c), os eventos inelásticos são tipo spin-flip, manifestando-se exclusivamente no canal de perda de energia (criação de excitações) ou ganho de energia (aniquilação de excitações). As regras de seleção de espalhamento dependente de spin - o princípio de conservação do momento angular de spin - proíbe a existência desses picos em ambos os canais de spin simultaneamente. . . . . . . 71 
2.34 Foto do interior da câmara de SPEELS, com seus principais componentes designados, em especial o espectrômetro de SPEELS, com seus quatro estágios: o pré-monocromador de $90^{\circ}$ e o monocromador principal de $180^{\circ}$, de secções retas cilíndricas; a câmara de espalhamento e o analizador, seguido do detector channeltron. É possível girar o analizador em relação ao monocromador através do braço rotatório, o que confere a resolução em vetor de onda durante o espalhamento. (Obtido da ref. [83]) . . . . . . . . . . . . . 75

2.35 Esquema do experimento de SPEELS em curso. Vê-se em destaque o espectrômetro de elétrons, em seus dois estágios (monocromador e analizador), as trajetórias do laser circularmente polarizado (em vermelho) e dos elétrons (em azul), o cátodo de GaAs, gerador do feixe de elétrons spin-polarizados e a amostra, com a direção da magnetização indicada em verde. No detalhe vemos a geometria de espalhamento, com os vetores de onda inicial e final e a definição dos ângulos $\theta$ e $\theta_{0}$. (Obtido da ref. [83]). . . . . . . . . . . . . . 76

3.1 Corrente elétrica através da célula eletrolítica durante as anodizações. Mudanças no perfil da corrente indicam diferentes regimes de crescimento da camada óxida, como indicado na figura. . . . . . . . . . . . . . . 78

3.2 Imagens de MEV da amostra $2\left[3^{\circ} \mathrm{C}, 40 \mathrm{~V} \mathrm{dc}\right.$, em $(\mathrm{COOH})_{2}$ a $0,3 \mathrm{~mol} / \mathrm{L}$, durante 1 hora $\left(1^{\underline{a}}\right) / 40$ minutos $\left(2^{\underline{a}}\right)$ ] após as etapas de (a) primeira anodização e (b) remoção da camada de alumina. . . . . . . . . . . . . . . . 80

3.3 Imagens de MEV da amostra $2\left[3^{\circ} \mathrm{C}, 40 \mathrm{~V} \mathrm{dc}\right.$, em $(\mathrm{COOH})_{2}$ a 0,3 mol/L, durante 1 hora $\left(1^{\mathrm{a}}\right) / 40$ minutos $\left(2^{\mathrm{a}}\right)$ ] após as etapas de (a) segunda anodização

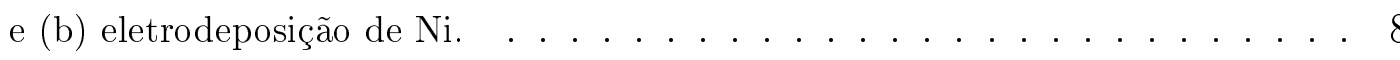

3.4 Imagens de MEV do perfil de amostras anodizadas a $5^{\circ} \mathrm{C}$, em $(\mathrm{COOH})_{2}$ a 0,3 mol/L, durante 4 horas $\left(1^{\mathrm{a}}\right) / 1$ hora $\left(2^{\mathrm{a}}\right)$, sob tensões de (a) $40 \mathrm{~V}$ e (b) $45 \mathrm{~V}$, com medidas do espaçamento entre os poros (periodicidade). . . . . . . . . .

3.5 Imagens de MEV do perfil de amostras anodizadas a $5^{\circ} \mathrm{C}$, em $(\mathrm{COOH})_{2}$ a 0,3 mol/L, por 4 horas $\left(1^{\mathrm{a}}\right) / 1$ hora $\left(2^{\underline{a}}\right)$, sob tensões de (a) $40 \mathrm{~V}$ e (b) $45 \mathrm{~V}$, com medidas do diâmetro interno dos poros. . . . . . . . . . . . . . . 8 
3.6 Imagens de $\mathrm{MEV}$ (a) da amostra anodizada a $5^{\circ} \mathrm{C}, 35 \mathrm{~V}$, em $(\mathrm{COOH})_{2}$ a 0,3 mol/L, durante 4 horas $\left(1^{\underline{a}}\right) / 75$ minutos $\left(2^{\underline{a}}\right)$ em perpectiva. Em (b), vemos o perfil de uma amostra anodizada nas mesmas condições, sendo $V_{a n}=45 \mathrm{~V}$, por 1 hora ( $2^{\mathrm{a}}$ anodização), exibindo um comprimento dos poros um pouco maior que as demais amostras. . . . . . . . . . . . . . . 8

3.7 Imagens de MEV do perfil de diferentes regiões da amostra (a e b) anodizada a $5^{\circ} \mathrm{C}, 40 \mathrm{~V} \mathrm{dc}$, em $(\mathrm{COOH})_{2}$ a $0,3 \mathrm{~mol} / \mathrm{L}$, durante 4 horas $\left(1^{\mathrm{a}}\right) / 1$ hora $\left(2^{\underline{a}}\right)$, com medidas do comprimento dos poros. Percebe-se que há uma variação da espessura da camada de óxido devido a deformações da superfície. . . . . . . . . 86

3.8 Imagens de MEV do perfil de diferentes regiões (a e b) da amostra anodizada a $5^{\circ} \mathrm{C}, 35 \mathrm{~V}$, em $(\mathrm{COOH})_{2}$ a $0,3 \mathrm{~mol} / \mathrm{L}$, durante 4 horas $\left(1^{\mathrm{a}}\right) / 75$ minutos $\left(2^{\mathrm{a}}\right)$, mostrando diferentes valores do comprimento dos poros. . . . . . . . . . . . 87

3.9 Imagens de MEV de amostras preparadas a $3^{\circ} \mathrm{C}$, a $40 \mathrm{~V}$ dc, durante 1 hora $\left(1^{\mathrm{a}}\right) / 40$ minutos $\left(2^{\mathrm{a}}\right)$, em $(\mathrm{COOH})_{2}$ a $(\mathrm{a}) 0,1 \mathrm{~mol} / \mathrm{L}$ e (b) $0,3 \mathrm{~mol} / \mathrm{L} \ldots \ldots$. . . 88

3.10 Imagens de MEV de amostras preparadas a $3^{\circ} \mathrm{C}$, a $40 \mathrm{~V} \mathrm{dc}$, durante 1 hora $\left(1^{\mathrm{a}}\right) / 40$ minutos $\left(2^{\mathrm{a}}\right)$, em $(\mathrm{COOH})_{2}$ a (a) $0,5 \mathrm{~mol} / \mathrm{L}$ e (b) $0,6 \mathrm{~mol} / \mathrm{L} \ldots \ldots 9$

3.11 Imagens de $\mathrm{MEV}$ de amostras preparadas a $3^{\circ} \mathrm{C}$, em $(\mathrm{COOH})_{2}$ a $0,3 \mathrm{~mol} / \mathrm{L}$, durante 1 hora $\left(1^{\mathrm{a}}\right) / 40$ minutos $\left(2^{\underline{a}}\right)$, com tensões de (a) $15 \mathrm{~V}$ e (b) $30 \mathrm{~V}$. . . . 91

3.12 Imagens de MEV de amostras preparadas a $3^{\circ} \mathrm{C}$, em $(\mathrm{COOH})_{2}$ a $0,3 \mathrm{~mol} / \mathrm{L}$, durante 1 hora $\left(1^{\mathrm{a}}\right) / 40$ minutos $\left(2^{\mathrm{a}}\right)$, com voltagens de (a) $50 \mathrm{~V}$ e (b) $60 \mathrm{~V}$. . 92

3.13 Imagem de MEV da amostra obtida com $\left[3^{\circ} \mathrm{C}, 60 \mathrm{~V}\right.$ dc, em $(\mathrm{COOH})_{2}$ a 0,5 mol/L, durante 1 hora $\left(1^{\mathrm{a}}\right) / 40$ minutos $\left.\left(2^{\mathrm{a}}\right)\right] \ldots \ldots . \ldots . \ldots 93$

3.14 Imagens de Microscopia de Força Atômica (a) e de Força Magnética (b) de uma amostra obtida através do procedimento padrão $\left[3^{\circ} \mathrm{C}, 40 \mathrm{~V} \mathrm{dc}, \mathrm{em}(\mathrm{COOH})_{2}\right.$ a $0,3 \mathrm{~mol} / \mathrm{L}$, durante 1 hora $\left(1^{\mathrm{a}}\right) / 40$ minutos $\left.\left(2^{\mathrm{a}}\right)\right] . \ldots \ldots . \ldots . . \ldots 94$

3.15 Exemplo de medida da periodicidade da amostra a partir de uma imagem de AFM. 96

3.16 Distribuição de probabilidade do diâmetro dos poros (a, c, e, g) e da circularidade dos poros (b, d, f, h) para várias amostras anodizadas a $3{ }^{\circ} \mathrm{C}, \mathrm{em}(\mathrm{COOH})_{2}$ a 0,3 mol/L, durante 1 hora $\left(1^{\mathrm{a}}\right) / 40$ minutos $\left(2^{\mathrm{a}}\right)$, em ordem crescente de voltagem de anodização: $15 \mathrm{~V}(\mathrm{a}-\mathrm{b}), 30 \mathrm{~V}(\mathrm{c}-\mathrm{d}), 40 \mathrm{~V}$ (e-f) e $60 \mathrm{~V}(\mathrm{~g}-\mathrm{h}) . \quad \ldots . . . . .998$ 
3.17 (a) Diâmetro médio e (b) distância média entre poros em função da tensão aplicada durante a anodização. Ambos mostram uma evidente dependência linear com $V_{a n}$, de acordo com a literatura [42]. Taxas de crescimento calculadas foram de $1,53 \mathrm{~nm} / \mathrm{V}$ para $\langle D\rangle$ e $2,19 \mathrm{~nm} / \mathrm{V}$ para $\left\langle d_{\text {int }}\right\rangle$. . . . . . . . . . 99

3.18 (a) Densidade superficial e (b) circularidade média dos poros em função da tensão aplicada durante a anodização. Os poros exibiram alta circularidade, acima de 0,8. A densidade exibe uma dependência com $V_{a n}^{-2}$, em acordo com a literatura

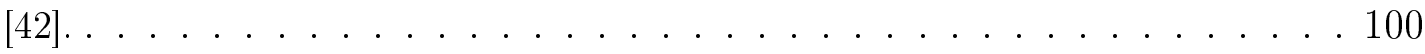

3.19 Difratogramas de raios $\mathrm{X}$ do substrato de $\mathrm{Al}_{2} \mathrm{O}_{3} / \mathrm{Al}$ utilizado nas amostras. . . . 104

3.20 Difratogramas de raios X de nanofios de Ni referentes às amostras(a) 41-1 ( $V_{a n}=$

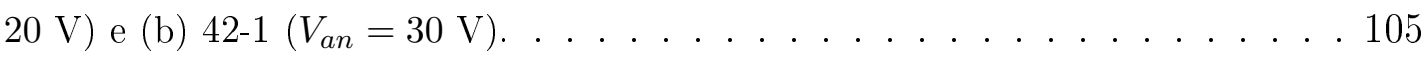

3.21 Difratogramas de raios X de nanofios de Ni referentes às amostras (a) 43-1 ( $V_{a n}=$

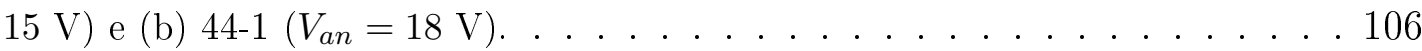

3.22 Difratogramas de amostras de nanofios de Co anodizadas a (a) $30 \mathrm{~V}$, (b) $35 \mathrm{~V}$ e (c) $40 \mathrm{~V}$. Apenas duas delas apresentaram fracos traços de Co. O pico $\mathrm{Co}(110)$ observado está presente tanto no difratograma da fase $h c p$ quanto no da $f c c$ do Co. Uma análise quantitativa confiável não é possível nesse caso devido à baixa intensidade dos picos. . . . . . . . . . . . . . . . . 107

3.23 Tamanho médio de grão cristalino de Ni em cada direção cristalográfica em função do diâmetro médio dos fios. . . . . . . . . . . . . . . . . . . . . 109

3.24 Ciclos de histerese da amostra 43-1 de nanofios de Ni, realizados em SQUID, a $300 \mathrm{~K}$, com campo aplicado nas direções paralela (em vermelho) e perpendicular (azul) ao eixo dos nanofios. . . . . . . . . . . . . . . . 111

3.25 Diagramas FORC das amostras de nanofios de Ni (a) 40-2 ( $\left.V_{a n}=30 \mathrm{~V}\right)$ e (b) 43-1 $\left(V_{a n}=15 \mathrm{~V}\right)$, preparadas nas mesmas condições $\left[3^{\circ} \mathrm{C},(\mathrm{COOH})_{2}\right.$ a 0,3 mol/L, 1 hora $\left(1^{\mathrm{a}}\right) / 40$ minutos $\left(2^{2}\right)$; eletrodeposição $\left.\mathrm{AC} \operatorname{com} f=100 \mathrm{~Hz}\right] . . . .112$

3.26 FORCs experimentais (a) e diagrama FORC (b) da amostra de nanofios de Ni anodizada a $V_{a n}=15 V, \operatorname{com}\langle D\rangle=31 \mathrm{~nm} \ldots \ldots \ldots \ldots \ldots$

3.27 FORCs experimentais (a) e diagrama FORC (b) da amostra de nanofios de Ni anodizada a $V_{a n}=18 V, \operatorname{com}\langle D\rangle=38 \mathrm{~nm}$. . . . . . . . . . 116 
3.28 FORCs (a) e diagrama FORC (b) da amostra de nanofios de Ni anodizada a

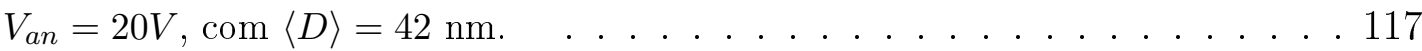

3.29 FORCs (a) e diagrama FORC (b) da amostra de nanofios de Ni anodizada a $V_{a n}=30 V, \operatorname{com}\langle D\rangle=48 \mathrm{~nm}$.

3.30 Perfil da distribuição FORC das amostras 43-1 $\left(V_{a n}=15 \mathrm{~V}\right)$ a $42-1\left(V_{a n}=30\right.$ V) para (a) $H_{c}=0$ e (b) $H_{b}=0 \ldots \ldots \ldots \ldots \ldots$

3.31 (a) Pico principal da distribuição FORC de cada uma das amostras para $H_{c}$ fixo e (b) comportamento da coercividade, da posição e da largura do pico principal de cada amostra em função do diâmetro médio. . . . . . . . . . . . . . . 122

3.32 Distribuição FORC da amostra de nanofios de Ni 43-1 $\left(V_{a n}=15 \mathrm{~V}\right.$ de nanofios de $\mathrm{Ni},\langle D\rangle=31 \mathrm{~nm})$ representada sobre a própria histerese. . . . . . . . . 124

3.33 Distribuição FORC da amostra de nanofios de Ni 44-1 ( $V_{a n}=18 \mathrm{~V}$ de nanofios de $\mathrm{Ni},\langle D\rangle=38 \mathrm{~nm}$ ) representada sobre a própria histerese. . . . . . . . . 124

3.34 Distribuição FORC da amostra de nanofios de Ni 41-1 $\left(V_{a n}=20 \mathrm{~V}\right.$ de nanofios de $\mathrm{Ni},\langle D\rangle=42 \mathrm{~nm}$ ) representada sobre a própria histerese. . . . . . . . 125

3.35 Distribuição FORC da amostra de nanofios de Ni 42-1 ( $V_{a n}=30 \mathrm{~V}$ de nanofios de $\mathrm{Ni},\langle D\rangle=48 \mathrm{~nm})$ representada sobre a própria histerese.

3.36 FORCs (a) e correspondentes diagramas FORC (b) de uma amostra de nanofios de $\mathrm{Co}\left[5^{\circ} \mathrm{C},(\mathrm{COOH})_{2}\right.$, a $0,3 \mathrm{~mol} / \mathrm{L}, V_{a n}=25 \mathrm{~V}, 4$ horas $\left(1^{\mathrm{a}}\right) / 1$ hora $\left.\left(2^{-}\right)\right]$, para campo magnético aplicado num ângulo $\theta=0^{\circ}$ em relação à normal à superfície. . 126

3.37 FORCs (a) e correspondentes diagramas FORC (b) de uma amostra de nanofios de $\mathrm{Co}\left[5^{\circ} \mathrm{C},(\mathrm{COOH})_{2}\right.$, a $0,3 \mathrm{~mol} / \mathrm{L}, V_{a n}=25 \mathrm{~V}, 4$ horas $\left(1^{\mathrm{a}}\right) / 1$ hora $\left.\left(2^{\mathrm{a}}\right)\right]$, para campo magnético aplicado num ângulo $\theta=15^{\circ}$ em relação à normal à superfície. 127

3.38 FORCs (a) e correspondentes diagramas FORC (b) de uma amostra de nanofios de $\mathrm{Co}\left[5^{\circ} \mathrm{C},(\mathrm{COOH})_{2}\right.$, a $0,3 \mathrm{~mol} / \mathrm{L}, V_{a n}=25 \mathrm{~V}, 4$ horas $\left(1^{\mathrm{a}}\right) / 1$ hora $\left.\left(2^{\underline{a}}\right)\right]$, para campo magnético aplicado num ângulo $\theta=30^{\circ}$ em relação à normal à superfície. 128

3.39 FORCs (a) e correspondentes diagramas FORC (b) de uma amostra de nanofios de $\mathrm{Co}\left[5^{\circ} \mathrm{C},(\mathrm{COOH})_{2}\right.$, a $0,3 \mathrm{~mol} / \mathrm{L}, V_{a n}=25 \mathrm{~V}, 4$ horas $\left(1^{-}\right) / 1$ hora $\left.\left(2^{\mathrm{a}}\right)\right]$, para campo magnético aplicado num ângulo $\theta=45^{\circ}$ em relação à normal à superfície. 129 
3.40 FORCs (a) e correspondentes diagramas FORC (b) de uma amostra de nanofios de $\mathrm{Co}\left[5^{\circ} \mathrm{C},(\mathrm{COOH})_{2}\right.$, a $0,3 \mathrm{~mol} / \mathrm{L}, V_{a n}=25 \mathrm{~V}, 4$ horas $\left(1^{-}\right) / 1$ hora $\left.\left(2^{-}\right)\right]$, para campo magnético aplicado num ângulo $\theta=60^{\circ}$ em relação à normal à superfície. 130

3.41 FORCs (a) e correspondentes diagramas FORC (b) de uma amostra de nanofios de $\mathrm{Co}\left[5^{\circ} \mathrm{C},(\mathrm{COOH})_{2}\right.$, a $0,3 \mathrm{~mol} / \mathrm{L}, V_{a n}=25 \mathrm{~V}, 4$ horas $\left(1^{\mathrm{a}}\right) / 1$ hora $\left.\left(2^{\mathrm{a}}\right)\right]$, para campo magnético aplicado num ângulo $\theta=75^{\circ}$ em relação à normal à superfície. 131

3.42 FORCs (a) e correspondentes diagramas FORC (b) de uma amostra de nanofios de $\mathrm{Co}\left[5^{\circ} \mathrm{C},(\mathrm{COOH})_{2}\right.$, a $0,3 \mathrm{~mol} / \mathrm{L}, V_{a n}=25 \mathrm{~V}, 4$ horas $\left(1^{\mathrm{a}}\right) / 1$ hora $\left.\left(2^{\underline{a}}\right)\right]$, para campo magnético aplicado num ângulo $\theta=90^{\circ}$ em relação à normal à superfície. 132

3.43 Perfil da distribuição FORC da amostra de nanofios de Co para (a) $H_{c}=0$ e (b)

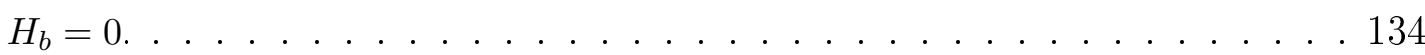

4.1 (a) Vista em perspectiva da câmara UHV utilizada neste trabalho. (b) Esquema pictórico da seção longitudinal da câmara e suas subpartes: o manipulador da amostra (em amarelo, ao longo do eixo principal do sistema), a câmara de análise (em vermelho), onde a amostra é preparada e analizada, a câmara de SPEELS (em azul) e a câmara de preparação do cátodo de GaAsP (em verde). Durante o experimento de SPEELS, o cátodo é transferido para a câmara de SPEELS. As diversas técnicas experimentais utilizadas neste trabalho estão discriminadas na figura. (Obtido da ref. [85]) . . . . . . . . . . . . . . . . 139

4.2 Padrões de LEED do substrato de W(001), após ciclos de flash de baixa e alta potência, para elétrons com energias de (a) 96, (b) 113 e (c) 160 eV. . . . . . . . 142

4.3 Padrões de LEED de (a) $30 \mathrm{ML} \mathrm{Fe/W(001),} \mathrm{a} 120$ eV, (b) a mesma amostra, após exposição a $5 \mathrm{~L} \mathrm{O}_{2}$, a $120 \mathrm{eV}$ e $(\mathrm{c})$ a clara reconstrução $\mathrm{p}(1 \times 1) \mathrm{O}-\mathrm{Fe} / \mathrm{W}(001)$, a $90 \mathrm{eV}$, após annealing. . . . . . . . . . . . . . . . . . 144 
4.4 (a) Espectros de AES em diferentes etapas da preparação da amostra de $30 \mathrm{ML}$ O-Fe/W(001): somente o substrato de W(001), após o flash (curva preta); após a deposição de 30 ML Fe (curva vermelha); e após exposição a $5 \mathrm{~L}$ de $\mathrm{O}_{2}$ (curva azul). (b) Espectros de AES para a mesma amostra, 56 dias após sua preparação, exposta à atmosfera residual da câmara UHV (em preto), $\left(p_{\text {base }} \approx 4 \times 10^{-10} \mathrm{mbar}\right.$, e logo após um annealing de $30 \mathrm{~s}$ a $500 \mathrm{~K}$ (em vermelho). A coincidência entre as curvas prova a boa estabilidade da amostra. . . . . . . . . . . . . 145

4.5 Padrões de LEED de 46,7 ML O-Fe/W(001) para elétrons com energias de (a) 88, (b) 113, (c) 170, (d) 187, (e) 253 e (f) 277 eV. (g) Espectros de AES em diferentes posições da amostra ao longo do eixo do manipulador, mostrando a homogeneidade da superfície da amostra. . . . . . . . . . . . . . 147

4.6 Curva de histerese de $30 \mathrm{ML} \mathrm{O}-\mathrm{Fe} / \mathrm{W}(001)$ a temperatura ambiente. Para garantir a saturação da amostra, campos magnéticos de até 2400 Oe foram aplicados. No detalhe, curvas de histerese realizadas com incremento menor, a fim de se determinar a coercividade com melhor precisão. . . . . . . . . . . . . . . . 148

4.7 Esquema pictórico da (a) estrutura cristalina da superfície de 30 ML O$\mathrm{Fe} / \mathrm{W}(001)$, com os átomos de $\mathrm{O}$ ocupando os sítios vazios da rede bcc do $\mathrm{Fe}(001)$, e (b) sua respectiva zona de Brillouin de superfície, com seus pontos de alta simetria e as direções da magnetização remanente (azul) e da direção de propagação das excitações elementares excitadas (verde). . . . . . . . . . . . . . 149

4.8 Espectros de SPEELS de $30 \mathrm{ML}$ O-Fe/W(001) em geometrias (a) especular e (b) não-especular. Os vetores de onda no plano são respectivamente 0 e $0,3 \AA^{-1}$. As assimetrias de spin são mostradas nos detalhes. A energia dos elétrons incidentes é de $4,1 \mathrm{eV}$, com resolução (FWHM) de $6 \mathrm{meV}$. . . . . . . . . . . . . . . 150 
4.9 Espectros de SPEELS de $30 \mathrm{ML}$ O-Fe/W(001) para os ramos (a) positivo e (b) negativo de vetores de onda paralelos à superfície, ao longo de toda a SBZ, na direção $\bar{\Gamma} \bar{X}$. As diferentes excitações estão marcadas com diferentes símbolos. Os losangos em preto e branco representam as excitações spin-flip, que são atribuídas a mágnons (ondas de spin) de grandes vetores de onda. Os demais símbolos representam as excitações não-spin-flip, detalhadas no texto. A energia dos elétrons incidentes é de $4 \mathrm{eV}$, com resolução (FWHM) de $6 \mathrm{meV}$, para $\Delta K<0,7 \AA^{-1}$, e $8 \mathrm{eV}$, com FWHM $11 \mathrm{meV}$, para $\Delta K>0,7 \AA^{-1}$. . . . . . . . . . . 151

4.10 Dispersão das excitações inelásticas de superfície observadas em 30 ML O$\mathrm{Fe} / \mathrm{W}(001)$ ao longo da direção [010] do cristal ( $\bar{\Gamma} \bar{X}$ da SBZ). Os losangos em preto e branco correspondem às excitações tipo spin-flip (ondas de spin), enquanto todas as outras são não-spin-fip. Os círculos vermelhos correspondem ao modo óptico de vibração dos átomos de O. Os triângulos verdes correspondem a modos ressonantes induzidos no volume do filme de Fe, mas com alguma amplitude na superfície. Os triângulos azúis correspondem ao modo óptico dos fônons de superfície em $\mathrm{FeO}$, no qual os átomos de $\mathrm{Fe}$ e $\mathrm{O}$ vibram em oposição de fase. Os losangos azúis-claros correspondem ao modo transversal acústico de superfície do Fe (modo de Rayleigh). Esse último modo apresenta um ótimo acordo com resultados de fônons de superfície obtidos por espalhamento de átomos de $\mathrm{He}$ numa superfície oxidada de $2 \mathrm{ML} \mathrm{Fe} / \mathrm{MgO}(001)$ [112], muito semelhante à estudada neste trabalho. As linhas tracejadas e pontilhadas são obtidas do modelo e correspondem a diferentes polarizações (longitudinal e transversal, respectivamente) dos modos calculados. A zona hachurada corresponde à banda de volume da camada de Fe subjacente. . . . . . . . . . . . . . . . 153 


\section{Lista de Tabelas}

2.1 Constantes de anisotropia magneto-cristalina e de forma estimada para os nanofios de Fe, Co e Ni $[18,29,43] . \ldots \ldots \ldots \ldots$

2.2 Valores típicos da largura de parede de domínio e dos comprimentos de coerências paralelo e perpendicular para Fe, Co e Ni (calculados para $A=10^{-6} \mathrm{erg} / \mathrm{cm}=$

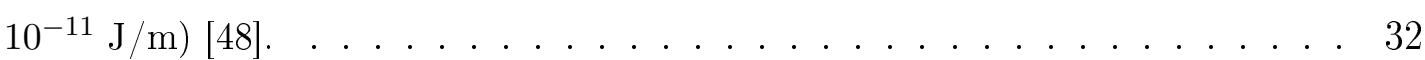

3.1 Parâmetros morfológicos dos arranjos de nanoporos em lâminas de $\mathrm{Al}_{2} \mathrm{O}_{3}$ anodizadas e utilizadas para eletrodeposição de Ni e Co. . . . . . . . . . . . . . . 102

3.2 Parâmetros de varredura da difratometria de raios X para amostras de nanofios de $\mathrm{Ni} \mathrm{e} \mathrm{Co.} \mathrm{.} \mathrm{.} \mathrm{.} \mathrm{.} \mathrm{.} \mathrm{.} \mathrm{.} \mathrm{.} \mathrm{.} \mathrm{.} \mathrm{.} \mathrm{.} \mathrm{.} \mathrm{.} \mathrm{.} \mathrm{.} \mathrm{.} \mathrm{.} \mathrm{.} \mathrm{.} \mathrm{.} \mathrm{.} 103$

3.3 Valores típicos da razão $d_{g r} / l_{e x}$ e diâmetros médios $\langle D\rangle$ das amostras de nanofios de Ni e Co em função da tensão de anodização. . . . . . . . . . . . . . . . . 108 


\section{CAPÍTULO 1}

\section{Introdução}

O magnetismo dos materiais é um dos fenômenos físicos mais antigos conhecidos pela humanidade. Embora desde cedo tenha conquistado a atenção do homem, a busca pelo entendimento do magnetismo - e sua intrigante ação à distância - levou o ser humano por caminhos tortuosos (às vezes errôneos) ao longo da história, de conceitos pré-científicos até mesmo a idéias pseudo-científicas e/ou sobrenaturais e práticas esotéricas. Nessa jornada de mais de vinte e um séculos, uma compreensão mais lúcida e sofisticada só começou a ser desenvolvida a partir do século XIX, com as teorias clássicas da eletricidade e do magnetismo, culminando com o brilhante trabalho de James Clerk Maxwell. Sua maior contribuição foi unificar a eletricidade, o magnetismo e a óptica numa única teoria, encerrada em quatro célebres equações - o eletromagnetismo clássico. Muitas das questões em aberto na virada para o século XX se concentravam no magnetismo da matéria. O que acontecia na escala microscópica?

Essa motivação não se restringia ao magnetismo. A própria estrutura da matéria era questão aberta na época e intensamente discutida nas Conferências de Solvay. Somente em meados do século XX, chegou-se à melhor descrição teórica do magnetismo da matéria e ao seu pilar mais fundamental: respectivamente, a teoria quântica e o spin do elétron. Com Richard Feynman, o homem se deu conta de que o caminho certo era "para baixo": buscou a origem do magnetismo nas menores escalas da matéria, motivado pela velha questão atômica grega - o que acontece se dividirmos a matéria em partes cada vez menores ad infinitum? E descobriu que o magnetismo se deve essencialmente a uma propriedade fundamental inerente ao elétron, o momento angular de spin, um efeito relativístico de uma partícula elementar carregada - o elétron -, que não pode nunca se encontrar totalmente 
em repouso. A analogia clássica mais próxima disso, embora insatisfatória, é a de um pião girando, com um momento angular constante, bem definido. No caso do elétron, esse momento angular de spin resulta num momento de dipolo magnético elementar, que é a causa fundamental do magnetismo da matéria (juntamente com o momento magnético associado ao momento angular orbital do elétron em torno do átomo).

A partir dos anos 30, a pesquisa em teoria quântica passou a incorporar os avanços tecnológicos - em grande parte motivado pela corrida bélica - e tomou rumos que levaram à manipulação de materiais em escalas microscópicas, de modo a tirar proveito de efeitos quânticos mesoscópicos, que não eram observados nos materiais na sua forma ordinária, como encontrados na natureza. O transistor, por exemplo, foi um produto dessa linha de pesquisa. Mais do que nunca, ciência e tecnologia passaram a caminhar juntas e a se desenvolverem mutuamente. Ao longo dos últimos setenta anos a física de materiais tem levado a um progresso científico, tecnológico e econômico sem precedentes [1]. Em poucas décadas, o ser humano desenvolveu e acumulou tanto conhecimento sobre o comportamento quântico da matéria, que fez explodir a quantidade de aplicações tecnológicas baseadas no desenvolvimento de novos materiais em escalas micro-, nano- e subnanométricas. Hoje, podemos dizer que toda a economia e o próprio modo de vida humano dependem dos produtos da nanociência e nanotecnologia. E o avanço continua, alimentado pela demanda sempre crescente do mercado por novas tecnologias, como a spintrônica, e por dispositivos eletrônicos de armazenamento, leitura, gravação e transmissão de dados cada vez mais rápidos, seguros e eficientes [2]. Ainda hoje, o estudo de sistemas magnéticos em nanoescala vem pondo à prova hipóteses, modelos e teorias do magnetismo de materiais e gerando descobertas e patentes revolucionárias, que levaram a prêmios Nobel em física, tais como o prêmio Nobel de 1970, para Louis Néel, por suas contribuições ao entendimento dos materiais ferromagnéticos e antiferromagnéticos; e, mais recentemente, em 2007, para Albert Fert e Peter Grünberg, pela descoberta simultânea da magneto-resistência gigante (GMR) em tricamadas de $\mathrm{Fe} / \mathrm{Cr} / \mathrm{Fe}[3,4]$. Hoje, a GMR é a tecnologia utilizada nos cabeçotes de leitura magnética em discos rígidos de computadores e sensores de fuga de fluxo magnético.

A pesquisa em materiais magnéticos hoje em dia dispõe de uma grande variedade de técnicas experimentais de caracterização estrutural e magnética. Em geral, busca-se a des- 
crição qualitativa e quantitativa do comportamento estático e dinâmico da magnetização na presença de campos magnéticos externos e de propriedades de transporte dependente de spin. Esses comportamentos são determinados por grandezas micromagnéticas típicas do material, que por sua vez são definidos e descritos pelas teorias e modelos micromagnéticos. A compreensão desses fenômenos e do papel dos parâmetros físicos é de extrema importância para o desenvolvimento e uso de novos materiais em aplicações tecnológicas. Em particular, os sistemas nanomagnéticos, tais como nanofios e filmes finos magnéticos, apresentam fenômenos mesoscópicos interessantes, dos pontos de vista científico e tecnológico, pois encontram-se numa escala intermediária entre os comportamentos quântico e clássico da matéria. Nessa escala, a descrição teórica dos fenômenos físicos observados (limite clássico) deve ser construída sobre parâmetros físicos mensuráveis que representem e/ou guardem alguma relação com quantidades físicas fundamentais (limite quântico). Exemplos desses fenômenos são a forte anisotropia de forma perpendicular em arranjos auto-organizados de nanofios magnéticos e a alta polarização de spin de elétrons em superfícies ferromagnéticas estáveis a temperatura ambiente. O estudo de tais fenômenos são de grande interesse para o desenvolvimento das ciências físicas e de novas aplicações tecnológicas.

\subsection{Estrutura da Tese}

Neste trabalho, estudamos o comportamento estático, as interações magnetostáticas e os processos de magnetização de arranjos de nanofios magnéticos através da análise de curvas de inversão de primeira ordem, ou análise FORC, e a dinâmica de spin de superfície em filmes finos magnéticos via espectroscopia por perda de energia de elétrons spin-polarizados (SPEELS). Portanto, abordamos dois distintos sistemas magnéticos nanoestruturados e dois diferentes aspectos da pesquisa experimental em magnetismo e materiais magnéticos: o comportamento magnético estático e dinâmico de sistemas de spins. O trabalho está dividido da seguinte maneira.

O capítulo 2 apresenta uma revisão bibliográfica do estudo de arranjos de nanofios magnéticos fabricados por anodização e eletrodeposição, abordando as técnicas experimentais e a caracterização microestrutural e magnética desses sistemas. Nele, apresente- 
mos princípios de modelagem micromagnética, o método da análise FORC, sua origem, operacionalização e interpretação. O capítulo apresenta também uma revisão bibliográfica sobre as técnicas mais tradicionais de caracterização estrutural e magnética de filmes finos em física de superfícies. Em particular, apresentamos uma breve revisão sobre espalhamento inelástico de elétrons da técnica de SPEELS e da investigação de modos vibracionais e da dinâmica de spins de superfícies por SPEELS.

O capítulo 3 trata do comportamento estático e de modos de inversão da magnetização de redes auto-organizadas de nanofios magnéticos (Ni e Co). Apresentamos os materiais e métodos experimentais aplicados na fabricação e caracterização das amostras e nas medidas de FORCs. Realizamos a análise FORC das amostras, tentando entender a influência de dois diferentes fatores sobre os diagramas FORC obtidos: a influência do diâmetro médio dos nanofios e a direção de aplicação do campo magnético externo em relação ao eixo de anisotropia de forma, que é perpendicular à superfície da amostra. Apresentamos as assinaturas típicas das componentes reversível e irreversível da magnetização nos diagramas FORC em função dos diâmetros médios e da direção do campo aplicado e discutimos os resultados em comparação com resultados da literatura.

O capítulo 4 aborda a pesquisa realizada durante o estágio de doutorado-sanduíche pelo CNPq, na cidade de Halle(Saale), Alemanha, junto ao Instituto Max Planck de Física de Microestruturas, sob orientação do Prof. Dr. Jürgen Kirschner, no período de abril de 2008 a abril de 2009. Estudamos a dinâmica de spins em filmes de Fe/W(001) passivados por $\mathrm{O}_{2}$, à temperatura ambiente, em ambiente de ultra-alto vácuo (UHV). Para isso utilizamos a nova técnica de SPEELS, que é a única técnica hoje conhecida capaz de detectar mágnons (ondas de spin) de grandes vetores de onda, ao longo de toda a zona de Brillouin de superfície $(\mathrm{SBZ})^{1}$, em superfícies e filmes finos. Apresentamos as primeiras medidas simultâneas de fônons e ondas de spin de superfície em O-Fe/W(001) detectadas simultaneamente por SPEELS e suas curvas de dispersão ao longo de toda a SBZ (na direção $\bar{\Gamma} \bar{X}$ ). Comparamos nossos resultados com resultados da literatura e interpretamos os picos inelásticos segundo modelos tradicionais de vibrações da rede

\footnotetext{
${ }^{1} \mathrm{~A}$ zona de Brillouin da superfície corresponde à projeção da zona de Brillouin de volume (BBZ) numa determinada superfície. Se essa superfície é um dos planos de Bragg, a SBZ também terá pontos (e direções) de alta simetria correspondentes aos da BBZ, denotados pela mesma letra, com uma barra em cima [5].
} 
cristalina e de ondas de spin.

No capítulo 5, apresentamos um breve sumário dos principais resultados da tese e nossas conclusões e perspectivas para trabalhos futuros. 


\section{CAPÍTULO 2}

\section{Revisão Bibliográfica}

Neste capítulo segue uma breve revisão bibliográfica sobre o estudo de nanofios e filmes finos magnéticos. Ambos os sistemas têm sido extensivamente pesquisados há vários anos e a revisão apresentada aqui está longe de abordar todos os apectos desses sistemas ou de pretender esgotar o tema. Concentramo-nos nas configurações de equilíbrio, nos mecanismos reversíveis e irreversíveis e modos de inversão magnética e na dinâmica de spins desses sistemas. Revisamos também a teoria fenomenológica da análise FORC e a teoria micromagnética desses sistemas.

\subsection{Propriedades Físicas de Arranjos de Nanofios Mag- néticos}

Hoje, a forte aplicabilidade de novos materiais magnéticos de baixa dimensionalidade (filmes finos, multicamadas, super-redes, nanofios, aglomerados de partículas, "dots", etc.) na indústria de magneto-eletrônicos tem incentivado cada vez mais o estudo desses materiais. A possibilidade de se fabricar tais estruturas artificiais tem levado ao surgimento de novas tecnologias e de novas áreas da pesquisa básica. As mais diversas heteroestruturas possíveis de se fabricar hoje em dia constituem sistemas-modelos e verdadeiros laboratórios de pesquisas físicas, as mais fundamentais. Isso tem contribuído enormemente para o desenvolvimento das ciências físicas (teórica e experimental) e para o avanço do entendimento fenomenológico do magnetismo em escalas cada vez menores e em condições geométricas especiais, nas quais o comportamento quântico da matéria se torna cada vez 
mais relevante. Por exemplo, a descoberta de novos fenômenos físicos nas últimas décadas, como a magneto-resistência gigante e a válvula de spin [3, 4], o exchange-bias [6] e a junção túnel magnética (MTJ) [7] desencadearam um desenvolvimento tecnológico vertiginoso na indústria de leitura e gravação magnética de dados. Atualmente, a capacidade de armazenamento de informação (i.e., o número de bits de informação) por unidade de área em discos rígidos duplica a cada 12 meses (lei de Kryder ou "lei de Moore para discos rígidos" ${ }^{\prime 1}$, tendo crescido cerca de 50 milhões de vezes desde a introdução do primeiro disco rígido da história (RAMAC, 1956) [8] - uma taxa de crescimento superior à da Lei de Moore de semicondutores [9]. Isso tem possibilitado a contínua redução das dimensões dos bits de informação. Um bit é um aglomerado de partículas magnéticas micrométricas, as quais mantêm uma mesma orientação de seus momentos magnéticos.

Mas esse crescimento exponencial tem dado sinais de saturação, pois quanto mais se diminui o tamanho do bit magnético, mais as partículas ficam suscetíveis a flutuações térmicas, perdendo estabilidade magnética e, conseqüentemente, a confiabilidade para o armazenamento permanente de dados. Este limite inferior de estabilidade magnética para uma partícula é chamado limite superparamagnético e tem um comportamento exponencial com o volume da partícula e com sua energia de anisotropia da forma [10]

$$
\tau=\tau_{0} \exp \left(\frac{K V}{k_{B} T}\right)
$$

onde $\tau$ é o tempo em que o momento magnético de uma partícula se mantém estável num certo mínimo de energia, $\tau_{0}$ é uma constante típica do material (da ordem de $10^{-9}$ a $10^{-10}$ s) relacionada à taxa média de inversão termicamente ativada do momento magnético da partícula, $K$ é a constante de anisotropia magnética efetiva da partícula, $V$ é o volume da partícula, $k_{B}$ é a constante de Boltzmann e $T$ é a temperatura. Esse comportamento resulta da competição entre os termos de energia magnética $K V$, que tende a ordenar o momento magnético da partícula num estado magnético bem definido, e de energia térmica $k_{B} T$, que tende a desestabilizá-la. Quando $K V>>k_{B} T$, a partícula está bloqueada $(\tau \rightarrow \infty)$, pois a energia térmica não é suficiente para vencer a barreira de potencial $K V$ entre dois mínimos de energia magnética. Mas se $K V \approx k_{B} T$, as flutuações térmicas

\footnotetext{
${ }^{1}$ Em analogia à Lei de Moore de semicondutores, segundo a qual o número de transistores num circuito integrado dobra a cada 18 meses [9].
} 
são grandes o suficiente para fazer o momento magnético da partícula transitar entre os mínimos de energia magnética numa freqüência $f=\tau^{-1}$. Devido a seu comportamento exponencial, $\tau$ sofre sensíveis mudanças em função do volume da partícula. Por exemplo [10], uma partícula esférica de Co com $68 \AA$ de diâmetro, a uma temperatura fixa de $20^{\circ} \mathrm{C}$, tem um tempo de relaxação $\tau \approx 0,1 \mathrm{~s}$. Isso significa que essa partícula transitaria entre os mínimos de energia cerca de 10 vezes por segundo e qualquer medida magnética mais longa que esse tempo registraria uma partícula desmagnetizada. Mas se aumentarmos o diâmetro da partícula de $68 \AA$ para $90 \AA$, o tempo de relaxação aumenta para $\tau \approx 10^{9} \mathrm{~s}$, o que corresponde a cerca de 100 anos. Ou seja, a partícula seria tão estável, que levaria cerca de 100 anos para mudar de estado.

Atualmente, enormes esforços técnicos têm sido dedicados para se vencer o limite superparamagnético [11]. Uma possibilidade é a gravação magnética perpendicular [12], na qual os bits de informação têm magnetização perpendicular à superfície. Esta configuração pode ser concretizada a partir de um arranjo de nanofios magnéticos depositados numa membrana de alumina $\left(\mathrm{Al}_{2} \mathrm{O}_{3}\right)$ porosa ordenada. Nesta aplicação, a magnetização correspondente a um bit de informação tem dimensão lateral da ordem de nanômetros a dezenas de nanômetros e possui uma forte anisotropia de forma, perpendicular à superfície, capaz de vencer o limite superparamagnético a que estaria sujeito na gravação longitudinal. Além disso, esse conjunto de nanofios exibem uma alta densidade superficial $\left(10^{10}\right.$ a $10^{11}$ poros $\left./ \mathrm{cm}^{2}\right)$, permitindo armazenar até $80 \mathrm{Gbits} / \mathrm{cm}^{2}$, contra o limite atual de $15 \mathrm{Gbits} / \mathrm{cm}^{2}$ na gravação longitudinal.

A obtenção de filmes de alumina $\left(\mathrm{Al}_{2} \mathrm{O}_{3}\right)$ anódica porosa é bem conhecida há pelo menos setenta anos [13]. Mas há menos de duas décadas foi descoberta a possibilidade de se fabricar um arranjo auto-organizado de poros cilíndricos, com diâmetros nanométricos, formando uma rede hexagonal altamente ordenada. Isso foi obtido primeiramente por Masuda e Fukuda através de um processo conhecido por anodização em dois passos [14, $15,16]$. Desde então, esse procedimento tem sido extensivamente explorado com o objetivo de se alcançar o controle das propriedades estruturais desses materiais.

Além disso, através de uma outra técnica eletroquímica, conhecida por eletrodeposição, pode-se preencher esses poros com metais de transição [17, 18], ligas metálicas [19], óxidos semicondutores [20], dentre outros materiais [21]. Isso permite a obtenção de arranjos de 
nanofios desses materiais com uma alta razão de aspecto. Em particular, a deposição de metais de transição magnéticos (Fe, Co e Ni) dá origem a nanofios magnéticos com alta anisotropia de forma $[22,23,24,25,26]$. Essa característica, combinada à baixa dimensionalidade do sistema e à simetria da rede, confere ao arranjo de nanofios interessantes propriedades magnéticas, diferentes daquelas do material volumoso.

O controle experimental das características estruturais desses novos materiais magnéticos é de grande interesse científico e tecnológico. Primeiro, porque suas propriedades magnéticas, ópticas e de transporte dependem fortemente das propriedades estruturais do arranjo de poros (forma, diâmetro e comprimento dos poros, distância entre poros e densidade de poros). Segundo, porque esse controle experimental permite a fabricação de materiais com as propriedades desejadas para uma dada aplicação. Do ponto de vista científico, novos métodos de caracterização magnética têm sido desenvolvidos e aplicados aos mais diversos sistemas magnéticos. Um desenvolvimento recente é conhecido como análise FORC. Este método consiste na construção de um "mapa" da resposta magnética do material, obtido a partir de curvas de magnetização, logo após a saturação do material e sua parcial desmagnetização, via alguma técnica de magnetometria (VSM, AGM, SQUID, etc.). Curvas assim obtidas são denominadas curvas de inversão de primeira ordem (FORCs, First Order Reversal Curves). A análise e interpretação desses mapas é realizada segundo o modelo de Preisach da histerese [27, 28], que pressupõe um sistema magnético particulado, cuja resposta magnética é intrisecamente descontínua e não-linear. No modelo, o comportamento individual das partículas é dado por um ciclo de histerese quadrado e unitário $\left(M_{S}= \pm 1\right)$, caracterizado por um campo de inversão $h_{c}$ e um campo de interação local $h_{b}$, respectivamente análogos ao campo coercivo e ao campo de deslocamento (exchange-bias) de curvas de histerese experimentais. O comportamento do material como um todo em função de um campo magnético externo é determinado pela distribuição $P\left(h_{c}, h_{b}\right)$ das partículas que compõem o sistema. A análise FORC se vale da analogia que a distribuição FORC guarda com a distribuição de Preisach (revisamos a analogia entre a análise FORC e o modelo de Preisach na seção 2.1.6). Porém, esta última tem um sentido essencialmente estatístico, enquanto a primeira traz informações do comportamento real do material, que é determinado por suas propriedades micromagnéticas, interações magnetostáticas e processos de inversão da magnetização [29, 30]. 


\subsubsection{Anodização em Dois Passos}

A anodização consiste em uma eletrólise na qual o eletrodo de trabalho (ânodo, eletrodo positivo) da célula eletrolítica (CE) é um metal e o contra-eletrodo (cátodo, eletrodo negativo) deve ser um material inerte no meio eletrolítico, como carbono, chumbo, mercúrio ou platina. O objetivo da anodização é formar uma camada de óxido sobre o eletrodo de trabalho (ET), a partir da incorporação de oxigênio da solução sobre o metal. Dependendo da solubilidade da $\mathrm{Al}_{2} \mathrm{O}_{3}$ (alumina) no eletrólito, a camada de óxido crescida pode ser homogênea (tipo barreira) ou porosa [13]. Em geral, a solubilidade depende do pH, da temperatura da solução e da tensão aplicada. Em soluções ácidas fracas (com pH entre 5 e 7), a alumina é insolúvel e a camada formada é do tipo barreira; em soluções ácidas fortes (com pH entre 1 e 3), a alumina é solúvel e formam-se camadas porosas. Exemplos típicos dessas últimas são soluções aquosas de ácidos fosfórico $\left(\mathrm{H}_{3} \mathrm{PO}_{4}\right)$, sulfúrico $\left(\mathrm{H}_{2} \mathrm{SO}_{4}\right)$, crômico $\left(\mathrm{H}_{2} \mathrm{CrO}_{4}\right)$ e oxálico $\left[\mathrm{H}_{2} \mathrm{C}_{2} \mathrm{O}_{4}\right.$ ou $\left.(\mathrm{COOH})_{2}\right]$, em concentrações acima de $0,1 \mathrm{~mol} / \mathrm{L}$ [13]. Estes parâmetros determinam as taxas de dissolução e formação de $\mathrm{Al}_{2} \mathrm{O}_{3}$ no banho eletrolítico utilizado e, conseqüentemente, a taxa de crescimento da camada porosa.

Em 1995, no estudo de anodização de camadas óxidas porosas em Al, Masuda e Fukuda [14] observaram que, ao se remover a camada de óxido crescida após uma longa anodização (várias horas), a superfície do Al encontrava-se texturizada, com um ordenamento hexagonal de concavidades semi-esféricas. Ao realizarem uma segunda anodização, a camada de $\mathrm{Al}_{2} \mathrm{O}_{3}$ obtida exibiu uma superfície com poros cilíndricos, paralelos entre si e perpendiculares à superfície, com o mesmo arranjo hexagonal do Al subjacente. Além disso, esses poros exibiam alta razão de aspecto, dependendo do tempo da segunda anodização $[13,31]$. Desde então, essa técnica ficou conhecida por anodização em dois passos e tem sido bastante utilizada para a obtenção de alumina porosa para os mais diversos fins.

Entretanto, mesmo quando anodizada em soluções ácidas fortes, a camada de $\mathrm{Al}_{2} \mathrm{O}_{3}$ não é uniformemente porosa. Sua estrutura varia no espaço: o perfil poroso se inicia acima de uma camada tipo barreira, que se forma em contato direto com o Al subjacente durante o transiente inicial da anodização. O regime de crescimento da camada óxida está intimamente ligado ao perfil da corrente elétrica através da CE durante as anodizações. Na figura 2.1 mostramos um exemplo típico do comportamento da corrente elétrica na CE [32]. Pode-se identificar três regimes de corrente (marcada por diferentes cores na figura), 


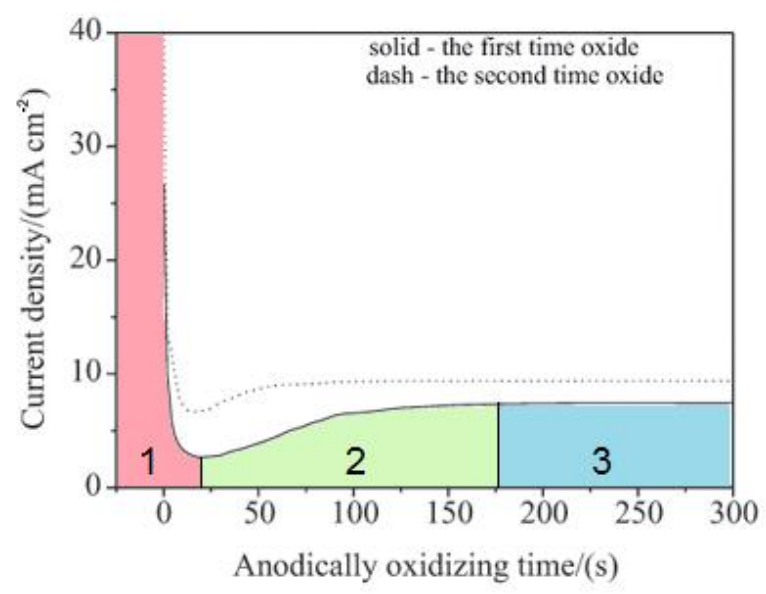

Figura 2.1: Exemplo do perfil da corrente elétrica através da célula eletrolítica durante a primeira (linha sólida) e segunda (linha pontilhada) anodizações [32]. Os três diferentes regimes de corrente marcam (1) o crescimento da camada de barreira, (2) o início da formação dos poros e (3) o crescimento estacionário da camada porosa.

que são explicados a seguir. Ao se aplicar uma tensão dc constante à CE, os átomos de $\mathrm{Al}$ da superfície do ET perdem elétrons e ficam positivamente carregados, podendo reagir com o oxigênio disponível na solução. Íons de oxigênio $\left(\mathrm{O}^{2-}\right)$ incorporam-se entre os sítios de $\mathrm{Al}$ segundo a reação química

$$
2 \mathrm{Al}(s)+3 \mathrm{O}^{2-} \rightarrow \mathrm{Al}_{2} \mathrm{O}_{3}(s)+6 e^{-} .
$$

Assim, forma-se inicialmente uma camada de barreira uniforme durante um transiente de alguns segundos, - caracterizado por uma alta corrente que rapidamente decai à medida que a camada se forma, aumentando a resistência elétrica do sistema (regime 1, na figura 2.1). A partir de uma certa espessura, inicia-se a formação dos poros, acompanhada pela mudança do comportamento da corrente. Essa espessura $t_{B}$ depende do eletrólito, de sua concentração, da temperatura e da tensão de anodização [13]. Para as condições típicas utilizadas neste trabalho, estimamos $t_{B}$ entre 40 e $100 \mathrm{~nm}$. Daí, a corrente começa a aumentar (regime 2, na figura 2.1), uma vez que passa a ocorrer a dissolução da $\mathrm{Al}_{2} \mathrm{O}_{3}$ assistida pelo campo elétrico [33]. A figura 2.2(a) representa a distribuição das linhas de campo elétrico através da camada de barreira nesse momento. A rugosidade natural da superfície induz o gradiente do campo elétrico a formar núcleos de oxidação na superfície, que aos poucos crescem e coalescem, como é mostrado na figura 2.2(b). Â medida em que crescem, as linhas de campo concentram-se em regiões cada vez menores nas interfaces, 
onde a dissolução da $\mathrm{Al}_{2} \mathrm{O}_{3}$ é favorecida. Inicialmente a taxa de dissolução da $\mathrm{Al}_{2} \mathrm{O}_{3}$ na interface óxido/solução é maior que sua taxa de formação na interface metal/óxido, favorecendo o consumo da $\mathrm{Al}_{2} \mathrm{O}_{3}$ nas regiões de alto gradiente de campo elétrico. A figura 2.2(c) marca o início da formação dos poros - no momento do mínimo da corrente elétrica (fig. 2.1). À medida que o poro se aprofunda, a camada de barreira diminui em espessura (no fundo dos poros) e a taxa de dissolução da $\mathrm{Al}_{2} \mathrm{O}_{3}$ decai até se igualar a sua taxa de formação. Daí em diante, a espessura da camada de barreira mantémse constante e estabelece-se o crescimento estacionário da camada porosa, marcado pela corrente constante no sistema (regime 3 na fig. 2.1).

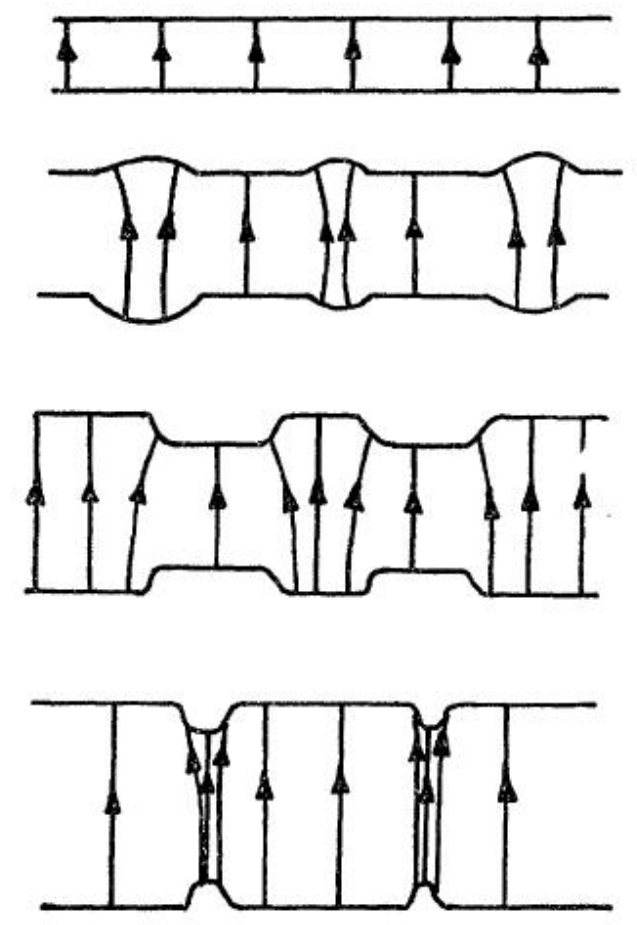

Figura 2.2: Esquema pictórico do gradiente do campo elétrico durante a anodização. Após a formação da camada de barreira (a), a rugosidade natural da superfície induz o gradiente do campo elétrico, criando núcleos de oxidação (b), que crescem e coalescem (c). Isso leva à concentração das linhas de campo em regiões muito pequenas nas interfaces (d), onde a dissolução da $\mathrm{Al}_{2} \mathrm{O}_{3}$ é favorecida. Essa dissolução ocorre a uma taxa inicial mais alta que a de formação de $\mathrm{Al}_{2} \mathrm{O}_{3}$ na interface metal/óxido, que diminui até se igualar a esta última. Daí em diante, a espessura da camada de barreira mantém-se constante e estabelece-se o crescimento estacionário da camada porosa [33].

A partir da formação da camada de barreira, nos primeiros segundos da anodização, estabelece-se a distinção entre três meios bem definidos: a solução, a camada de óxido e o metal. Os processos que ocorrem nas interfaces óxido/solução e metal/óxido são 


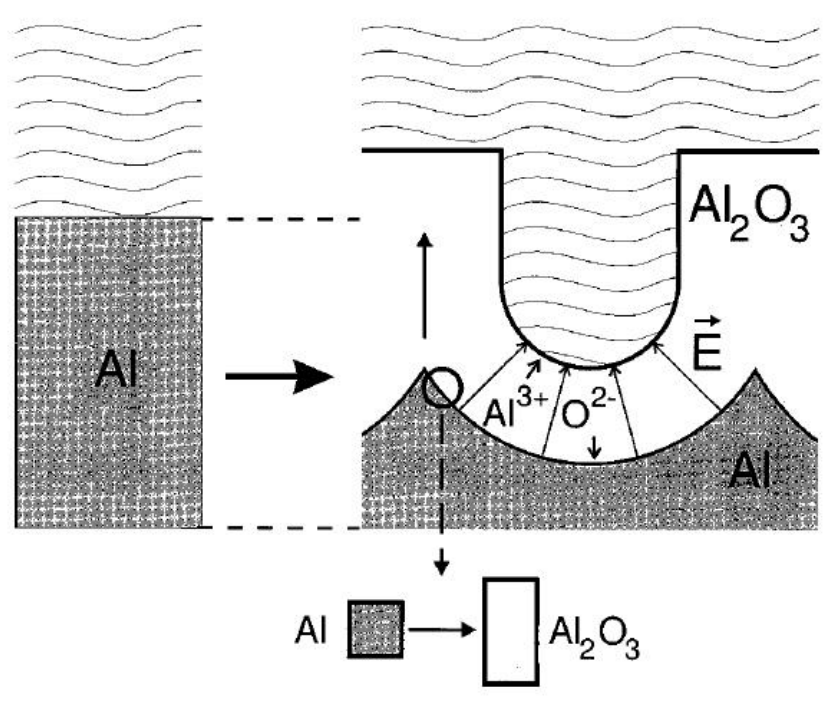

Figura 2.3: Esquema pictórico da formação da camada de óxido porosa [34]. A espessura da camada de barreira $t_{B}$ depende da tensão de anodização e do eletrólito [13]. Para soluções de $(\mathrm{COOH})_{2}$ em tensões típicas de trabalho, $t_{B}$ deve variar entre 40 e $100 \mathrm{~nm}$.

governados por diferentes semi-reações químicas. A incorporação do oxigênio na estrutura cristalina do Al causa um aumento de volume de sua célula unitária [34, 35, 36]. Esta expansão dá uma alta mobilidade aos íons $\mathrm{Al}^{3+}$ e $\mathrm{O}^{2-}$ através da camada óxida. $\mathrm{O}$ campo elétrico é responsável pela migração de íons $\mathrm{Al}^{3+}$ e $\mathrm{O}^{2-}$ através das camadas $[13,34,35,36,37]$, como podemos ver na figura 2.3. Assim, a topologia da camada de óxido é determinada pelo gradiente de campo elétrico através da camada [34]. A formação de $\mathrm{Al}_{2} \mathrm{O}_{3}$ na interface metal/óxido se dá pela migração de $\mathrm{O}^{2-}$ para dentro do ânodo, enquanto o $\mathrm{Al}^{3+}$ migra direto para a solução [34]. Este processo é representado pela equação

$$
2 \mathrm{Al}+3 \mathrm{O}^{2-} \rightarrow \mathrm{Al}_{2} \mathrm{O}_{3}+6 e^{-}
$$

Ao mesmo tempo, no contra-eletrodo de carbono, ocorre a evolução de hidrogênio,

$$
6 H^{+}+6 e^{-} \rightarrow 3 H_{2}(g)
$$

balanceando a transferência de cargas na CE. Há ainda reações paralelas que ocorrem espontaneamente devido ao contato da alumina com a água, que é a hidratação parcial da alumina e a formação de óxidos intermediários, que permanecem presentes na estrutura final em pequenos traços, como o $\mathrm{AlO}(\mathrm{OH})$ e o $\mathrm{AlO}(\mathrm{OH}) \cdot \mathrm{H}_{2} \mathrm{O}$. Essas reações, quando 
favorecidas pelo aumento de temperatura, podem levar ao selamento dos poros, o que dificulta o preenchimento dos poros numa subseqüente eletrodeposição. A reação global que ocorre na CE é dada pelo balanço das semi-reações anteriores, resultando em

$$
2 \mathrm{Al}+3 \mathrm{H}_{2} \mathrm{O} \rightarrow \mathrm{Al}_{2} \mathrm{O}_{3}(s)+3 \mathrm{H}_{2}(g)
$$

onde $\mathrm{o} \mathrm{Al}_{2} \mathrm{O}_{3}$ sólido se forma na superfície do ânodo ( $\mathrm{Al}$ ) e o $\mathrm{H}_{2}$ gasoso se forma sobre o cátodo.

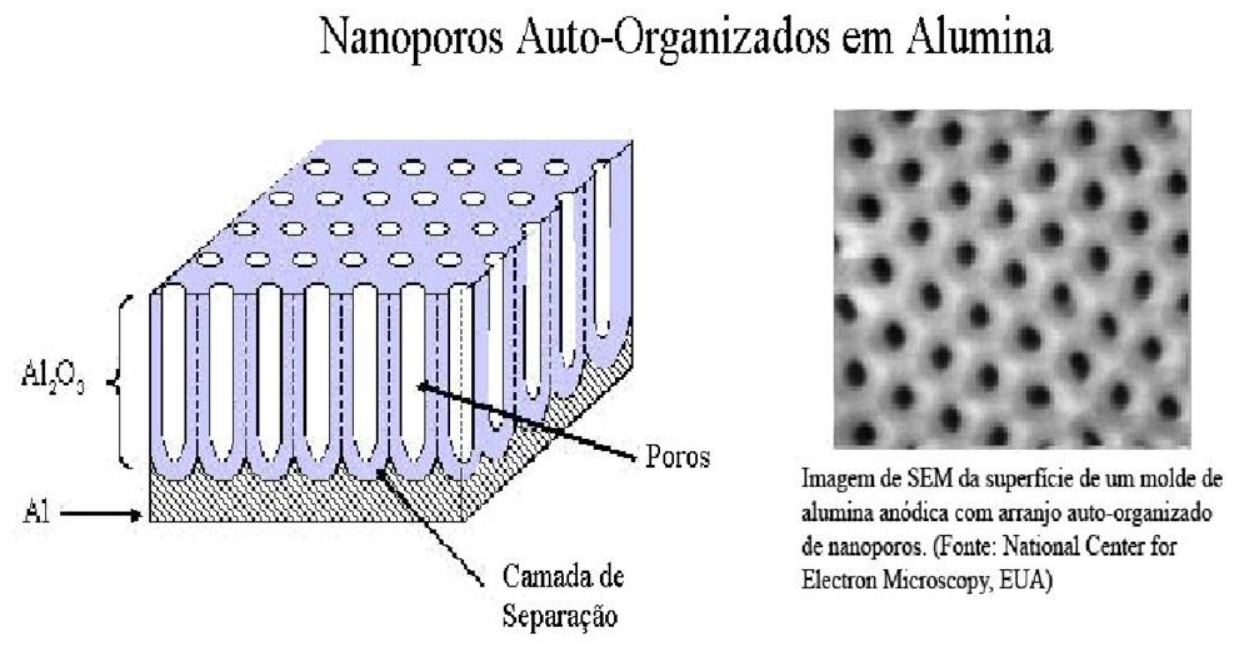

Figura 2.4: Esquema pictórico (à esquerda) e imagem de SEM (à direita) de uma lâmina de $\mathrm{Al}_{2} \mathrm{O}_{3}$ porosa auto-organizada, obtida por anodização em dois passos de uma lâmina de $\mathrm{Al}$ puro $(99,9995 \%)$ em meio ácido.

Na primeira anodização, a rede de poros formada é aleatória, devido ao mecanismo de formação explicado acima (fig. 2.2). Quando se remove a camada de óxido através de uma abrasão química em meio ácido, a altas temperaturas $\left(40-80^{\circ} \mathrm{C}\right)$, expõe-se a superfície de $\mathrm{Al}$ subjacente. Ao final da primeira anodização, a interface de $\mathrm{Al}$ encontra-se texturizada, num padrão de concavidades bem regular, que serve de "guia" para a formação de novos núcleos de oxidação na segunda anodização. Como resultado, a rede de poros forma uma estrutura hexagonal auto-organizada, como mostrada na figura 2.4. Nesse ponto, a lâmina de $\mathrm{Al}_{2} \mathrm{O}_{3}$ está pronta para ser utilizada como matriz para eletrodeposição dos mais diversos materiais. O procedimento completo de obtenção de uma arranjo de nanofios está resumido nas figuras 2.5. Nelas, vemos esquemas pictóricos do perfil da amostra após cada uma das etapas de fabricação: (a) a lâmina de $\mathrm{Al}$ de alta pureza, (b) após a primeira 
anodização, (c) após a abrasão química, (d) após a segunda anodização e (e) após a eletrodeposição do metal magnético.

(a)

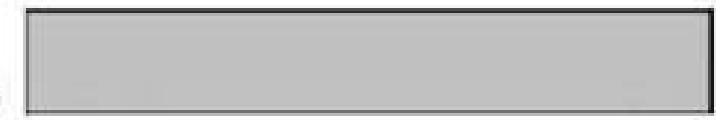

(b)

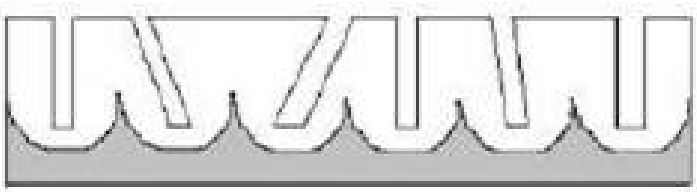

(c)

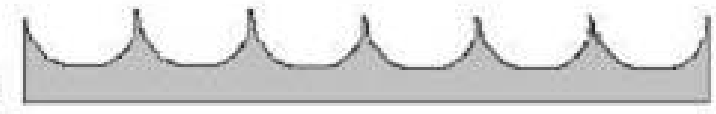

(d)

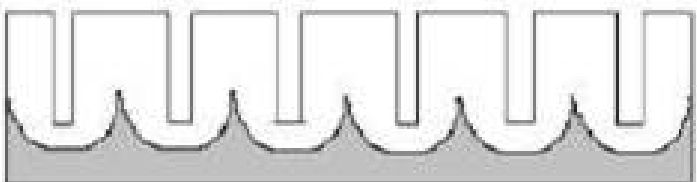

(e)

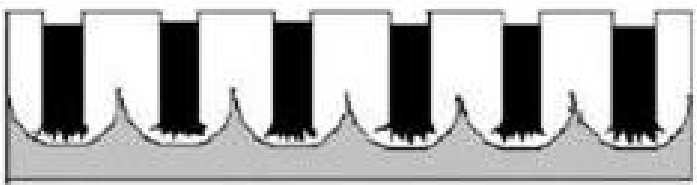

Figura 2.5: Perfil da amostra em cada etapa de fabricação das lâminas de $\mathrm{Al}_{2} \mathrm{O}_{3}$ porosa: (a) lâmina de $\mathrm{Al}$ antes da anodização, (b) após a primeira anodização, (c) após remoção da camada de óxido, (d) após segunda anodização e (e) após eletrodeposição do metal magnético (obtido da ref. [39]).

\subsubsection{Eletrodeposição}

Um método muito versátil e barato de crescimento de filmes e preenchimento de matrizes de nanoporos é a deposição eletroquímica, ou simplesmente eletrodeposição. Ela é bem difundida no meio industrial e tem ganhado bastante popularidade ultimamente no meio científico. Nessa etapa ocorre a redução do íon metálico $\left(M^{2+}+2 e^{-} \rightarrow M^{0}\right.$, onde $\mathrm{M}=\mathrm{Fe}$, Co ou Ni) da solução sobre a superfície de $\mathrm{Al}_{2} \mathrm{O}_{3}$ (no interior dos poros), formando núcleos de deposição. Diferentes métodos de eletrodeposição têm sido colocados à prova, visando a eficiência do preenchimento dos poros: deposições galvanostáticas (a corrente constante), potenciostáticas (a tensão constante), a correntes ou potenciais pulsados, alternados, com formas de onda quadrada, dente de serra e senoidal [18, 23, 24, 34, 38]. O eletrólito utilizado deve conter íons do material que se deseja depositar e um pH adequado, que, 
para deposição de metais, em geral é ácido. No caso da deposição de Fe, Co ou Ni, costuma-se utilizar uma solução aquosa de $\mathrm{MSO}_{4} \cdot 6 \mathrm{H}_{2} \mathrm{O},\left(\mathrm{M}=\mathrm{Fe}, \mathrm{Co}\right.$ ou Ni), com $\mathrm{H}_{3} \mathrm{BO}_{3}$ (ácido bórico) a 30-55 g/L, para baixar o pH da solução para em torno de 1 a 3 . Um pH baixo garante uma boa oferta de íons $\mathrm{H}^{+}$livres na solução, aumentando sua condutância e facilitando a deposição.

Numa eletrodeposição DC, a superfície a ser tratada deve ser utilizada como pólo negativo. Convencionalmente, o eletrodo de trabalho (ET) é o ânodo, sendo este positivo quando polarizado no sentido anódico ou negativo quando polarizado no sentido catódico. Assim, ao se aplicar uma tensão catódica nos terminais da célula eletrolítica, os íons positivos são acelerados na direção do ânodo, depositando-se em sua superfície, enquanto os íons negativos se movem na direção do cátodo. Numa eletrodeposição AC, o sistema passa ora por um ciclo catódico, ora por um ciclo anódico, de modo que o material é depositado durante o ciclo catódico de corrente e removido durante o ciclo anódico.

Apesar de a eletrodeposição DC ser uma abordagem mais direta a primeira vista, seus resultados são muito sensíveis à espessura da camada de barreira $[13,18,22,23]$ e, portanto, pouco reprodutível. $\mathrm{A} \mathrm{Al}_{2} \mathrm{O}_{3}$ é um material dielétrico e diamagnético. Como as membranas de $\mathrm{Al}_{2} \mathrm{O}_{3}$ porosa anodizadas têm vários micrômetros de espessura e uma $\mathrm{ca}$ mada de barreira homogênea em contato com o Al, esses sistemas possuem alta resistência elétrica. Para vencer esse obstáculo, é comum o uso de métodos de abrasão química para o alargamento dos poros e redução da espessura da camada de barreira ou deposição de uma camada metálica na parte traseira da amostra anteriormente à eletrodeposição para aumentar sua condutividade e facilitar a migração de íons para o interior dos poros. Além disso, a condutividade das bicamadas anodizadas de $\mathrm{Al} / \mathrm{Al}_{2} \mathrm{O}_{3}$ porosa são diferentes nos sentidos catódico e anódico, semelhante ao que ocorre num diodo quando polarizado direta ou inversamente $[13,18]$. Essa propriedade particular do sistema pode favorecer uma deposição mais homogênea e estável no interior dos poros no caso de uma eletrodeposição AC ou pulsada. A corrente durante o ciclo de deposição (catódico) é maior do que no ciclo de remoção (anódico). No ciclo catódico, os íons metálicos são acelerados contra o eletrodo, depositando-se em toda a sua superfície - dentro e fora dos poros. Durante o ciclo anódico, apenas os íons mais fracamente adsorvidos na superfície são removidos [18]. Os íons eficientemente depositados em sítios estáveis permanecem adsorvidos e o pro- 
cesso se repete. Assim, a deposição prevalece no interior dos poros, onde o gradiente do campo elétrico é mais forte, enquanto os íons depositados na superfície são eventualmente removidos.

Ao se aplicar uma tensão constante na CE, podem ocorrer diversos processos eletroquímicos: efeitos capacitivos (polarização), efeitos resistivos (transporte eletrônico e/ou iônico), reações químicas, adsorção/remoção de material nos eletrodos, etc. [40]. Dependendo do valor da ddp aplicada, um dado processo pode predominar sobre os outros. Por exemplo, uma ddp muito alta favorece a eletrólise da molécula de água, gerando $\mathrm{H}_{2}$ gasoso em excesso na superfície dos eletrodos e atrapalhando a deposição. Assim, a eficiência da deposição (i.e., o grau de homogeneidade do preenchimento dos poros) depende da densidade de corrente percorrendo o sistema (e também da freqüência, no caso AC [18]).

Desta forma, é possível que haja um valor (ou uma faixa de valores) de tensão que favoreça a deposição do material sobre o ET. Nesse caso, haveria um pico de corrente elétrica em torno de $E=V_{R}$. De fato, cada íon de um elemento químico possui um potencial de redução $V_{R}$ típico. Quando a ddp aplicada atinge esse valor, os íons dissolvidos na solução reduzem, ou seja, ganham elétrons, transformando-se na sua forma metálica (neutra). Isto significa que houve deposição, uma vez que a carga eletrônica é transmitida através do eletrodo quando os íons se depositam sobre ele.

Portanto, é importante se conhecer o(s) potencial(is) de redução dos íons que se deseja depositar antes de se executar a eletrodeposição. Para isso, é preciso realizar um procedimento denominado voltametria cíclica, que consiste em variar linearmente o potencial aplicado $E$ entre dois valores, monitorando a corrente $I$ em função de $E^{2}$. O voltamograma assim obtido revela quais possíveis processos eletroquímicos são dominantes em cada faixa de potenciais, como por exemplo, os potenciais de redução dos íons $\mathrm{Ni}^{2+}$. Em geral, varia-se a tensão aplicada entre o potencial de circuito aberto ( $V_{C A}$, quando o ET não está submetido a potencial externo algum) e um valor negativo de potencial (polarização catódica), tipicamente entre $-3 \mathrm{~V}$ e $-5 \mathrm{~V}$.

Submetemos algumas amostras a voltametrias em solução de $\mathrm{NiSO}_{4} \cdot 6 \mathrm{H}_{2} \mathrm{O}$ a $0,1 \mathrm{~mol} / \mathrm{L}$ $+\mathrm{H}_{3} \mathrm{BO}_{3}$ a $45 \mathrm{~g} / \mathrm{L}$, que é a solução-padrão utilizada em todas as eletrodeposições deste

\footnotetext{
${ }^{2}$ Este potencial deve ser medido em relação a um eletrodo de referência (ER), que é um terceiro eletrodo, inerte, que não participa das reações e tem um potencial fixo em relação ao ET. Utilizamos como ER um eletrodo de solução de $\mathrm{Ag} / \mathrm{AgCl}$ saturada.
} 


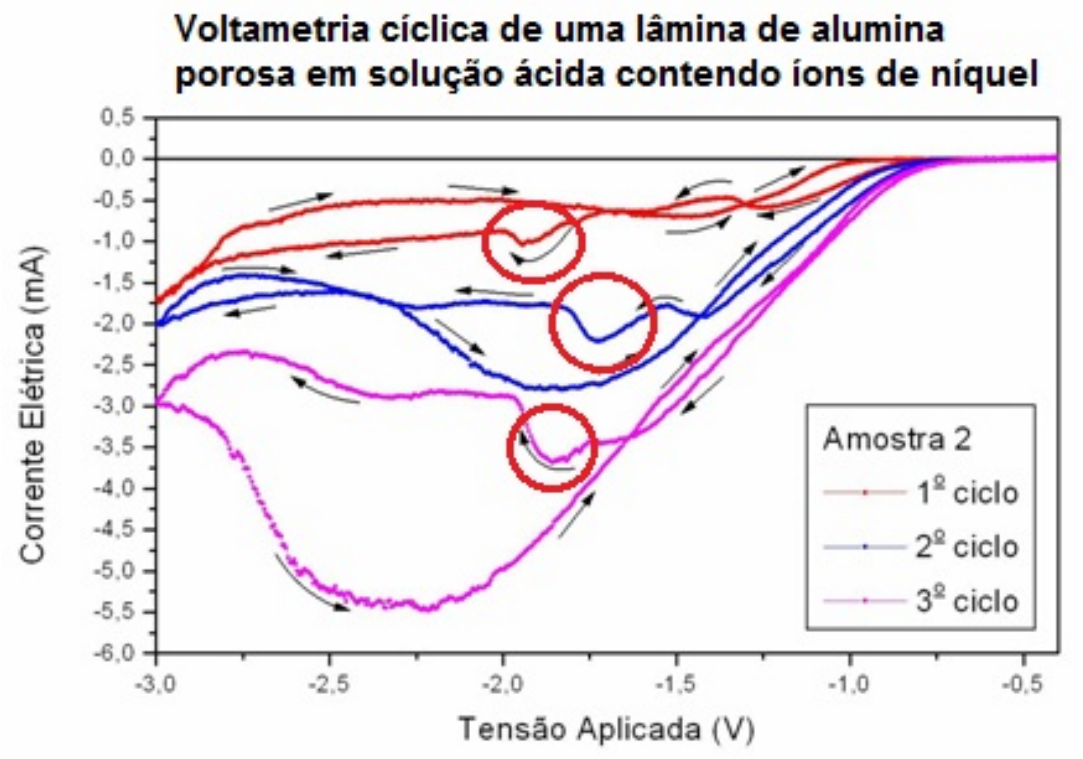

Figura 2.6: Voltamograma de uma amostra anodizada sob as condições padrão $\left[3^{\circ} \mathrm{C}\right.$, em 0,3 $\mathrm{mol} / \mathrm{L}(\mathrm{COOH})_{2}$, a $40 \mathrm{~V}$, por 1 hora $\left(1^{\mathrm{a}}\right) / 40$ minutos $\left.\left(2^{\mathrm{a}}\right)\right]$, e eletrodepositada em solução de $\mathrm{NiSO}_{4} \cdot 6 \mathrm{H}_{2} \mathrm{O}$ a $0,1 \mathrm{~mol} / \mathrm{L}+\mathrm{H}_{3} \mathrm{BO}_{3}$ a $45 \mathrm{~g} / \mathrm{L}$, à temperatura ambiente. Os círculos vermelhos indicam os picos de redução dos íons $\mathrm{Ni}^{2+} \rightarrow \mathrm{Ni}^{0}$, quando estes se depositam sobre a superfície interna dos poros.

trabalho. Em todas as voltametrias, a tensão aplicada variou entre $V_{C A}$ e $-3 \mathrm{~V}$ (polarização catódica), numa taxa de $50 \mathrm{mV} / \mathrm{s}$. Variamos também o número de ciclos de cada uma das amostras. Os resultados obtidos têm a forma do gráfico da figura 2.6, obtido para uma amostra anodizada segundo o procedimento padrão. A voltametria foi realizada em solução de $\mathrm{NiSO}_{4} \cdot 6 \mathrm{H}_{2} \mathrm{O}$ a $0,1 \mathrm{~mol} / \mathrm{L}+\mathrm{H}_{3} \mathrm{BO}_{3}$ a $45 \mathrm{~g} / \mathrm{L}$, à temperatura ambiente. Este tipo de gráfico é chamado voltamograma. Ele mostra o comportamento da corrente elétrica em função da tensão aplicada no sistema durante a voltametria cíclica. Nele podemos identificar um regime capacitivo até aproximadamente $-0,75 \mathrm{~V}$, na qual ocorre a polarização da CE (eletrodos + solução). A partir daí, estabelece-se uma corrente elétrica no sistema, que aumenta até atingir o pico de redução do $\mathrm{Ni}^{2+}$ em aproximadamente $-1,9$ $\mathrm{V}$ (no $1^{\mathrm{O}}$ ciclo, em vermelho). Estes picos de corrente indicam quais os valores de tensão mais adequados para maximizar a eficiência da deposição para uma dada amostra. A partir de $-2,8 \mathrm{~V}$, onde as curvas de ida e volta coincidem, a corrente elétrica no sistema se deve majoritariamente a evolução de $\mathrm{H}_{2}$ (gasoso), dificultando a deposição do Ni. Vemos ainda que a cada ciclo o potencial de redução do Ni varia entre -2 e $-1,5 \mathrm{~V}$, bem como todo o perfil da curva, uma vez que o eletrodo sofre modificações durante o processo. Isso 
sugere que, para a amostra 2, eletrodeposições dc são mais eficientes se realizadas nessa faixa de potenciais.

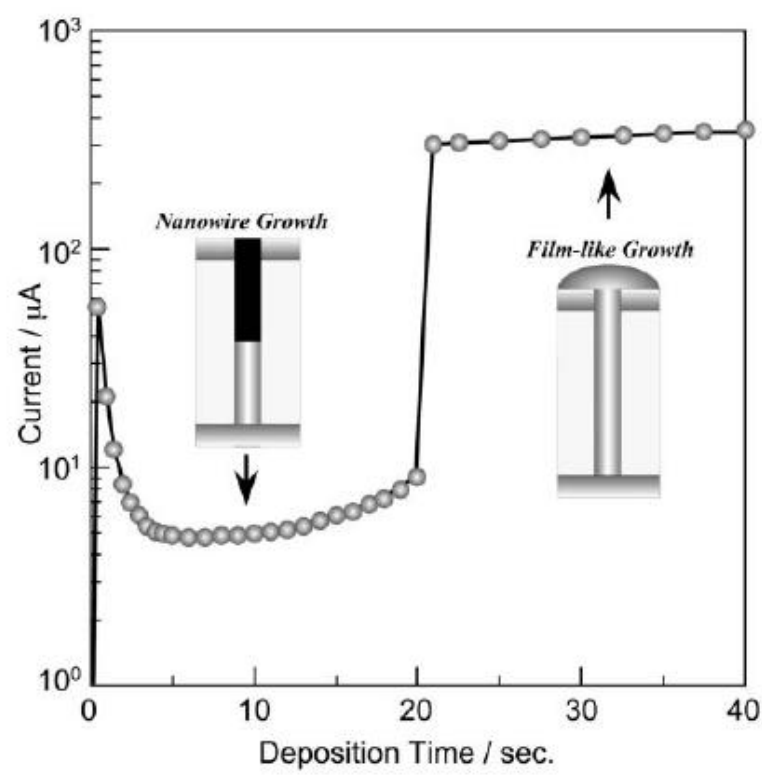

Figura 2.7: Perfil típico da corrente elétrica na célula eletrolítica durante uma eletrodeposição DC de nanofios de Ni numa matriz porosa de $\mathrm{Al}_{2} \mathrm{O}_{3}$ [22].

Ao monitorar a corrente elétrica na CE durante uma eletrodeposição DC, é possível determinar - para uma amostra ideal, cujos poros não se encontram obstruídos -, o momento em que os poros são totalmente preenchidos e a deposição passa a ocorrer na superfície. Na figura 2.7, vemos um perfil típico da corrente elétrica na CE durante uma eletrodeposição DC. À medida que os poros são preenchidos com metal, a resistência elétrica do eletrodo diminui e a corrente tende a aumentar gradativamente. No momento em que os nanofios atingem a superfície, a corrente deve dar um salto brusco, marcando o início de um novo regime de crescimento, uma vez que a deposição passa a formar um filme metálico [22]. Podemos ver ainda que o tempo típico de uma eletrodeposição DC é muito curto - cerca de 20 segundos. Vimos que tensões típicas de deposição estão entre -1,0 V e -1,5 V (contra um ER de $\mathrm{Ag} / \mathrm{AgCl}$ ). Embora a taxa de crescimento dos nanofios dependa da tensão aplicada, valores típicos encontram-se entre 100 e $150 \mathrm{~nm} / \mathrm{s}$ para aquela faixa de tensão [22]. Entretanto, uma deposição muito rápida pode ser ineficiente, pois pode obstruir poros antes mesmo que eles sejam efetivamente preenchidos. Numa eletrodeposição DC, o campo elétrico constante próximo ao ET provoca uma corrente contínua de cátions no interior dos poros. Isso pode causar uma saturação de íons dentro dos poros, 
que não têm tempo de difundirem [40], obstruindo-os e atrapalhando uma deposição eficiente, principalmente quando a estrutura dos poros apresentam irregularidades. Assim, a eletrodeposição DC pode levar a arranjos de nanofios de baixa qualidade (quanto ao preenchimento dos poros).

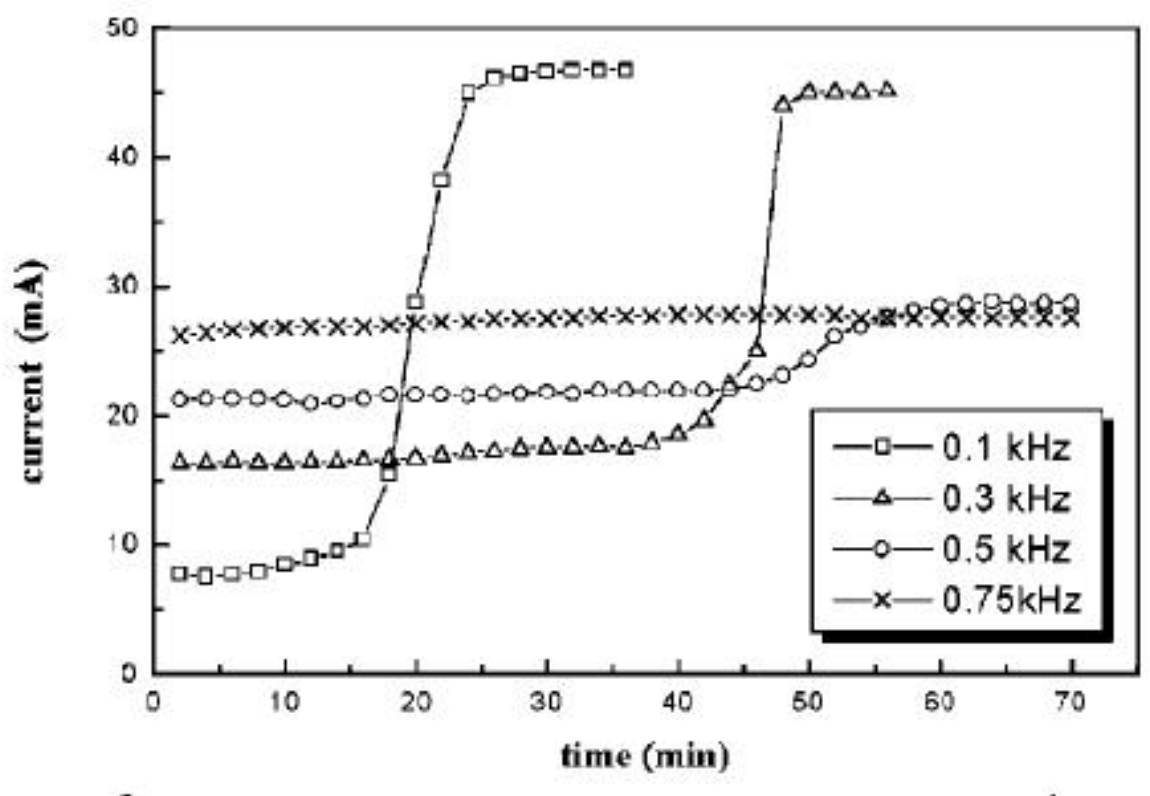

Figura 2.8: Perfil típico da corrente elétrica na célula eletrolítica durante uma eletrodeposição $\mathrm{AC}$ de nanofios de Ni numa matriz porosa de $\mathrm{Al}_{2} \mathrm{O}_{3}$ [18].

Em contrapartida, numa eletrodeposição AC (e/ou pulsada), a taxa de deposição é bem mais baixa que na eletrodeposição DC e depende fortemente da freqüência do sinal AC [18], uma vez que ciclos de deposição, difusão e remoção de íons se alternam [40]. Porém, na maioria dos casos a eletrodeposição AC dispensa um preparo prévio da amostra para aumentar a condutividade. O preenchimento total dos poros pode levar acima de 30 minutos [18]. Além de depender da tensão aplicada, a taxa de crescimento nesse caso deve depender também da freqüência do sinal AC [18]. Assim como na eletrodeposição DC, cada íon tem faixas ideais de tensão e de freqüência de deposição, a serem determinadas empiricamente. O perfil da corrente na CE apresenta um comportamento semelhante ao caso DC, conforme o regime de deposição (nanofios ou filme). Na figura 2.8 exibimos um comportamento típico da corrente elétrica na CE durante uma eletrodeposição AC [18]. Ela apresenta três regimes de corrente: dois patamares aproximadamente constantes e um estágio intermediário de crescimento. À medida que a freqüência aumenta (de 100 a 750 


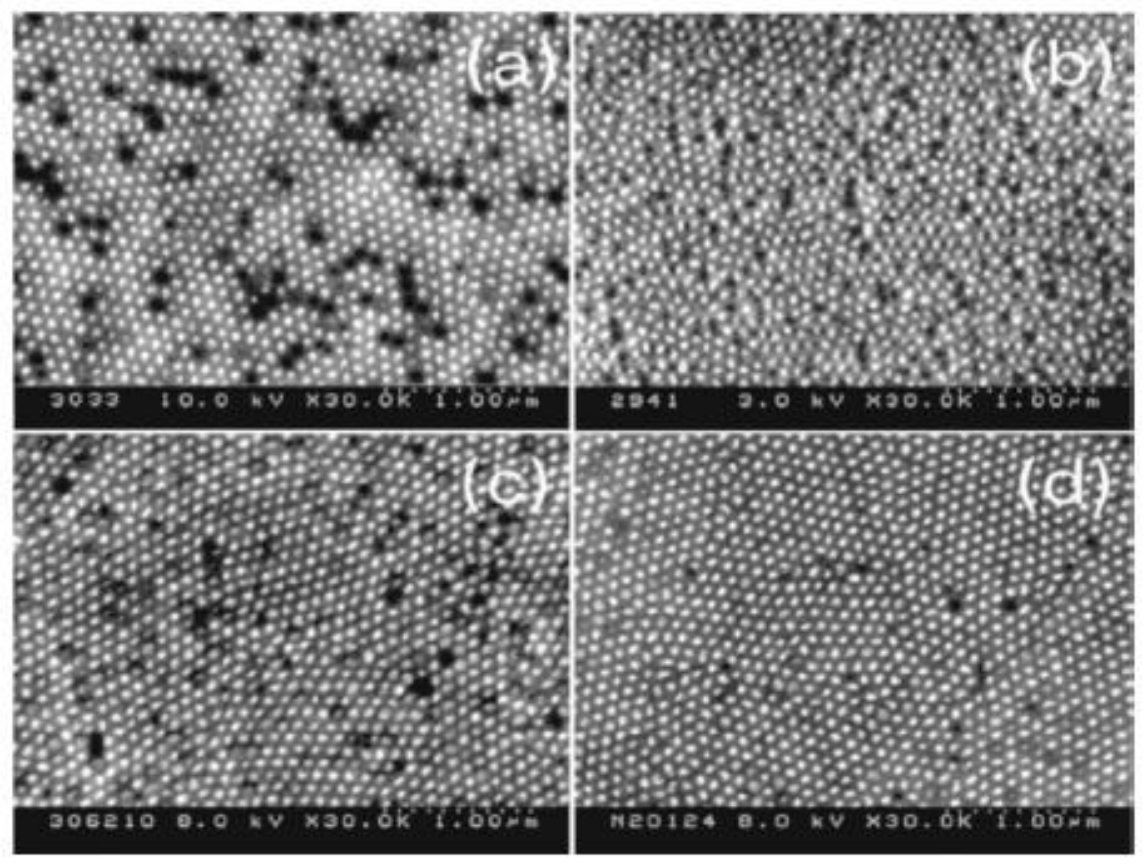

Figura 2.9: Imagens de MEV de nanofios eletrodepositados numa matriz de poros, mostrando o efeito da freqüência do sinal $\mathrm{AC}$ sobre o grau de preenchimento dos poros de uma matrix de $\mathrm{Al}_{2} \mathrm{O}_{3}$. As freqüências são (a) 100, (b) 300, (c) 500 e (d) $750 \mathrm{~Hz}$ [18] para Ni.

$\mathrm{Hz}$ ), o primeiro patamar tende a aumentar, enquanto o segundo patamar (mais alto) tende a cair, diminuindo o trecho de crescimento, até praticamente suprimi-lo por completo para $f=750 \mathrm{~Hz}$ [18]. Isso acontece por dois motivos [18]: (1) com o aumento da freqüência, há um aumento da polarização da camada de $\mathrm{Al}_{2} \mathrm{O}_{3}$ (efeito capacitivo), responsável pelo aumento da corrente total, em detrimento do transporte de massa (íons) ao interior dos poros; e (2) a taxa de deposição é limitada pelo transporte de massa através da camada de polarização. Com isso, a taxa de deposição tende a diminuir com o aumento da freqüência. Yin et al. [18] estimaram taxas de 74, 40 e $32 \mathrm{~nm} / \mathrm{min}$ para freqüências de 100, 300 e $500 \mathrm{~Hz}$, respectivamente. Um efeito particular da freqüência sobre a eletrodeposição pode ser observado na figura 2.9 e diz respeito ao grau de preenchimento dos poros: dentro de uma certa faixa de freqüência, quanto mais alta a freqüência, mais lento o preenchimento dos poros, porém maior o número de poros efetivamente preenchidos [18]. A freqüências mais altas, mais núcleos cristalinos são formados no interior dos poros, resultando num crescimento mais homogêneo dos nanofios, especialmente nos poros mais estreitos [18].

Dado o exposto acima e o aparato experimental disponível no LMM-IFUSP, optamos pela eletrodeposição AC para o preparo de nossas amostras. 


\subsubsection{Microestrutura dos Arranjos de Nanofios de Fe, Co e Ni}

Alguns dos parâmetros determinantes das propriedades magnéticas de arranjos de nanofios magnéticos são: o diâmetro dos fios $D=2 r_{f}$ ( $r_{f}$ é o raio dos fios), a distância (centro a centro) entre fios $d_{i n t}$, o comprimento dos nanofios $L$, a densidade superficial de poros $n$ e o grau de empacotamento dos fios $P$, definido como [41, 42]

$$
P=\frac{2 \pi}{\sqrt{3}}\left(\frac{r_{f}}{d_{i n t}}\right)^{2} .
$$

Estes são definidos pelas condições de anodização (pH, temperatura, tensão de anodização) da matriz de $\mathrm{Al}_{2} \mathrm{O}_{3}$ em que são depositados. Outros dependem das condições de deposição e do próprio material constituinte dos nanofios, como o tamanho do grão cristalino. O controle desses parâmetros estruturais a partir das condições de anodização é desejável para a obtenção de arranjos auto-organizados de poros com alta qualidade, isto é, arranjos com alta densidade de poros cilíndricos e paralelos. Com esse propósito, Nielsch et al. [42] propuseram que um arranjo hexagonal auto-organizado ideal pode ser obtido para quaisquer condições de anodização, desde que seja satisfeita a condição de um grau de empacotamento $P=10 \%$. Como a distância inter-fio é diretamente proporcional à tensão de anodização [42],

$$
d_{\text {int }}=k V_{a n}
$$

as duas equações acima podem ser combinadas para se determinar uma voltagem otimizada de anodização

$$
V_{a n}=\sqrt{\frac{2 \pi}{\sqrt{3} P}} \frac{r_{f}}{k},
$$

onde $k \approx 2,5 \mathrm{~nm} / \mathrm{V}[42]$. Assim, a voltagem ideal para se obter um arranjo hexagonal auto-organizado para poros com um dado diâmetro pode ser calculado para um conjunto de parâmetros fixos de anodização ( $\mathrm{pH}$, temperatura, eletrólito). Quanto à densidade de poros, o comportamento esperado com a tensão de anodização é da forma [42]

$$
n=\frac{2}{\sqrt{3}}\left(\frac{1}{k V_{a n}}\right)^{2} .
$$

A geometria e as escalas envolvidas determinam a magnitude das interações magne- 
tostáticas presentes nesses sistemas, tanto intra-fio quanto inter-fio e, conseqüentemente, todo o comportamento magnético do sistema. Nanofios de Fe, Co e Ni crescidos por eletrodeposição em matrizes porosas de $\mathrm{Al}_{2} \mathrm{O}_{3}$ podem exibir diâmetros que variam de alguns nanômetros a alguns micrômetros e comprimentos variando de centenas de nanômetros a dezenas de micrômetros. Possuem, portanto, alta razão de aspecto $(R=L / D \geq 50)$ e, conseqüentemente, forte anisotropia de forma. Além disso, quando dispostos num arranjo em paralelo altamente compacto, com cerca de $10^{10} \mathrm{fios} / \mathrm{cm}^{2}$, a interação dipolar entre os fios torna-se importante. Como exemplo de efeitos intra-fio, o tamanho dos grãos cristalinos determinam se os mesmos são grãos monodomínio ou multidomínio. Esses grãos possuem eixos de anisotropia magneto-cristalinos próprios, que podem ter uma distribuição direcional aleatória ou podem estar aproximadamente alinhados entre si. A existência de uma direção preferencial de crescimento dos grãos pode determinar um eixo de anisotropia efetiva. As unidades magnéticas (partículas) podem interagir entre si via interação de troca ou dipolar. Os mecanismos e os modos de inversão da magnetização são determinados por grandezas físicas diretamente ligadas a todas essas propriedades. Para se conhecer e dominar esses processos, é necessária uma boa caracterização estrutural e magnética desses sistemas.

A estrutura e a morfologia de arranjos de nanofios são extensivamente estudadas por métodos de microscopia eletrônica de varredura (MEV) ou de transmissão (MET) e microscopia de força atômica e magnética (AFM/MFM). Por exemplo, na figura 2.10, vemos imagens de MEV de nanofios de $\mathrm{Ni}$ (a e b) e Bi (c e d) obtidos por eletrodeposição AC [18]. Nas imagens, eles estão parcialmente expostos, após uma abrasão química que ataca apenas a matriz de $\mathrm{Al}_{2} \mathrm{O}_{3}$. Os nanofios de $\mathrm{Ni}$ foram depositados em arranjos de poros de $2 \mu \mathrm{m}$ de comprimento, enquanto os de Bi têm comprimentos de $25 \mu \mathrm{m}$.

Idealmente os nanofios são cilíndricos e compostos de grãos cristalinos muito menores que seus diâmetros. Mas na verdade, uma análise mais rigorosa das imagens de nanofios isolados revelam os defeitos e irregularidades de sua estrutura. Na figura 2.11, vemos imagens de MET de nanofios de Co em diferentes escalas [43]. Esses fios têm diâmetro médio de $40 \mathrm{~nm}$ e comprimento médio de $22 \mu \mathrm{m}$. Nos detalhes, podemos ver fios com indentações 2.11(b), rugosidades 2.11(c), extremidades retas 2.11(d), rombudas 2.11(e) ou pontiagudas 2.11(f). Essas falhas certamente influenciam o comportamento magnético 

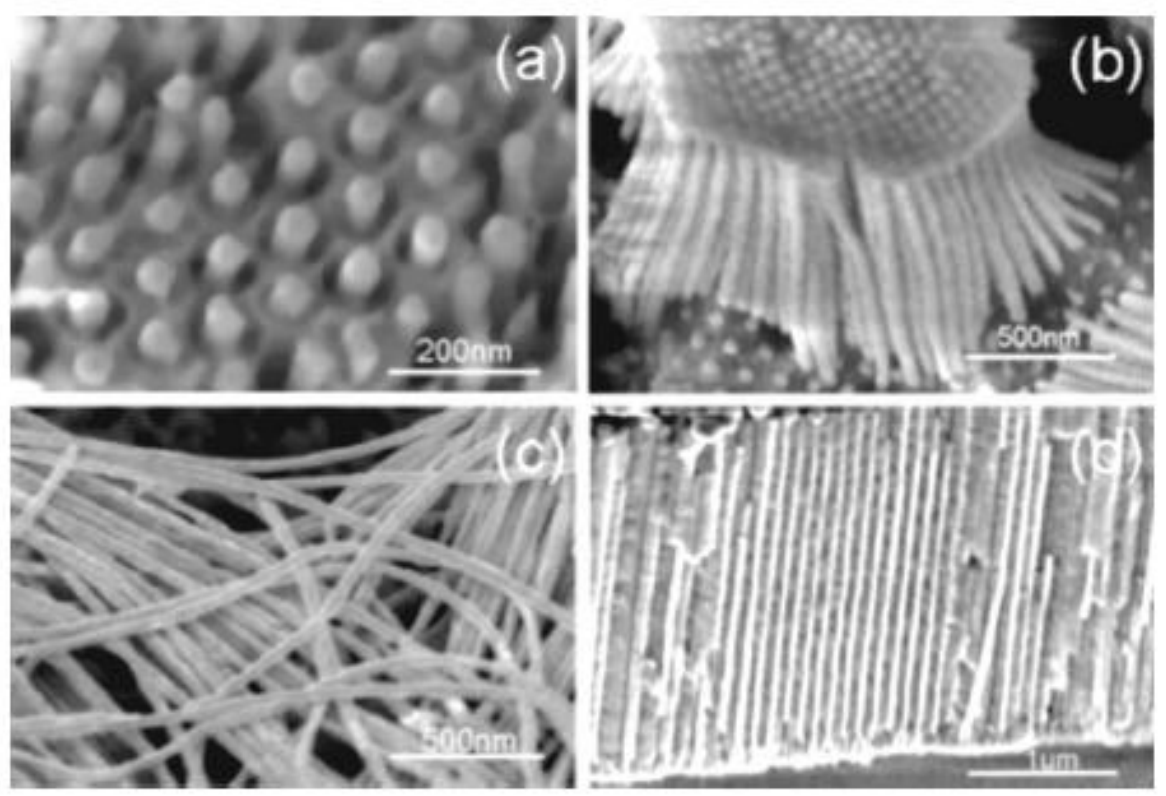

Figura 2.10: Imagens de MEV de nanofios de Ni (a e b) e Bi (c e d) obtidos por eletrodeposição $\mathrm{AC}[18]$.
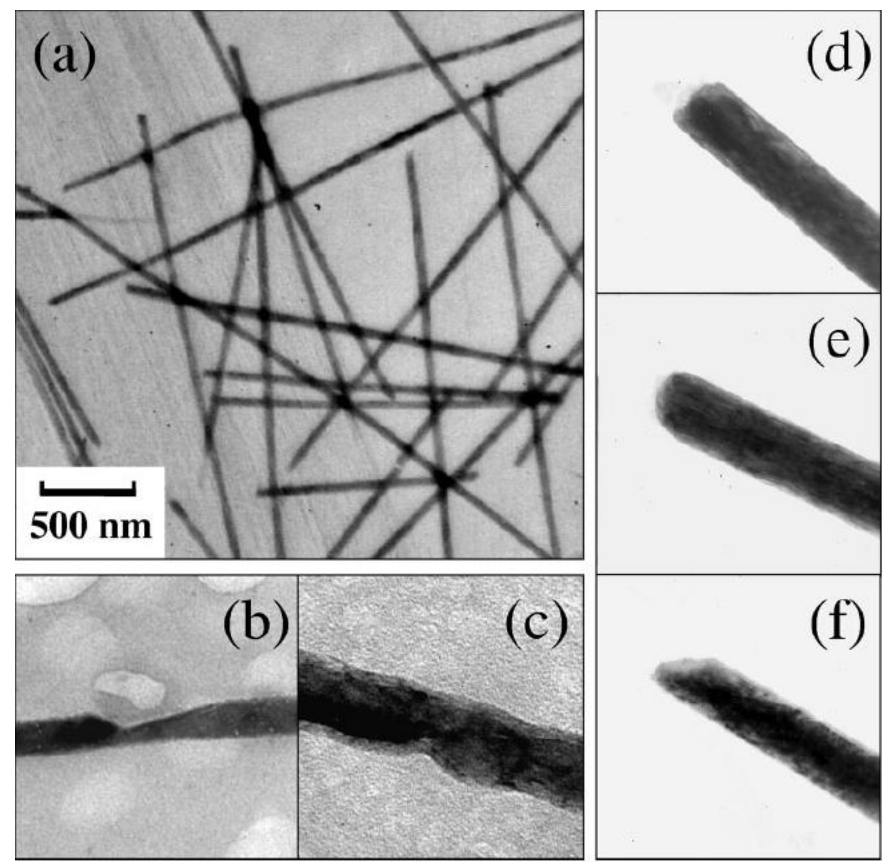

Figura 2.11: Imagens de MET de (a) nanofios de Co obtidos por eletrodeposição DC, com 40 $\mathrm{nm}$ de diâmetro e $22 \mu \mathrm{m}$ de comprimento e seus defeitos mais comuns: (b) indentações, (c) rugosidades, extremidades (d) planas, (e) rombudas e (f) pontiagudas [43]. 
dos fios. Em particular, na nucleação e propagação de modos não-uniformes de inversão da magnetização.

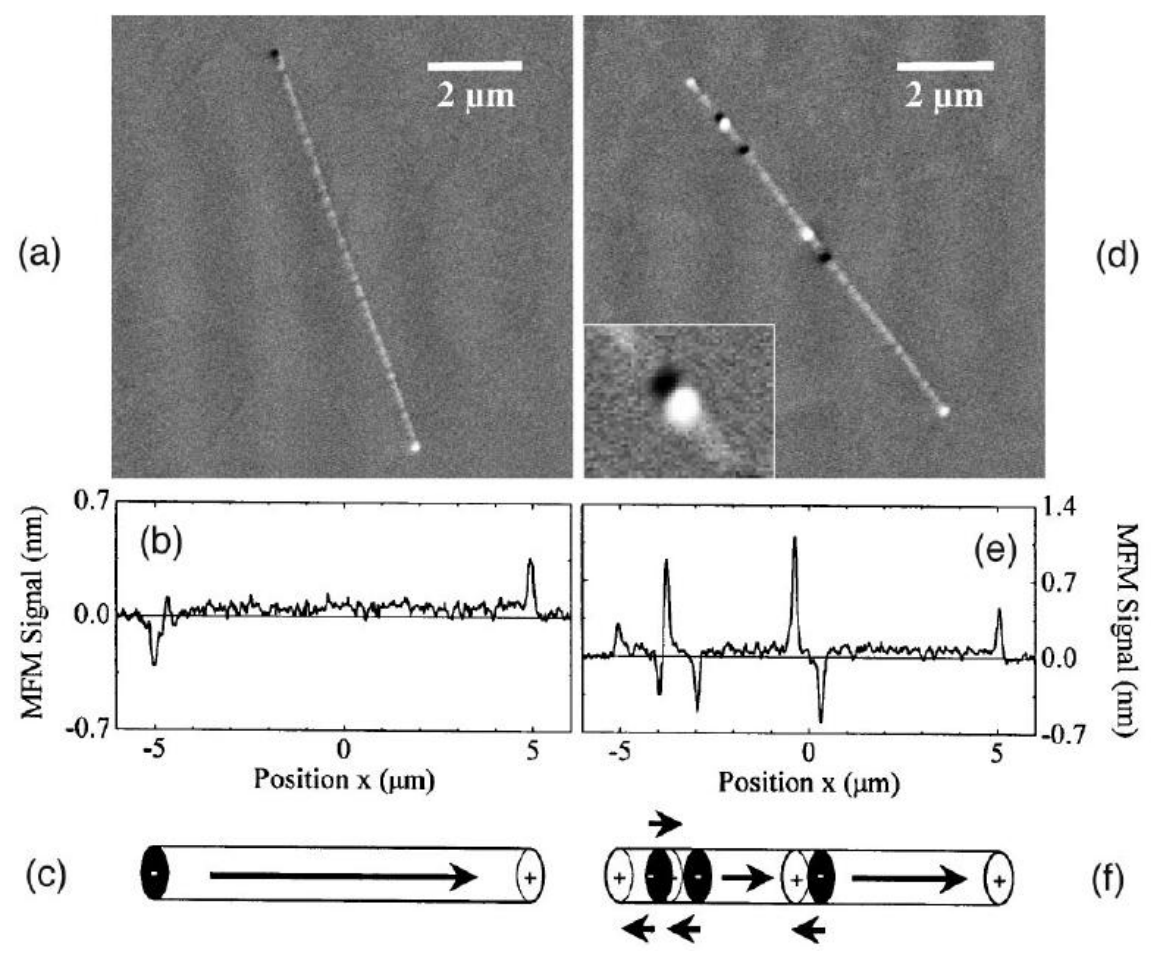

Figura 2.12: Imagens de MFM de nanofios de Co de $40 \mathrm{~nm}$ de diâmetro e $10 \mu \mathrm{m}$ de comprimento, obtidos por eletrodeposição DC. [43].

Imagens de MFM nos dão informações dos domínios magnéticos de uma estrutura e a correlação com sua morfologia. Um estudo desejável, mas um tanto difícil de se executar, é a microscopia de nanofios magnéticos isolados, sob influência de campo magnético externo. Nas figuras 2.12, vemos imagens de um nanofio isolado de Co com $40 \mathrm{~nm}$ de diâmetro e $10 \mu \mathrm{m}$ de comprimento, obtido por eletrodeposição DC. O contraste dá informação sobre a componente da magnetização no plano (ao longo do fio). Nas figuras 2.12(a-c), vemos imagens de MFM o estado remanente do nanofio após a aplicação de um campo magnético (suficiente para saturá-lo) ao longo do fio. Após a remoção do campo, o nanofio se comporta como um monodomínio magnético, com uma magnetização remanente longitudinal quase igual a $M_{S}$. Já nas figuras $2.12(\mathrm{~d}-\mathrm{f})$, vemos o estado remanente do nanofio após a aplicação do campo magnético na direção perpendicular ao fio. Agora, o estado remanente do fio não mais é um monodomínio magnético, muito embora a maior parte da sua magnetização seja longitudinal. O nanofio exibe uma estrutura de domínios magnéticos orientados ao longo do fio, em sentidos alternados [43]. Em posições bem definidas ao 
longo do fio, observa-se pequenas regiões de fortes contrastes, que são paredes de domínio de $180^{\circ}$. Na figura 2.12(e), podemos ver que essas paredes de domínio em nanofios de Co exibem larguras típicas de $\delta_{d w} \approx 1 \mu \mathrm{m}$. Se, durante o processo de desmagnetização $(H \rightarrow 0)$, as duas direções ao longo do fio forem equivalentes, a tendência predominante é a de os fios caírem num estado com dois domínios magnéticos opostos, separados por uma parede de domínio, com magnetização resultante muito pequena ou praticamente nula [43]. Isso ocorre para campos aplicados ao longo de direções $\theta=90^{\circ} \pm \epsilon$ em relação ao eixo principal do fio, onde $|\epsilon|<<90^{\circ}$. Quando o campo é removido, os momentos magnéticos sofrem um considerável torque de volta à direção longitudinal dos fios, devido à forte anisotropia uniaxial nessa direção. Se as duas direções colineares ao fio forem equivalentes e quaisquer duas regiões do nanofio que estiverem distantes e desacopladas entre si têm seus momentos magnéticos livres para girar em direções opostas. A partir de um certo $\epsilon$ crítico, uma das direções colineares ao fio passa a ser energeticamente mais favorável que a outra e o estado remanente volta a ser monodomínio ao longo da direção privilegiada [43].

Dentre as técnicas típicas utilizadas para determinação da fase cristalina dos nanofios estão a difratometria de raios X (XRD) e a difração de elétrons de baixas energias (LEED). A primeira tem uma maior penetração no material, permitindo detectar a estrutura cristalina do volume da amostra. A análise quantitativa dos picos de difração observados permite o cálculo do tamanho de grão cristalino e a direção preferencial de crescimento do material. Já a técnica de LEED é mais sensível à superfície e tem pouca penetração, fazendo-se necessário expor a superfície do material a ser analisado, o que nem sempre é possível. Na figura 2.13, vemos difratogramas de raios X para amostras de nanofios de (a) Co e (b) Ni, obtidos com radiação de tudo de Co. As fases estáveis identificadas foram $\mathrm{Co}(h c p)$ e $\mathrm{Ni}(f c c)$, com direções preferenciais de crescimento [0001] e [110], respectivamente. O cálculo do tamanho de grão resultou em grãos de Co com vários micrômetros de comprimento, muito maior que o diâmetro dos fios, orientados ao longo dos fios [43]. Portanto, a direção de anisotropia magneto-cristalina uniaxial do Co coincide com o eixo de anisotropia de forma dos fios. Para nanofios de Ni, a situação é bem diferente: eles são compostos de grãos menores que o diâmetro médio dos poros e sem uma orientação preferencial dos eixos de anisotropia magneto-cristalina [43]. São, portanto, policristalinos e 
têm sua anisotropia majoritariamente determinada pela anisotropia de forma [39, 44, 45].
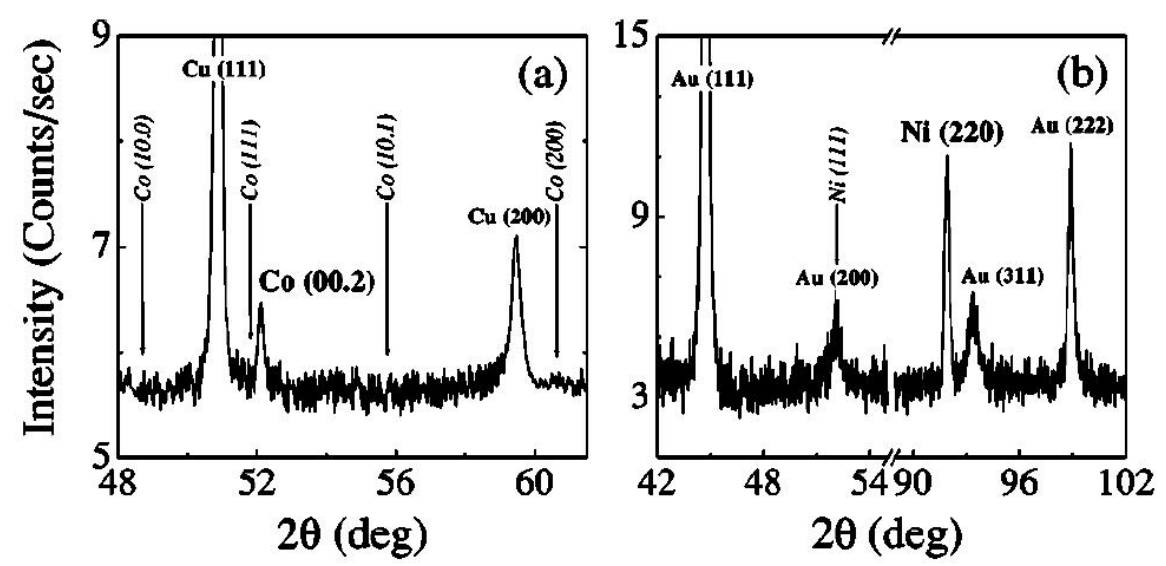

Figura 2.13: Difratogramas de raios $\mathrm{X}$ de amostras de nanofios de (a) Co e (b) Ni, obtidos com tubo de Co. Os nanofios de Co e Ni se encontram respectivamente nas fases $h c p$ e fcc, com direções preferenciais de crescimento respectivas [0001] e [110]. Vê-se também picos de Cu e Au, que foram depositados na parte traseira das amostras para facilitar o contato elétrico [43].

Os nanofios estudados por Henry et al. [43] exibem razão de aspecto $R=550$, o que se aproxima de um cilindro infinito, para efeitos de anisotropia de forma. Dessa maneira, eles devem apresentar uma constante de anistropia de forma $K_{f}=\pi M_{S}^{2}$, uniaxial, ao longo do fio. Isso resulta em $K_{f}^{N i}=7,4 \times 10^{5} \mathrm{erg} / \mathrm{cm}^{3}\left(M_{S}^{N i}=485 \mathrm{emu} / \mathrm{cm}^{3}\right)$ e $K_{f}^{C o}=6,2 \times 10^{6}$ $\mathrm{erg} / \mathrm{cm}^{3}\left(M_{S}^{C o}=1400 \mathrm{emu} / \mathrm{cm}^{3}\right)^{3}$. Por outro lado, a anisotropia magneto-cristalina do Ni é $K_{c}^{N i}=-4,5 \times 10^{5} \mathrm{erg} / \mathrm{cm}^{3}$, enquanto a do Co é de $K_{c}^{C o} \approx 2 \times 10^{6} \mathrm{erg} / \mathrm{cm}^{3}$. Portanto, a anisotropia magneto-cristalina é comparável à anisotropia de forma nos dois casos, como encontrado na literatura [43]. Pelo tamanho de grão apresentado pelo Co nos nanofios, sua orientação preferencial de crescimento é longitudinal aos fios, de modo que a anisotropia magneto-cristalina deve reforçar o efeito da anisotropia de forma ao longo do fio [43]. Já no caso do Ni, os nanofios geralmente são policristalinos, sem uma direção preferencial de anisotropia magneto-cristalina $[24,44]$ - há uma distribuição aleatória de orientação dos eixos de anisotropia das partículas. Isso reduz o efeito da anisotropia magneto-cristalina no material, prevalecendo a influência da anisotropia de forma.

Na figura 2.14, vemos um difratograma de nanofios de Fe crescidos por eletrodeposição AC, sob tensão de $15 \mathrm{~V}$, a $60 \mathrm{~Hz}$, a temperatura ambiente. Eles apresentaram diâmetro

\footnotetext{
${ }^{3} 1 \mathrm{~J}=10^{7}$ erg, logo $1 \mathrm{erg} / \mathrm{cm}^{3}=10^{-2} \mathrm{~J} / \mathrm{m}^{3}$.
} 


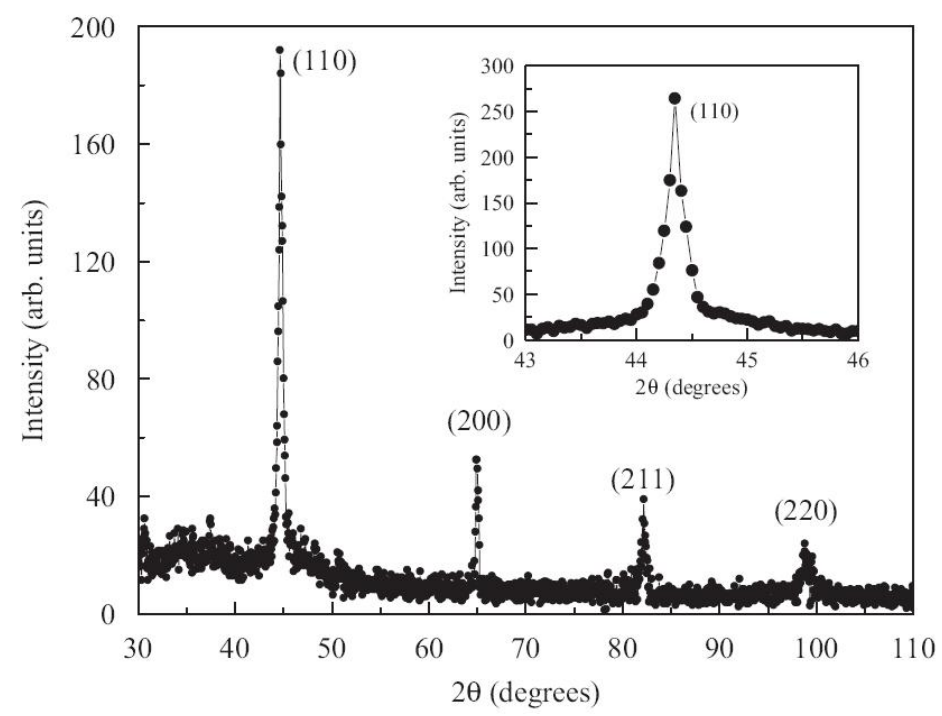

Figura 2.14: Difratograma de raios X de nanofios de Fe com $56 \pm 6 \mathrm{~nm}$ de diâmetro e 3-5 $\mu \mathrm{m}$ de comprimento, com uma clara textura [200] da fase $b c c$ e grãos de $48 \pm 2 \mathrm{~nm}$ [29].

\begin{tabular}{c|cc|cc} 
& $K_{c}\left(\times 10^{6} \mathrm{erg} / \mathrm{cm}^{3}\right)$ & Simetria & $K_{f}\left(\times 10^{6} \mathrm{erg} / \mathrm{cm}^{3}\right)$ & Simetria \\
\hline $\mathrm{Fe}$ & 0,5 & cúbica & 9,2 & uniaxial \\
$\mathrm{Co}$ & 2 & uniaxial (\| ao fio $)$ & 6,2 & uniaxial \\
$\mathrm{Ni}$ & $-0,45$ & cúbica & 0,74 & uniaxial
\end{tabular}

Tabela 2.1: Constantes de anisotropia magneto-cristalina e de forma estimada para os nanofios de Fe, Co e Ni [18, 29, 43].

médio de $56 \pm 6 \mathrm{~nm}$ e comprimentos de 3 a $5 \mu \mathrm{m}$ [29]. O Fe se estabiliza na fase $b c c$, com tamanhos de grãos em torno de $48 \mathrm{~nm}$, orientados ao longo da direção [200] [29, 41]. O Fe possui $M_{S}^{F e}=1707 \mathrm{emu} / \mathrm{cm}^{3}$, o que resulta numa constante de anisotropia de forma $K_{f}^{F e}=9,2 \times 10^{6} \mathrm{erg} / \mathrm{cm}^{3}$. Sua anisotropia magneto-cristalina é uma ordem de grandeza menor, $K_{c}^{F e}=5 \times 10^{5} \mathrm{erg} / \mathrm{cm}^{3}$, portanto, desprezível em comparação a $K_{f}^{F e}$. Resumimos esses resultados na tabela 2.1 .

O estudo da microestrutura dos nanofios de Fe, Co e Ni mostra que o tamanho e orientação dos grãos cristalinos são regulados pela morfologia dos poros (diâmetro e comprimento), podendo formar desde fios monocristalinos, como os de Co, cujos grãos podem atingir vários micrômetros, até fios totalmente policristalinos, como os de $\mathrm{Ni}[39,44,45]$. Embora a anisotropia de forma domine o comportamento magnético dos nanofios, a anisotropia magneto-cristalina pode exercer alguma influência quando há alguma orientação cristalina preferencial. Mas no caso de nanofios policristalinos, ela é desprezível frente à anisotropia de forma. Além disso, é importante levar em consideração a razão 
entre o comprimento de coerência do material e o diâmetro dos nanofios para se determinar a existência de paredes de domínio dentro dos fios e, conseqüentemente, a nucleação e propagação de modos não-uniformes de inversão da magnetização dos nanofios.

\subsubsection{Micromagnetismo de Nanofios Magnéticos}

Uma abordagem muito bem difundida da descrição do comportamento magnético estático e dinâmico de materiais em escala micro- e nanométrica é a modelagem micromagnética. Essa abordagem foi desenvolvida por Landau [46] e mais tarde generalizada por W. F. Brown [47]. Ela parte da determinação de uma equação de energia livre magnética para o sistema, cujos termos descrevem diferentes mecanismos que contribuem para a energética da magnetização, como interações entre momentos magnéticos (ou spins) numa rede (interação de troca, dipolar, etc.), anisotropias magnéticas (magneto-cristalina, de forma, de superfície, de interface, de troca, etc.), interação Zeeman (campo magnético externo), energia magnetostática, dentre outros. Em geral, esses termos competem entre si para determinar as configurações de equilíbrio magnético, os modos de inversão da magnetização e os modos coletivos do sistema. As configurações de equilíbrio são obtidas a partir da minimização da energia livre magnética [47], enquanto o comportamento dinâmico é determinado a partir da solução da equação de Landau-Lifshitz [46] para soluções harmônicas dos campos envolvidos. Vamos aplicar a teoria micromagnética para discutir alguns aspectos importantes da fenomenologia de sistemas de partículas magnéticas e nanoestruturas magnéticas.

\section{Termos de Energia Magnética e o Comportamento da Magnetização}

As propriedades magnéticas de um material dependem fortemente de sua estrutura cristalina e de sua geometria. Isto se deve ao fato da estrutura cristalina servir de suporte físico para as interações magnéticas, que em geral dependem da distância. Por exemplo, a interação coulombiana entre os átomos e a interação spin-órbita intra-atômica resultam numa quebra de simetria do potencial cristalino em torno de cada sítio da rede. Isso induz uma anisotropia local, um campo cristalino, que depende da simetria da estrutura cristalina (octaédrica, tetraédrica, etc.). Assim, o material como um todo exibe uma anisotropia magneto-cristalina, ou seja, uma direção preferencial para a orientação 
da magnetização de equilíbrio. Em materiais uniaxiais, existe um eixo de anisotropia magnética bem definido, ao longo do qual a magnetização tende a se orientar. A energia livre magnética associada à anisotropia magneto-cristalina uniaxial, com eixo-fácil $\hat{u}$, é da forma

$$
F_{K}=K V \frac{(\vec{M} \cdot \hat{u})^{2}}{M_{S}^{2}}=K V \cos ^{2} \theta,
$$

onde $K$ é a constante de anisotropia do material, $\theta$ é o ângulo entre a magnetização e o eixo de anisotropia $\hat{u}$. Em materiais de simetria cúbica, pode haver um conjunto de eixos-fáceis equivalentes e a energia de anisotropia pode ser expressa em termos dos cossenos diretores da magnetização [48]. Mas, em geral, a anisotropia magneto-cristalina de materiais cúbicos é mais baixa do que outras contribuições presentes.

Além da anisotropia magneto-cristalina, os momentos magnéticos atômicos interagem localmente por acomplamento de troca (exchange-coupling) e tendem a se orientar cooperativamente com sua vizinhança, levando a uma ordem magnética de longo alcance. Esse termo de energia tem sua origem no princípio da exclusão de Pauli e na anti-simetria da função de onda total dos elétrons num sólido. Ele pode ser expresso fenomenologicamente da forma

$$
F_{J}=-\sum_{\langle i j\rangle} J_{i j} \frac{\vec{M}_{i} \cdot \vec{M}_{j}}{M_{S}^{2}}=-\sum_{\langle i j\rangle} J_{i j} \cos \theta_{i j},
$$

onde $J_{i j}$ é a constante de troca entre dois sítios vizinhos e $\theta_{i j}$ é o ângulo entre as magnetizações $\vec{M}_{i}$ e $\vec{M}_{j}$. Se $J_{i j}>0$, um acoplamento ferromagnético é favorecido; se $J_{i j}<0$, um estado antiferromagnético é mais estável. Embora o acoplamento de troca seja de curto alcance, ele é muito forte em materiais ferromagnéticos, levando a uma ordem de longo alcance, abaixo da temperatura de Curie do material. Isso favorece um ordenamento coletivo dos momentos magnéticos ao longo de uma mesma direção. Entretanto, isso acarreta um aumento da energia magnetostática junto à interface entre o material e o meio externo. Essa energia é armazenada no campo de fuga devido a pólos magnéticos não compensados na interface entre os dois meios. Quando um material é magnetizado, há formação de pólos magnéticos não compensados nas faces. Para que as condições de contorno de $\vec{B}$ e $\vec{H}$ nas interfaces sejam satisfeitas, é necessário haver um campo desmagnetizante $\vec{H}_{d}$ no 
interior do material, dado por [48]

$$
\vec{H}_{d}=-\mathbb{N} \vec{M}
$$

onde $\vec{M}$ é a magnetização e $\mathbb{N}$ é o tensor desmagnetizante de traço unitário, determinado pela geometria do material. Este efeito pode ser descrito como uma anisotropia de forma [48]. Para um cilindro magnetizado ao longo do eixo (z), o tensor de forma se reduz a [45]

$$
\mathbb{N}=\left(\begin{array}{ccc}
N_{\perp} & 0 & 0 \\
0 & N_{\perp} & 0 \\
0 & 0 & N_{\|}
\end{array}\right)
$$

No caso limite de um cilindro infinito, $N_{\perp}=1 / 2$ e $N_{\|}=0$. O termo de energia magnetostática é da forma

$$
F_{M}=-\vec{M} \cdot \vec{H}_{d}=\vec{M} \cdot \mathbb{N} \vec{M}=M_{S}^{2}\left(N_{\|}-N_{\perp}\right) \cos ^{2} \theta_{M}
$$

onde $\theta_{M}$ é o ângulo entre a magnetização e a direção do eixo maior (ou de anisotropia de forma) do material [48].

Esses dois efeitos - acoplamento de troca e energia magnetostática - competem entre si, de modo que a configuração de equilíbrio do material é determinada pela minimização da energia livre magnética total, que em geral é proporcional ao volume do material. Para minimizar essa energia, as condições de contorno de Maxwell exigem que as linhas de campo se fechem no interior do material. Para isso, é necessário que a magnetização do sistema seja não-uniforme, isto é, que existam regiões do material com diferentes orientações de magnetização, mas dentro das quais a coerência magnética é mantida. Essas regiões são chamadas de dominios magnéticos e podem ter volumes de alguns micrômetros cúbicos a vários centímetros cúbicos. Nas regiões limítrofes entre domínios vizinhos, a magnetização sofre uma transição gradual entre as duas orientações, ao longo de uma certa distância $\delta_{d w}$. Essa região é chamada parede de domínio e, para um sistema com anisotropia uniaxial (magneto-cristalina ou de forma), tem uma espessura dada por 


\begin{tabular}{ccccc} 
& Anisotropia magneto-cristalina & $\delta_{d w}(\mathrm{~nm})$ & $l_{e x}^{\|}(\mathrm{nm})$ & $l_{\text {ex }}^{\perp}(\mathrm{nm})$ \\
\hline $\mathrm{Fe}$ & fraca & 7,23 & 14 & 2,3 \\
$\mathrm{Co}$ & forte & 15,7 & 5 & 2,9 \\
$\mathrm{Ni}$ & fraca & 25,8 & 47 & 8,2 \\
\hline
\end{tabular}

Tabela 2.2: Valores típicos da largura de parede de domínio e dos comprimentos de coerências paralelo e perpendicular para Fe, Co e Ni (calculados para $A=10^{-6} \mathrm{erg} / \mathrm{cm}=10^{-11} \mathrm{~J} / \mathrm{m}$ ) [48].

$$
\begin{aligned}
\delta_{d w} & =\pi \sqrt{\frac{A}{K}}, \text { para materiais de alta anisotropia, e } \\
\delta_{d w} & =\pi \sqrt{\frac{A}{2 \pi M_{S}^{2}}}, \text { para materiais de baixa anisotropia, e }
\end{aligned}
$$

onde $A$ é a constante de rigidez da interação de troca (exchange stiffness), $K$ é a constante de anisotropia e $M_{S}$ é a magnetização de saturação do material. Paredes de domínios podem ter espessuras entre alguns nanômetros e vários micrômetros. Diretamente correlato à largura de parede de domínio é o conceito de comprimento de coerência de um material, definido como

$$
l_{e x}=\frac{\delta_{d w}}{\pi}
$$

Ele representa a distância dentro da qual o acoplamento de troca é capaz de comunicar a direção de equilíbrio da magnetização de uma dada região do material [48], isto é, a distância dentro da qual os momentos magnéticos são capazes de manterem-se estáveis numa mesma direção. Se a magnetização tiver alguma componente perpendicular próxima à interface entre duas regiões de diferentes direções de equilíbrio, a energia magnetostática é mais alta e $l_{e x}^{\perp}=\sqrt{A / 2_{S}^{2}}$. Caso contrário, a anisotropia local prevalece e $l_{e x}^{\|}=\sqrt{A / K}$. Em metais de transição magnéticos $l_{e x}$ é da ordem de vários nanômetros. Na tabela 2.2, temos valores típicos de $l_{e x}$ e $d w$ para Fe, Co e Ni.

Assim, a formação e o tamanho de domínios magnéticos estão associados ao tamanho dos grãos cristalinos. Para grãos menores que a largura de parede típica do material e na ausência de campos externos, as paredes de domínio localizam-se nos contornos dos grãos cristalinos. Para grãos cristalinos maiores, paredes de domínios também se formam no interior dos grãos, a fim de minimizar a energia magnetostática do sistema. Sítios de aprisionamento de paredes de domínios devem, então, se localizar sobre os contornos de 
grãos, em defeitos da estrutura cristalina e sobre impurezas não magnéticas no material [48].

Por último, na presença de um campo magnético externo $\vec{H}$, os momentos magnéticos tendem a se alinhar na direção do campo. Esse efeito é conhecido por efeito Zeeman e seu termo de energia é dado por

$$
F_{H}=-\vec{M} \cdot \vec{H}=-M_{S} H \cos \theta_{H}
$$

onde $\theta_{H}$ é o ângulo entre o campo magnético $\vec{H}$ e a magnetização $\vec{M}$.

Esses são os principais mecanismos que determinam os comportamentos estático e dinâmico dos sistemas micromagnéticos e de seus processos de magnetização. O comportamento estático pode ser calculado, construindo-se a equação da energia magnética total, que consiste na soma desses termos,

$$
F=F_{K}+F_{J}+F_{M}+F_{H}
$$

e minimizando a energia do sistema em relação à magnetização (ou ao ângulo que a magnetização faz com uma dada direção). O comportamento magnético dinâmico é determinado a partir da equação de Landau-Lifshitz, que é a equação de movimento da magnetização. Para isso, primeiramente se calcula o campo efetivo $\vec{H}_{e f}$ sobre a magnetização, dado por

$$
\vec{H}_{e f}=-\vec{\nabla}_{\vec{M}} F
$$

Em seguida, resolve-se a equação de Landau-Lifshitz

$$
\frac{d \vec{M}}{d t}=-\gamma \vec{M} \times \vec{H}_{e f}
$$

para $|\vec{M}| \propto M_{S} e^{-i \omega t}$. Na equação, $\gamma=-1,761 \times 10^{11} \mathrm{~Hz} / \mathrm{T}$ é a razão giro-magnética do elétron.

A modelagem micromagnética consiste na resolução analítica ou numérica dessas equações. Ela nos permite reproduzir o comportamento da magnetização em função de um parâmetro de controle externo - o campo magnético $\vec{H}$-, tal qual num experimento. 
Ao contrário do modelo de Preisach, que é um modelo fenomenológico e estatístico - seus parâmetros não necessariamente têm significado físico -, a modelagem micromagnética parte da física real do problema e se constrói sobre parâmetros físicos mensuráveis [49]. Ambas as abordagens têm suas vantagens e desvantagens, e juntas constituem poderosas ferramentas matemáticas complementares.

\section{Modos de inversão da magnetização}

Nanoestruturas (estruturas com ao menos uma das dimensões abaixo de $100 \mathrm{~nm}$ ) são muito pequenas para suportar estruturas multidomínio bem desenvolvidas, mas grandes demais para permanecerem uniformemente magnetizadas (monodomínio) [50]. Dessa forma, elas contém pequenas regiões de transição nas quais a magnetização sofre mudança de direção, como vórtices [43, 50], "sanfonas" [48], ou "efeito dominó", como mostrado na figura 2.15 [48]. Esses são, portanto, fenômenos magnéticos mesoscópicos, que ocorrem em escalas intermediárias entre partículas monodomínio e materiais volumosos. Na figura 2.15(a), vemos o caso limite inferior na escala mesoscópica: a rotação coerente ocorre em partículas monodomínio. Como todos os momentos magnéticos giram em uníssono, não há regiões não-uniformes de magnetização. Já os modos de curling 2.15(b) e buckling 2.15(c) ocorrem em partículas com forte anisotropia de forma devido a razões de aspecto maiores, tendendo a uma simetria cilíndrica [48]. Os modos de inversão por efeito sanfona 2.15(d) e efeito dominó 2.15(f) são mais comuns em cadeias lineares de partículas esféricas ou nanofios $\operatorname{com} D<l_{\text {ex }}[48]$.

O modo de inversão da magnetização de sistemas mesoscópicos será sempre aquele de menor campo de inversão [48]. Em geral, modos não-uniformes custam energia de troca, desviando levemente da posição de equilíbrio a direção de uns poucos momentos magnéticos do material, e poupando energia magnetostática. Esse balanço de energia magnética pode ser determinado pela análise micromagnética do sistema. Em nanofios magnéticos policristalinos, dois fatores importantes são a razão de aspecto $(R=L / D)$ dos fios e a razão $D / l_{e x}$. Na figura 2.16, vemos um diagrama de fases do estado remanente da magnetização de nanofios de $\mathrm{Ni}, \mathrm{Co}, \mathrm{CoNi}$ e $\mathrm{CoP}$ em função dessas duas grandezas [50]. As amostras foram divididas em três grupos, segundo a forma de suas histereses: aquelas de arranjos com alta razão de aspecto $(R \geq 1)$ e pequenos diâmetros $\left(D<3 l_{e x}\right)$, 

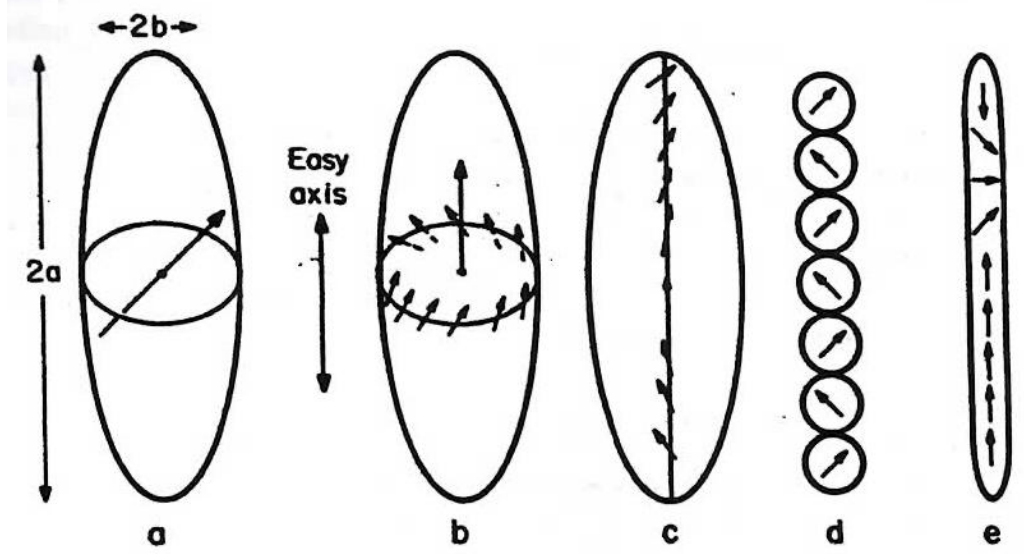

Figura 2.15: Modos de inversão da magnetização em partículas elipsoidais: (a) rotação coerente, (b) formação de vórtices (curling), (c) dobramento (buckling) (d) "efeito sanfona" (fanning) e (e) efeito dominó [48].

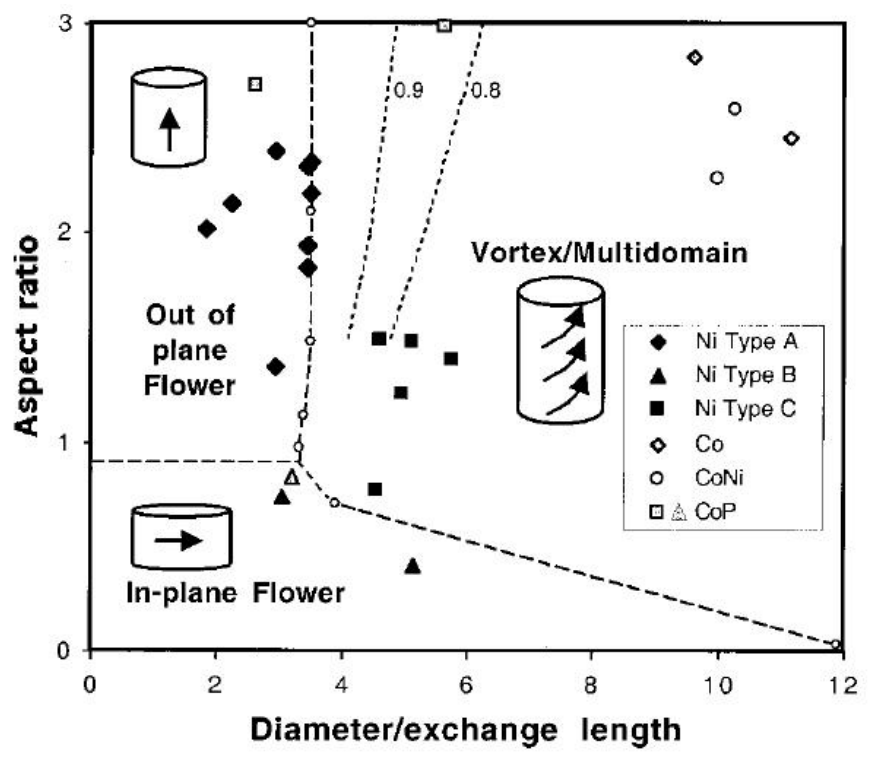

Figura 2.16: Diagrama de fases do estado remanente em função da razão de aspecto e do diâmetro dos cilindros. As curvas tracejadas foram obtidas por modelagem micromagnética. Três diferentes estados remanentes são encontrados: um uniforme paralelo ao plano (in plane flower), um uniforme fora do plano (out of plane flower) e um não-uniforme, com a formação de um vórtice no cilindro (vortex/multidomain). Os pontos experimentais foram obtidos para arranjos de nanofios policristalinos de $\mathrm{Ni}, \mathrm{Co}, \mathrm{CoNi}$ e $\mathrm{CoP}$ crescidos por eletrodeposição em matrizes de Si porosas. As curvas pontilhadas correspondem a cilindros de mesma $M_{R}$ [50]. 
que exibiram um eixo-fácil fora do plano (tipo A); as de baixa razão de aspecto, que exibiram um eixo-fácil no plano (tipo B); e aquelas de grandes diâmetros, que demonstraram fraca anisotropia de forma, com baixas remanências e coercividades (tipo C) [50]. As curvas tracejadas foram obtidas a partir de um modelo micromagnético que considera cada nanofio como um cilindro composto por conjunto de pelo menos 31 células cúbicas (na secção reta), de tamanhos menores que $0,5 l_{e x}$. Os autores resolveram a equação de Landau-Lifshitz nas condições de equilíbrio, levando em conta a energia magnetostática, o acoplamento de troca entre primeiros vizinhos, anisotropia local efetiva (uniaxial) e a interação Zeeman [50]. As medidas experimentais caíram exatamente nas regiões correspondentes obtidas pela simulação [50]. Em arranjos de nanofios com baixa razão de aspecto $(R \leq 0,9$, amostras tipo $\mathrm{B})$, a magnetização de equilíbrio tende a se manter na horizontal, com saturações de $23 \%$ a $34 \%$ menores do que seu valor em amostras volumosas [50]. O estado remanente no plano tende a ser suprimido à medida que o diâmetro aumenta. Para $R>0,9$ ele não é mais acessível, independentemente do diâmetro.

Nanofios com razões de aspecto acima de 1 apresentaram dois possíveis modos distintos, dependendo da razão entre diâmetro e comprimento de coerência. No limite inferior $\left(D / l_{\text {ex }} \leq 3,5\right.$, amostras tipo A), os nanofios apresentaram um estado remanente uniforme ao longo do cilindro, exceto nas extremidades, onde tendem a divergirem devido à quebra de simetria de translação. Esse estado remanente pode ser visualizado nas figuras 2.17(a e b). Como os fios têm diâmetros pouco maiores que o comprimento de coerência, eles invertem via rotação coerente dos momentos magnéticos. A nucleação de modos não-homogêneos nesse caso não é energeticamente favorável.

No limite de $D / l_{e x}>3,5$, um estado remanente não-uniforme torna-se favorável - o estado de vórtice (fig. 2.16). Esse estado está bem representado nas figuras 2.17(c e d) [50]. Ele é caracterizado por dois domínios com magnetização líquida ao longo do cilindro e componentes transversais em oposição, separados por um vórtice aproximadamente no meio do cilindro, em acordo com [43]. A componente longitudinal da magnetização só é uniforme no centro do cilindro, enquanto os momentos magnéticos mais externos formam um vórtice no plano tranversal, aproximadamente na metade do cilindro. Nas extremidades, os momentos magnéticos tendem a se orientar paralelamente à superfície. A presença do vórtice no meio do cilindro e de dois domínios magnéticos com compo- 

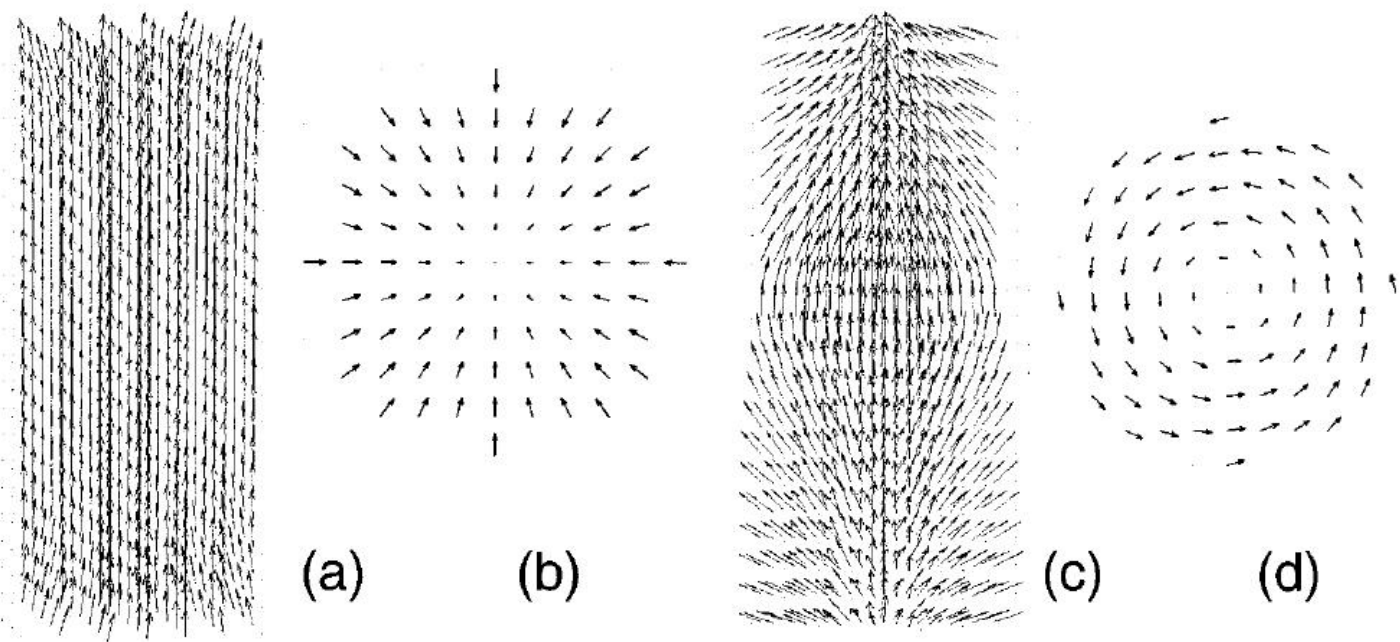

Figura 2.17: Resultados de simulações micromagnéticas do estado remanente de cilindros magnéticos. Vistas lateral (a) e da extremidade (b) de um cilindro que estabiliza num estado uniforme ao longo do eixo $\left(R=2,1\right.$ e $\left.D=2,61 l_{e x}\right)$. Vistas lateral (c) e da extremidade (d) de um cilindro que estabiliza num estado de vórtice $\left(R=2,1\right.$ e $\left.D=6,10 l_{e x}\right)$. Neste último caso, percebese a componente longitudinal da magnetização no centro do cilindro, enquanto os momentos magnéticos mais externos formam o vórtice no plano tranversal [50].

nentes longitudinais reduzidas diminuem consideravelmente a magnetização remanente do sistema. Assim, o sistema reduz a forte energia magnetostática à custa da energia de troca de pequenos desvios dos momentos magnéticos no vórtice. Ao se aplicar um campo magnético no sistema, a inversão da magnetização se dá pelo movimento do vórtice ao longo do cilindro - curling -, a um campo de inversão bem mais baixo do que o necessário para rotação coerente dos momentos magnéticos [48, 50]. Por isso, a coercividade do sistema também apresenta valores menores, como observados nos ciclos de histerese das amostras tipo C [50].

O efeito da formação de estados não-uniformes sobre a remanência do sistema é mostrado na figura 2.18. Podemos ver que à medida que o diâmetro $D$ aumenta, a remanência decresce lentamente enquanto o sistema permanece no estado uniforme, independentemente da razão de aspecto. Mas quando $D / l_{e x}$ atinge o valor crítico de 3,5, o sistema sofre uma transição de fase para o estado de vórtice, caracterizado pela rápida queda da remanência em função do diâmetro. Essa queda é mais acentuada, quanto menor for a razão de aspecto [50]. Ainda na figura 2.16, vemos duas curvas pontilhadas que correspondem a curvas de remanência constante $(0,8$ e 0,9$)$ para cilindros do tipo vórtice com alta razão de aspecto. 


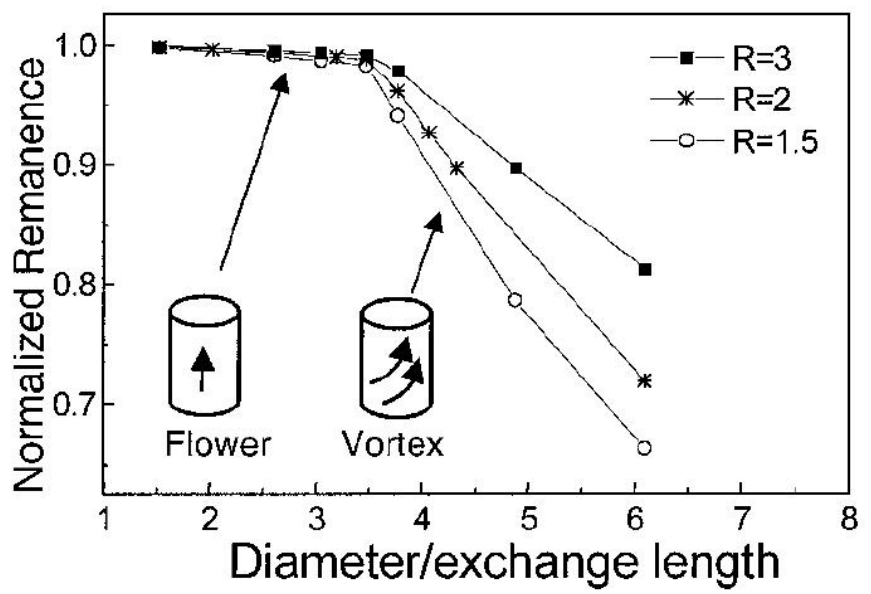

Figura 2.18: Remanência normalizada calculada ao longo do cilindro em função do diâmetro. O valor crítico $D / l_{e x}=3,5$ marca a transição entre as fases remanentes uniforme e de vórtice. A remanência só apresenta dependência com a razão de aspecto na fase de vórtice. Antes da transição, a remanência é praticamente igual a 1 e decresce fortemente após a transição [50].

Os autores analisaram ainda o efeito de uma anisotropia efetiva uniaxial $K_{u}$, paralela ao eixo do cilindro, sobre a estabilidade dos estados remanentes. Na figura 2.19, vemos como varia a linha de transição entre os estados uniforme e de vórtice em função do diâmetro e da constante de anisotropia uniaxial normalizada $\left(Q=K_{u} / 2 \pi M_{S}^{2}\right)$, para cilindros com alta razão de aspecto $(R=1,5-3,0)$. Esta anisotropia efetiva pode ser devido a uma orientação preferencial dos grãos cristalinos ao longo dos fios, por exemplo. Pode ser observado que até $Q=0,2$, o efeito da anisotropia sobre o estado remanente é desprezível. Mas para amostras com razões de aspecto mais altas, a anisotropia tende a estabilizar o estado uniforme. A título de comparação, para Co $h c p Q=0,35$ e a transição ocorre para $D=16,8 l_{e x}$ para $R=1,5$. Para nanofios de Co com $R=3$, a transição para o estado de vórtice só ocorre a $D=20 l_{e x}$.

Nossas amostras de nanofios de $\mathrm{Ni}$ e Co apresentam razões de aspecto bem maiores do que das amostras discutidas acima, devido ao longo comprimento dos fios, mas com características micromagnéticas muito semelhantes. Desta forma, é de se esperar que, nos arranjos de nanofios estudados neste trabalho, o número de vórtices ao longo dos nanofios seja maior, com mais de dois domínios magnéticos coexistindo no interior dos fios, contribuindo para a diminuição dos campos de inversão da magnetização e para um maior efeito desmagnetizante. 


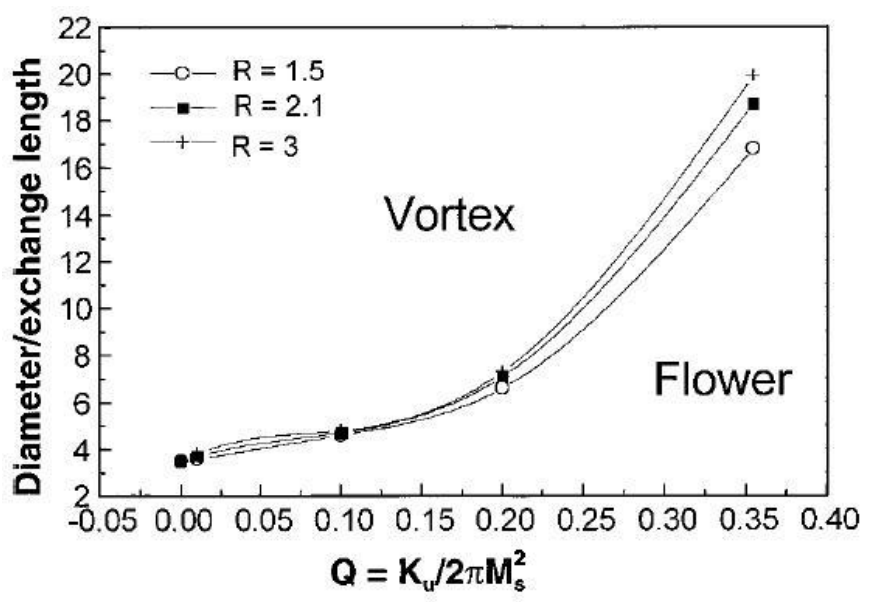

Figura 2.19: Transição entre as fases remanentes uniforme e de vórtice em função do parâmetro de anisotropia uniaxial $Q$, para cilindros com razões de aspecto $R=1,5-3,0$. A anisotropia uniaxial favorece o estado de vórtice para nanofios com diâmetros maiores [50].

\subsubsection{Ciclos Internos e Curvas de Inversão de Primeira Ordem (FORCs)}

Ciclos internos e curvas de inversão de primeira ordem (FORCs) são curvas de magnetização obtidas entre máximos e mínimos variáveis do campo magnético externo, a partir de um mesmo estado de magnetização (e.g., o estado virgem ou um estado saturado). Os ciclos internos devem ser obtidos com a amostra ainda desmagnetizada, realizando-se ciclos de histerese consecutivos entre valores de campo de retorno $\left(H_{r}\right)$. Ou seja, primeiramente aplicamos um campo $H_{r}>0$ e realizamos um ciclo de histerese no intervalo $\left[-H_{r}, H_{r}\right]$. Ao final de cada ciclo, incrementamos o valor de $H_{r}$ e repetimos o procedimento enquanto $H_{r} \leq H_{\max }$, onde $H_{\max }$ é um valor de campo necessário para saturar o material, isto é, quando $M(H)$ se torna uma curva reversível no limite de altos campos. O valor da magnetização remanente medida em cada ciclo interno em função de $H_{r}$, ou seja, obtido durante um processo de magnetização a partir de um estado desmagnetizado inicial (virgem), pode ser denotado por $M_{r}\left(H_{r}, H=0\right)$ e é chamada curva de remanência magnetizante ou isotérmica.

Para obtermos um conjunto de FORCs, primeiramente saturamos a amostra, aplicando um campo $H_{\max }$. Em seguida, levamos o campo até um certo valor $H_{r}<H_{\max }$ e invertemos o campo, levando a amostra de volta à saturação. Essa curva de "subida" é uma curva de inversão de primeira ordem, ou FORC. A curva obtida é mostrada na 
figura 2.20. Daí, repetimos este procedimento para valores decrescentes de $H_{r}$, enquanto $H_{r} \geq-H_{\max }$. Nesse caso, a magnetização remanente de cada FORC é obtida durante um processo de desmagnetização e é denotada por $M_{d}\left(H_{r}, H=0\right)$, a curva de remanência desmagnetizante ou recuperada. A memória magnética construída ao saturar amostra é parcialmente destruída pelo campo $H_{r}$ aplicado no sentido oposto. Mede-se, então, a magnetização a partir deste estado de desmagnetização. Assim, obtemos um conjunto de curvas como a da figura 2.20 .

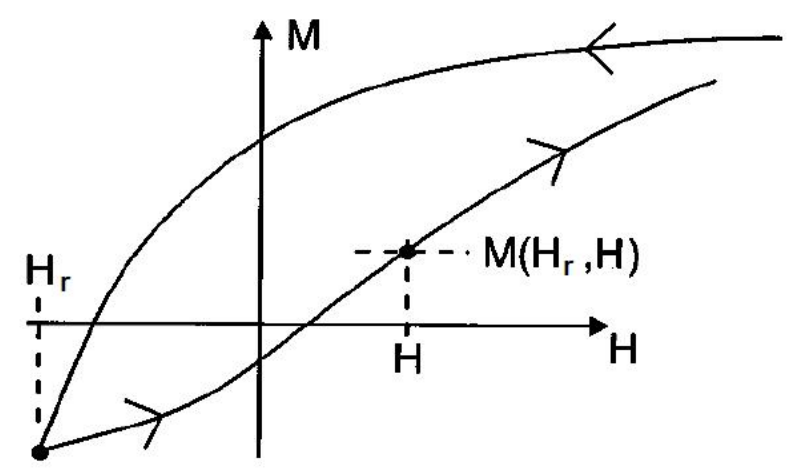

Figura 2.20: Definição de uma curva de inversão de primeira ordem (FORC). Uma FORC $M\left(H_{r}, H\right)$ é determinada por um campo de retorno $H_{r}$, aplicado a partir do estado saturado, e pelo campo magnético instantâneo $H$ [30].

Para tentar compreender os processos de magnetização de arranjos de nanofios magnéticos e os tipos de interações predominantes inter- e intra-fios, realizamos medidas de ciclos internos e de FORCs a $300 \mathrm{~K}$ das amostras de nanofios de Ni e Co. Variamos $H_{r}$ entre 50 e 3000 Oe nas medidas de ciclos internos e entre 2500 e -3000 Oe nas medidas de FORCs. Nas figuras 2.21, mostramos exemplos dessas medidas realizadas em SQUID para uma amostra de nanofios de $\mathrm{Ni}$, feita nas seguintes condições [anodização: $7^{\circ} \mathrm{C}, 30$ $\mathrm{V}$ dc, $(\mathrm{COOH})_{2}$ a $0,3 \mathrm{~mol} / \mathrm{L}, 1 \mathrm{~h}\left(1^{\mathrm{a}}\right) / 40 \mathrm{~min}$. (2 $\left.2^{\mathrm{a}}\right)$; eletrodeposição: solução-padrão de $\mathrm{Ni}, 30 \mathrm{~V} \mathrm{ac}, 100 \mathrm{~Hz}$, à temperatura ambiente, por 15 minutos]. Apesar de levarmos o sistema à saturação a campos de até $20 \mathrm{kOe}$, limitamos as medidas e análises apresentadas a $H_{\max }=3000$ Oe.

A partir das remanências magnetizante e desmagnetizante, obtidas respectivamente das medidas de ciclos internos e FORCs, construímos a curva $\Delta M\left(H_{r}\right)$ do material. A curva $\Delta M\left(H_{r}\right) \equiv M_{d}\left(H_{r}\right)-\left[M_{R}-2 M_{r}\left(H_{r}\right)\right]$ dá uma medida de quanto o sistema se afasta de um sistema de Stoner-Wohlfarth, de partículas uniaxiais, não-interagentes, no 


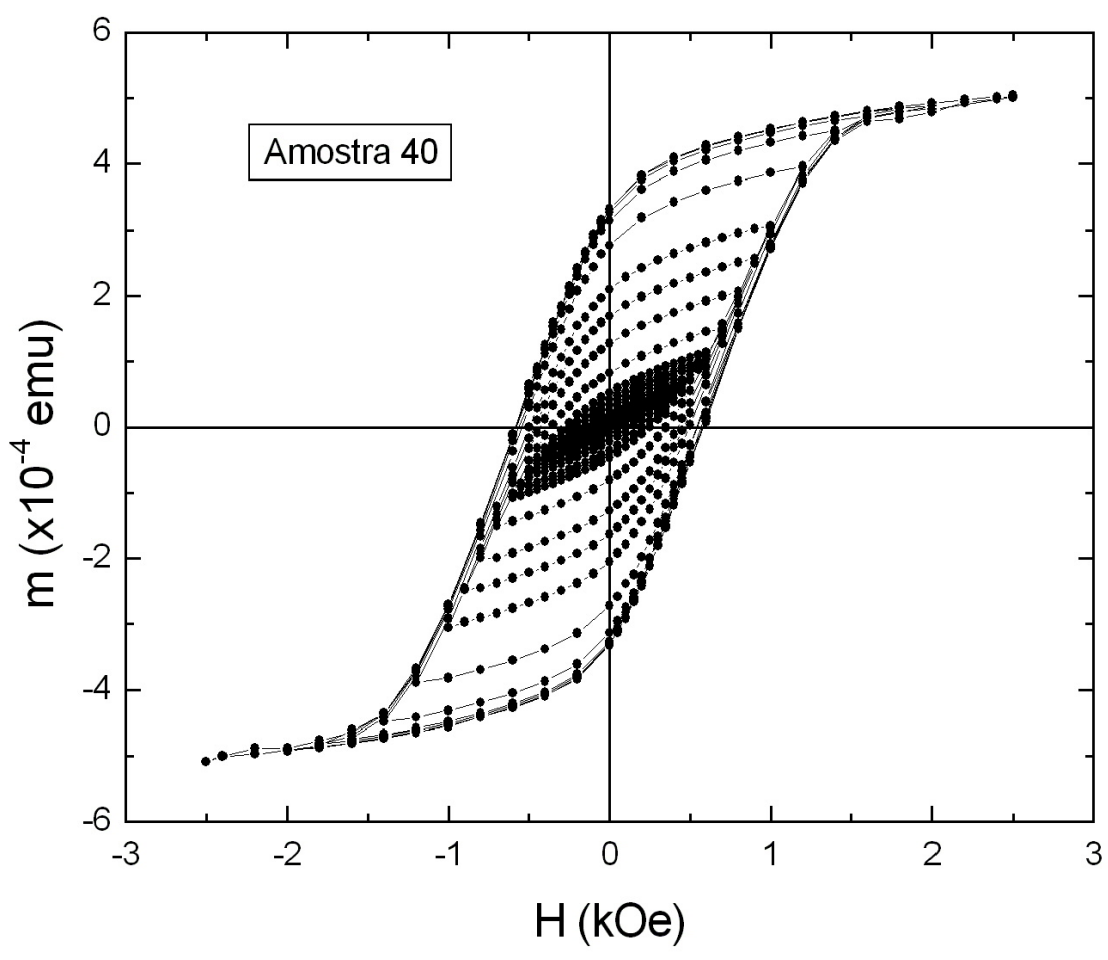

(a)

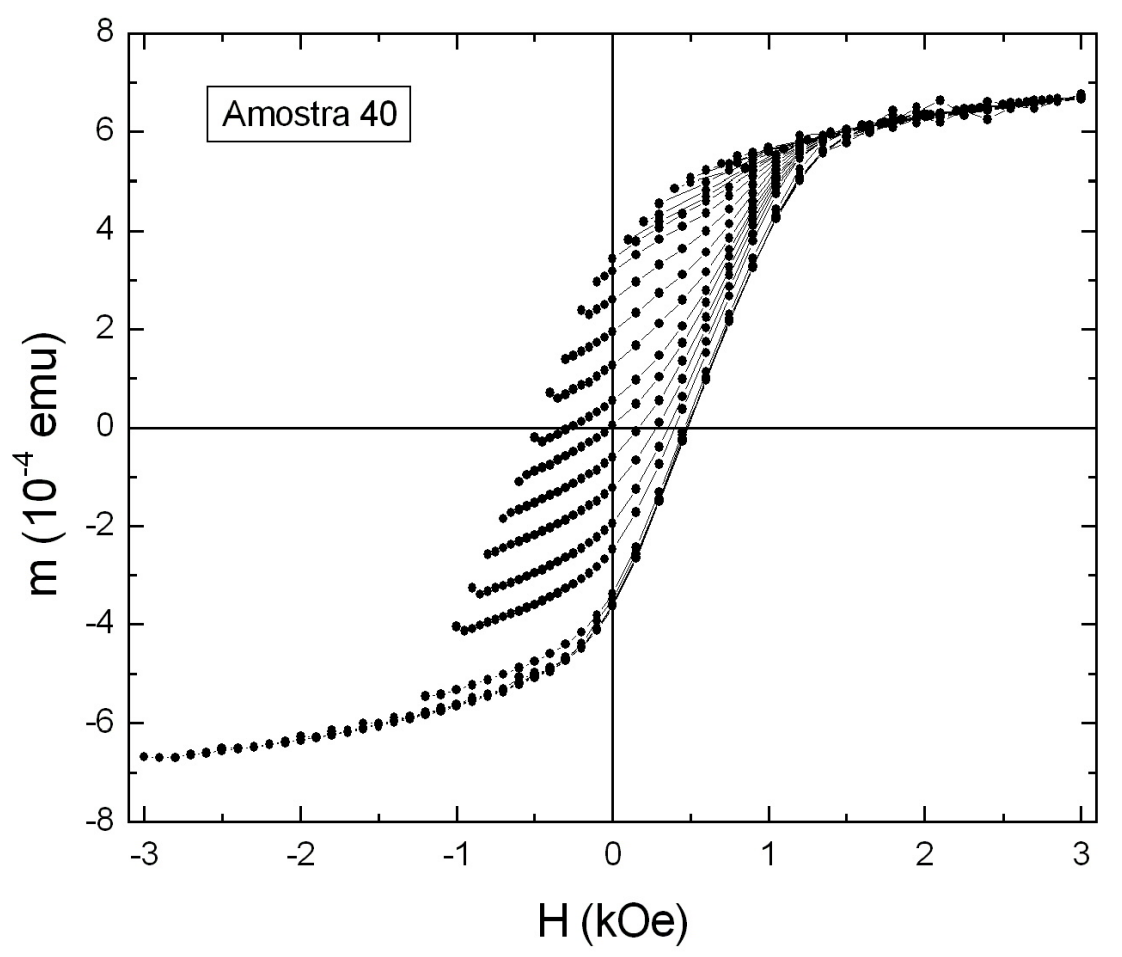

(b)

Figura 2.21: Ciclos internos de histerese (a) e FORCs (b) de uma amostra de nanofios de Ni, preparada nas condições-padrões de anodização $\left(V_{a n}=30 \mathrm{~V}\right)$ e eletrodeposição $\mathrm{AC}$ a $30 \mathrm{~V}, 100$ $\mathrm{Hz}$, por 15 minutos. As medidas foram realizadas em SQUID, a $300 \mathrm{~K}$, com campo perpendicular à superfície. 


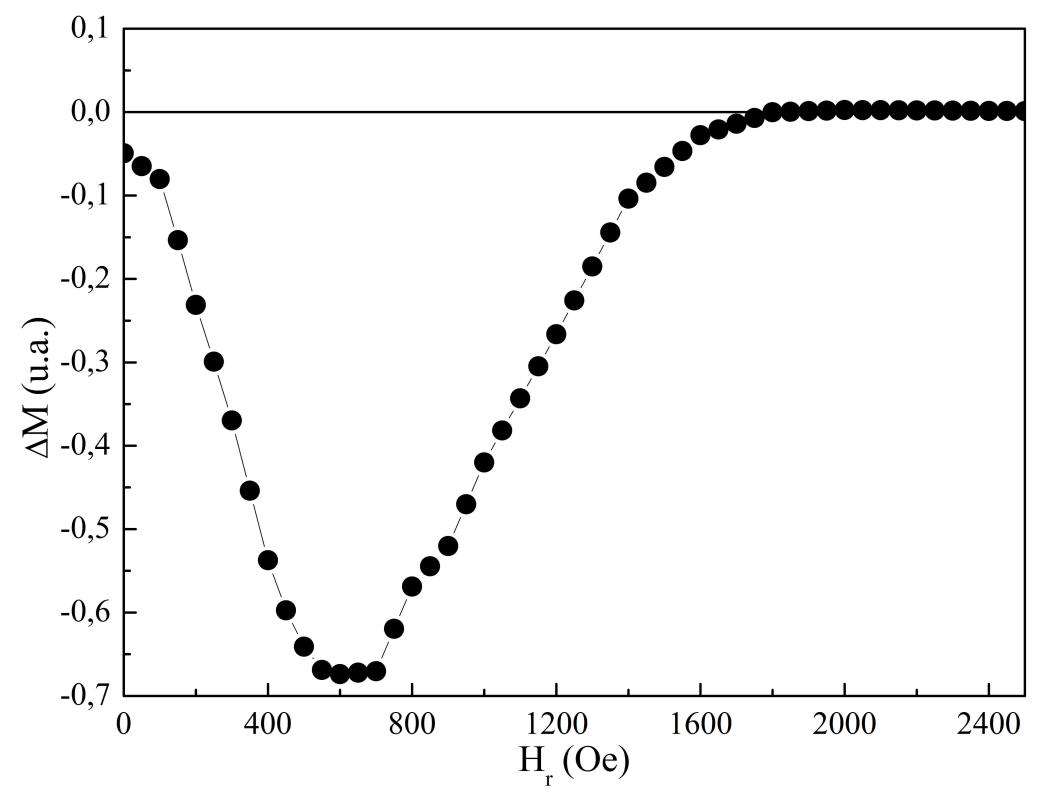

Figura 2.22: Curva $\Delta M \equiv M_{d}-\left[M_{R}-2 M_{r}\left(H_{r}\right)\right]$ da mesma amostra das figs. 2.21(a e b), calculada a partir das remanências isotérmica $M_{r}\left(H_{r}\right)$ e recuperada $M_{d}\left(H_{r}\right)$ obtidas das medidas de ciclos internos e FORCs, respectivamente. A predominância da curva sob o eixo $\Delta M<0$ revela o caráter desmagnetizante dos processos de magnetização no sistema.

qual vale a relação $M_{d}\left(H_{r}\right)=M_{R}-2 M_{r}\left(H_{r}\right)^{4}$ [51]. Nesses sistemas, a curva $\Delta M\left(H_{r}\right)$ é uma reta com inclinação -2. A consideração de um sistema de partículas não-interagentes, com anisotropia cúbica (3 ou 4 eixos fáceis) resulta numa curva $\Delta M\left(H_{r}\right)$ claramente nãolinear, com tendência magnetizante [52, 53]. Um estudo bastante detalhado [53] sobre a competição entre anisotropias uniaxial e cúbica em sistemas de partículas não-interagentes resultou numa grande variedade de comportamento de curvas $\Delta M\left(H_{r}\right)$, mostrando que sua interpretação nem sempre está diretamente associada a interações entre partículas, sendo necessária a análise particular de cada caso. Em sistemas reais, um desvio da curva em relação ao comportamento linear pode indicar não só a existência de anisotropias nãouniaxiais ou da competição entre diferentes anisotropias, como também a presença de interações magnéticas entre partículas, processos incoerentes de magnetização ou efeitos superparamagnéticos [29, 52]. Essas medidas nos permitem testar modelos fenomenológicos que descrevem os processos de magnetização e evidenciam as interações magnetostáticas predominantes no sistema. A curva obtida para uma amostra típica de nanofios de Ni é mostrada na figura 2.22. Ela apresenta uma clara predominância da curva na região

\footnotetext{
${ }^{4}$ Nessas expressões, $M_{R}$ é a remanência obtida quando o campo magnético vem do infinito (saturação) a zero.
} 
$\Delta M<0$, com um mínimo bem definido para $H_{r}=H_{C}$. Esse é um comportamento típico de um sistema com predomínio de efeitos desmagnetizantes. Porém, essa curva não dá informações sobre mecanismos de inversão da magnetização [29].

\subsubsection{A Análise FORC e o Modelo de Preisach}

A partir da medida de ciclos internos e de FORCs, é possível estudar a discrepância entre as remanências magnetizante e desmagnetizante a partir de duas diferentes abordagens fenomenológicas: a análise de curvas $\Delta M\left(H_{r}\right)$ e curvas de $M_{r e v}\left(M_{i r r}\right)_{H_{r}}[29]$ e a análise FORC [30, 54]. Ambos os métodos revelam o tipo de interação magnetostática predominante no sistema. Mas uma vantagem da análise FORC sobre as curvas $\Delta M$ é que a primeira, ademais, permite mapear os eventos de inversão de magnetização do sistema. Discutimos a seguir as origens, a aplicação e a interpretação da análise FORC, que toma por base o modelo de Preisach de histerese.

$$
M(H, t)=M_{S} \int_{-H_{\max }}^{H_{\max }} \int_{H_{r}}^{H} P\left(H_{r}, H\right) \hat{\Gamma}_{H_{r}, H} H(t) d H d H_{r},
$$

onde $\hat{\Gamma}_{H_{r}, H} H(t)= \pm 1$, dependendo de como o campo $H(t)$ ultrapassou os valores críticos mencionados acima, ou seja, da história magnética do sistema. O modelo de Preisach,

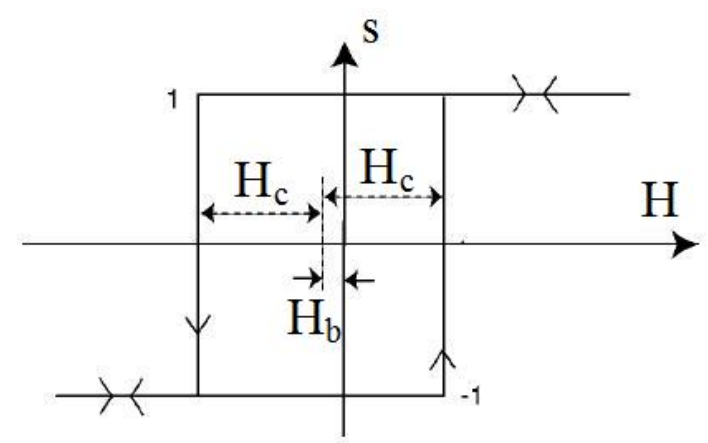

Figura 2.23: Resposta magnética elementar de uma partícula no modelo de Preisach, representada pelo operador $\hat{\Gamma}_{H_{c}, H_{b}}$. Os dois parâmetros $H_{c}$ e $H_{b}$ caracterizam o comportamento individual da partícula (reversível ou irreversível, bloqueada ou superparamagnética). O sistema como um todo é, então, é caracterizado por uma distribuição de campos de inversão e de interação $P\left(H_{c}, H_{b}\right)[55]$.

introduzido na década de 1930, é uma tentativa de descrever o fenômeno de histerese em materiais magnéticos a partir de um modelo fenomenológico intrinsecamente não-linear 
$[27,28]$. Ele considera um conjunto de partículas monodomínios, cada qual caracterizada por um ciclo de histerese elementar (representado por um operador $\hat{\Gamma}_{H_{c}, H_{b}}$ ), retangular, com largura $H_{c}$ e deslocado de $H_{b}$ em relação à origem, como mostrado na figura 2.23 [55]. Na presença de campo magnético externo, essas partículas respondem invertendo sua orientação magnética na direção do campo quando este ultrapassa os valores críticos $H_{b} \pm$ $H_{c} / 2$ característicos de cada partícula, como se iniciasse a nucleação de um domínio bem localizado ou executasse saltos tipo Barkhausen. Isto significa que cada partícula só possui dois possíveis estados magnéticos $\left(\hat{\Gamma}_{H_{c}, H_{b}} H(t)= \pm m_{S}\right)$ e que uma inversão representa um salto descontínuo de um estado para o outro. Este mecanismo de inversão é claramente irreversível e não-linear, pois o retorno do campo externo ao valor inicial não causará a inversão das mesmas partículas no sentido oposto, ou seja, o sistema não retornará ao estado inicial. Os parâmetros fenomenológicos $H_{c}$ e $H_{b}$ dependem das características de cada partícula, como volume, momento magnético de saturação, anisotropia magnetocristalina, interações entre partículas, campo local efetivo, etc. Mas relacionam-se com o campo aplicado $H$ e o campo de retorno $H_{r}$ de maneira simples, a saber, $H=H_{b}+$ $H_{c}$ e $H_{r}=H_{b}-H_{c}$. Assim, o comportamento magnético macroscópico do material é determinado pela história magnética $\hat{\Gamma}_{H_{c}, H_{b}} H(t)$ do sistema, ponderada pela distribuição $P\left(H_{c}, H_{b}\right)$ característica do sistema. Essa média deve ser calculada em função das variáveis de controle experimental $\left\{H, H_{r}\right\}$ da forma

Da mesma forma, a partir da resposta macroscópica do material é possível obter a função $P\left(H_{c}, H_{b}\right)$ característica do material, ou seja, o conjunto de parâmetros $H_{c}$ e $H_{b}$ que representa um dado sistema de partículas magnéticos. Para isso, basta realizar a operação inversa à da equação 2.18 , ou seja,

$$
P\left(H, H_{r}\right)=-\frac{1}{2} \frac{\partial^{2} M\left(H_{r}, H\right)}{\partial H_{r} \partial H},
$$

cujo pré-fator $(-1 / 2)$ aparece devido à mudança de variáveis. Para ter sentido físico, $P\left(H_{c}, H_{b}\right)$ deve ser uma distribuição estatística, isto é, deve ser sempre positiva, não divergir e tender a zero no infinito. Além disso, a validade do modelo atribui propriedades muito restritivas ao sistema, como a congruência (de área e forma) entre ciclos menores (internos à histerese maior) obtidos entre dois valores extremos de campo quaisquer, 
independente do estado inicial [28]. Portanto, a aplicação do modelo de Preisach impõe limites à descrição dos sistemas estudados, os quais muitas vezes não são satisfeitos pelos sistemas reais [30]. Dado um sistema de partículas, o modelo de Preisach pressupõe que haja uma única e bem definida distribuição $P\left(H_{c}, H_{b}\right)$ que representa esse sistema. Mas isso não é verdade para a maioria dos sistemas reais, pois o modelo não possui uma base física muito rigorosa [30]: a suposição de que existe uma interação local constante em cada sítio onde se encontra um momento magnético não é fisicamente válida. Assim como a suposição de que cada partícula possui um campo de inversão bem definido, pois ele depende da interação da partícula com outras em seu entorno. Ou seja, o modelo pressupõe uma completa independência entre os parâmetros fenomenológicos $H_{c}$ e $H_{b}$. Assim, a distribuição de Preisach será sempre, de certo modo, uma construção teórica arbitrária [30].

Inspirado nesse modelo, Pike et al. [30] introduziram um novo método de caracterização magnética. Eles obtém uma "função de distribuição" $\rho\left(H_{r}, H\right)$ análoga à distribuição de Preisach a partir de uma transformada bem definida sobre um conjunto de dados experimentais - as FORCs -, que não requer pressuposição alguma. Essa função, que eles chamam distribuição FORC, é definida como

$$
\rho\left(H_{r}, H\right) \equiv-\frac{1}{2 M_{S}} \frac{\partial^{2} M\left(H_{r}, H\right)}{\partial H_{r} \partial H},
$$

onde $M\left(H_{r}, H\right)$ é a magnetização em função de $H_{r}$ e $H$, como dada nas FORCs experimentais. Assim, a distribuição obtida não se baseia em nenhuma pressuposição.

Em geral, o diagrama FORC é construído num sistema de coordenadas girado de $45^{\circ}$, dado por $\left\{H_{c}, H_{b}\right\}=\left\{\left(H-H_{r}\right) / 2,\left(H+H_{r}\right) / 2\right\}$. Nessa base, é possível fazer uma analogia entre a distribuição FORC e a distribuição de Preisach, ou seja, com uma distribuição de partículas monodomínios, com interações entre elas, na qual cada partícula é caracterizada por um campo de inversão $H_{c}$ e campo de interação $H_{b}$. A função $\rho\left(H_{r}, H\right)$ assim calculada extrapola o conceito de uma distribuição estatística, pois traz informações do comportamento histerético real do material, como a nucleação de modos de inversão de magnetização, viscosidade magnética, interações magnetizantes e desmagnetizantes, campo médio local e outros fenômenos magnéticos. Ou seja, a distribuição FORC não obe- 
dece às limitações do modelo de Preisach - admitindo valores negativos ou contribuições reversíveis, por exemplo. A medida de FORCs permite o sistema visitar (virtualmente) todos os estados acessíveis de magnetização. Assim, $\rho\left(H_{r}, H\right)$ é um "mapa" real do comportamento magnético do material e, por isso, contém muito mais informações do que um simples ciclo de histerese.

Embora ainda não seja totalmente compreendida, a análise FORC traz informações complementares a outras abordagens, como a análise das curvas $\Delta M\left(H_{r}\right)$ e curvas de Henkel $\left[M_{r e v}\left(M_{i r r}\right)\right]$, bem como o desenvolvimento de modelos computacionais, físicos e/ou fenomenológicos, como simulações de Monte Carlo [56], modelagem micromagnética $[41,45,55]$ e mesmo modelos de Preisach [30, 55, 57]. No início, esses modelos ajudaram a interpretar assinaturas observadas nos diagramas FORC de sistemas bem conhecidos. Por exemplo, a análise FORC foi primeiramente aplicada em estudos de paleomagnetismo em rochas e minerais magnéticos [58] e amostras de meteoritos [59] e filmes de gravação magnética [30]. Ao mesmo tempo, para entender melhor as informações contidas nos diagramas, a análise FORC era aplicada a simulações computacionais de sistemas bem conhecidos, como sistemas de Stoner-Wohlfarth (partículas monodomínio não-interagentes), sistemas de campo médio [30, 55], sistemas frustrados, como o modelo de Ising de campos aleatórios e vidros de spin [60], e também em arranjos de nanopartículas [61] e nanofios magnéticos [55]. Nesses estudos, os autores conseguem associar traços e assinaturas dos modos de inversão da magnetização e das interações magnetostáticas nos diagramas FORC e mostrar o poder da análise FORC em relação a outros métodos (e.g., curvas $\Delta M$ e de Henkel) [30].

No estudo de arranjos auto-organizados de nanofios magnéticos via análise FORC, padrões reprodutíveis têm sido observados nos diagramas FORC. Na figura 2.24 temos as FORCs (a) e o diagrama FORC (b) de um arranjo de nanofios de Ni crescidos por eletrodeposição numa matriz porosa de Si, obtida por litografia [55]. Assim, esses arranjos tinham parâmetros morfológicos bem definidos. Eles eram fios policristalinos, com tamanho de grão entre 10 e $20 \mathrm{~nm}$, diâmetros de $92 \mathrm{~nm}$, distância inter-fio de $200 \mathrm{~nm}$ e comprimentos de $250 \mathrm{~nm}$. O diagrama FORC é caracterizado por três aspectos principais: (1) um forte pico ao longo de $H_{c}=0$, chamado pico "reversível"; (2) uma estrutura que os autores denomina de "dois-ramos", sendo uma "cauda" mais alongada na horizontal e 

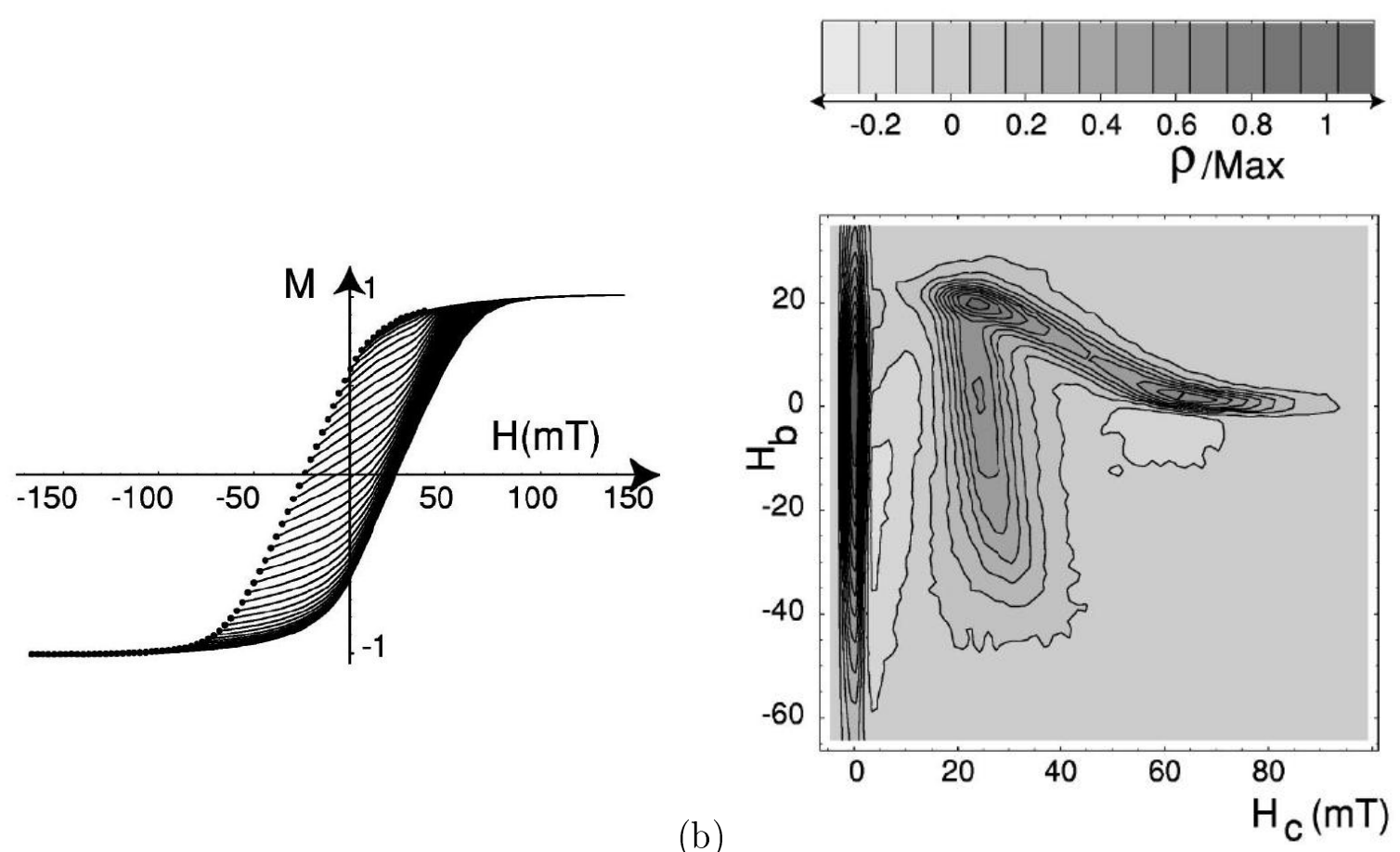

(a)

(b)

Figura 2.24: (a) FORCs de um arranjo de nanofios de Ni, policristalinos, com tamanho de grão de 10 a $20 \mathrm{~nm},\langle D\rangle=92 \mathrm{~nm}, d_{\text {int }}=200 \mathrm{~nm}$ e $L=250 \mathrm{~nm}$ e (b) seu diagrama FORC. O arranjo de nanofios foi fabricado por litografia e eletrodeposição [55].

outro ramo mais vertical, fortemente deslocado para a região $H_{b}<0$ e (3) regiões onde $\rho<0$, uma adjacente ao pico reversível, para $0<H_{c}<20 \mathrm{mT}$, e outra adjacente à cauda da estrutura de dois-ramos, para $H_{c} \approx 60 \mathrm{mT}$ [fig. 2.24(b)]. Esses traços gerais são recorrentes nos diagramas FORC de arranjos de nanofios magnéticos, salvo as particularidades de cada amostra. No diagrama, a estrutura mais proeminente é o pico localizado em $H_{c}=23 \mathrm{mT}$ e $H_{b}=20 \mathrm{mT}$, que é em torno da coercividade do material. Em analogia com o modelo de Preisach, esse pico é chamado "irreversível", pois se encontra na região de partículas com altos campos de inversão. Há um outro pico para altos valores de $H_{c} \mathrm{e}$ $H_{b} \rightarrow 0$, sobre a cauda da distribuição, que é acompanhado de uma região de $\rho<0$.

Na figura 2.25, vemos o perfil vertical do pico reversível, ou seja, uma secção da distribuição FORC ao longo do eixo $H_{c}=0$. Este pico é chamado de reversível em analogia com a distribuição de Preisach: essa região do diagrama corresponde a partículas com baixos campos de inversão, isto é, partículas pequenas, facilmente reversíveis. Ele também exibe uma certa assimetria (uma cauda) para $H_{b}<0$.

Para tentar entender esses aspectos da distribuição FORC, os autores (ref. [55]) desenvolveram um modelo de Preisach com campo médio desmagnetizante, simulando a 


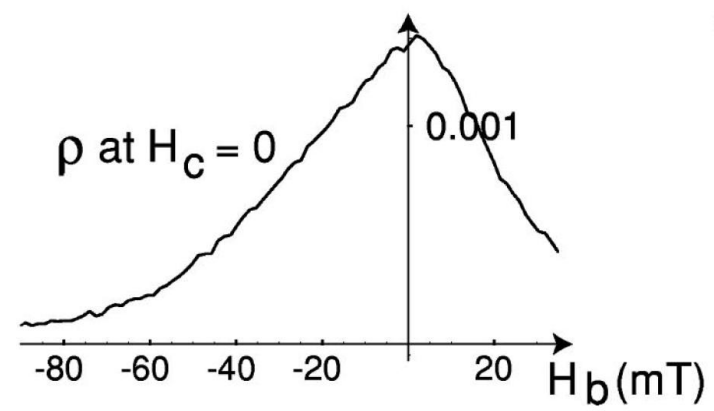

Figura 2.25: Perfil vertical da distribuição FORC da fig. 2.24(b) ao longo de $H_{c}=0$, chamado de "pico reversível" [55].

interação dipolar inter-fio. Quando os fios estão magnetizados, o campo dipolar de um fio tende a desmagnetizar seus vizinhos [55]. Assim, o campo efetivo ao qual cada momento magnético estaria sujeito seria

$$
H_{e f}=H-J M
$$

onde $H$ é o campo externo, $J$ é a magnitude da interação dipolar (em termos de um campo médio) e $M$ é a magnetização da amostra, dada pela soma de todos os ciclos elementares $s_{i}$

$$
M=\frac{1}{N} \sum s_{i}
$$

Se as partículas são isotrópicas e o ciclo de histerese não apresenta deslocamento, é razoável considerar uma distribuição de Preisach simples $P\left(H_{c}, H_{b}\right)=f\left(H_{c}\right) g\left(H_{b}\right)$, onde $g\left(H_{b}\right)$ é simétrica e de média zero (gaussiana) ao longo de $H_{b}$ e $f\left(H_{c}\right)$ é uma distribuição tipo lognormal ou gama ao longo de $H_{c}$, com uma coercividade bem definida (pequena FWHM) [55]. Com esse modelo simples, eles demonstram que o resultado para $J=21,1 \mathrm{mT}$ se aproxima muito (qualitativamente) do observado experimentalmente. Na figura 2.26, mostramos os resultados obtidos pelo modelo de Pike et al. para (a) $J=0$ e (b) $J=$ 21,1 mT. Portanto, a marcante assimetria da estrutura de dois ramos é conseqüência de um efeito de um campo dipolar médio de caráter desmagnetizante sobre os nanofios $[30,55]$. Em seguida, melhores resultados foram obtidos quando consideraram a interação dipolar fora da aproximação de campo médio, mas numa interação entre fios até primeiros vizinhos [55]. Porém, uma modificação ainda mais interessante foi a substituição de ciclos elementares retangulares por ciclos curvilíneos para a resposta magnética das partículas [55], simulando assim uma componente reversível intrínseca às partículas. Isso resulta 

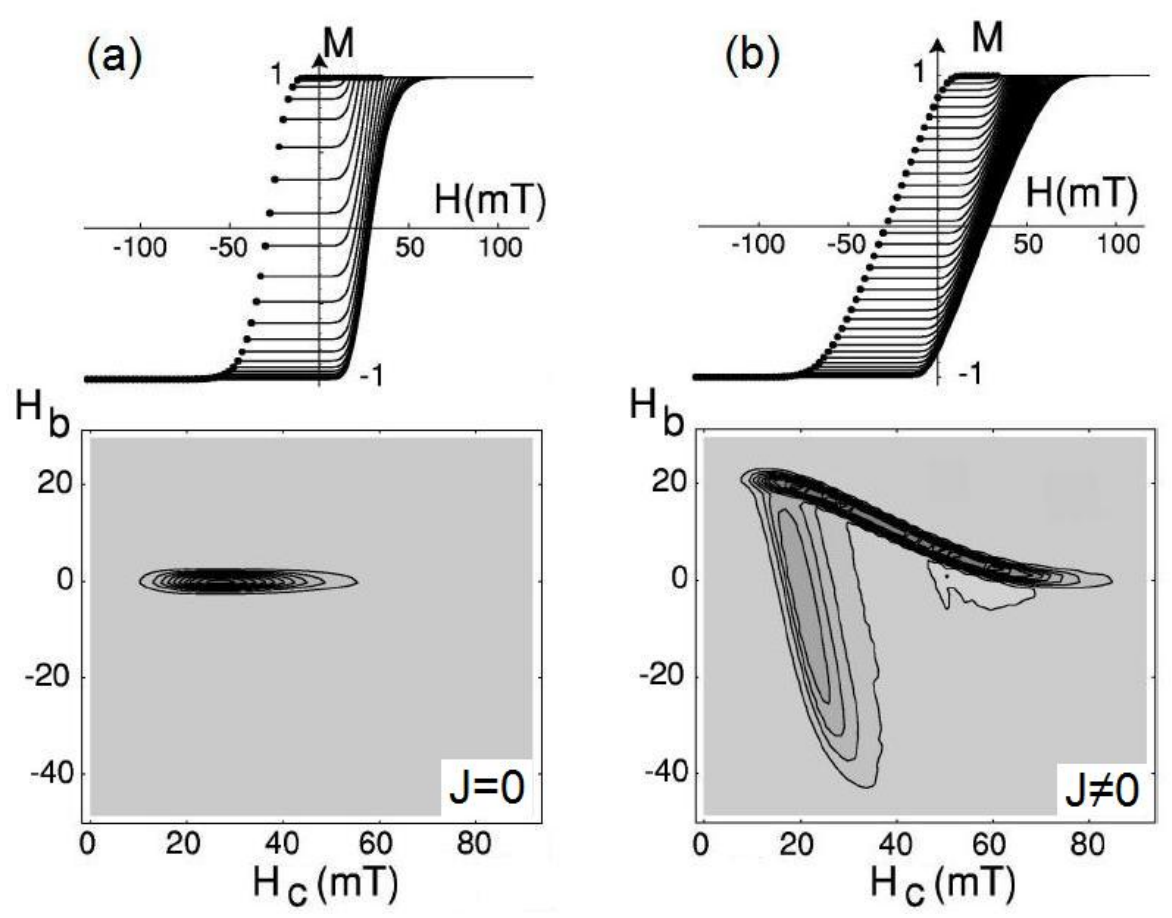

Figura 2.26: Resultados do modelo de Preisach com campo médio para (a) $J=0$ e (b) $J=21,1$ mT. A forma típica de "dois ramos" da distribuição FORC de nanofios deve-se à interação dipolar desmagnetizante entre os fios [55].

na recuperação do pico reversível no diagrama FORC, como podemos ver na figura 2.27. Além do pico reversível em $H_{c}=0$, podemos ver também a região $\rho<0$ adjacente, para $H_{b}<0$. Estes valores negativos de $\rho$ são causados pela mudança na inclinação das FORCs para um dado valor de $H$ fixo, à medida que $H_{r}$ varia. Se as FORCs superiores tiverem uma inclinação (susceptibilidade) maior do que as inferiores para um mesmo $H$, a derivada $\partial \chi / \partial H_{r}<0$. Isso ocorre quando há uma certa "inércia" ou viscosidade magnética no sistema [55].

Para o cálculo da distribuição FORC, deve-se realizar uma diferenciação de segunda ordem sobre dados experimentais, os quais em geral exibem flutuações, ruídos e imprecisões. Tal procedimento magnifica muito essas flutuações, mascarando a informação real da distribuição FORC [62, 63]. Desde a introdução do método FORC, diferentes algoritmos têm sido empregados para o cálculo da distribuição, com o intuito de otimizá-lo [64]. Em 1999, Pike et al. [30] propuseram um método de mínimos-quadrados para o ajuste de um polinômio de segunda ordem, contínuo por partes aos dados experimentais, isto é, o ajuste de $M\left(H_{r}, H\right)$ em torno de um ponto por uma superfície de ordem quadrática em $H$ e $H_{r}$. Com isso, eles calculavam $\rho\left(H_{r}, H\right)$ - o coeficiente do termo misto da expansão - ao 


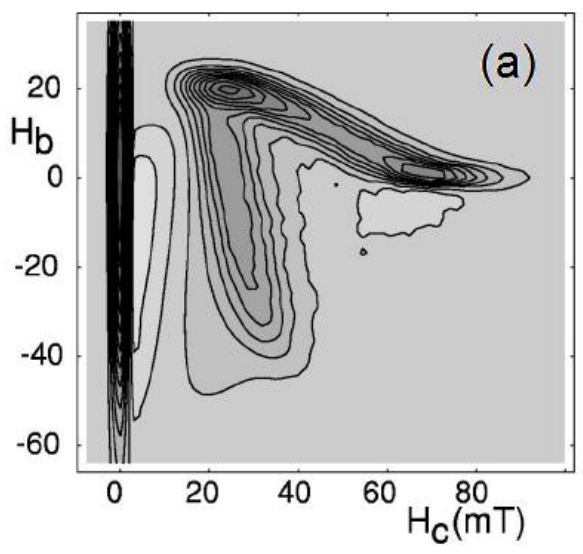

(b)

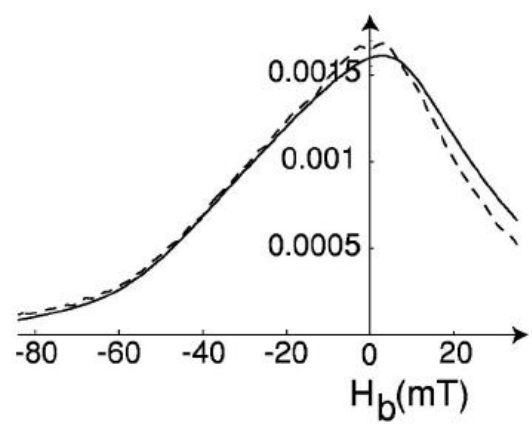

Figura 2.27: Resultados do modelo de Preisach com campo médio $(J=21,1 \mathrm{mT})$ para ciclos elementares curvilíneos, em vez de retangulares, como no modelo de Preisach clássico. Com isso recupera-se o pico reversível em $H_{c}=0$ [55].

mesmo tempo em que suavizavam as curvas experimentais, removendo ruídos artificiais indesejados. Este método assume que a magnetização (experimental) $M\left(H_{r}, H\right)$ é uma função contínua e suave das variáveis $H_{r}$ e $H$, de modo que numa pequena região em torno de um dado ponto do domínio $\left\{H_{r}, H\right\}$ o comportamento de $M$ pode ser aproximado por uma superfície de $2^{\mathrm{a}}$ ordem nas variáveis $H_{r}$ e $H$. Isto significa que podemos de realizar uma interpolação dos dados em duas dimensões, da forma

$$
M\left(H_{r}, H\right)=a_{1}+a_{2} H_{r}+a_{3} H_{r}^{2}+a_{4} H+a_{5} H^{2}+a_{6} H_{r} H
$$

na vizinhança de um ponto. Para isso, definimos uma rede quadrada de tamanho $\left(2 n_{v i z}+\right.$ $1) \times\left(2 n_{v i z}+1\right)$ em torno do ponto, onde $n_{v i z}$ é o número de vizinhos do ponto tomado, como mostrado na figura 2.28 [54]. Dessa forma, $n_{v i z}$ determina o grau de suavização do polinômio a ser interpolado - quanto maior $n_{v i z}$, mais suave é a curva ajustada. O valor de $\rho$ no ponto será o próprio coeficiente $a_{6}$ da expansão polinomial, o que é obtido através da resolução de uma equação matricial para a inversa da matriz de coeficientes $a_{n}$. Calculado o valor de $\rho$ num ponto da rede, incrementa-se um passo no domínio $\left\{H_{r}, H\right\}$ e repete-se o procedimento para todos os pontos do domínio $\left\{H_{r}, H\right\}$. É importante ressaltar que $M\left(H_{r}, H\right)$ só é definida para $H \geq H_{r}$, isto é, numa região triangular do domínio $\left\{H_{r}, H\right\}$, como mostrado na figura 2.29 - conseqüentemente, a distribuição FORC só pode ser calculada nessa mesma região. 


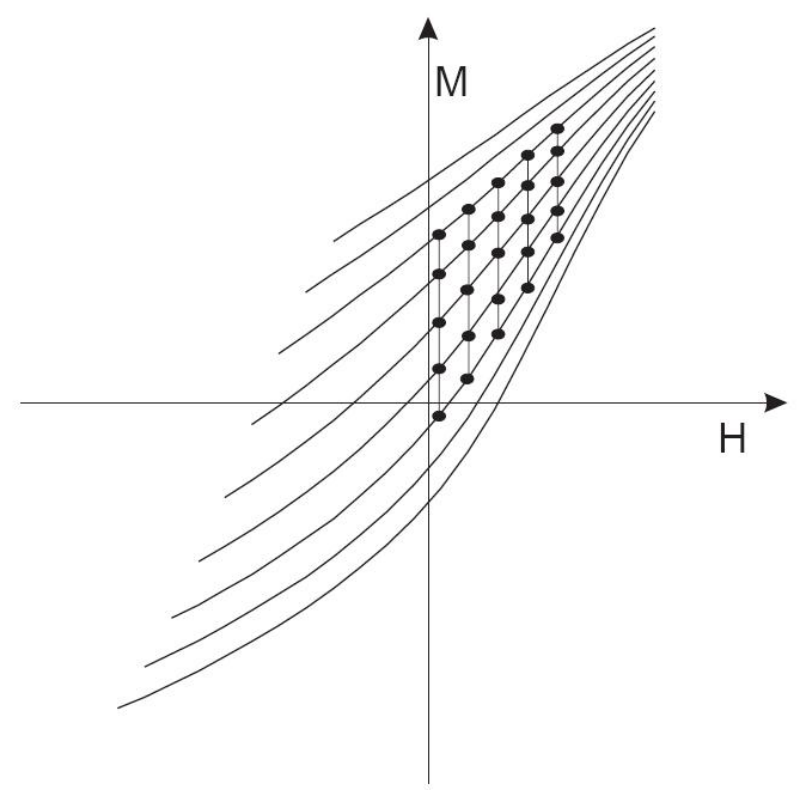

Figura 2.28: Rede de pontos $\left(H_{r}, H\right)$, de tamanho $2 n_{v i z}+1 \times 2 n_{v i z}+1\left(n_{v i z}=2\right)$, em torno de um ponto $i$ (no centro), sobre a qual o polinômio 2.23 aproximará $M_{\text {exp }}\left(H_{r}, H\right)$ para calcular o valor da distribuição FORC no ponto $i$ [54].

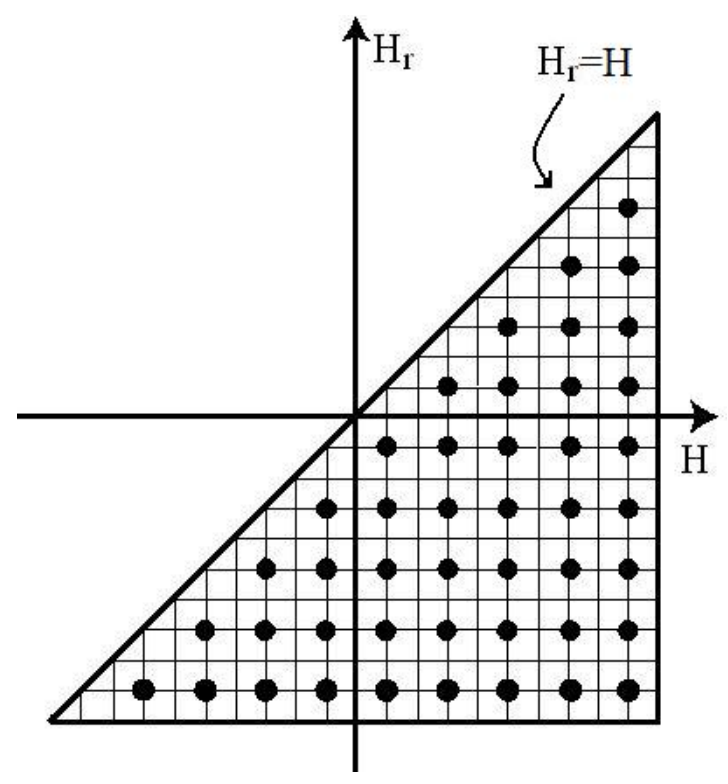

Figura 2.29: Domínio no qual $M\left(H_{r}, H\right)$ e, conseqüentemente, a distribuição FORC são definidas. A borda diagonal do triângulo corresponde ao eixo $H_{r}=H$. A transformação de variáveis $\left\{H_{r}, H\right\} \rightarrow\left\{H_{c}, H_{b}\right\}$ corresponde a uma rotação de $45^{\circ}$ no sentido anti-horário do triângulo da figura. Para o cálculo, os dados experimentais devem ser primeiramente interpolados numa rede discreta definida sobre o domínio, com um espaçamento $\left(\Delta H_{r}, \Delta H\right)$ regular. 

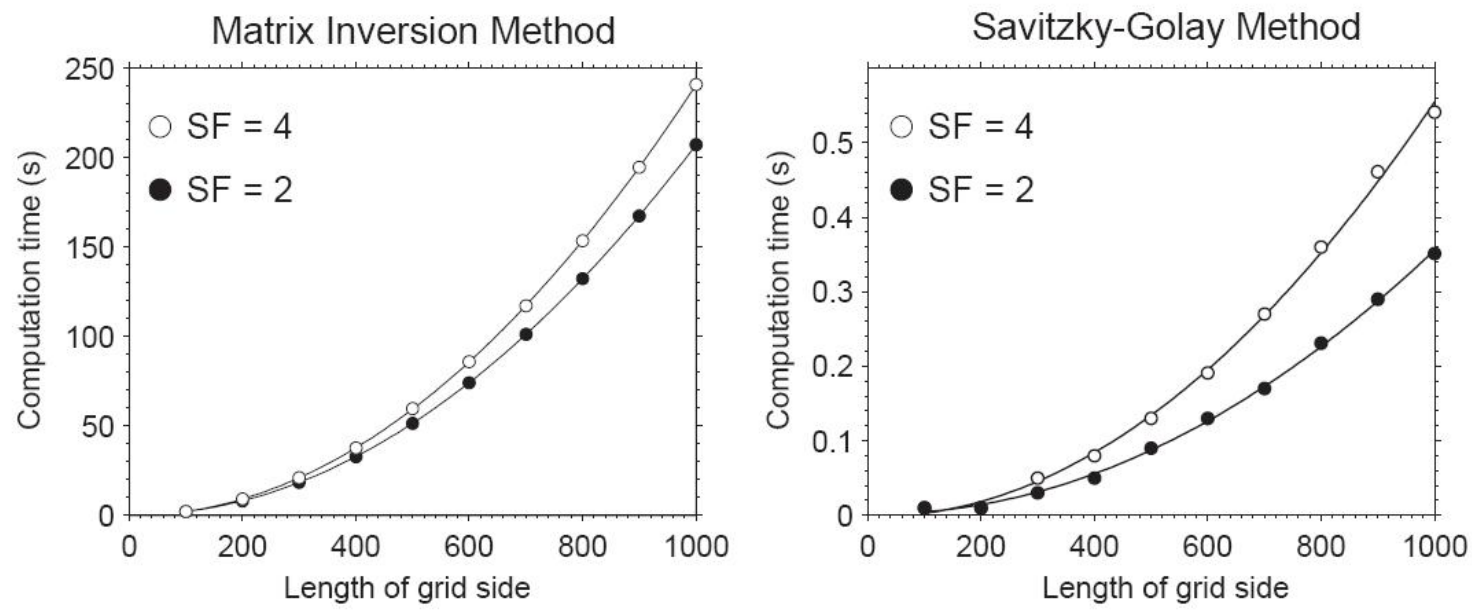

Figura 2.30: Comparação do tempo computacional para o cálculo da distribuição FORC entre o método de Pike et al. [30] (à esquerda) e o de Heslop e Muxworthy [54] (à direita) em função do tamanho lateral da rede, para $n_{v} i z=2$ e 4 ( $S F$, smoothing factor $)$. Percebe-se uma redução de até 500 vezes no tempo de computação [54].

A desvantagem desse método é seu custo computacional, já que requer a inversão de uma matriz em torno de cada ponto de uma rede bidimensional para a obtenção do ajuste de mínimos-quadrados. Ao final, teremos um total de $\left(n_{1}-n_{v i z}\right) \times\left(n_{2}-n_{v i z}\right)$ inversões de matrizes para uma rede de tamanho $n_{1} \times n_{2}$. Assim, em 2005, Heslop e Muxworthy propuseram um método alternativo equivalente, que requer apenas a inversão de uma única matriz, acelerando o cálculo da distribuição FORC em até 500 vezes [54]. Este método é chamado de método de convolução de Savitzky-Golay [65] e se baseia em calcular o ajuste de mínimos-quadrados num ponto $\left(H_{r}, H\right)$ a partir de uma combinação ponderada de $M$ no próprio ponto com os pontos vizinhos, dentro de uma rede de lado $2 n_{v i z}+1$ em torno do dado ponto. Os pesos associados a cada ponto da rede local constituem um filtro de convolução padrão e é a única matriz do cálculo a ser invertida. É possível mostrar que a apliação desse filtro equivale ao cálculo da derivada mista pelo método de Pike [65]. A comparação entre os dois métodos é mostrada na figura 2.30. Nela vemos o tempo de computação da distribuição FORC pelo método de Pike et al. [30] (à esquerda) e pelo método de Heslop e Muxworthy [54] (à direita) em função do tamanho lateral da rede, para $n_{v} i z=2$ e 4 (SF, smoothing factor). De fato, percebe-se uma redução de até 500 vezes no tempo de computação.

Por esses motivos, adotamos neste trabalho o método proposto por Heslop e Muxworthy [54] para o cálculo da distribuição FORC. Os autores chamam atenção para o critério 
de decisão do valor ideal de $n_{v i z}$ para o cálculo, que é um tanto arbitrário, mas deve ser orientado segundo a razão sinal-ruído dos dados experimentais [54]. Deve-se tomar cuidado, entretanto, para não escolhê-lo muito pequeno, a ponto de flutuações instrumentais resultarem em picos artificiais na distribuição FORC, nem muito grande, a ponto de suavizar em excesso os dados, impondo uma tendência quadrática inexistente. Em ambos os casos, teremos uma interpretação errônea da análise FORC. Para isso, Heslop e Muxworthy propõem um robusto teste estatístico baseado no cálculo da autocorrelação espacial dos resíduos $e_{M}\left(H_{r}, H\right)=M_{e x p}\left(H_{r}, H\right)-M\left(H_{r}, H\right)$ da expansão polinomial em função da razão sinal-ruído dos diagramas FORC [54]. Os resultados sugeriram valores de $n_{v i z}$ entre 2 e 4 para níveis de ruído branco seguindo distribuições normais com desviospadrões de 0 a 0,01 e magnitudes máximas iguais a $M_{S}$ [54]. Como nossas FORCs foram medidas em SQUID de alta precisão e estabilidade, e não demonstraram grandes flutuações, utilizamos $n_{v i z}=2$ em todas as distribuições calculadas para amostras de Ni. Para as amostras de Co, que foram medidas no VSM, utilizamos $n_{v i z}=3$. Testes com valores mais altos de $n_{v i z}$ foram realizados e esses valores deram os melhores resultados por não causarem uma suavização excessiva, induzindo tendências que não estão presentes nos dados experimentais e/ou encobrindo assinaturas características do material. O algoritmo desenvolvido para o cálculo das distribuições FORC é descrito a seguir.

Seja um ponto $M\left(H_{r}, H\right)$ do conjunto de dados experimentais designado pelo índice i. Para calcular $\rho\left(H_{r}, H\right)$ neste ponto, primeiramente tomamos um vetor-coluna $m$ com $(2 n+1)^{2}$ posições, no qual armazenamos os pontos da "janela" em torno do ponto $i$, de modo que este esteja na posição central do vetor, ou seja,

$$
m=\left(M_{i-2 n_{v i z}-1}, \ldots, M_{i}, \ldots, M_{i+2 n_{v i z}+1}\right)^{T} .
$$

Assim, o vetor $m$ contém a rede local introduzida anteriormente (fig. 2.28). A interpolação designada pela equação (2.23) é então realizada nesse conjunto de dados a partir da equação matricial

$$
m=\mathbb{X} a,
$$

onde

$$
a=\left(a_{1}, a_{2}, a_{3}, a_{4}, a_{5}, a_{6}\right)^{T}
$$


é o vetor dos coeficientes de interpolação que queremos determinar e

$$
\mathbb{X}=\left(\begin{array}{cccccc}
1 & H_{r\left(i-2 n_{v i z}-1\right)} & H_{r\left(i-2 n_{v i z}-1\right)}^{2} & H_{\left(i-2 n_{v i z}-1\right)} & H_{\left(i-2 n_{v i z}-1\right)}^{2} & H_{r} H_{\left(i-2 n_{v i z}-1\right)} \\
\vdots & \vdots & \vdots & \vdots & \vdots & \vdots \\
1 & H_{r(i)} & H_{r(i)}^{2} & H_{(i)} & H_{(i)}^{2} & H_{r} H_{(i)} \\
\vdots & \vdots & \vdots & \vdots & \vdots & \vdots \\
1 & H_{r\left(i+2 n_{v i z}+1\right)} & H_{r\left(i+2 n_{v i z}+1\right)}^{2} & H_{i+2 n_{v i z}+1} & H_{i+2 n_{v i z}+1}^{2} & H_{r} H_{\left(i+2 n_{v i z}+1\right)}
\end{array}\right)
$$

é a matriz de interpolação em torno do ponto $i$. Para resolver esse sistema matricial, que não é quadrado, temos que calcular a pseudo-inversa de $\mathbb{X}$, que é dada por

$$
a=\left(\mathbb{X}^{T} \mathbb{X}\right)^{-1} \mathbb{X}^{T} m=\mathbb{B} m
$$

Daí, o valor de $\rho\left(H_{r}, H\right)$ (no ponto $i$ ) corresponde ao coeficiente $-a_{6} / 2$, onde $a_{6}$ é dado pelo produto escalar da última linha de $\mathbb{B}$ com o vetor $m$. Finalmente, incrementa-se a rede local para o próximo vizinho do ponto $i$ e repete-se o procedimento para todos os pontos do domínio triangular da figura 2.29.

\subsection{Dinâmica de Spins em Filmes Finos Magnéticos}

Além do comportamento estático dos materiais magnéticos, um outro aspecto importante é o estudo da sua dinâmica de spins. Embora o estudo de excitações elementares (fônons, mágnons, éxcitons, poláritons, etc.) seja um tópico canônico em física do estado sólido, o contínuo desenvolvimento de novos materiais e estruturas permite o estudo de excitações elementares em condições e geometrias nunca antes investigadas. Por exemplo, o advento de multicamadas magnéticas introduziu um sistema com novas condições de contorno, descontinuidades e efeitos de confinamento, que levaram à descoberta de fenômenos de grande interesse tecnológico, como já foi citado na seção 2.1. A possibilidade de se crescer camadas tão finas quanto se queira (até mesmo com espessuras monoatômicas) enfatizou os importantes efeitos da razão área/volume das camadas. O comportamento de um dado material em volume pode ser totalmente distinto do que ocorre em sua superfície. Assim, quanto mais se reduz o volume (espessura) da camada, mais os efeitos de superfície 
tornam-se relevantes. Em especial, o efeito da hibridização dos níveis eletrônicos onde o sistema exibe quebra de simetria (na superfície e na interface entre camadas de diferentes materiais) sofre forte influência da geometria e da razão área/volume dos materiais no sistema, os quais são determinantes dos modos coletivos de excitações elementares, como fônons e mágnons. Tudo isso levou ao desenvolvimento de toda uma sub-área da física da matéria condensada: a física de superfícies e interfaces. Nela, esses novos materiais magnéticos têm constantemente renovado o interesse no estudo da dinâmica de spins e da rede cristalina em sólidos. Materiais magnéticos nanoestruturados, como filmes ultrafinos, multicamadas, super-redes, nanofios e nanopartículas, têm sido extensivamente estudados e explorados nas últimas décadas devido também à sua aplicação em dispositivos de alta tecnologia, como sensores magnéticos, sistemas magnéticos de alta freqüência e de resposta ultra-rápida para a transmissão de ondas eletromagnéticas. Camadas de materiais magnéticos são sistemas de grande interesse tecnológico devido às suas aplicações em sensores GMR, válvulas de spin e junções-túnel magnéticas. Eles estão profundamente envolvidos na revolução econômica e tecnológica trazida pelo desenvolvimento da nanociência e da nanotecnologia. Os progressos da alta tecnologia, porém, requerem um sólido conhecimento e compreensão das propriedades físicas desses sistemas. Neste contexto, os estudos das excitações magnéticas elementares são de grande importância porque estas excitações estão intimamente associadas com propriedades magnéticas fundamentais e permitem uma descrição verdadeiramente microscópica da dinâmica de spins de sistemas multicamadas.

Atualmente, o único método que permite o estudo de ondas de spin de grandes vetores de onda em filmes finos e superfícies é a espectroscopia por perda de energia de elétrons spin-polarizados (SPEELS) [67, 68, 69]. A importância do estudo de ondas de spin de grandes vetores de onda (com valores tendendo ao limite da primeira zona de Brillouin) reside no fato de que suas propriedades estão intimamente ligadas com a interação de troca entre momentos magnéticos no sistema, que não pode ser explicada por um modelo baseado na descrição fenomenológica magnetostática de ondas de spin, aplicada no caso de mágnons de pequenos vetores de onda (longos comprimentos de onda). Ondas de spin de grandes vetores de onda podem ser normalmente observadas por espalhamento inelástico de nêutrons (INS) em amostras volumosas [70], inclusive estados que estão próximos do 
limite da zona de Brillouin. Infelizmente, as medidas de INS exigem amostras volumosas, com maior seç̧ão de choque de espalhamento. Portanto, experimentos de INS para a investigação de ondas de spin de grandes vetores de onda em filmes finos e superfícies são fortemente limitados [71].

Ondas de spin de pequenos vetores de onda $\left(\Delta K<0,01 \AA^{-1}\right)$ foram estudados experimentalmente em filmes finos magnéticos por várias décadas via espalhamento de luz Brillouin (BLS) [72, 73] e de ressonância ferromagnética (FMR) [74, 75]. Estes estudos experimentais focaram-se em ondas de spin de pequenos vetores de onda, isto é, com comprimentos de onda muito maior do que os parâmetros de rede do material. As ondas de spin excitadas revelam um caráter magnetostático e somente uma fração muito pequena da zona de Brillouin de superfície (SBZ) pode ser explorada.

Foi recentemente demonstrado que os mágnons de superfície podem ser excitados por tunelamento inelástico de elétrons em espectroscopia de tunelamento de elétrons spinpolarizados (SP-STS) [76]. Este método porém, não prevê qualquer resolução no vetor de onda ainda. Embora a técnica de EELS já tenha sido introduzida no Brasil - mas ainda não tão difundida -, a sua versão com resolução em spin ainda não é aplicada no país, já que SPEELS é um desenvolvimento bastante recente. Atualmente, existem muito poucos laboratórios no mundo onde experiências similares são realizadas, introduzidas pelo trabalho pioneiro do Prof. Dr. Jürgen Kirschner e colaboradores [67, 68, 69, 77]. No início, as pesquisas se concentravam na obtenção de um feixe de elétrons spin-polarizado a partir do espalhamento de um feixe não-polarizado numa superfície ferromagnética [78, 79] e na observação do espectro de excitações de Stoner, de energias na faixa de alguns eV [80, 81, 82]. Para a detecção de ondas de spin, foi necessário o desenvolvimento de um espectrômetro de elétrons de alta resolução [69], dada a menor secção de choque de espalhamento de mágnons, em comparação à de fônons [68]. A primeira observação experimental de ondas de spin de grandes vetores de onda se deu em filmes finos de $\mathrm{Co} / \mathrm{Cu}(001)$ [68, 83], num espectrômetro com resolução (FWHM) de $40 \mathrm{meV}$. Desde então, as tentativas se concentraram num sistema-padrão das pesquisas em superfícies magnéticas: o sistema $\mathrm{Fe} / \mathrm{W}(110)$ [84, 85] em diferentes espessuras, de 1 a 24 monocamadas atômicas (ML). O sistema $\mathrm{Fe} / \mathrm{W}(001)$ pareceu ser o próximo passo mais plausível. Mas, embora essa superfície fosse ferromagnética a temperatura ambiente, ela apresentou dificuldades para o 
espalhamento de elétrons e, conseqüentemente, para a detecção de picos de ondas de spin nos espectros de SPEELS. Embora tenha sido utilizado feixes de elétrons com polarização de spin de até $80 \%$, o constraste de spin entre os espectros de elétrons para cima $I_{\uparrow} \mathrm{e}$ para baixo $I_{\downarrow}$ não era grande o suficiente para a determinação precisa dos picos spin-flip para toda a SBZ. Curiosamente, a passivação da superfície de Fe/W(001) por $\mathrm{O}_{2}$, a baixos níveis de exposição, aumentou a magnetização de saturação e a coercividade da superfície, estabilizando-a magneticamente. A adsorção do oxigênio atômico nos sítios vazios da rede cristalina do Fe reduziu o caráter metálico da superfície, "blindando" o excesso de elétrons de condução e tornando a superfície mais suscetível ao espalhamento de elétrons. Isso favorece uma maior ocorrência de eventos de espalhamento por impacto (dependente em spin), no qual o elétron penetra na superfície, aumentando o contraste entre os espectros $I_{\uparrow}$ e $I_{\downarrow}$. Além disso, a superfície oxidada revelou uma estabilidade química muito mais longa, mesmo na presença de gases residuais na câmara de vácuo.

Essas características da superfície O-Fe/W(001) a tornam uma ótima candidata a aplicações spintrônicas e de espalhamento dependente em spin a temperatura ambiente, tanto como superfície polarizadora de elétrons incidentes, quanto como em sensores e analizadores de spin de longa vida útil. Além disso, este sistema é considerado um dos mais promissores para se observar a interação mágnon-fônon [86, 87, 88] através de SPEELS. Para isso, entretanto, ainda é necessário ultrapassar os limites instrumentais de resolução em energia de hoje, para que permitam uma melhor precisão na determinação dos picos inelásticos próximos ao limite da SBZ e na resolução de picos inelásticos muito próximos ou sobrepostos.

\subsubsection{Técnicas e Métodos em Física de Superfícies}

A seguir, revisamos as técnicas de crescimento e caracterização estrutural, morfológica e magnética de filmes finos utilizadas neste trabalho. Essas técnicas estão dentre as mais difundidas e aplicadas na área de ciência de superfícies, em sistemas de UHV.

\section{Epitaxia por Feixe Molecular (MBE)}

Esta é uma das técnicas mais utilizadas para o crescimento epitaxial de filmes finos. Nela, um determinado elemento (metal ou semicondutor), com alto grau de pureza, é 
bombardeado por elétrons, dentro de um compartimento fechado, contendo um pequeno orifício (célula de efusão) [89]. O elemento (na forma de bastão ou contido num cadinho de tungstênio) é aquecido ao ponto de sublimação. Devido à pressão dentro da célula, o vapor do material é ejetado pelo orifício, na forma de um feixe de átomos e íons do elemento. O feixe é direcionado ao substrato, sobre o qual se condensa a taxas tão baixas quanto 1 monocamada atômica por segundo (aproximadamente $1 \AA / \mathrm{s}$ ) [5]. Devido à sua versatilidade e controle fino das taxas de deposição, pode-se crescer filmes finos monocristalinos, multicamadas ou super-redes de elementos puros, ligas ou outros compostos, com mudanças abruptas de composição, mantendo um alto grau de qualidade estrutural $[89,5]$.

A quantidade de material depositado por MBE (i.e., a espessura dos filmes) é usualmente controlada por uma microbalança de quartzo montada próxima à amostra, bem como por oscilações de RHEED (Reflection High-Energy Electron Diffraction) e por espectroscopia de elétrons Auger (AES). Essas técnicas permitem identificar o modo de crescimento (por formação de ilhas, por camadas ou misto) e o número de camadas depositadas $[5,96]$.

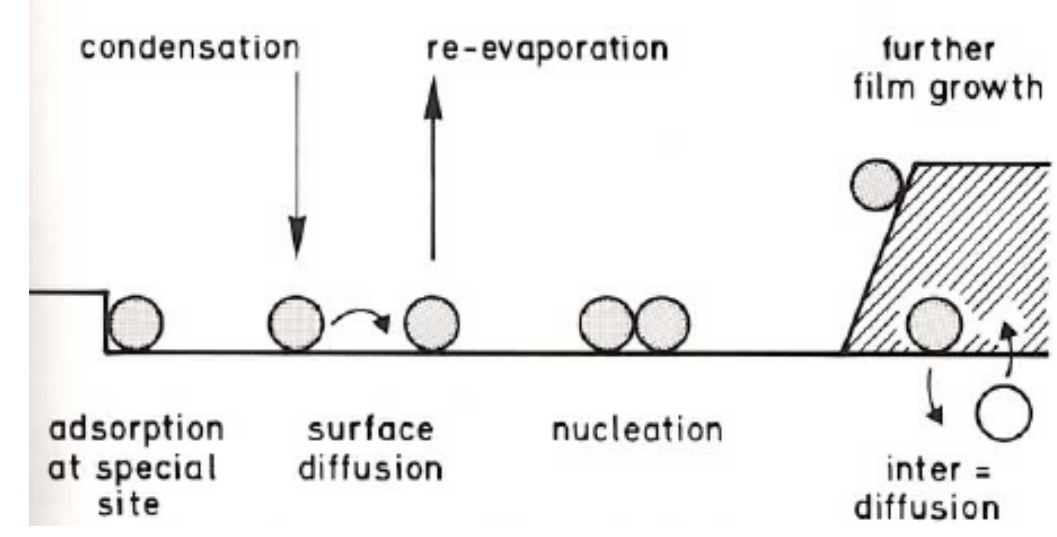

Figura 2.31: Representação pictórica dos processos atômicos individuais que determinam o modo de crescimento de um filme sobre um substrato sólido. A velocidade e a estabilidade de cada um desses processos é determinado pela interação entre adsorvatos e entre adsorvatos e substrato. (Obtido da ref. [5])

O modo e a taxa de crescimento de filmes finos em superfícies são determinados por processos atômicos individuais, tais como condensação, difusão superficial e re-evaporação de espécies, nucleação de ilhas, adsorção em sítios especiais (cantos, bordas e defeitos), interdifusão entre filme e substrato, dentre outros [5]. Alguns desses processos são mostra- 
dos na figura 2.31. Cada um desses processos depende de energias de ativação típicas do sistema adsorvato/substrato e do número de partículas que participam do processo [5]. Assim, se há um excesso ou escassez de partículas disponíveis num processo particular, sua taxa pode aumentar ou diminuir, alterando o crescimento do cristal como um todo, de modo que o estado final não necessariamente é o de mínima energia [5]. Além disso, no equilíbrio termodinâmico cada processo ocorre em duas direções opostas (e.g., condensação e re-evaporação) à mesma taxa e portanto não haveria crescimento do filme [5]. Desta forma, o crescimento de filmes é essencialmente um processo cinético e fora do equilíbrio termodinâmico, governado por princípios de validade local [5].

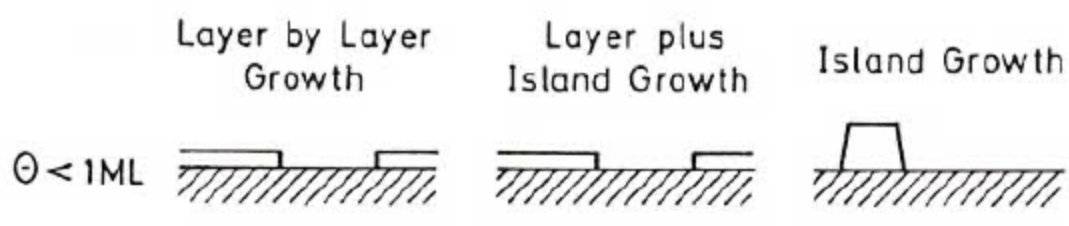

$1 \mathrm{ML}<\Theta<2 \mathrm{ML}$
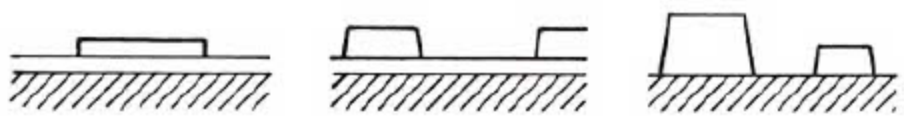

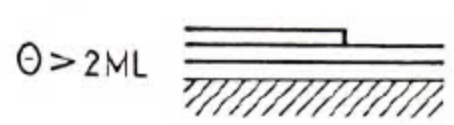

(a)

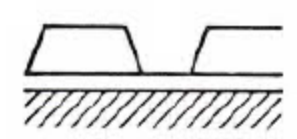

(b)

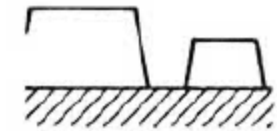

(c)

Figura 2.32: Representação pictórica dos possíveis modos de crescimento de um filme sobre um substrato sólido em função da espessura $(\Theta)$ em monocamadas atômicas (ML). (a) Modo Frank-van der Merve (FM) ou crescimento por camadas, (b) modo Stransky-Krastanov (SK) ou crescimento por camadas e ilhas (misto) e (c) modo Vollmer-Weber (VW) ou crescimento por formação de ilhas. (Obtido da ref. [5]).

Do ponto de vista macroscópico, o balanço entre os processos descritos acima determinam a taxa de deposição e resultam em pelo menos três diferentes modos de crescimento de filmes, como mostrado na figura 2.32 [5]: (a) crescimento por camadas (ou modo Frankvan der Merve, FM), (c) crescimento por formação de ilhas (ou modo Vollmer-Weber, VW), ou ainda (b) um regime de crescimento misto (ou modo Stransky-Krastanov, SK). No modo FM, a interação entre os adsorvatos vizinhos é mais fraca do que a interação entre adsorvato e substrato, facilitando a difusão de átomos na superfície, de modo que uma nova camada só começa a crescer quando a subjacente está completa. No modo VW, a 
interação entre adsorvatos é mais forte do que a interação adsorvato/substrato. Assim, os átomos da superfície se difundem até encontrarem um outros átomos já condensados, nucleando ilhas. Cada ilha pode ter uma espessura de várias monocamadas atômicas, mesmo se o substrato ainda estiver exposto. No modo SK, uma situação intermediária ocorre. O crescimento inicia-se por camadas e após um certo número de monocamadas completas $(\geq 1)$, o sistema passa a formar ilhas. Diferentes mecanismos podem ser responsáveis por este modo de crescimento. Um deles é o descasamento (mismatch) entre os parâmetros de rede do filme depositado e do substrato, associado à tensão superficial característica de cada um dos sistemas (filme/vácuo, substrato/vácuo e filme/substrato) [5]. Inicialmente, o crescimento tende a ser epitaxial, isto é, o filme cresce com o mesmo parâmetro de rede do substrato e, portanto, estruturalmente frustrado. Em certo ponto do crescimento, a energia de superfície acumulada é tal que o sistema não suporta manter esta frustração e tende a relaxar para o parâmetro de rede típico do material do filme (puro, volumoso) [5], gerando diferentes morfologias (relaxação, reconstrução, kinks, defeitos, degraus, terraços, linhas ou redes de deslocamentos, etc.) [5].

\section{Difração de Elétrons de Baixas Energias (LEED)}

A difração de elétrons é, de longe, a técnica mais utilizada em física de superfícies para a verificação da qualidade estrutural e cristalográfica de uma superfície [97]. Neste experimento, um feixe de elétrons com energias na faixa de 20 a 200 eV incide sobre a superfície da amostra e é retroespalhado em diferentes direções. Devido à estrutura cristalina da superfície e ao comportamento dual do elétron, os elétrons são difratados, trazendo informações sobre a posição e a periodicidade dos centros espalhadores.

Devido à forte interação coulombiana dos elétrons livres com a matéria (i.e., os elétrons de valência do material), o livre caminho médio de elétrons de baixas energias em sólidos é muito curto (5 a $10 \AA$ ). Os elétrons, portanto, interagem apenas com as primerias monocamadas atômicas do material. Isso torna a técnica de LEED bem adequada ao estudo de superfícies. A rigor, o livre caminho médio de elétrons em sólidos depende de sua energia cinética inicial e é mínimo na faixa de energia utilizada em LEED, devido à sua forte interação com plásmons e fônons de superfície e elétron-elétron [5, 98].

Por isso, uma descrição teórica completa de difração de elétrons deve levar em conta 
o caráter inelástico da interação do elétron com os átomos da rede cristalina, a posição instantânea dos centro espalhadores e o espalhamento múltiplo dos elétrons nas camadas próximas à superfície. Esta descrição dinâmica [5] da difração de elétrons deve portanto explicar não só a posição dos picos de difração, bem como a variação da intensidade dos picos em função da energia do feixe primário (curva I-V) e a estrutura fina do padrão de LEED [102].

Uma simplificação razoável da descrição do espalhamento de elétrons em superfícies é a teoria cinemática [5, 97, 98]. Esta teoria baseia-se em duas simples suposições: (i) de que o tempo de interação do elétron com o centro espalhador é muito menor que o tempo do recuo sofrido por este devido à transferência de momento linear; e (ii) o elétron só interage uma única vez com o centro espalhador, antes de ser espalhado para longe do material (espalhamento simples ou aproximação de Born) [5, 97, 98]. Portanto, os elétrons interagem elasticamente com átomos fixos em suas posições de equilíbrio. As únicas condições a serem satisfeitas são as leis de Bragg e Laue de difração no plano [98]. Deste modo, a teoria prevê apenas as posições dos picos de difração e, conseqüentemente, a simetria da estrutura cristalina. Na maioria dos casos, esta descrição é suficiente para a interpretação de padrões de LEED.

O aparato experimental para LEED é bastante simples [97]. Ele é composto de um canhão de elétrons, a amostra e um analisador com campo de retardo (RFA, Retarding Field Analyzer). O canhão de elétrons consiste em um filamento de tungstênio, que é aquecido por uma corrente elétrica, enquanto uma alta diferença de potencial ( 5 a $10 \mathrm{kV}$ ) acelera os elétrons entre o canhão e a amostra. Outros potenciais podem ser aplicados ao longo do caminho dos elétrons para defleti-los ou focalizá-los. A amostra é montada sobre um braço manipulador (ou goniômetro), que pode girar, mudando o ângulo de incidência do feixe primário. Na maioria dos casos, a difração é realizada com incidência normal. O detector RFA é composto de quatro grades hemisféricas, concêntricas, e uma tela fosforescente. Entre a amostra e a tela, há uma alta voltagem positiva aplicada, para atrair os elétrons retro-espalhados. As grades mais externa e mais interna são aterradas e servem para isolar, respectivamente, a tela e a região da amostra de campos elétricos indesejáveis, que podem causar deflexões do feixe. As grades intermediárias são sujeitas a potenciais negativos e servem de "filtro", impedindo a passagem apenas de elétrons que 
sofreram espalhamento inelástico [97]. São por isso chamadas de grades supressoras.

A observação do padrão de difração dá informações sobre a simetria e periodicidade da estrutura cristalina da superfície ou da superestrutura dos adsorvatos, mas não permite se determinar a posição dos átomos na célula unitária, nem as distâncais interplanares, nem as amplitudes de vibração dos átomos [97]. Para isso é necessária a análise do perfil de intensidade dos picos de difração em função da energia do feixe primário (curva $I \times V$ ). Sua análise depende da comparação de resultados experimentais com cálculos numéricos baseados na teoria dinâmica [97].

Para uma análise correta do padrão de LEED de uma supefície, deve-se levar em conta que os elétrons trazem informações não só da primeira camada, como também de algumas camadas mais internas. Dessa maneira, a presença de adsorvatos sobre uma superfície cristalina (e.g., um substrato cristalino) gera um padrão típico de difração superposto ao padrão da superfície subjacente. Se os adsorvatos formam uma rede bem ordenada (super-rede), com periodicidade diferente da do cristal que lhes serve de base, dizemos que houve reconstrução. Sua periodicidade pode ser descrita em função dos vetores primitivos do substrato (notação de Wood), da seguinte maneira [5].

Sejam $\mathbf{a}_{1}$ e $\mathbf{a}_{2}$ vetores primitivos da rede principal (bidimensional) e $\mathbf{b}_{1}$ e $\mathbf{b}_{2}$ vetores primitivos da super-rede. Nos casos em que a reconstrução ocorre de modo que $\mathbf{b}_{1} \| \mathbf{a}_{1} \mathrm{e}$ $\mathbf{b}_{2} \| \mathbf{a}_{2}$,

$$
\mathbf{b}_{1}=m \mathbf{a}_{1}, \mathbf{b}_{2}=n \mathbf{a}_{2}
$$

onde $m$ e $n$ são inteiros. Assim, a reconstrução de um certo adsorvato $A$ sobre um dado substrato $X\{h k l\}$ pode ser descrita pela notação

$$
p(m \times n)-A / X\{h k l\} \text { ou } c(m \times n)-A / X\{h k l\},
$$

onde $p$ (primitiva) e $c$ (centrada) referem-se respectivamente à ausência ou presença de um átomo de $A$ no centro da célula unitária. Nos casos em que os vetores primitivos da superestrutura não são paralelos aos do substrato, atribui-se ainda um certo ângulo de rotação $\theta=R^{\circ}$ e a notação fica

$$
p(m \times n) R^{\circ}-A / X\{h k l\} \text { ou } c(m \times n) R^{\circ}-A / X\{h k l\} .
$$




\section{Espectroscopia de Elétrons Auger (AES)}

Espectroscopia de elétrons Auger é outra técnica muito difundida e utilizada no estudo da pureza e constituição química de superfícies. Ela se baseia no efeito Auger, o fenômeno no qual a emissão de um elétron mais interno (do "caroço") de um átomo causa a emissão de um elétron mais externo. Este último é chamado elétron Auger.

Para isso, um elétron das camadas mais internas deve ser excitado por fótons (de raios $\mathrm{X}$ ) ou por feixes de elétrons com energias de 2 a $50 \mathrm{keV}$. Ao ser excitado, ele deixa um buraco no nível original. Como esse estado é energeticamente instável, um elétron de um nível mais alto decai, ocupando o estado vago e emitindo um fóton, com energia igual à diferença entre seus estados final e inicial. Se esta energia for igual ou maior que a energia de ionização típica do átomo, esse fóton pode excitar elétrons de camadas mais externas. Esse último elétron é emitido do átomo com uma energia cinética igual à diferença entre a energia do fóton e a do seu estado inicial. Energias típicas estão na faixa de 30 a $3000 \mathrm{eV}$. Nessa faixa, o livre caminho médio do elétron na superfície é da ordem de 0,3 a $3 \mathrm{~nm}$. Portanto, os elétrons Auger detectados são emitidos das primeiras 10 monocamadas atômicas da superfície. Assim, AES é capaz de fornecer informações sobre a identidade dos átomos na superfície e em sua vizinhança, sendo sua sensibilidade função da espessura da camada depositada. Essa técnica permite, portanto, uma medida do grau de contaminação de uma superfície e a calibração da espessura e/ou da taxa de deposição de elementos num sistema de UHV [5].

O arranjo experimental é semelhante ao necessário para LEED. Para AES, entretanto, um analisador de espelho cilíndrico (cylindrical mirror analyzer, CMA) é mais adequado do que o RFA, utilizado em LEED. Esse espectrômetro é formado por dois cilindros metálicos coaxiais, com o canhão de elétrons e o sistema de lentes eletrostáticas ao longo do eixo do cilindro. O cilindro mais interno é mantido aterrado, enquanto o mais externo é mantido num potencial negativo. Os elétrons Auger espalhados penetram no cilindro e são defletidos pelo campo elétrico, de modo que apenas elétrons com uma determinada energia cinética atingem o detector, no fundo do cilindro [5, 98]. 


\section{Magnetometria por Efeito Kerr Magneto-Óptico (MOKE)}

Este tipo de magnetometria baseia-se no efeito Kerr magneto-óptico. Este efeito consiste na mudança da polarização e/ou intensidade da luz refletida pela superfície de um material magnetizado [99]. Esta mudança da polarização deve-se à quebra de inversão temporal introduzida pela magnetização [100], de modo que a refletividade do material torna-se diferente para diferentes estados de polarização circular da luz (birrefringência circular). Isto introduz componentes complexas não-diagonais no tensor permissividade elétrica do material, que são funções ímpares da magnetização [100, 101]. Isso torna possível a medida de mudanças locais da magnetização de uma superfície através de medidas ópticas.

Microscopicamente, o efeito Kerr em materiais ferromagnéticos resulta da combinação da polarização de spin das bandas eletrônicas e da interação spin-órbita. Este último acopla a componente de spin da função de onda dos elétrons à componente espacial (ou orbital), que é responsável pelas propriedades ópticas do material, como os elementos da matriz de dipolo elétrico e as regras de seleção de transições [100].

Devido ao caráter vetorial da magnetização, distinguem-se três geometrias de MOKE, sendo cada uma sensível a uma componente da magnetização, com respeito à geometria de espalhamento do feixe luminoso $[100,101]$. Seja o plano de incidência o plano formado pelos feixes incidente e refletido e, portanto, ortogonal à superfície. Na geometria polar, mede-se a componente da magnetização que é perpendicular à superfície. Na geometria longitudinal, mede-se a componente da magnetização que é simultaneamente paralela à superfície e ao plano de incidência. Na geometria transversal, mede-se a componente da magnetização paralela à superfície e perpendicular ao plano de incidência.

A montagem experimental para MOKE requer uma bobina para geração do campo magnético externo na região da amostra, uma fonte de luz monocromática e coerente (usualmente, um laser de He-Ne vermelho) e um polarizador linear, no estágio anterior à amostra, e um comutador de fase, um polarizador-analisador e um fotodetector, no estágio posterior à amostra [99, 101]. A montagem da posição da amostra e da direção de aplicação do campo magnético com o plano de incidência determinam a modalidade (geometria) de MOKE aplicada (longitudinal, transversa ou polar). Neste trabalho, todas as medidas de MOKE foram realizadas em geometria longitudinal, com momento magnético dado em unidades de elipticidade Kerr $(\mu r a d)$. É importante salientar que não é possível 
se obter valores absolutos do momento magnético através de MOKE, apenas sua variação, que é proporcional à variação da intensidade da luz refletida [101]. Devido à forte refletividade dos metais, a penetração da luz só alcança algumas dezenas de nanômetros, o que torna esta técnica muito adequada ao estudo de superfícies e filmes ultrafinos, sem sofrer influência do substrato [101]. Uma outra vantagem é a natureza local da medição, já que a secção transversal do feixe luminoso usualmente apresenta áreas da ordem de $1 \mathrm{~mm}^{2}$. Isso permite focalizar o feixe onde se deseja estudar o comportamento magnético (na presença ou ausência de condições de contorno). Na montagem utilizada neste trabalho, a bobina magnética é capaz de gerar campos de até 2400 Oe, o suficiente para saturar a amostra.

\subsubsection{Espectroscopia por Perda de Energia de Elétrons Spin- Polarizados (SPEELS)}

As técnicas de caracterização estrutural e magnética disponíveis na câmara de análise servem, em suma, para garantir boas condições da amostra para conseguinte investigação das excitações de superfície. Uma das técnicas mais adequadas para esse estudo é a espectroscopia por perda de energia de elétrons (EELS ou HREELS), que é muito sensível aos modos vibracionais de adsorvatos na superfície, dentre outras excitações. Ela tem sido extensivamente aplicada em ciência de superfícies e química do estado sólido, na caracterização do comportamento dinâmico e dos modos vibracionais de adsorvatos em superfícies sólidas $[103,104,105,106]$. Trabalhos pioneiros sobre catálise em interfaces gás/sólido, em que se utiliza esta e outras técnicas de investigação típicas de ciência de superfícies, deram o Prêmio Nobel de Química de 2007 ao físico Gerhard Ertl [107, 108, 109].

Em princípio, esta técnica é muito semelhante a LEED, principalmente no espalhamento em geometria especular. Ela é, portanto, muito sensível à superfície devido ao curto livre caminho médio dos elétrons de baixas energias. Em LEED, o espalhamento observado é tipicamente um espalhamento elástico. Em EELS, estamos interessados no espalhamento inelástico, no qual um elétron incidente com energia $E_{0}=\epsilon$ pode ocupar um nível de energia $E_{F}+\epsilon$, desocupado, próximo ao nível de Fermi, liberando um outro elétron num nível com energia $E_{F}-\epsilon$, com mesmo spin ou spin oposto. Em sua versão 
spin-polarizada, SPEELS, sua maior vantagem é a possibilidade de se observar simultaneamente a dinâmica de spins e elástica de adsorvatos magnéticos em superfícies e filmes finos [110]. Em SPEELS, um feixe de elétrons spin-polarizados incide sobre a superfície de uma amostra e o feixe refletido é analizado em energia, para cada polarização de spin. A energia do feixe primário é bem conhecida e a perda (ou ganho) de energia dos elétrons emergentes é medida para as duas polarizações de spin, após interagirem com a superfície. O spin dos elétrons pode ser paralelo ou antiparalelo à direção de quantização dos spins do material. Adotaremos neste trabalho a convenção de que spins "para cima" ("para baixo") significa paralelos aos spins majoritários (minoritários) do material. O ângulo de incidência do feixe eletrônico com a normal à superfície determina a transferência de momento linear paralelo à superfície (ou simplesmente vetor de onda paralelo). Na geometria especular $\left(\theta_{r}=\theta_{i}\right)$, o vetor de onda paralelo é zero. À medida que se afasta o analizador da posição especular $\left(\theta_{r}=\theta_{i} \pm \delta \theta\right)$, detecta-se elétrons que transferiram um certo momento linear não-nulo ao material. Isto permite medir a interação de elétrons com quasipartículas típicas do sistema, como fônons, plásmons, mágnons ou éxcitons (pares elétron-buraco ou excitações de Stoner).

Além de sua sensibilidade à superfície, SPEELS é capaz de medir energias de excitações com grandes vetores de onda, isto é, até o limite da SBZ. Valores típicos de vetores de onda paralelos encontram-se na faixa de 0,2 a $1,8 \AA^{-1}$, com energias $\left(E_{\text {loss }}\right)$ acima de $10 \mathrm{meV}$. Em princípio, é possível medir excitações fora dessa faixa, mas há limitações experimentais para $E_{\text {loss }}<10 \mathrm{meV}$, devido à superposição com o pico quasi-elástico, que é muito intenso. Para $\Delta K_{\|}>0,7 \AA^{-1}\left(E_{\text {loss }} \approx 90 \mathrm{meV}\right)$, os picos de ondas de spin sofrem um forte amortecimento (alargamento e queda da intensidade), o que torna a determinação de sua energia difícil e imprecisa.

Portanto, SPEELS é uma técnica promissora na investigação de mágnons de superfície no limite de grandes vetores de onda. Este é um regime experimentalmente pouco investigado do espectro de mágnons, devido a limitações experimentais. SPEELS é atualmente o único método que permite o estudo de mágnons de grandes vetores de onda em filmes ultrafinos e superfícies [67, 68, 69]. Isto é importante porque as propriedades dos mágnons de grandes vetores de onda estão intimamente relacionadas com a interação de troca entre momentos magnéticos no sistema, que não pode ser explicada por modelos 
fenomenológicos baseados numa descrição magnetostática, aplicada no limite de longos comprimentos de onda (pequenos vetores de onda). Ondas de spin de grandes vetores de onda podem ser normalmente observadas por medidas de INS [70], mas infelizmente exigem amostras suficientemente volumosas, para aumentar a secção de choque de espalhamento. Portanto, experimentos de INS para a investigação de mágnons de grandes vetores de onda em filmes ultrafinos e superfícies são fortemente limitados [71]. Ondas de spin de pequenos vetores de onda (abaixo de $\Delta K=0,01 \AA^{-1}$ ) têm sido estudados experimentalmente em filmes finos magnéticos há várias décadas utilizando-se BLS [72, 73, 74] e FMR [74, 75]. As ondas de spin assim excitadas exibem um caráter magnetostático e apenas uma fração muito pequena da zona de Brillouin de superfície (SZB) pode ser explorada.

Recentemente foi demonstrado que mágnons de superfície podem ser excitados por tunelamento inelástico de elétrons, a partir de SP-STS [76]. Hoje, as principais técnicas de investigação experimental de ondas de spin já consolidadas são FMR, BLS e INS. Essas técnicas são complementares, pois possuem diferentes capacidades e limites de aplicação. Mas, ainda assim, não encerram todos os aspectos do estudo de ondas de spin.

FMR é adequada ao estudo da resposta magnética dinâmica, tanto de amostras volumosas, quanto de super-redes, multicamadas e filmes ultrafinos, com boa sensibilidade à superfície, uma vez que a medida é realizada em condição de ressonância. O experimento consiste em medir a absorção de uma amostra magnética, na presença de um campo magnético estático, colocada numa cavidade ressonante, saturada com radiação eletromagnética na faixa de gigahertz. O campo estático é variado até que a condição de ressonância seja atingida. Nesse momento, a radiação da cavidade é consideravelmente absorvida pela amostra e excita modos magnetostáticos , que são ondas de spin com vetores de onda nulos ou próximos do centro da zona de Brillouin. A desvantagem dessa técnica é a falta de resolução do vetor de onda, uma vez que a faixa de freqüências medidas é definida pela cavidade ressonante. Isso impede a observação da dispersão de ondas de spin para grandes vetores de onda, ao longo da zona de Brillouin.

Em contrapartida, BLS é um experimento muito similar a SPEELS - sendo fótons (luz) as quase-partículas espalhadas, em vez de elétrons -, capaz de detectar excitações em freqüências mais altas que FMR. Neste experimento, incide-se um feixe de luz visível, 
monocromática, na superfície de uma amostra colocada na presença de campo magnético estático e analisa-se o feixe espalhado, fazendo-o interferir com o feixe original. A interação da luz com excitações elementares do material se dá por meio do espalhamento inelástico de fótons incidentes (com energia bem definida) com fônons, mágnons ou outras quasipartículas no sistema. Isso causa uma mudança na freqüência e polarização da luz espalhada. O evento de espalhamento pode criar (processo Stokes) ou aniquilar (processo anti-Stokes) um quantum de uma dessas excitações elementares, causando uma pequena diferença de freqüência entre os feixes incidente e espalhado, proporcional à energia da excitação criada ou aniquilada. Essa energia é obtida a partir da interferência entre esses dois feixes. Para isso utiliza-se um interferômetro de Fabry-Pérot [74], que é um instrumento de alto contraste e de alta resolução para a análise de pequenas diferenças de freqüência entre feixes luminosos. As franjas de interferência obtidas são bem definidas e permitem obter com precisão a energia das excitações para um dado vetor de onda (determinado pelo ângulo que o feixe incide na amostra). Obtendo-se espectros de BLS para diferentes vetores de onda, constrói-se a relação de dispersão das excitações elementares observadas. Embora BLS também seja adequada ao estudo de filmes ultrafinos (1-10 ML) e detecte freqüências mais altas que FMR, sua resolução em momento também é limitada pelo comprimento de onda da luz utilizada.

Já INS tem uma boa resolução em vetor de onda ao longo da zona de Brillouin, uma vez que a energia do feixe de nêutron pode ser sintonizada com maior liberdade do que dos fótons em BLS. Mas como a secção de choque de espalhamento de nêutrons é muito pequena, a técnica requer amostras muito volumosas. Com isso, o sinal detectado traz uma maior contribuição dos modos de volume, apresentando baixíssima sensibilidade aos modos de superfície.

\section{Espalhamento Inelástico de Elétrons em Superfícies}

Em SPEELS, tem-se o controle do spin dos elétrons incidentes na amostra. Conhecendo-se a direção de quantização dos spins do material, é possível obter espectros parciais, $I_{\uparrow}$ e $I_{\downarrow}$, para cada polarização de spin dos elétrons incidentes: paralelo aos elétrons majoritários ou aos minoritários do material, respectivamente. Os espectros parciais $I_{\uparrow}$ e $I_{\downarrow}$ obtidos consistem na superposição de eventos de espalhamento com e sem troca de spin, isto 
é, $I_{\uparrow}$ e $I_{\downarrow}$ correspondem respectivamente às somas das intensidades parciais $I_{\uparrow \uparrow}+I_{\uparrow \downarrow} \mathrm{e}$ $I_{\downarrow \uparrow}+I_{\downarrow \downarrow}$, onde o primeiro e o segundo índices denotam os elétrons incidente e emitido, respectivamente.

Para se ter a distinção definitiva entre as quatro intensidades parciais e, conseqüentemente, entre os eventos spin-flip e não-spin-flip reais, é preciso ter também a resolução em spin do feixe espalhado. Isso é possível por meio da instalação de um detector de spin na saída do espectrômetro analizador. Sem esse detector de spin (nosso caso), em princípio, os eventos spin-flip e não-spin-flip estão misturados num mesmo espectro e, portanto, indistinguíveis.

Porém, uma distinção virtual entre esses picos é possível a partir da análise da diferença $I_{\downarrow}-I_{\uparrow}$ e da diferença normalizada, que é uma grandeza adimensional denominada assimetria de spin ou simplesmente assimetria, definida por

$$
A \equiv \frac{1}{P_{0}} \frac{I_{\downarrow}-I_{\uparrow}}{I_{\downarrow}+I_{\uparrow}}
$$

onde $P_{0}$ é a polarização original do feixe eletrônico. Dessa forma, os picos spin-flip observados representam inversões de spin virtuais, que correspondem à troca de elétrons com spins opostos na vizinhança do nível de Fermi [77, 85]. A seguir, explicamos em detalhe o espalhamento inelástico de elétrons dependente em spin, cuja fenomenologia está representada pictoricamente na figura 2.33.

Uma amostra magnética saturada tem, em princípio, todos os seus spins alinhados numa dada direção - a direção de quantização de seus elétrons majoritários. Sendo assim, um elétron incidente com spin paralelo aos majoritários não pode transferir momento angular à amostra, pois esta já está com momento angular máximo. Por outro lado, elétrons incidentes com spins paralelos aos elétrons minoritários são os únicos capazes de transferir momento angular à amostra, contribuindo para baixar o estado do momento angular total. Assim, cada elétron incidente com spin para baixo contribui com $-1 \hbar$ para o momento angular total da amostra. Este momento angular é transferido à amostra através de um quantum de mágnon (seja uma onda de spin ou uma excitação de Stoner). Portanto, por conservação do momento angular, apenas elétrons com spin para baixo podem criar mágnons, perdendo energia para o sistema [67]. No regime de ganho de 
energia, o que ocorre é a situação inversa: um mágnon existente no sistema é aniquilado, transferindo energia para o elétron e aumentando o momento angular total da amostra em $+1 \hbar$. Nesse caso, pela conservação do momento angular, apenas elétrons incidentes com spin para cima podem aniquilar mágnons. Para eventos não-spin-flip [figura 2.33(a e b)], nada disso ocorre, pois como não há transferência de momento angular, ambos os elétrons com spin para cima ou para baixo têm (até primeira ordem) a mesma secção de choque de espalhamento por uma excitação não-spin-flip [77]. Assim, o princípio de conservação de momento angular de spin estabelece uma regra de seleção para o espalhamento inelástico de elétrons dependente em spin (picos spin-flip): a criação (aniquilação) de mágnons se manifesta como picos inelásticos exclusivamente no canal de spins minoritários (majoritários), no regime de perda (ganho) de energia.

Uma vez que eventos tipo spin-flip só se manifestam no espectro $I_{\downarrow}\left(I_{\uparrow}\right)$ no regime de perda (ganho) de energia [figura 2.33(c)], a diferença entre os espectros parciais nos dá exclusivamente informações das excitações de caráter magnético, ou seja, qualquer pico observado na diferença corresponde a uma excitação tipo spin-flip. Por sua vez, a assimetria traz informações de ambos os tipos de eventos, mas cada um destes exibe diferentes comportamentos: pela mesma razão acima, um pico não-spin-flip deve exibir uma mesma assimetria quando excitado via perda ou ganho de energia, ao passo que um pico spin-flip exibe assimetrias opostas para perda e ganho de energia. Quando o spin do elétron emergente é oposto ao do elétron incidente, aparentemente houve uma mera inversão de spin. É importante salientar que os eventos spin-flip não constituem inversões reais de spin, mas apenas aparentes $[77,85]$. No espalhamento por impacto, ocorre uma troca de elétrons (com mesmo spin ou não): o elétron incidente é "absorvido" num nível eletrônico acima de $E_{F}$ e um outro elétron é emitido de um nível abaixo de $E_{F}$.

O comportamento da assimetria é determinado por duas diferentes contribuições de natureza magnética, que têm diferentes dependências com a geometria de espalhamento: a interação spin-órbita e a interação de troca entre elétrons [78]. A assimetria de spin (assim como a diferença $I_{\downarrow}-I_{\uparrow}$ ) consiste, então, na superposição desses dois efeitos, e o fenômeno observado experimentalmente resulta da convolução desses efeitos intrínsecos com artefatos introduzidos pelo espectrômetro, principalmente quando este opera em alta resolução, o que torna sua interpretação difícil. 


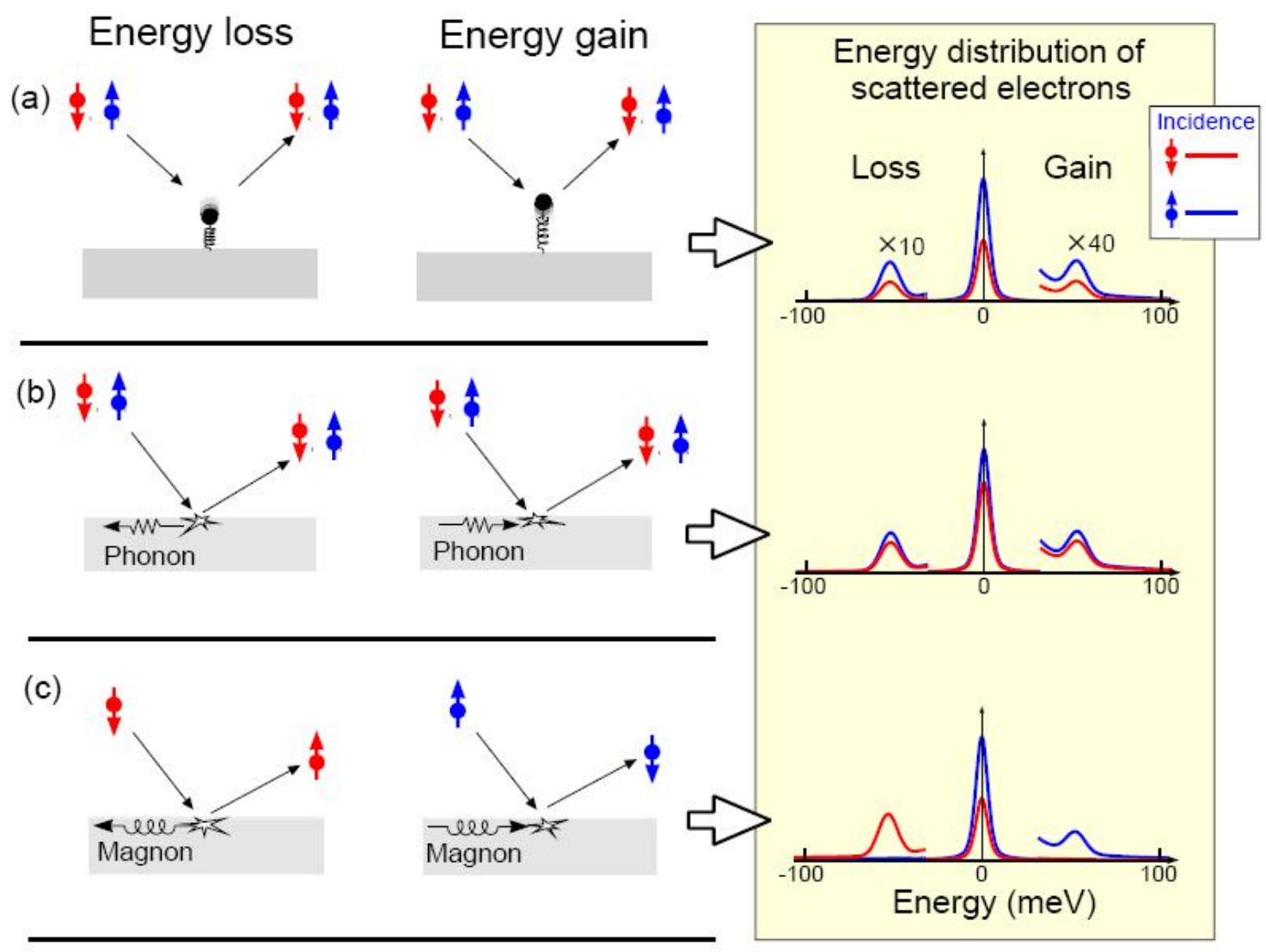

Figura 2.33: Representação esquemática do espalhamento inelástico de elétrons dependente em spin, em regimes de perda e ganho de energia, em geometrias especular (a) e não-especular (b) e (c), seguidos de seus respectivos espectros de SPEELS. A curva em azul, com seta para cima (vermelho, com seta para baixo) representa o espectro para incidência de elétrons majoritários (minoritários). Em (a) e (b), os eventos inelásticos são tipo não-spin-flip, pois ocorrem nos dois canais de spin. Em (c), os eventos inelásticos são tipo spin-flip, manifestando-se exclusivamente no canal de perda de energia (criação de excitações) ou ganho de energia (aniquilação de excitações). As regras de seleção de espalhamento dependente de spin - o princípio de conservação do momento angular de spin - proíbe a existência desses picos em ambos os canais de spin simultaneamente. 
No espalhamento em geometria especular [figura 2.33(a)], não há transferência de momento linear dos elétrons para a amostra, isto é, nos espectros vê-se apenas excitações elásticas e inelásticas que ocorrem no centro da zona de Brillouin. Todo o espectro é dominado pelo espalhamento dipolar, mediado pela interação coulombiana, que é de longo alcance e independente de spin. O espalhamento ocorre antes mesmo dos elétrons atingirem a superfície e o spin é conservado. Porém, ainda assim pode-se observar uma assimetria de spin em espalhamentos de elétrons em superfícies ferromagnéticas [79]. Como não há troca de elétrons com o material no espalhamento dipolar, todo o espectro exibe a mesma assimetria de spin, que corresponde ao desbalanço de spin da estrutura de bandas eletrônicas próximo à superfície $([111,112,113,114,115])$. Assim, a superfície ferromagnética funciona como um polarizador de spin adicional, atuando tanto em elétrons envolvidos tanto em processos elásticos quanto em inelásticos. Portanto, a assimetria observada é atribuída à forte interação de troca dos elétrons incidentes com aqueles nos estados eletrônicos da superfície [112, 113, 114], refletindo a dependência em spin dos níveis eletrônicos da superfície, ou seja, da barreira de potencial à qual os elétrons incidentes estão sujeitos.

Em geometria não-especular [figura 2.33(b e c)], o espalhamento se dá majoritariamente pelo mecanismo de impacto, isto é, os elétrons penetram no material e interagem diretamente com elétrons nos níveis eletrônicos mais externos (próximos ao nível de Fermi), com transferência de momento linear paralelo à superfície (a componente normal não se conserva devido ao curto comprimento de penetração do elétron no material) [98]. Desse modo, os elétrons podem interagir com excitações elementares tipo spin-flip e não-spin-flip, que podem exibir dispersão.

Os picos inelásticos devem ser simétricos em posição, correspondendo à mesma excitação, que ora é criada (perda de energia), ora é aniquilada (ganho de energia) (ver espectros na figura 2.33). Sabe-se que as excitações aniquiladas são aquelas presentes no material a uma temperatura finita, excitadas termicamente [85]. Assim sendo, a intensidade relativa entre os picos correspondentes deve ser proporcional ao peso de Boltzmann, $I_{\uparrow(\downarrow)}(-E) / I_{\uparrow(\downarrow)}(E) \propto \exp \left\{-E / k_{B} T\right\}$, e, com a diminuição da temperatura, deve-se observar uma queda na intensidade dos picos na região de ganho de energia. Isso de fato foi testado e observado em nossos experimentos. 


\section{Obtenção de um Feixe de Elétrons Spin-Polarizados}

O feixe de elétrons spin-polarizados é obtido por efeito fotoelétrico a partir de uma superfície semicondutora, excitada por luz circularmente polarizada. O semicondutor em questão é uma multicamada de $\operatorname{GaAs}_{1-x} \mathrm{P}_{x}(110)$ [116]. O GaAs é um conhecido semicondutor de gap de energia direto de $E_{g}=1,42 \mathrm{eV}$. No ponto $\Gamma$, as bandas eletrônicas de valência e de condução têm caráter predominante de orbitais $p$ e $s$ respectivamente. Dessa forma, a banda de valência é quadruplamente degenerada (orbital $p_{3 / 2}$ ), enquanto a banda de condução é duplamente degenerada (orbital $s_{1 / 2}$ ) [78]. Aplicando as regras de seleção de transições de dipolo elétrico com luz circularmente polarizada $(\Delta l= \pm 1$ e $\Delta m= \pm 1)$, há duas possíveis transições para esses níveis: para polarização $\sigma^{+}, m=-3 / 2 \rightarrow-1 / 2$ ou $m=-1 / 2 \rightarrow+1 / 2$ (com $\Delta l=-1$ em ambos os casos). Para polarização $\sigma^{-}$, a situação é recíproca. Considerando que estas tarnsições têm propabilidades relativas de 3 e 1 respectivamente e que os níveis populados têm números quânticos de spin opostos, isto resultaria numa polarização de spin de 50\% [78].

A dopagem com P introduz um forte acomplamento spin-órbita, que causa a quebra de degenerescência dos orbitais $p$ no ponto $\Gamma$ da banda de valência $(\Delta=0,34 \mathrm{eV})$ [78]. Com isso, ao se excitar o cristal com fótons de polarização $\sigma^{+}$e energia $E_{g}$, apenas transições $m=-3 / 2 \rightarrow-1 / 2$ são permitidas, o que teoricamente geraria uma polarização de spin $\left(P_{0}\right)$ de $100 \%$. Mas a forma real da banda de valência em torno do ponto $\Gamma$ deve ser levada em conta, bem como o monocromatismo não-ideal do laser. Experimentalmente, polarizações de até $85 \%$ podem ser obtidas, com eixo de polarização normal à superfície do fotocátodo. O fotocátodo utilizado nas medidas mostradas aqui exibiu uma polarização de spin de $P_{0}=70 \pm 10 \%$.

\section{Espectrômetro de Elétrons}

A realização deste experimento requer uma fonte de elétrons spin-polarizados; um espectrômetro monocromatizador, para selecionar elétrons com uma energia bem definida; a amostra, montada sobre um manipulador que permita sua rotação e translação; um espectrômetro analizador, um detector multiplicador de elétrons tipo channeltron e um contador de pulsos ligado a um computador. O aparato experimental utilizado para isso pode ser visto na figura 2.34, tal qual montado no interior da câmara de SPEELS. O 
espectrômetro é dividido em quatro estágios: um pré-monocromador de $90^{\circ}$, responsável por mudar a trajetória dos elétrons de modo que eles atinjam a superfície da amostra com spins paralelos à superfície; um monocromador principal de $180^{\circ}$, para a efetiva monocromatização dos elétrons de baixa energia; a câmara de espalhamento, que é uma região eletricamente e magneticamente isolada, onde ocorre a interação do feixe de elétrons com a amostra; e o analizador, que analiza a intensidade do feixe espalhado em função da energia. O analizador está conectado a um braço rotor, através do qual é possível girá-lo em relação ao monocromador principal, o que confere o grau de liberdade no momento linear transferido à amostra, paralelamente à superfície. Com isso, o espectrômetro é capaz de analizar o feixe de elétrons em energia e momento, com resoluções tão boas quanto $1 \mathrm{meV}$ e $0,05 \AA^{-1}$, respectivamente, para cada polarização de spin.

Um esquema pictórico do espectrômetro em funcionamento durante o experimento de SPEELS é mostrado na figura 2.35. Nele vemos os três estágios do espectrômetro, a amostra (sem a câmara de espalhamento em torno), com a direção de magnetização designada pelo vetor em verde, o laser (em vermelho) que excita os elétrons no fotocátodo e o caminho percorrido pelos elétrons (em azul). No detalhe, a definição dos ângulos $\theta$ e $\theta_{0}$ e os vetores de onda incidente $\overrightarrow{k_{i}}$ e espalhado $\overrightarrow{k_{f}}$. 


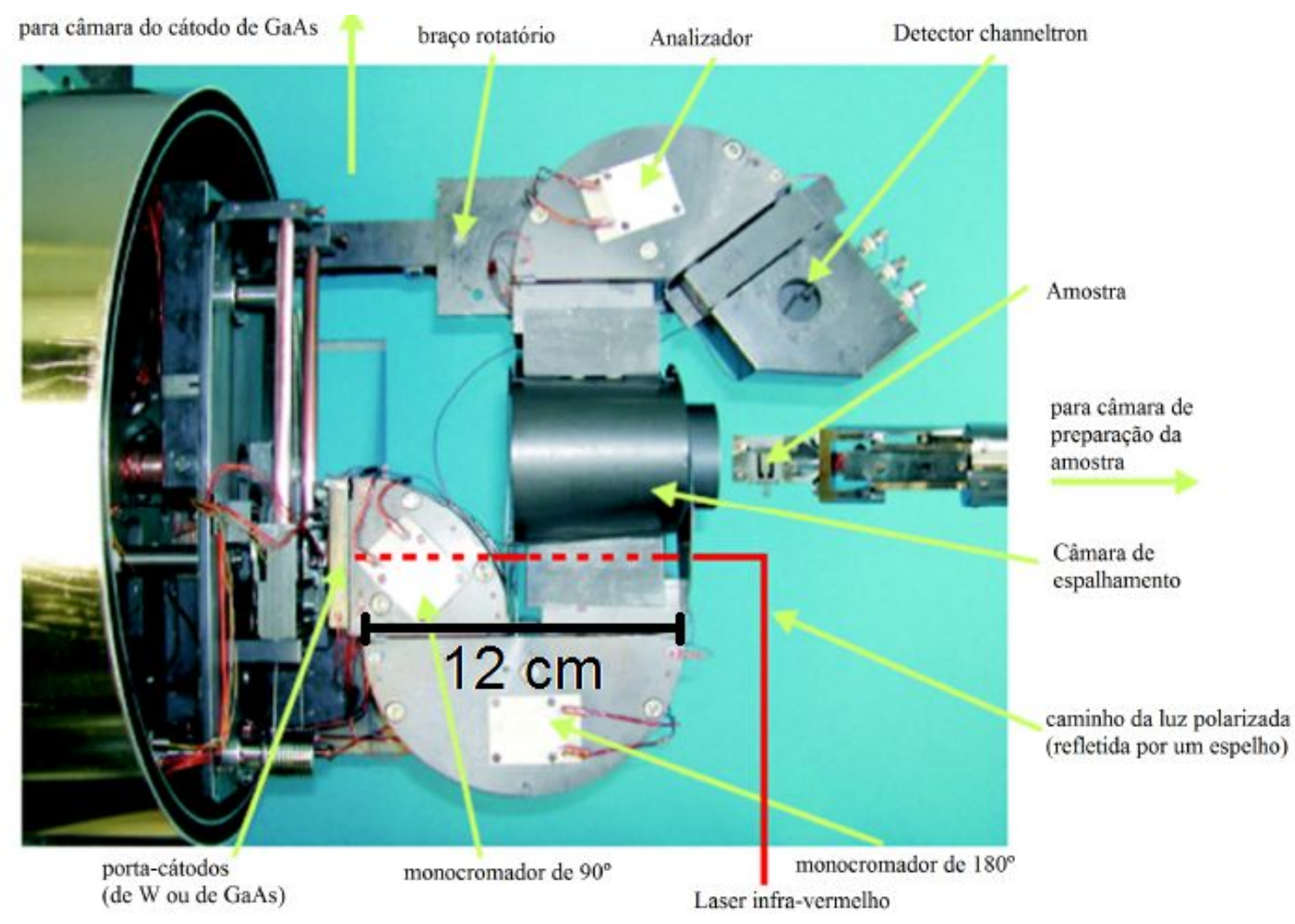

Figura 2.34: Foto do interior da câmara de SPEELS, com seus principais componentes designados, em especial o espectrômetro de SPEELS, com seus quatro estágios: o pré-monocromador de $90^{\circ}$ e o monocromador principal de $180^{\circ}$, de secções retas cilíndricas; a câmara de espalhamento e o analizador, seguido do detector channeltron. É possível girar o analizador em relação ao monocromador através do braço rotatório, o que confere a resolução em vetor de onda durante o espalhamento. (Obtido da ref. [83]). 


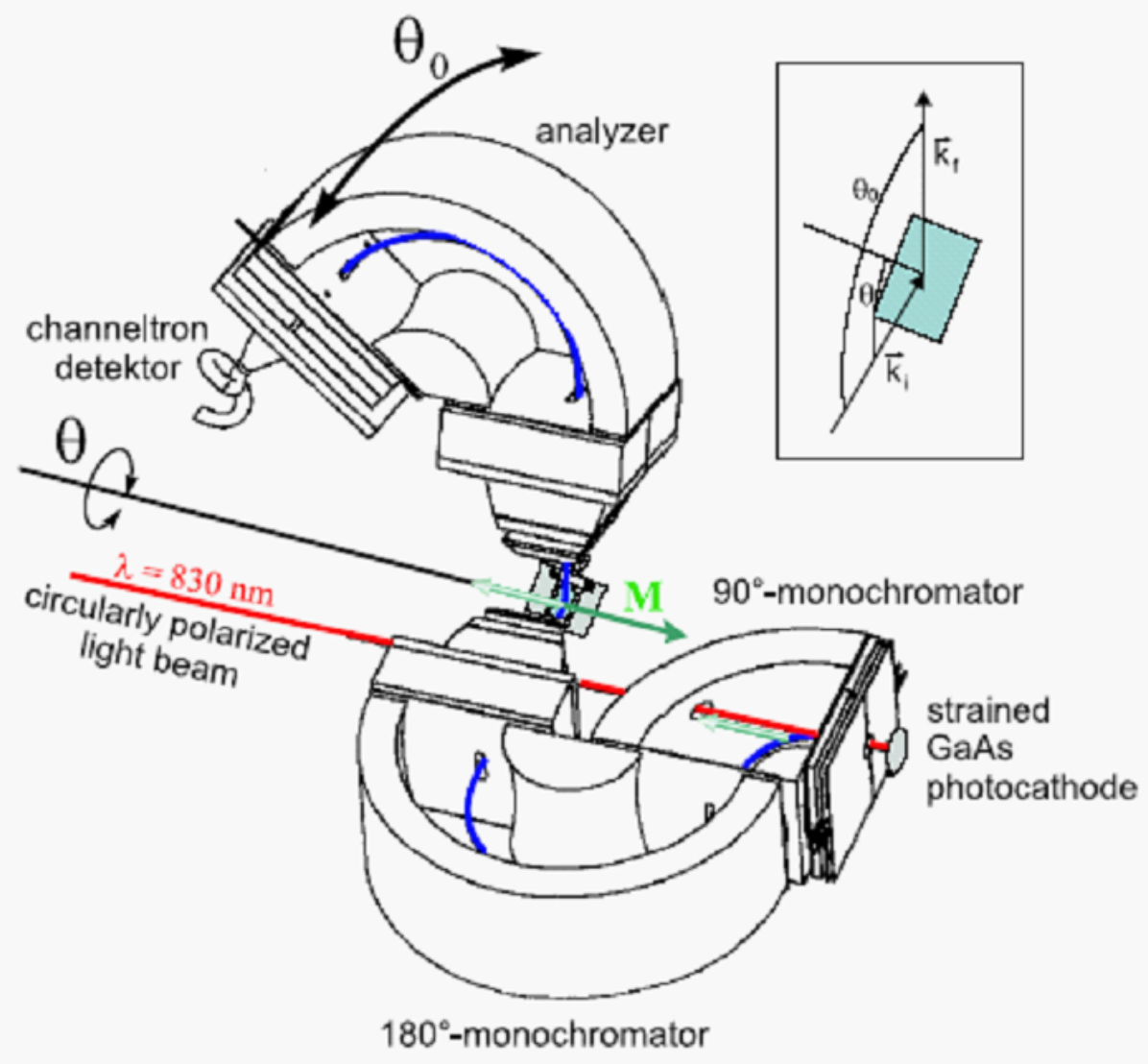

Figura 2.35: Esquema do experimento de SPEELS em curso. Vê-se em destaque o espectrômetro de elétrons, em seus dois estágios (monocromador e analizador), as trajetórias do laser circularmente polarizado (em vermelho) e dos elétrons (em azul), o cátodo de GaAs, gerador do feixe de elétrons spin-polarizados e a amostra, com a direção da magnetização indicada em verde. No detalhe vemos a geometria de espalhamento, com os vetores de onda inicial e final e a definição dos ângulos $\theta$ e $\theta_{0}$. (Obtido da ref. [83]). 


\section{CAPÍTULO 3}

\section{Arranjos Auto-Organizados de Nanofios Magnéticos}

Neste capítulo, estudamos arranjos de nanofios de Ni e Co, eletrodepositados numa matriz de $\mathrm{Al}_{2} \mathrm{O}_{3}$ porosa, com poros de diâmetros típicos variando de dezenas a centenas de nanômetros e alta razão de aspecto $(>50)$. Essas matrizes são obtidas a partir da anodização em dois passos de lâminas de $\mathrm{Al}$ de alta pureza, em solução ácida. O material magnético ( $\mathrm{Ni}$ ou $\mathrm{Co}$ ) é depositado posteriormente no interior dos poros via eletrodeposição AC ou pulsada. As amostras são caracterizadas estruturalmente por microscopia eletrônica de varredura (MEV), microscopia de força atômica e magnética (AFM/MFM) e difratometria de raios X (XRD), e magneticamente via magnetometrias SQUID e de amostra vibrante (VSM). A caracterização magnética consistiu de medida e análise de curvas de inversão de primeira ordem (FORCs), que se baseia no modelo de Preisach-Néel da magnetização $[27,28]$.

\subsection{Preparação e Caracterização Estrutural das Amostras}

Para o preparo das amostras utilizamos como eletrodo de trabalho lâminas de $\mathrm{Al}$ de 0,20 mm de espessura, com 99,9995\% de pureza, da marca Alfa Aesar. Antes da anodização, realizamos um procedimento padrão de pré-tratamento da amostra para proporcionar uma limpeza química da superfície e liberar frustrações e tensões mecânicas intrínsecas ao metal. O pré-tratameto consiste em:

1. Annealing da lâmina de $\mathrm{Al}$, a $500^{\circ} \mathrm{C}$, em vácuo melhor que $5 \times 10^{-5}$ torr, por 2 horas;

2. Limpeza orgânica da lâmina de $\mathrm{Al}$ em acetona, sob ultra-som, durante 15 minutos; 
3. Eletropolimento em solução de $\mathrm{H}_{2} \mathrm{SO}_{4}+\mathrm{H}_{3} \mathrm{PO}_{4}+\mathrm{H}_{2} \mathrm{O}$, na proporção de (2:2:1) em massa, sob voltagem de $20 \mathrm{~V}$, por 5 minutos;

4. Imersão em solução de $\mathrm{NaOH}$ a $3,0 \mathrm{~mol} / \mathrm{L}$, por 30 segundos.

Após esse pré-tratamento, a amostra é enxaguada em água deionizada e levada para a primeira anodização. Como contra-eletrodo, utilizamos placas de carbono de dimensões um pouco maiores $(50 \times 30 \times 5 \mathrm{~mm})$ que as lâminas de Al. Escolhemos como procedimento padrão a anodização em $(\mathrm{COOH})_{2}$ a $0,3 \mathrm{~mol} / \mathrm{L}$, a $40 \mathrm{~V} \mathrm{dc}$, a temperaturas em torno de $3^{\circ} \mathrm{C}$, durante 1 hora para a primeira anodização e 40 minutos para a segunda. Entre as duas anodizações, é realizado um ataque químico passivo em meio ácido para a remoção da camada de óxido. Nesta etapa intermediária, foi utilizada uma solução de $\mathrm{H}_{2} \mathrm{CrO}_{4}$ a $0,2 \mathrm{~mol} / \mathrm{L}+\mathrm{H}_{3} \mathrm{PO}_{4}$ a $0,4 \mathrm{~mol} / \mathrm{L}$, a aproximadamente $60^{\circ} \mathrm{C}$, por 40 minutos para todas as amostras. A partir deste procedimento, preparamos cerca de 50 amostras variando cada um dos parâmetros de anodização (tensão, tempo, temperatura e concentração dos reagentes) e eletrodeposição (tensão, freqüência e tempo).

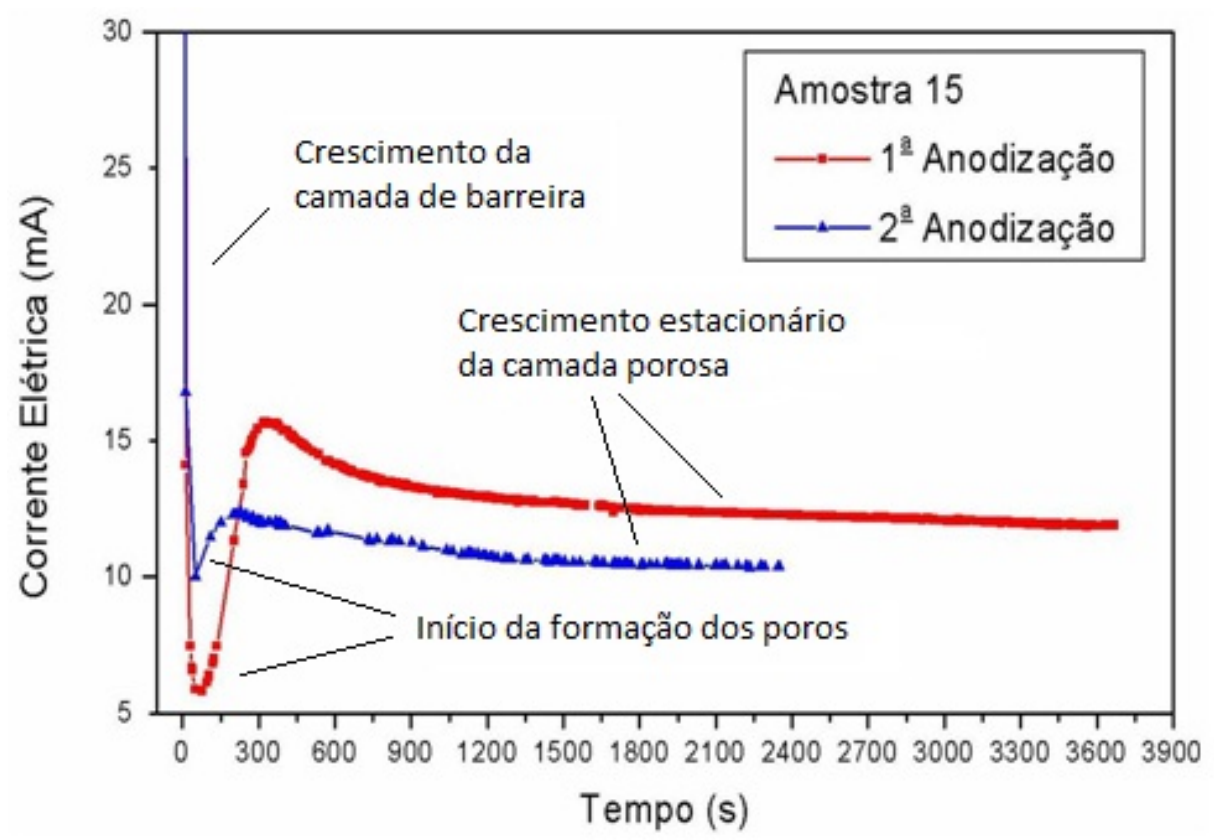

Figura 3.1: Corrente elétrica através da célula eletrolítica durante as anodizações. Mudanças no perfil da corrente indicam diferentes regimes de crescimento da camada óxida, como indicado na figura.

Na figura 3.1, visualizamos o comportamento da corrente através da célula eletrolítica durante as anodizações de uma amostra que seguiu o procedimento padrão de anodiza- 
ção $\left[3^{\circ} \mathrm{C}, 40 \mathrm{~V}\right.$ dc, em $(\mathrm{COOH})_{2}$ a $0,3 \mathrm{~mol} / \mathrm{L}$, durante 1 hora $\left(1^{\mathrm{a}}\right) / 40$ minutos $\left.\left(2^{\underline{a}}\right)\right]$. Em todas as amostras foi observado esse mesmo perfil de corrente elétrica em função do tempo, concordando com resultados da literatura [38]. A alta corrente inicial e seu rápido decaimento é associado à formação de uma camada de barreira homogênea, de alta resistividade elétrica. O pico negativo marca o início da formação dos poros, que continua até atingir um crescimento estacionário. Em geral, os valores típicos de corrente no regime estacionário estão na faixa de 1 a $20 \mathrm{~mA}$.

\subsubsection{Microscopia Eletrônica de Varredura}

Após fabricadas as amostras, realizamos sua caracterização estrutural. Primeiramente, fizemos imagens de Microscopia Eletrônica de Varredura (MEV) ao final de cada etapa, a fim de acompanhar a evolução do processo de formação do arranjo auto-organizado de poros. As imagens foram obtidas no Laboratório de Caracterização Tecnológica, no Departamento de Engenharia de Minas e Petróleo da Escola Politécnica da USP. Elas confirmaram satisfatoriamente a obtenção de redes auto-organizadas de poros, com estrutura hexagonal, com diferentes propriedades estruturais, de acordo com os parâmetros de anodização.

Nas figuras 3.2 e 3.3 vemos uma seqüência de imagens de MEV após cada uma das etapas de preparação da amostra. Na figura 3.2(a), vemos a superfície da amostra após a primeira anodização. Claramente ocorreu a formação de uma camada porosa de $\mathrm{Al}_{2} \mathrm{O}_{3}$. Entretanto, os poros não exibem nenhum ordenamento. A nucleação de poros nessa etapa é aleatória, concordando com resultados existentes na literatura [15, 37, 38, 90]. Após a abrasão da amostra em solução ácida, a camada de óxido é removida, expondo a superfície do $\mathrm{Al}$ subjacente. Na figura 3.2(b) vemos que o crescimento da camada de $\mathrm{Al}_{2} \mathrm{O}_{3}$ durante a primeira anodização induziu uma textura de concavidades na superfície do Al. O resultado de uma segunda anodização sobre essa superfície certamente é influenciado pelo padrão observado. De fato, a figura 3.3(a) mostra que a camada de $\mathrm{Al}_{2} \mathrm{O}_{3}$ porosa crescida sobre o Al texturizado exibe um alto ordenamento de poros para o conjunto de parâmetros de anodização utilizado. Após a eletrodeposição de Ni, o padrão hexagonal não se altera. Na figura 3.3(b) observamos que apesar de os poros não estarem completamente preenchidos para esta amostra, há algum acúmulo de depósito sobre a superfície. 
(a)
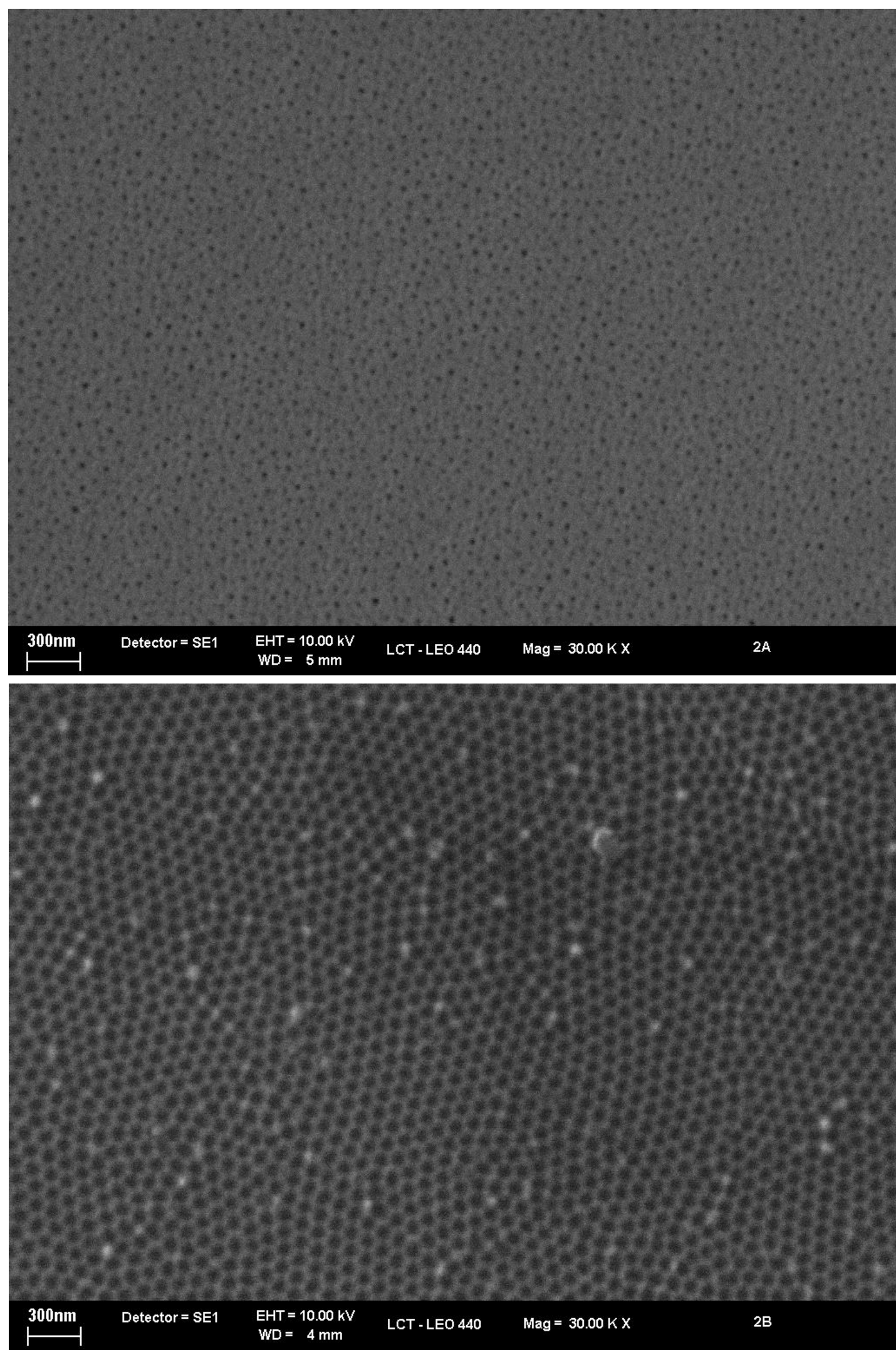

Figura 3.2: Imagens de MEV da amostra $2\left[3^{\circ} \mathrm{C}, 40 \mathrm{~V} \mathrm{dc}\right.$, em $(\mathrm{COOH})_{2}$ a $0,3 \mathrm{~mol} / \mathrm{L}$, durante 1 hora $\left(1^{-}\right) / 40$ minutos $\left.\left(2^{a}\right)\right]$ após as etapas de (a) primeira anodização e (b) remoção da camada de alumina. 
(a)
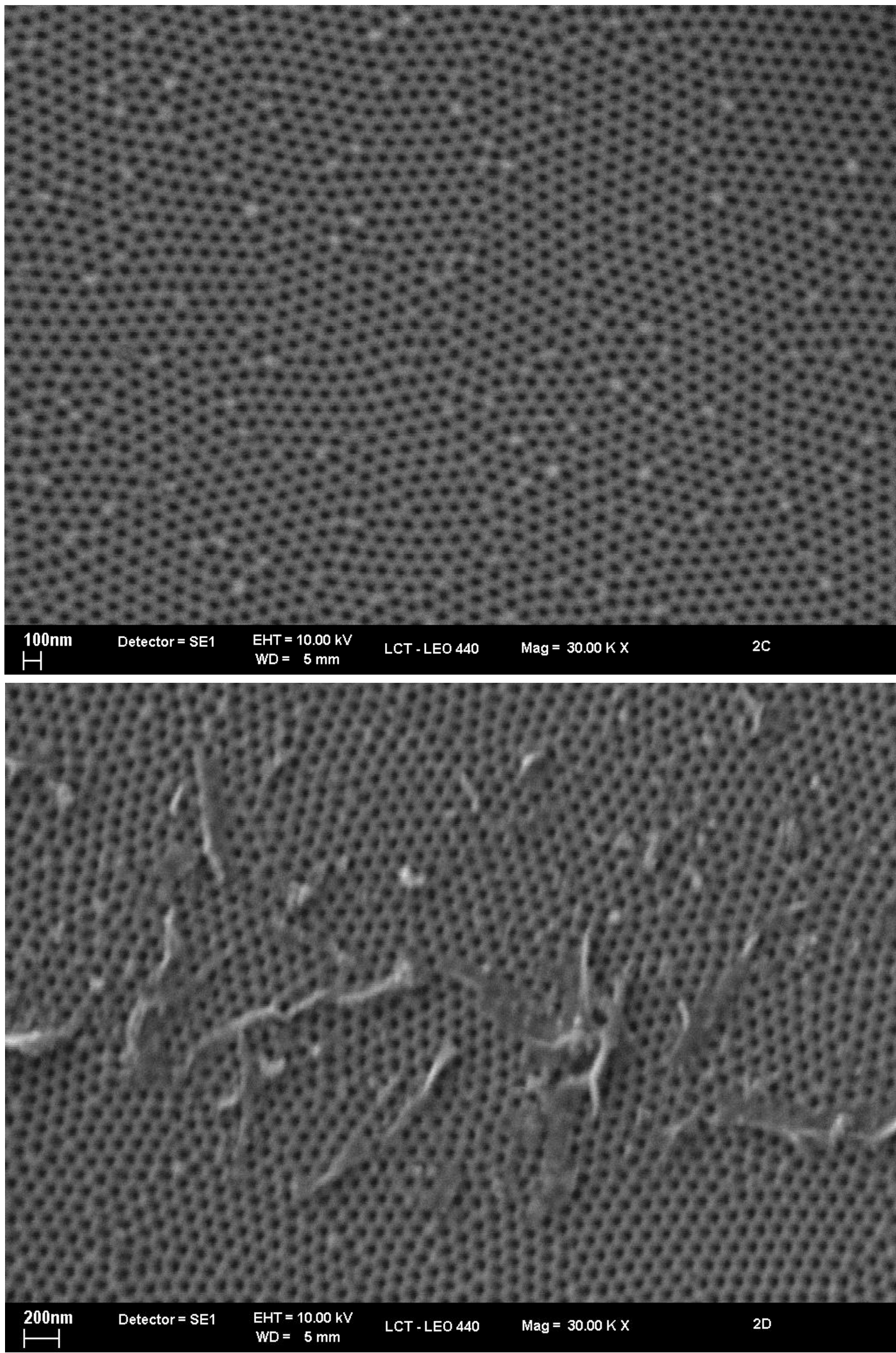

Figura 3.3: Imagens de MEV da amostra $2\left[3^{\circ} \mathrm{C}, 40 \mathrm{~V} \mathrm{dc}\right.$, em $(\mathrm{COOH})_{2}$ a $0,3 \mathrm{~mol} / \mathrm{L}$, durante 1 hora $\left(1^{\mathrm{a}}\right) / 40$ minutos $\left.\left(2^{\underline{a}}\right)\right]$ após as etapas de (a) segunda anodização e (b) eletrodeposição de Ni. 
Além das imagens da superfície, obtivemos imagens da secção reta das amostras para estudar a estrutura interna dos poros, sua profundidade e a espessura da camada de óxido. As figuras 3.4 e 3.5 mostram as secções retas de duas amostras anodizadas a $5^{\circ} \mathrm{C}$, em $(\mathrm{COOH})_{2}$ a $0,3 \mathrm{~mol} / \mathrm{L}$, por 4 horas $\left(1^{\mathrm{a}}\right) / 1$ hora $\left(2^{\mathrm{a}}\right)$, sendo uma a $V_{a n}=40 \mathrm{~V}$ e a outra a $V_{a n}=45 \mathrm{~V}$, com medidas do espaçamento entre os fios (fig. 3.4) e de seus diâmetros internos (fig. 3.5), respectivamente. Observa-se uma baixa dispersão entre os valores medidos, mostrando que a boa regularidade da rede, exibida nas imagens da superfície, se mantém ao longo de toda a secção reta da camada. Valores médios calculados para os diâmetros dos poros $D$ e para a distância inter-fio (centro a centro) $d_{\text {int }}$ foram, respectivamente, $\langle D\rangle=21,7 \pm 5 \mathrm{~nm}$ e $\left\langle d_{\text {int }}\right\rangle=101,1 \pm 6 \mathrm{~nm}$, para a amostra a $V_{a n}=40$ $\mathrm{V}$, e $\langle D\rangle=20,4 \mathrm{~nm}$ e $\left\langle d_{\text {int }}\right\rangle=108,5 \pm 5 \mathrm{~nm}$, para a amostra a $V_{a n}=45 \mathrm{~V}$.

Na figura 3.6(a) vemos uma típica imagem em perspectiva do perfil da camada porosa de $\mathrm{Al}_{2} \mathrm{O}_{3}$ sobre o $\mathrm{Al}$, da amostra anodizada a $5^{\circ} \mathrm{C}, 35 \mathrm{~V}$, por 4 horas $\left(1^{\mathrm{a}}\right) / 75$ minutos $\left(2^{\mathrm{a}}\right)$. Na figura 3.6(b), vemos uma imagem do perfil da amostra anodizada a $5^{\circ} \mathrm{C}, 45 \mathrm{~V}$, por 4 horas $\left(1^{\mathrm{a}}\right) / 1$ hora $\left(2^{\mathrm{a}}\right)$, com um comprimento típico dos poros de $7,7 \mu \mathrm{m}$.

Nas figuras 3.7 e 3.8, vemos imagens de duas regiões diferentes de duas amostras anodizadas nas mesmas condições $\left[5^{\circ} \mathrm{C}\right.$, em $(\mathrm{COOH})_{2}$ a $0,3 \mathrm{~mol} / \mathrm{L}$, por 4 horas ( $1^{\mathrm{a}}$ anod.) $]$, sendo uma (fig. 3.7) a $40 \mathrm{~V}$, por 60 minutos ( $2^{\mathrm{a}}$ anod.) e a outra (figs. 3.8) a $35 \mathrm{~V}$, por 75 minutos. As imagens demonstram que numa mesma amostra há uma dispersão do comprimento dos poros devido às imperfeições naturais da superfície da lâmina. Apesar disso, podemos estimar um comprimento médio dos poros em torno de 4,8 $\mu \mathrm{m}$ para anodizações de 60 minutos a $V_{a n}=40 \mathrm{~V}$ e $3,7 \mu \mathrm{m}$ para anodizações de 75 minutos a $V_{a n}=35 \mathrm{~V}$. Comparando os valores estimados nas imagens 3.6(b), 3.7 e 3.8, percebemos que o comprimento médio dos poros depende tanto do tempo das anodizações quanto da tensão de anodização, visto que este último regula a taxa de formação e dissolução da alumina, em concordância com a literatura [13]. No regime de crescimento estacionário, esperamos que todas essas taxas sejam constantes. Portanto, a taxa de crescimento da espessura da camada porosa deve ser linear com o tempo e a tensão de anodização.

Para se comparar os efeitos dos parâmetros de anodização sobre as propriedades estruturais da camada porosa de $\mathrm{Al}_{2} \mathrm{O}_{3}$, exibimos nas figuras 3.9 a 3.11 seqüências de imagens de diferentes amostras após a segunda anodização, em cada qual variamos um único 


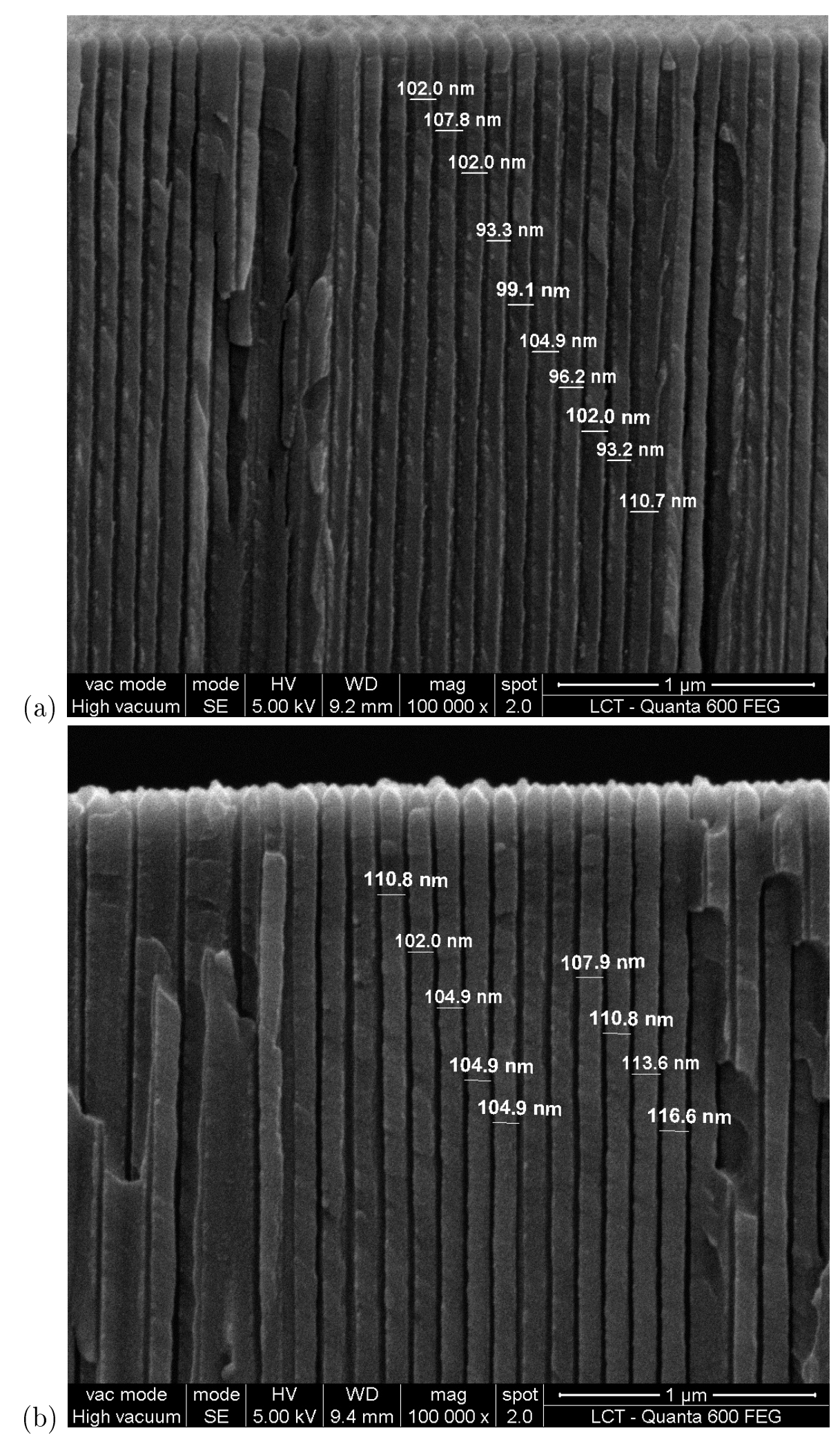

Figura 3.4: Imagens de MEV do perfil de amostras anodizadas a $5^{\circ} \mathrm{C}$, em $(\mathrm{COOH})_{2}$ a 0,3 mol/L, durante 4 horas $\left(1^{-}\right) / 1$ hora $\left(2^{\mathrm{a}}\right)$, sob tensões de (a) $40 \mathrm{~V}$ e (b) $45 \mathrm{~V}$, com medidas do espaçamento entre os poros (periodicidade). 


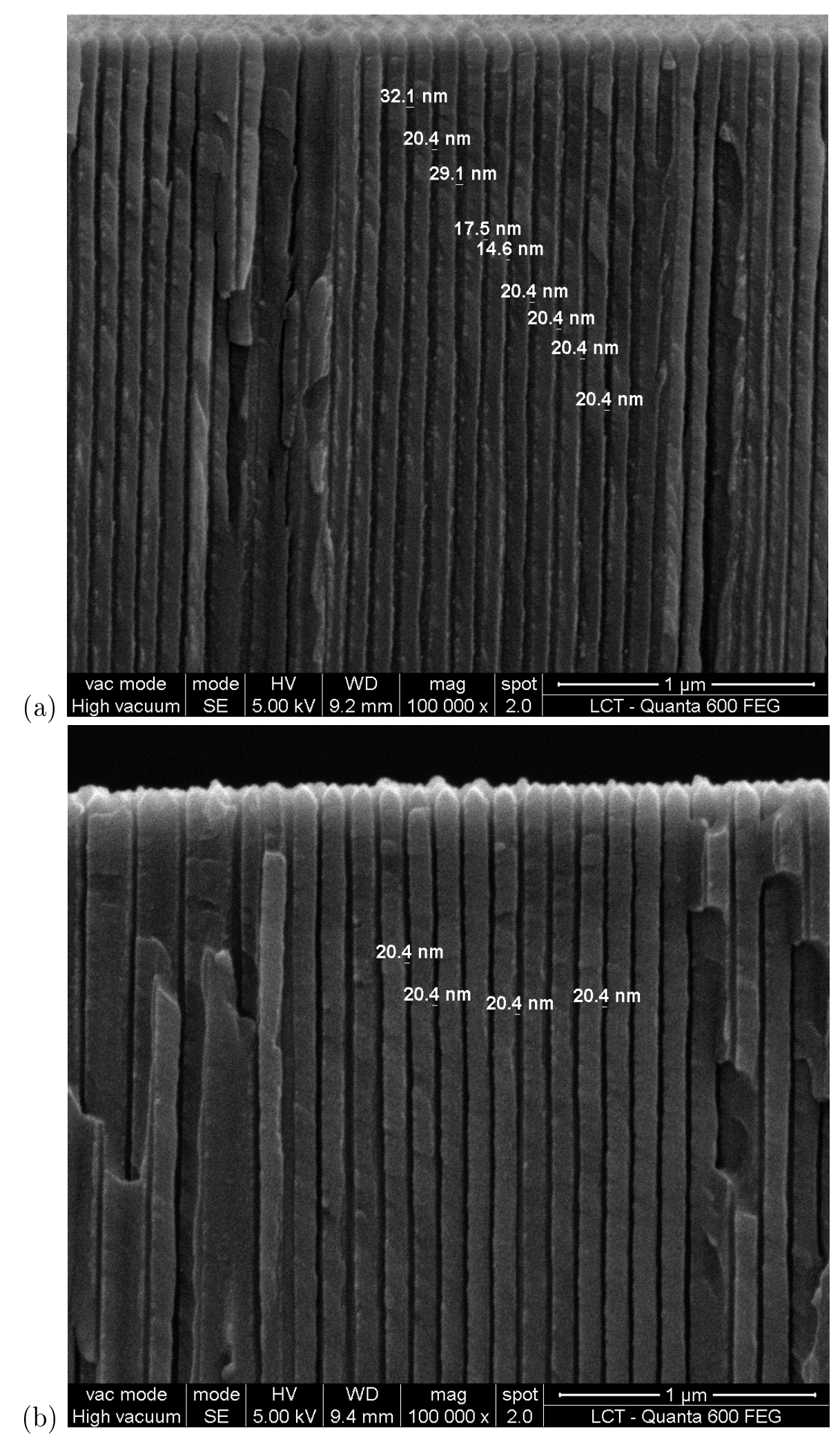

Figura 3.5: Imagens de MEV do perfil de amostras anodizadas a $5^{\circ} \mathrm{C}$, em $(\mathrm{COOH})_{2}$ a $0,3 \mathrm{~mol} / \mathrm{L}$, por 4 horas $\left(1^{\underline{a}}\right) / 1$ hora $\left(2^{\underline{a}}\right)$, sob tensões de (a) $40 \mathrm{~V}$ e (b) $45 \mathrm{~V}$, com medidas do diâmetro interno dos poros. 


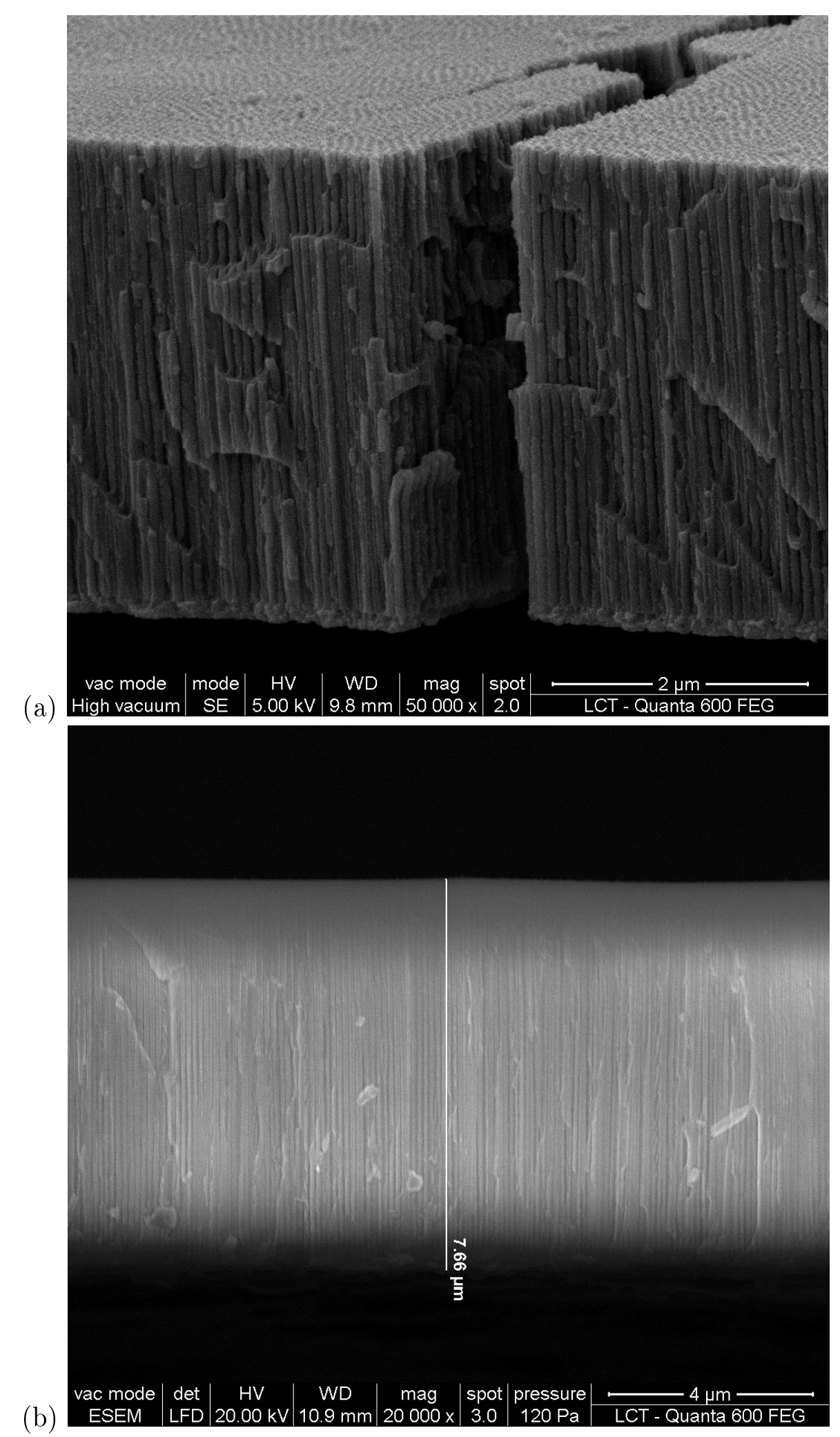

Figura 3.6: Imagens de MEV (a) da amostra anodizada a $5^{\circ} \mathrm{C}, 35 \mathrm{~V}$, em $(\mathrm{COOH})_{2}$ a $0,3 \mathrm{~mol} / \mathrm{L}$, durante 4 horas $\left(1^{\mathrm{a}}\right) / 75$ minutos $\left(2^{\mathrm{a}}\right)$ em perpectiva. Em (b), vemos o perfil de uma amostra anodizada nas mesmas condições, sendo $V_{a n}=45 \mathrm{~V}$, por 1 hora ( $2^{\mathrm{a}}$ anodização), exibindo um comprimento dos poros um pouco maior que as demais amostras. 


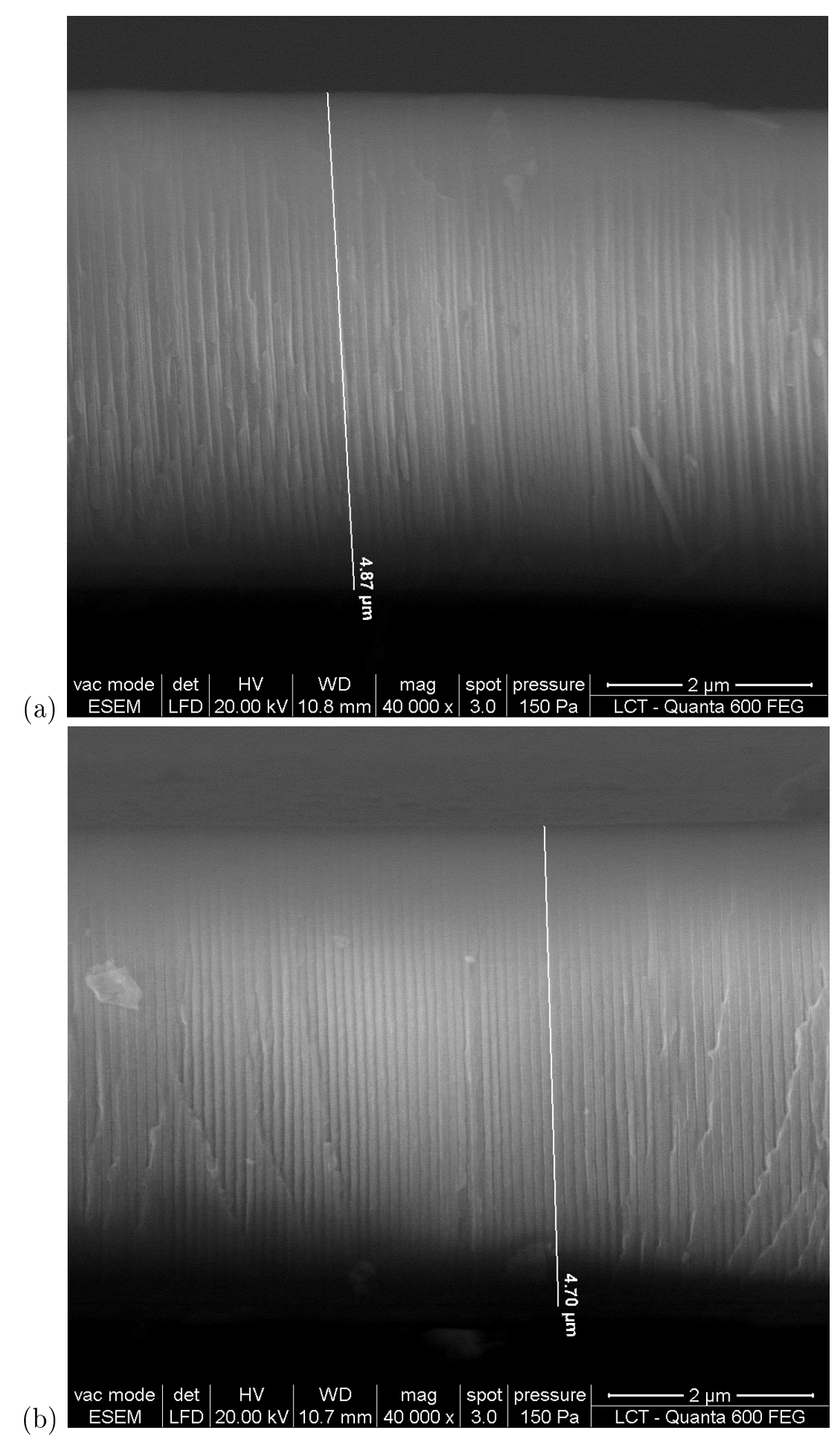

Figura 3.7: Imagens de MEV do perfil de diferentes regiões da amostra (a e b) anodizada a $5^{\circ} \mathrm{C}, 40 \mathrm{~V} \mathrm{dc}$, em $(\mathrm{COOH})_{2}$ a $0,3 \mathrm{~mol} / \mathrm{L}$, durante 4 horas $\left(1^{\underline{a}}\right) / 1$ hora $\left(2^{\mathrm{a}}\right)$, com medidas do comprimento dos poros. Percebe-se que há uma variação da espessura da camada de óxido devido a deformações da superfície. 


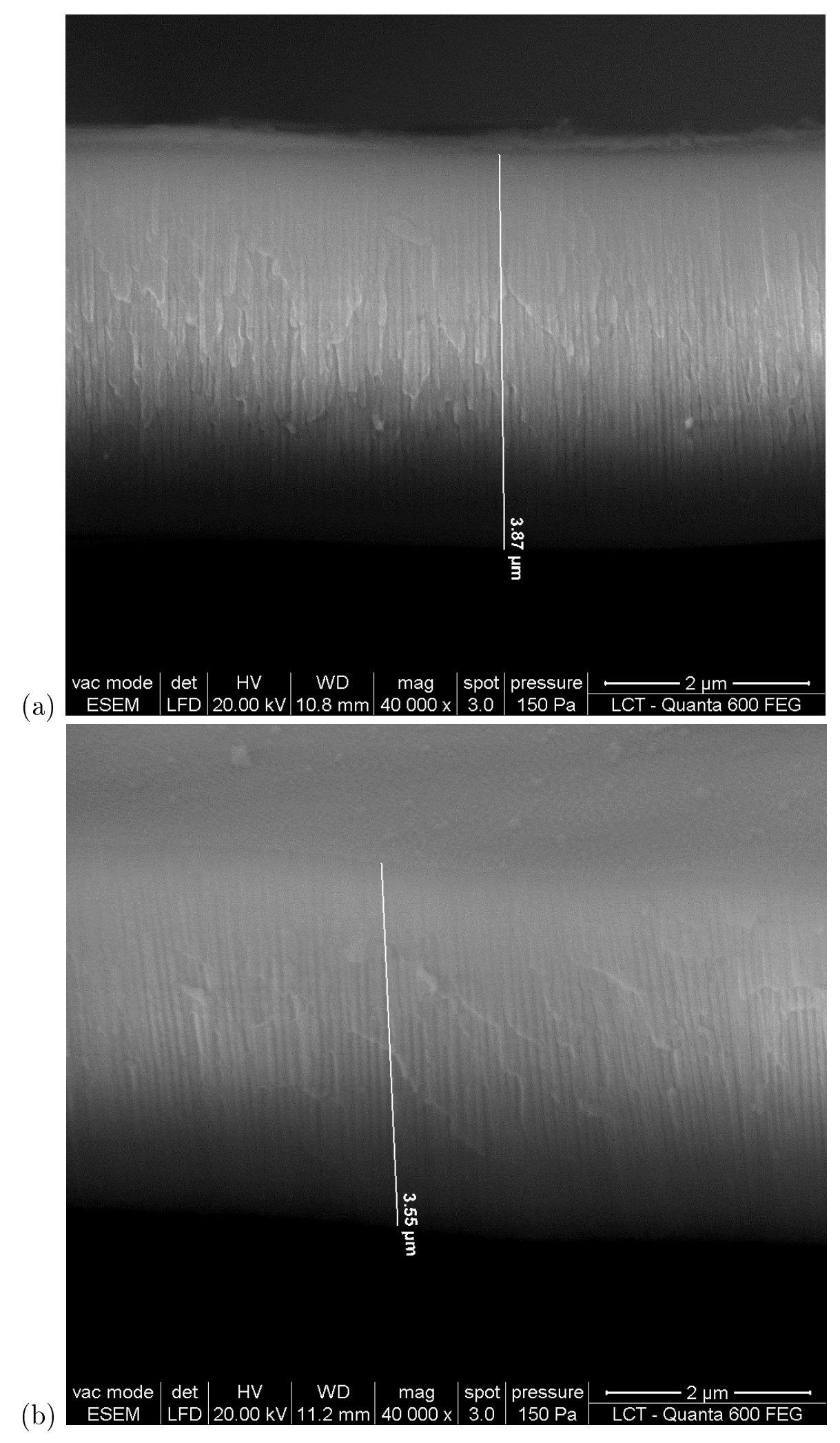

Figura 3.8: Imagens de MEV do perfil de diferentes regiões (a e b) da amostra anodizada a $5^{\circ} \mathrm{C}$, $35 \mathrm{~V}$, em $(\mathrm{COOH})_{2}$ a $0,3 \mathrm{~mol} / \mathrm{L}$, durante 4 horas $\left(1^{\mathrm{a}}\right) / 75$ minutos $\left(2^{-}\right)$, mostrando diferentes valores do comprimento dos poros. 
(a)
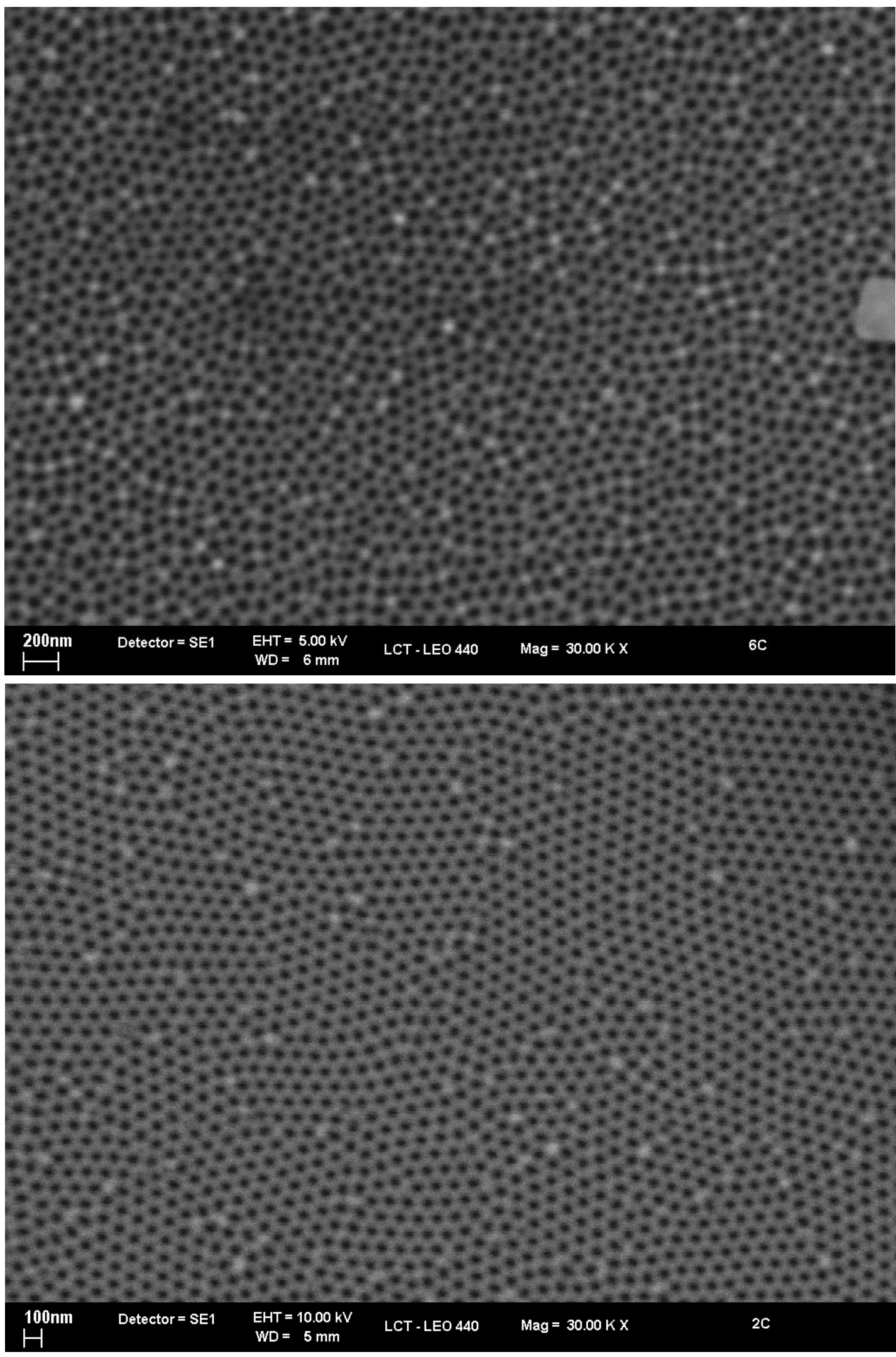

Figura 3.9: Imagens de MEV de amostras preparadas a $3^{\circ} \mathrm{C}$, a $40 \mathrm{~V}$ dc, durante 1 hora $\left(1^{\mathrm{a}}\right) / 40$ minutos $\left(2^{\underline{a}}\right)$, em $(\mathrm{COOH})_{2}$ a (a) $0,1 \mathrm{~mol} / \mathrm{L}$ e (b) $0,3 \mathrm{~mol} / \mathrm{L}$. 
(a)
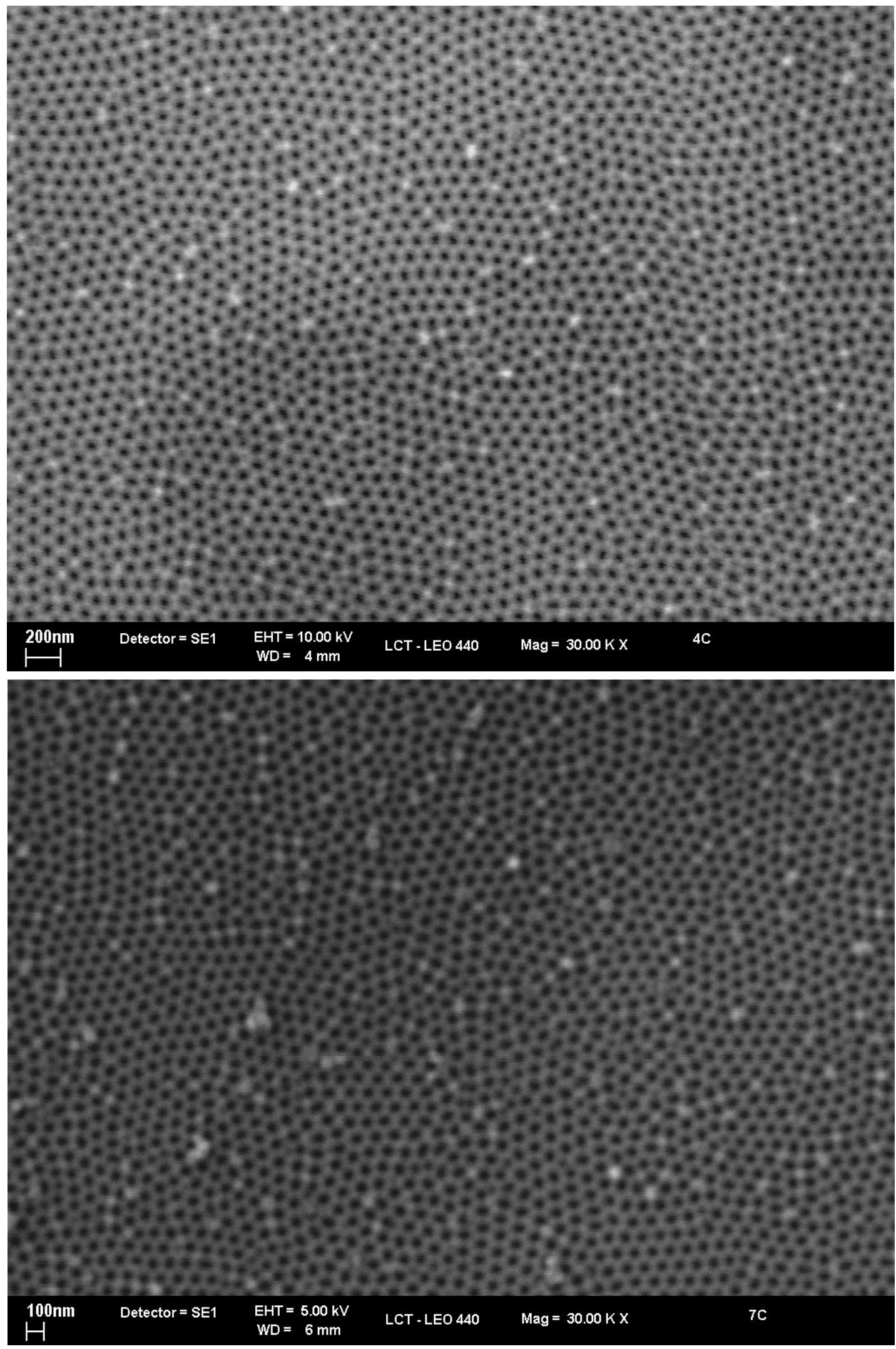

Figura 3.10: Imagens de MEV de amostras preparadas a $3{ }^{\circ} \mathrm{C}$, a $40 \mathrm{~V}$ dc, durante 1 hora $\left(1^{\mathrm{a}}\right) / 40$ minutos $\left(2^{\underline{a}}\right)$, em $(\mathrm{COOH})_{2}$ a (a) $0,5 \mathrm{~mol} / \mathrm{L}$ e (b) $0,6 \mathrm{~mol} / \mathrm{L}$. 
parâmetro enquanto mantemos os outros fixos. Nas figuras 3.9 e 3.10, exibimos a influência da concentração da solução sobre o arranjo de poros. Fixamos todos os parâmetros conforme o procedimento padrão e variamos a concentração de $(\mathrm{COOH})_{2}$ na solução entre 0,1 e $0,6 \mathrm{~mol} / \mathrm{L}$. Não houve grandes mudanças no diâmetro e na forma dos poros. A mudança mais notável está na variação do tamanho dos grãos superficiais - região na qual o arranjo de poros tem uma orientação constante, mantendo um perfeito ordenamento hexagonal. Podemos observar que na amostra feita com a 0,1 mol/L ([fig. 3.9(a)], os poros estão dispostos quase que aleatoriamente. A amostra preparada a $0,3 \mathrm{~mol} / \mathrm{L}$ [fig. 3.9(b)] é a que exibe o melhor ordenamento dos poros, ou seja, o maior tamanho de grãos superficiais. Para maiores concentrações [figs. 3.10(a) e 3.10(b)], os grãos tendem a diminuir gradativamente.

Nas figuras 3.11 e 3.12, mostramos a evolução das propriedades estruturais do arranjo de poros em função da tensão de anodização $\left(V_{a n}\right)$, mantendo os outros parâmetros fixos, de acordo com o procedimento padrão. Variamos $V_{a n}$ entre $15 \mathrm{~V}$ e $60 \mathrm{~V}$. Amostras feitas com valores abaixo de $15 \mathrm{~V}$ (em soluções de ácido oxálico) não exibiram ou exibiram muito incipientemente qualquer formação de poros. As figuras 3.11 e 3.12 comprovam que a estrutura dos poros varia sensivelmente em função da tensão de anodização. É observado um aumento gradativo do diâmetro dos poros e da distância entre poros à medida que $V_{a n}$ aumenta, enquanto a circularidade dos poros é comprometida. Os poros tendem a perder sua forma circular para tensões mais altas que $40 \mathrm{~V}$.

A imagem 3.13 é de uma amostra preparada com os parâmetros $\left[3^{\circ} \mathrm{C}, 60 \mathrm{~V} \mathrm{dc}\right.$, em $(\mathrm{COOH})_{2}$ a $0,5 \mathrm{~mol} / \mathrm{L}$, durante 1 hora $\left(1^{\mathrm{a}}\right) / 40$ minutos $\left.\left(2^{\mathrm{a}}\right)\right]$, ou seja, nas condiçõs mais extremas, na qual aumentamos simultanemente a tensão de anodização e a concentração da solução. Para esse conjunto de parâmetros, embora o diâmetro dos poros tenha aumentado, observamos uma menor deformidade dos poros quando comparados aos da figura 3.12(b). Isso sugere que há uma competição entre os efeitos dos parâmetros de anodização sobre a estrutura da alumina porosa [31, 34, 37, 42, 90]. Assim, é possível que existam diferentes conjuntos de parâmetros que permitam otimizar a auto-organização da estrutura [42]. Há teorias sobre a formação da estrutura porosa em $\mathrm{Al}_{2} \mathrm{O}_{3}$ que corroboram essa hipótese [13, 34, 36, 42].

Para quantificar essas observações, utilizamos softwares de processamento e análise de 
(a)

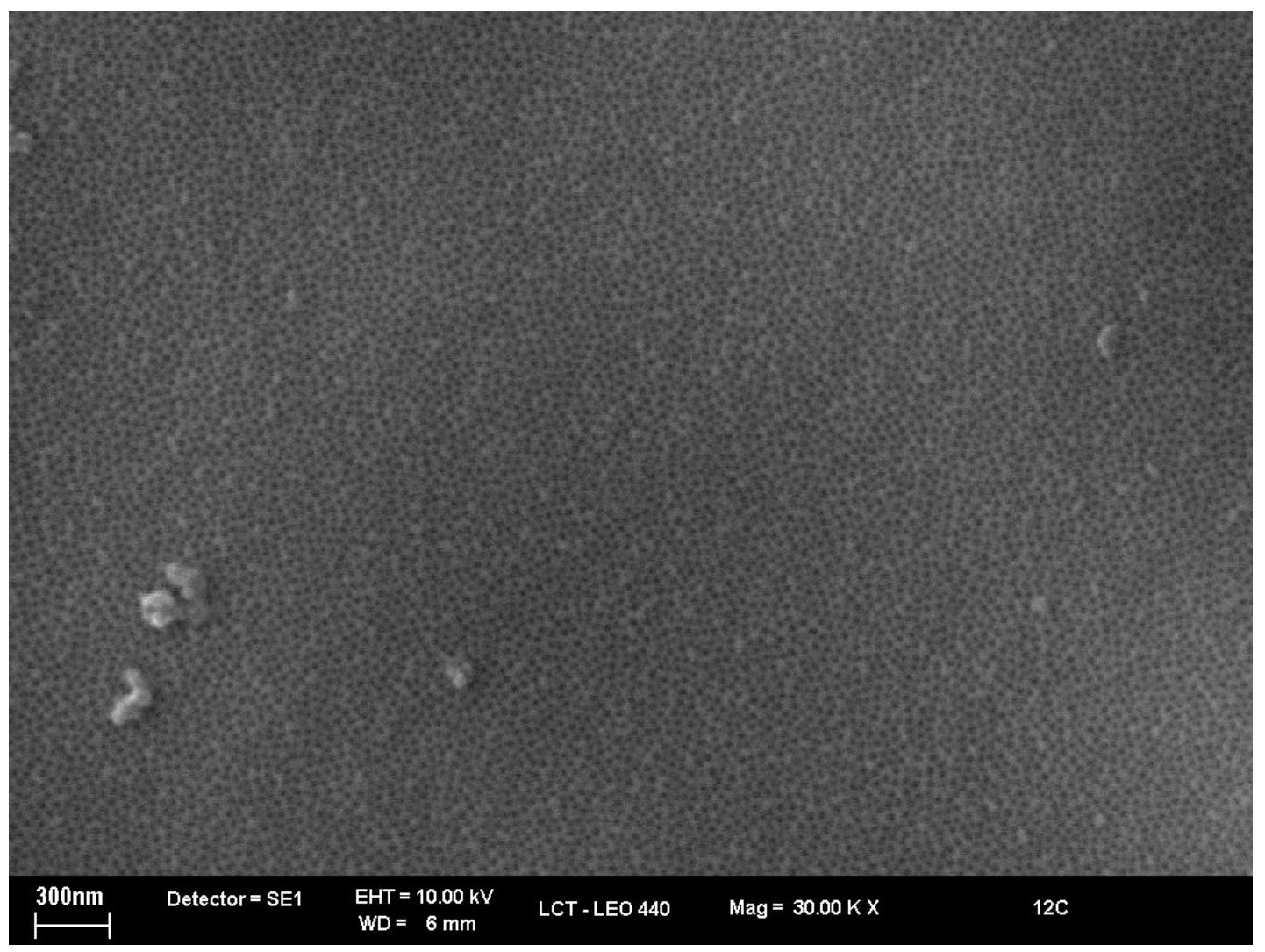

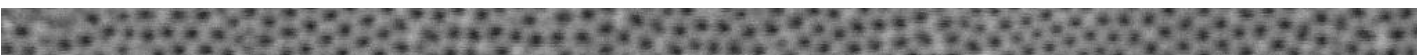

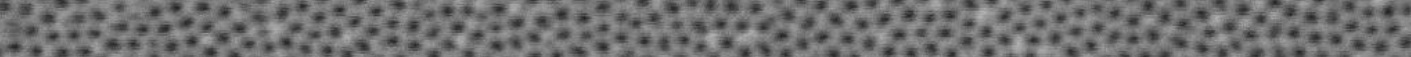

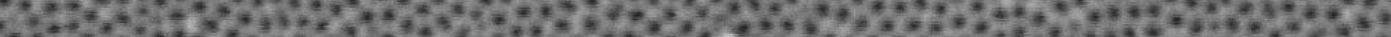

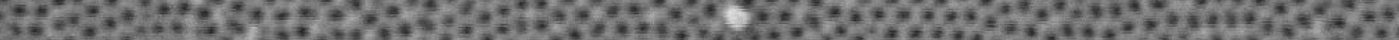

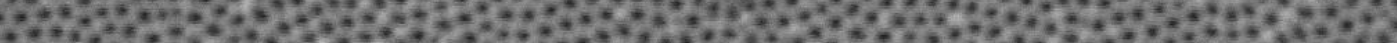

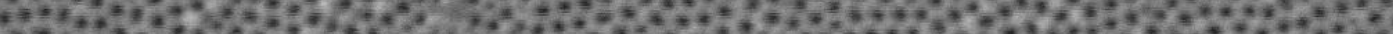

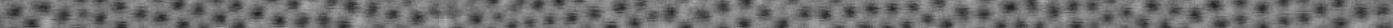
*

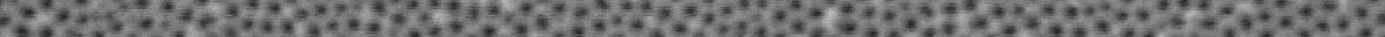

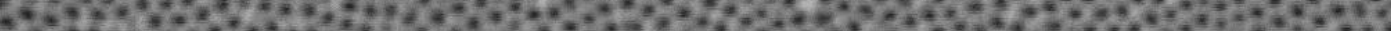

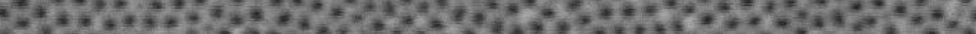

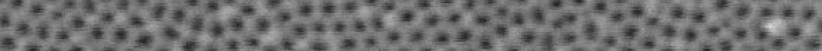

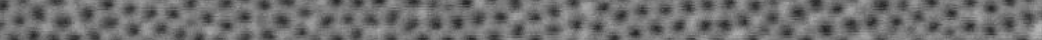

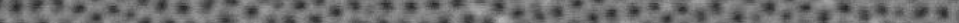

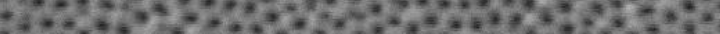

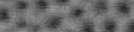

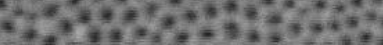

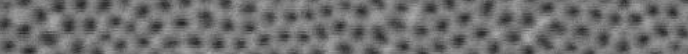

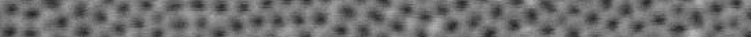
(a)

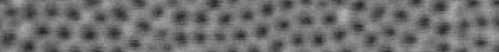

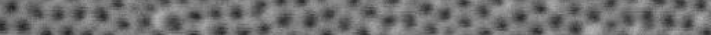

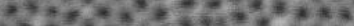

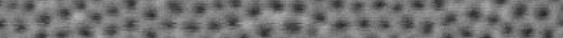

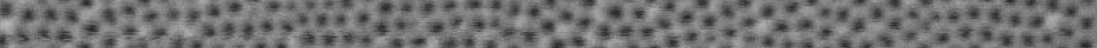

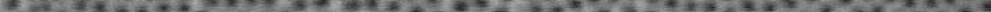

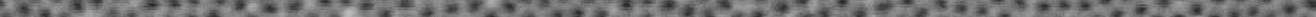

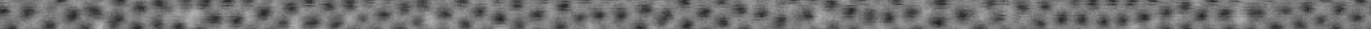

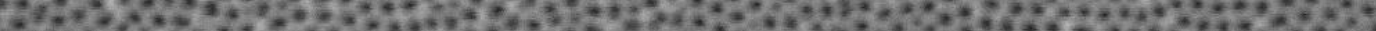

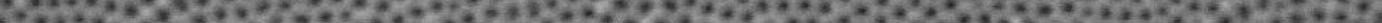

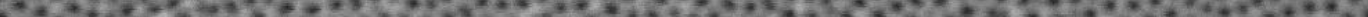

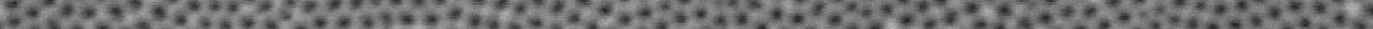

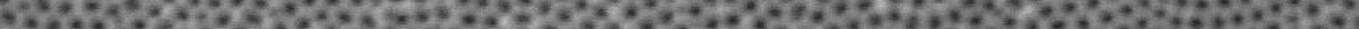

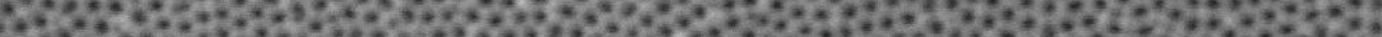
(b)

Figura 3.11: Imagens de MEV de amostras preparadas a $3^{\circ} \mathrm{C}$, em $(\mathrm{COOH})_{2}$ a $0,3 \mathrm{~mol} / \mathrm{L}$, durante 1 hora $\left(1^{\underline{a}}\right) / 40$ minutos $\left(2^{\underline{a}}\right)$, com tensões de (a) $15 \mathrm{~V}$ e (b) $30 \mathrm{~V}$. 
(a)

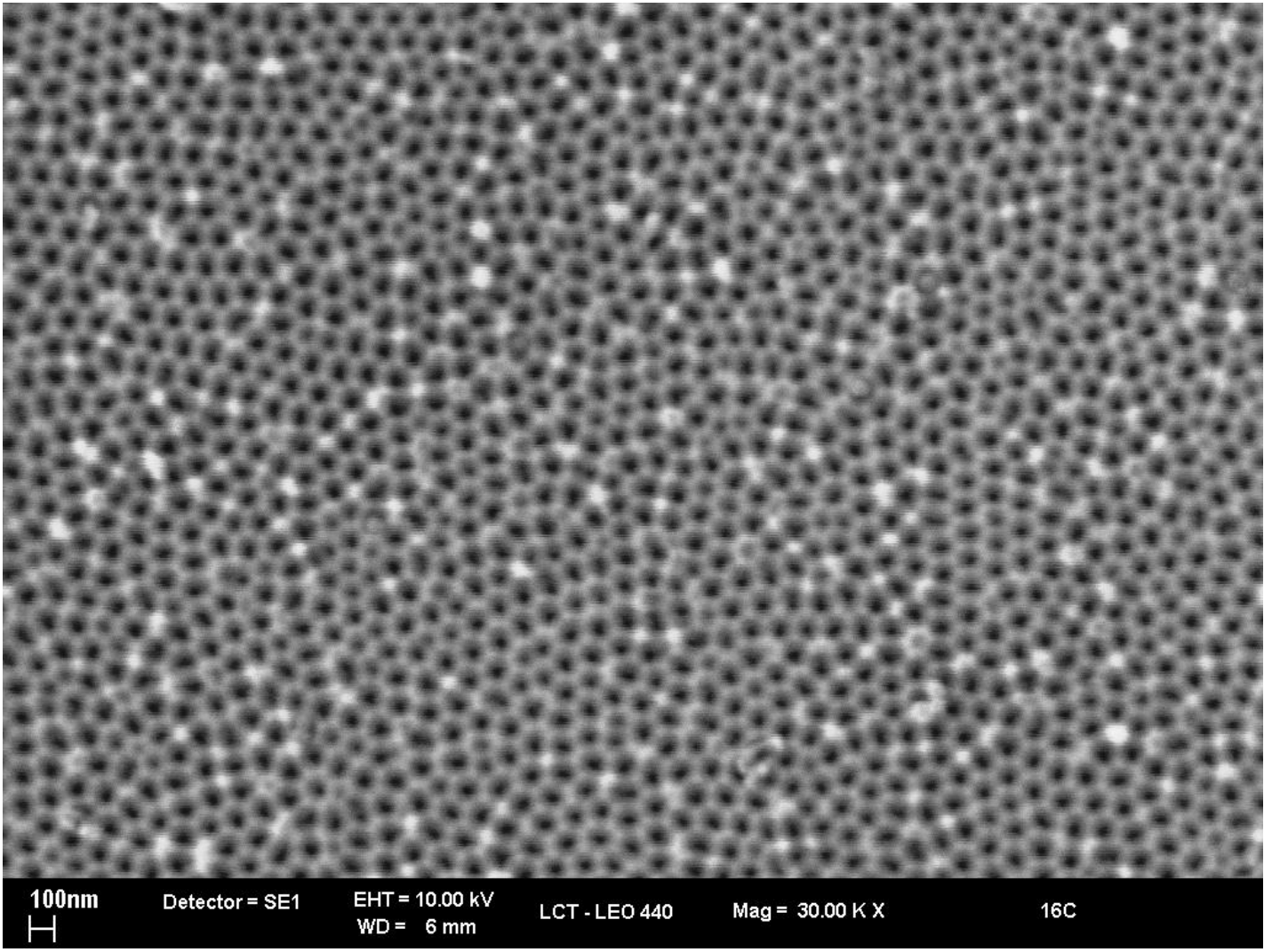

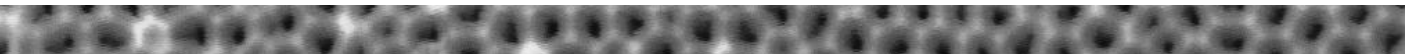

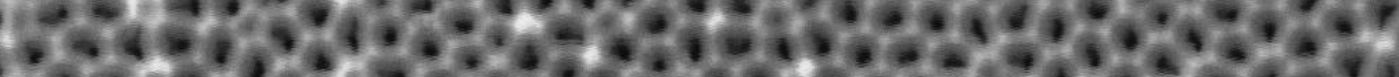

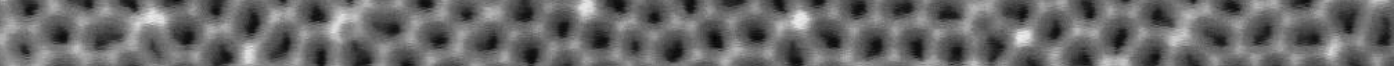

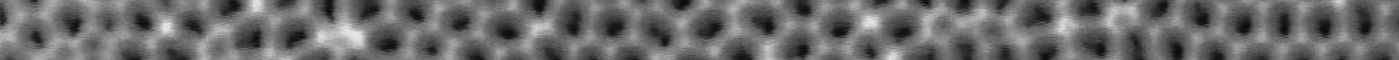

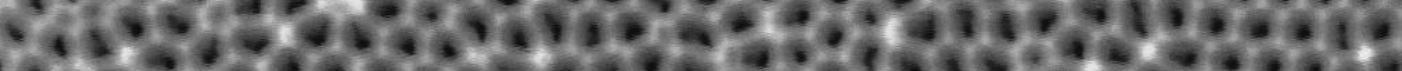

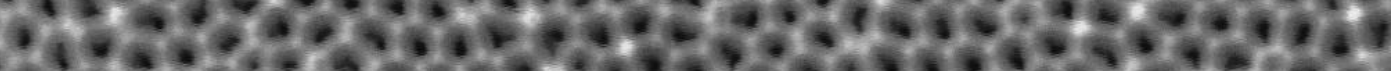

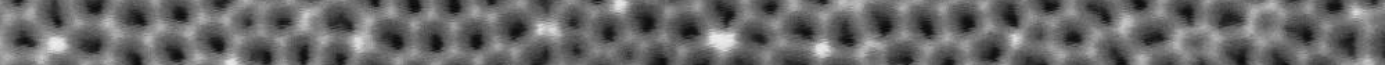

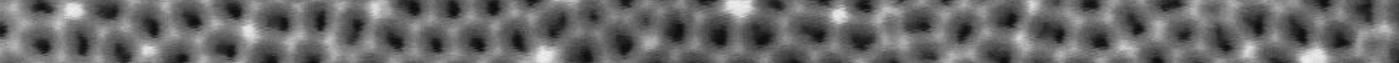

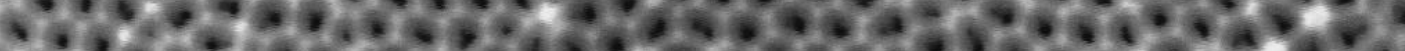

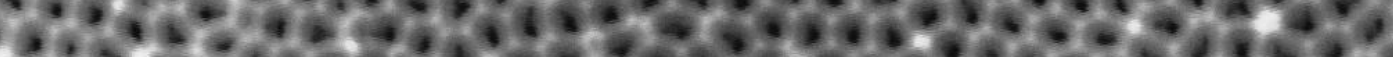

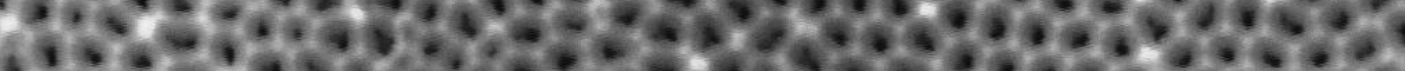

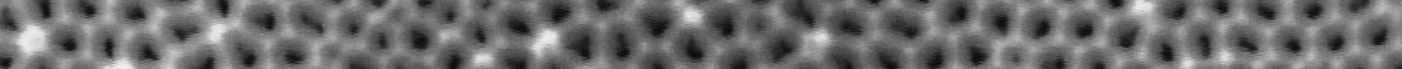

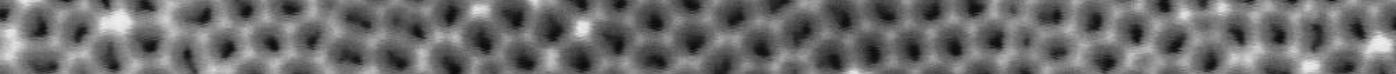

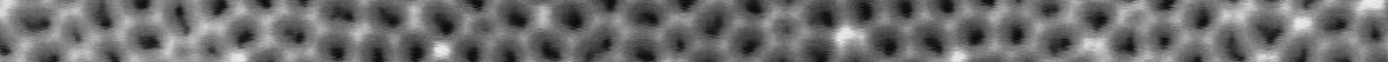

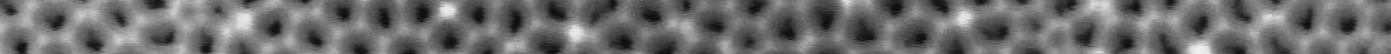

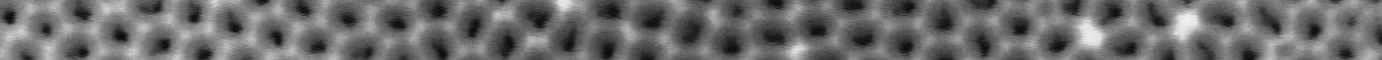

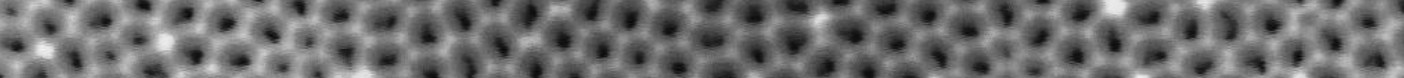

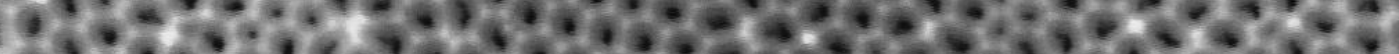

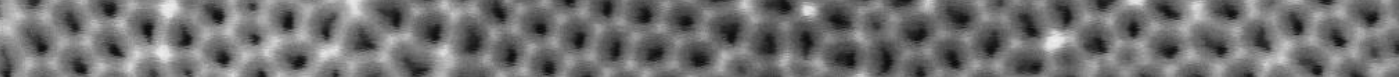

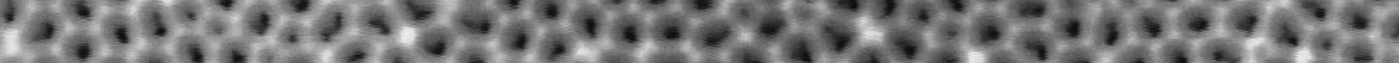

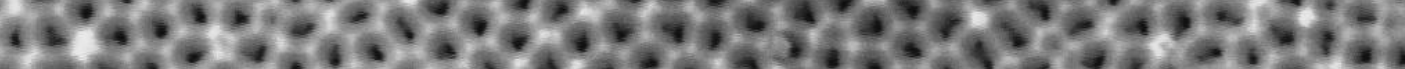

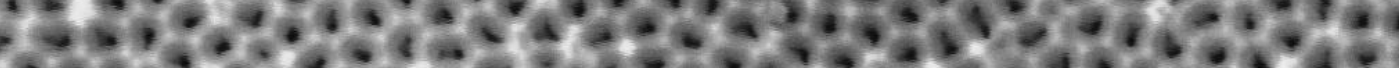

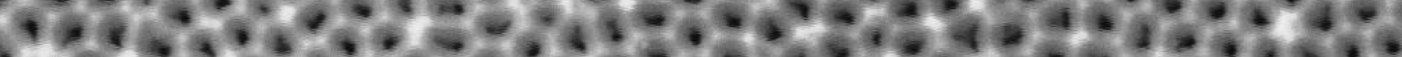

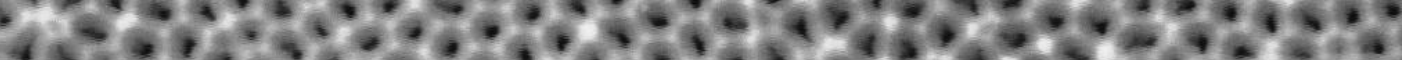

(b)

$\stackrel{200 \mathrm{~nm}}{\longmapsto}$ Detector $=S E 1 \quad \begin{aligned} & E H T=10.00 \mathrm{kV} \\ & W D=4 \mathrm{~mm}\end{aligned} \quad$ LCT - LEO $440 \quad$ Mag $=30.00 \mathrm{KX} \quad 3 \mathrm{C}$

Figura 3.12: Imagens de MEV de amostras preparadas a $3^{\circ} \mathrm{C}$, em $(\mathrm{COOH})_{2}$ a $0,3 \mathrm{~mol} / \mathrm{L}$, durante 1 hora $\left(1^{\mathrm{a}}\right) / 40$ minutos $\left(2^{\underline{a}}\right)$, com voltagens de (a) $50 \mathrm{~V}$ e (b) $60 \mathrm{~V}$. 


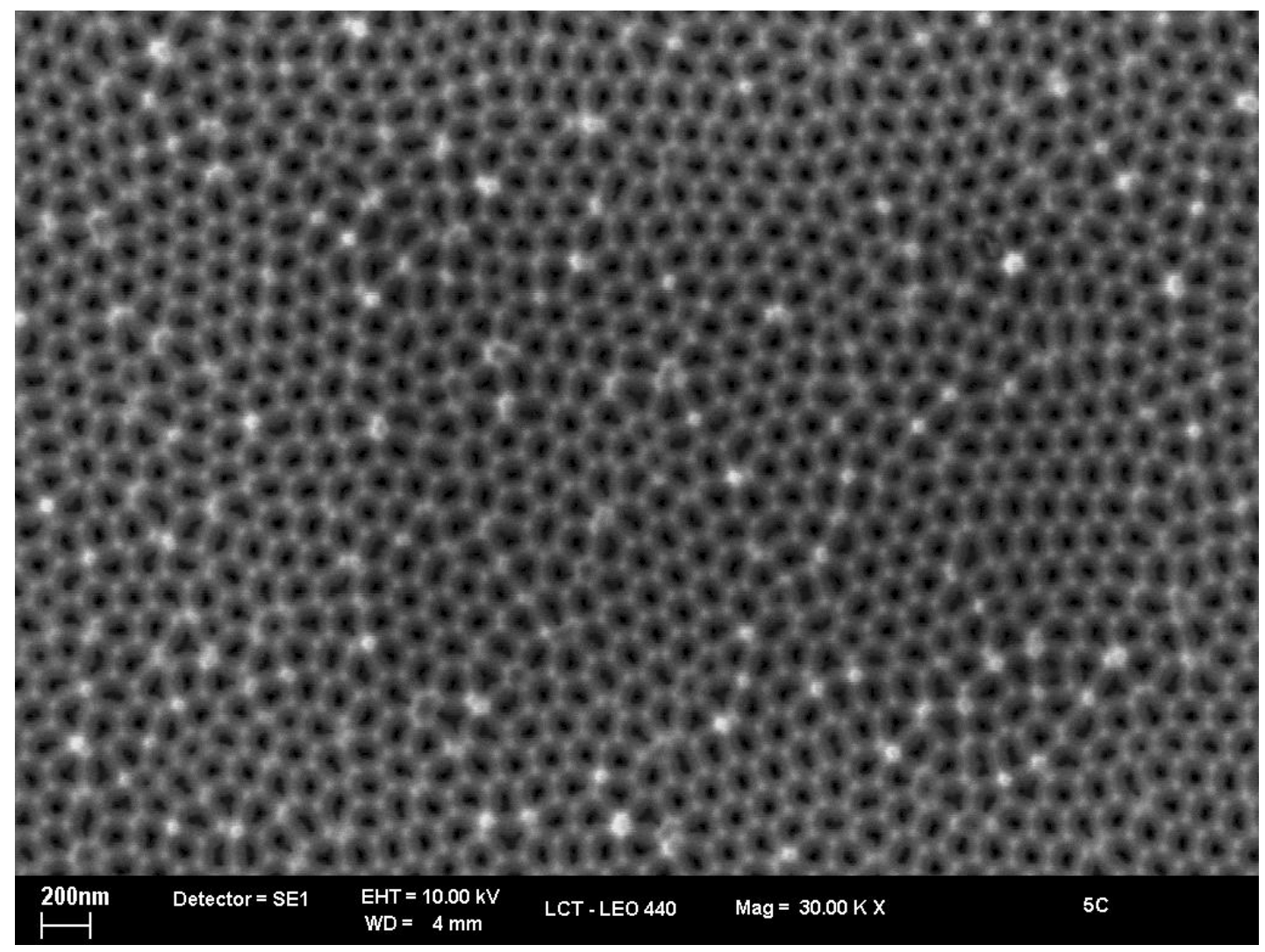

Figura 3.13: Imagem de MEV da amostra obtida com $\left[3{ }^{\circ} \mathrm{C}, 60 \mathrm{~V}\right.$ dc, em $(\mathrm{COOH})_{2}$ a $0,5 \mathrm{~mol} / \mathrm{L}$, durante 1 hora $\left(1^{-}\right) / 40$ minutos $\left.\left(2^{-}\right)\right]$.

imagens para calcular o período (distância média entre poros), circularidade, densidade e diâmetro médio dos poros. Essas medidas serviram de ponto de partida para estabelecer correlações entre as condições de anodização e as características morfológicas predominantes e para a tomada de decisões no sentido de otimizar o procedimento de preparação de amostras.

\subsubsection{Microscopias de Força Atômica e Força Magnética}

Obtivemos imagens de Microscopias de Força Atômica (AFM) e Força Magnética (MFM) das amostras de Ni eletrodepositadas, no Laboratório de Filmes Finos do Departamento de Física Aplicada (Instituto de Física da USP). A técnica de AFM permite obter imagens do relevo da superfície, enquanto a de MFM permite se obter imagens do perfil do campo magnético (componente do campo de fuga normal à superfície) intrínseco da amostra, ou seja, da configuração dos domínios magnéticos próximo à superfície.

As imagens 3.14(a) e 3.14(b) são respectivamente de AFM e de MFM e correspondem 


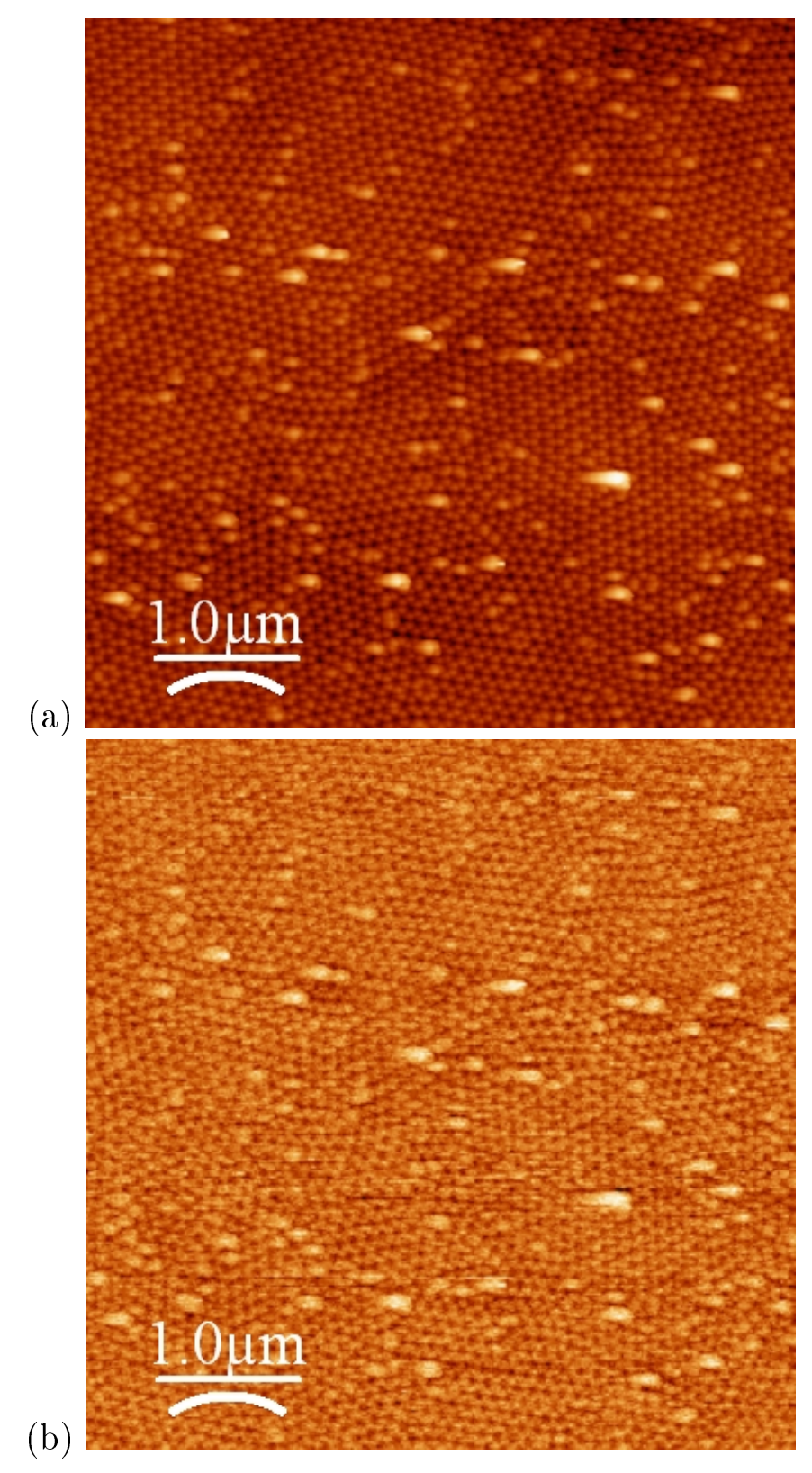

Figura 3.14: Imagens de Microscopia de Força Atômica (a) e de Força Magnética (b) de uma amostra obtida através do procedimento padrão $\left[3^{\circ} \mathrm{C}, 40 \mathrm{~V} \mathrm{dc}\right.$, em $(\mathrm{COOH})_{2}$ a $0,3 \mathrm{~mol} / \mathrm{L}$, durante 1 hora $\left(1^{\mathrm{a}}\right) / 40$ minutos $\left(2^{\mathrm{a}}\right)$ ]. 
a uma mesma região $(5 \times 5 \mu \mathrm{m})$ de uma amostra anodizada nas condições-padrão. Elas foram obtidas após uma voltametria cíclica de 6 minutos (3 ciclos), entre $V_{C A}$ e $-3 \mathrm{~V}$ contra um eletrodo de referência de $\mathrm{Ag} / \mathrm{AgCl}$ saturado (figura 2.6). A amostra foi magnetizada num campo acima de $5 \mathrm{kOe}$ antes da microscopia. Como se pode observar na primeira imagem (topográfica), as características morfolóficas observadas nas imagens de MEV se confirmam. Entretanto, na imagem de MFM, o perfil magnético observado é idêntico ao perfil topográfico, o que pode sugerir uma convolução entre os perfis topológico e magnético. Para testar essa hipótese, obtivemos imagens de MFM de um segmento da mesma amostra em estado magnético virgem. O perfil observado consistiu de puro ruído branco, como era de se esperar. Assim, o padrão observado na imagem 3.14(b) realmente tem uma componente magnética, muito embora não esteja claro um perfil perpendicular bem definido de campos de fuga, esperado para nanofios com forte anisotropia perpendicular, em estado remanente. Isso sugere que pode haver uma deposição excessiva de $\mathrm{Ni}$ acima dos poros, formando uma camada espessa o suficiente para comportar alguma componente da magnetização paralela à superfície. Sabe-se da literatura que a eletrodeposição em modo DC pode por vezes ser tão violenta a ponto de obstruir os poros antes mesmo de serem completamente preenchidos. Isso poderia mascarar o perfil magnético dos nanofios subjacentes, induzindo o padrão magnético observado. A existência dos nanofios, portanto, só poder ser comprovada por medidas de magnetometria.

\subsubsection{Análise Morfológica do Arranjo de Poros}

Na figura 3.15, mostramos como é medida a distância entre poros (periodicidade) por meio da análise de uma imagem de AFM. Um segmento de reta é traçado entre dois poros ao longo da estrutura periódica e o cálculo da periodicidade é dado por

$$
\text { Período }=\frac{\text { distância horizontal }}{\text { número de períodos }}=\frac{883,2 \mathrm{~nm}}{8}=110,4 \mathrm{~nm} \text {. }
$$

A partir de análises semelhantes das imagens de MEV obtidas, calculamos os valores médios e os desvios-padrões dessas grandezas para as amostras. Por exemplo, para a amostra que seguiu o procedimento padrão $\left[3{ }^{\circ} \mathrm{C}, 40 \mathrm{~V} \mathrm{dc}\right.$ em $(\mathrm{COOH})_{2}$ a $0,3 \mathrm{~mol} / \mathrm{L}$, durante 1 hora $\left(1^{\mathrm{a}}\right) / 40$ minutos $\left.\left(2^{\underline{a}}\right)\right]$, obtivemos uma distância média entre poros de 
$99 \pm 4 \mathrm{~nm}$, diâmetro médio de $67 \pm 5 \mathrm{~nm}$ e uma densidade de $7,36 \times 10^{9}$ poros $/ \mathrm{cm}^{2}$. Essa amostra foi a que exibiu as melhores propriedades morfológicas, como poros bem circulares, alta densidade de poros, menores diâmetros, maiores grãos e alta regularidade da rede hexagonal de poros, de acordo com os resultados da literatura [14, 15, 16, 34, 90]. Uma maior regularidade do arranjo pode ser obtida aumentando-se a duração da primeira anodização por várias horas [31]. Entretanto, um trabalho recente [41] apresentou arranjos de poros de alta qualidade para tempos de anodização relativamente baixos (menores que uma hora), como sugerido por Nielsch et al. [42].

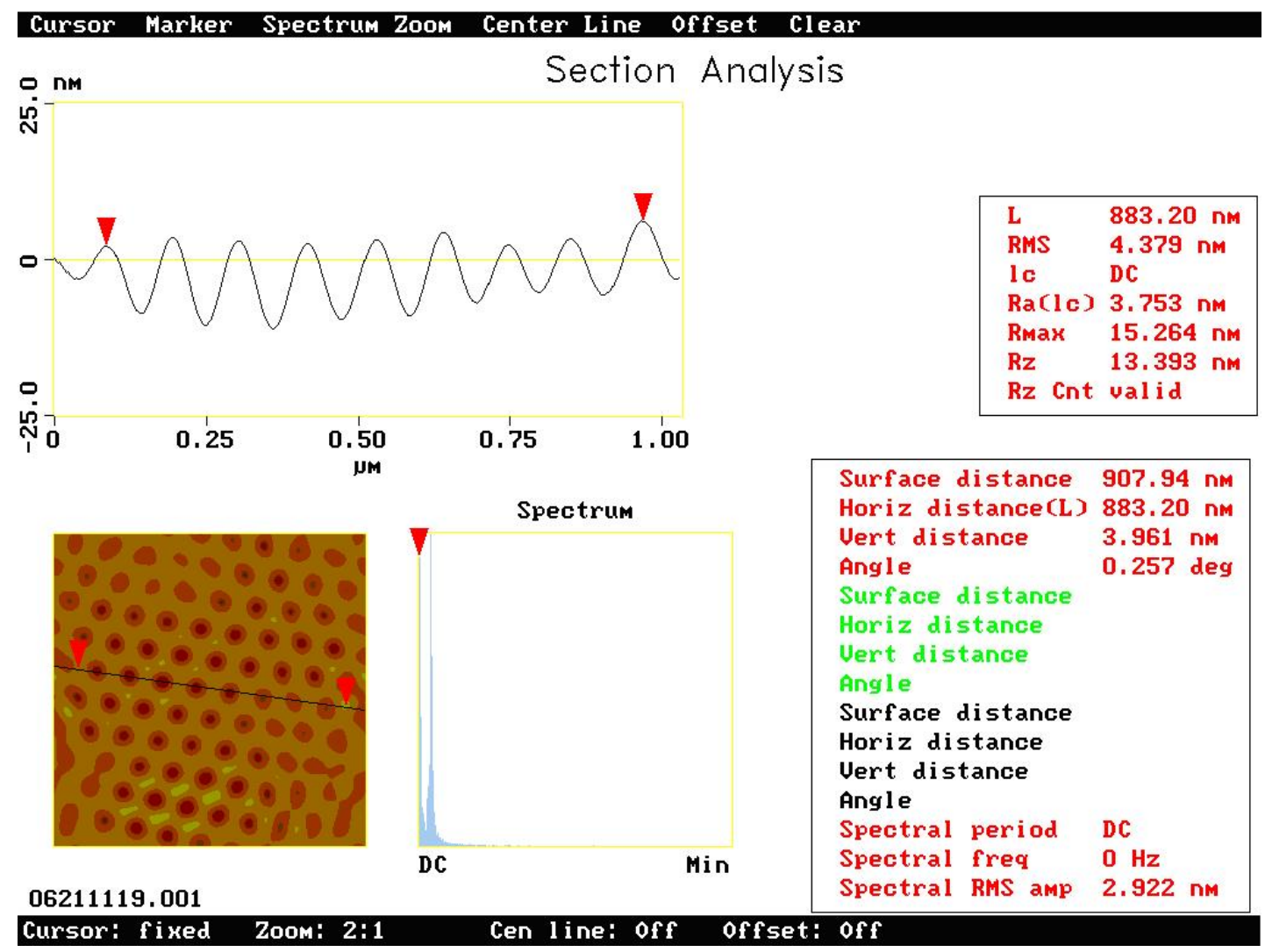

Figura 3.15: Exemplo de medida da periodicidade da amostra a partir de uma imagem de AFM.

Para estudar o grau de deformação dos poros, definimos a circularidade como sendo uma grandeza adimensional $C$ dada por

$$
C=4 \pi \times \frac{\text { Área do poro }}{(\text { Perímetro do poro })^{2}} \text {. }
$$

Para poros perfeitamente circulares, $C=1$. À medida que $C$ tende a zero, o poro torna-se cada vez mais achatado, como uma elipse. Nas figuras 3.16, mostramos histogramas da 
distribuição de diâmetros e da circularidade dos poros para várias amostras, em ordem crescente de tensão de anodização e, conseqüentemente, de diâmetro médio. Nesses gráficos, a escala vertical foi normalizada para mostrar a probabilidade de se encontrar um poro com a característica dada no eixo horizontal. É interesante notar que as amostras exibiram perfis de distribuição bem diferentes. Para evidenciar isso, traçamos curvas de melhor ajuste para cada histograma. Alguns deles são bem ajustados segundo uma simples gaussiana, enquanto outros seguem um comportamento tipo dupla gaussiana, como se houvesse duas diferentes populações de poros (com dois diferentes diâmetros médios ou circularidades médias). Por exemplo, esta característica é mais evidente no perfil da circularidade da amostra da figura $3.16(\mathrm{~b})$, anodizada a $V_{a n}=15 \mathrm{~V}$.

A partir desses histogramas, construímos gráficos do comportamento das quantidades médias em função da tensão de anodização. Para tensões abaixo de $15 \mathrm{~V}$, torna-se difícil dizer se realmente houve formação de poros, seja em virtude das condições de anodização ou por atingirmos o limite de resolução do microscópio eletrônico para amostras tão resistivas, como a alumina. Na figura 3.17(a) temos um gráfico que mostra esse comportamento para o diâmetro médio de um conjunto de amostras. Os diâmetros médios dos poros variaram entre 30 e $95 \mathrm{~nm}$. Neste gráfico, observamos um evidente crescimento linear do diâmetro dos poros com a tensão aplicada, a uma taxa de $1,53 \mathrm{~nm} / \mathrm{V}$, de acordo com a literatura [13, 42]. O mesmo comportamento linear é observado para a distância média entre poros, na figura 3.17(b), como é bem conhecido e aceito pela literatura (equação 4 da referência [42], reproduzida aqui na eq. 2.4), com uma taxa de 2,19 nm/V, próxima à taxa de $2,5 \mathrm{~nm} / \mathrm{V}$ estimada por Nielsch et al. A distância média entre poros variou entre 40 e $145 \mathrm{~nm}$. Também em bom acordo com a literatura [42] está a dependência da densidade superficial de poros com $V_{a n}$, mostrado na figura 3.18(a), assim como previsto pela equação 2.5, extraída da ref. [42], e da ordem de $10^{10}$ poros $/ \mathrm{cm}^{2}$. Na figura $3.18(\mathrm{~b})$, observamos o comportamento da circularidade média dos poros em função da tensão de anodização. Os poros exibiram alta circularidade, acima de 0,80 , mostrando que a grande maioria dos poros são cilíndricos.

De modo geral, os poros tendem a deformar para potenciais mais altos, pois a densidade de corrente durante a anodização é alta e o crescimento da camada de alumina ocorre de maneira mais rápida e desordenada. Apesar de terem uma circularidade média acima 
(a)

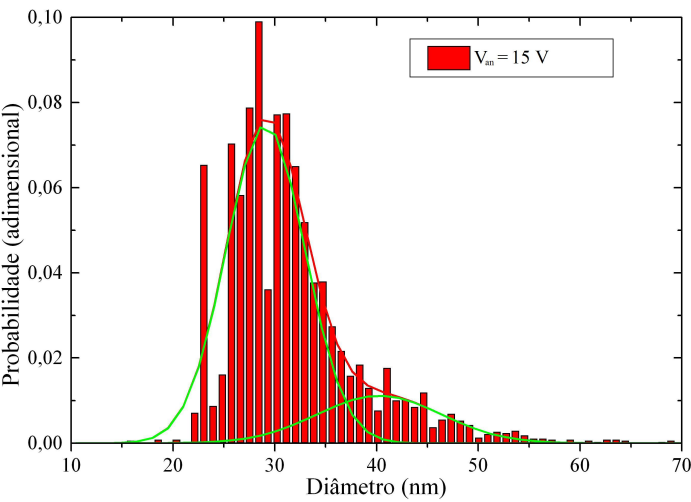

(c)

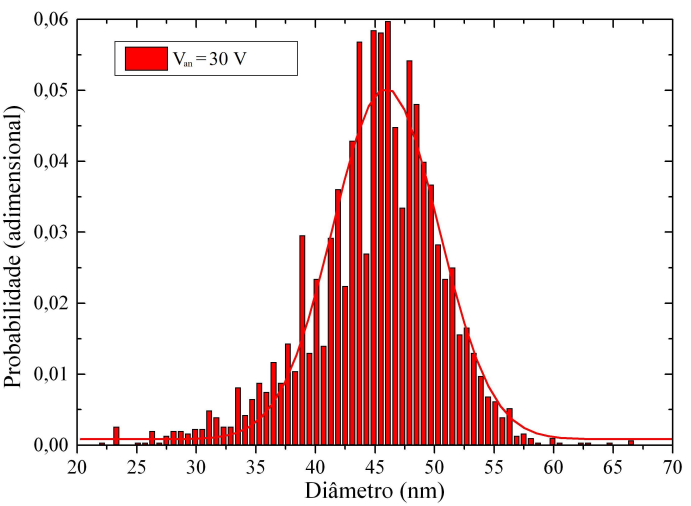

(e)
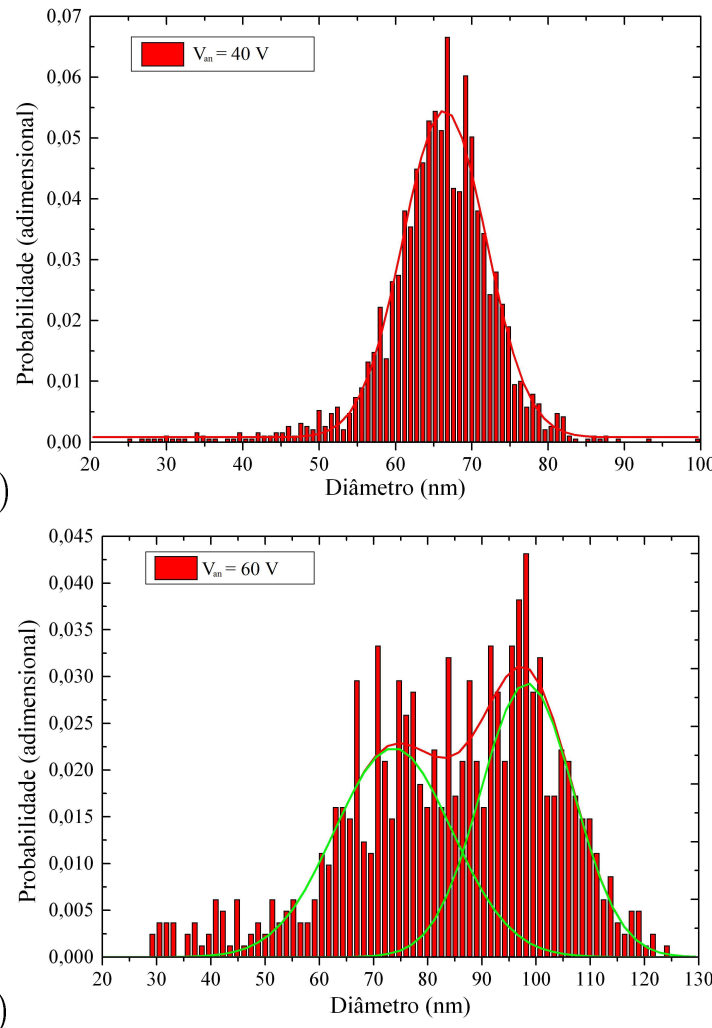

(b)

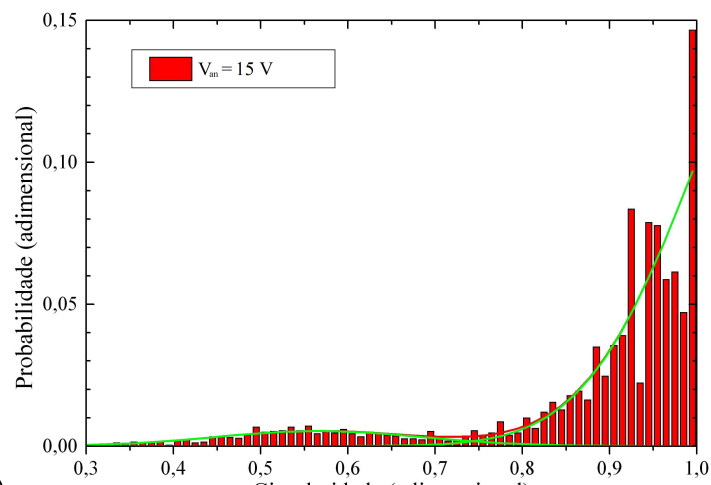

(d)

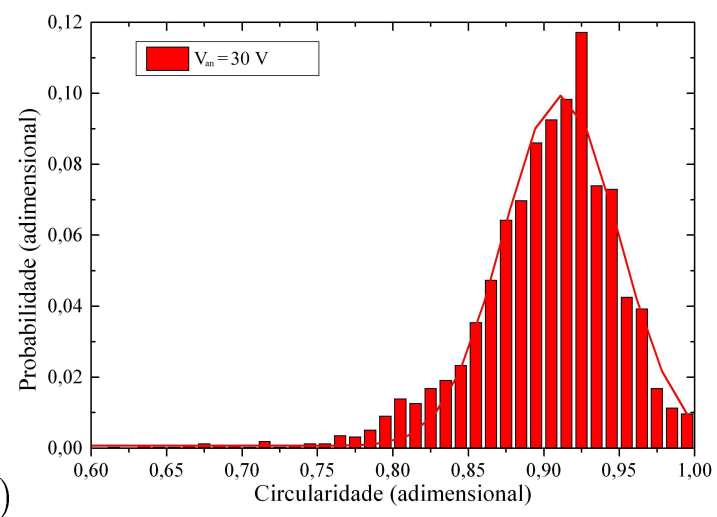

(f)

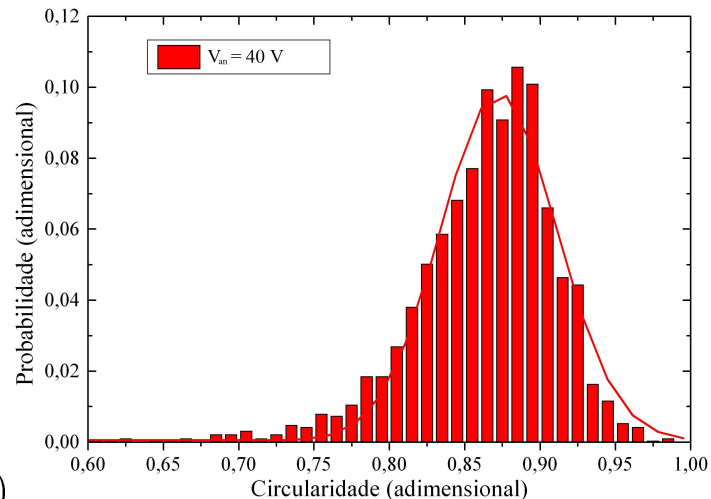

(h)

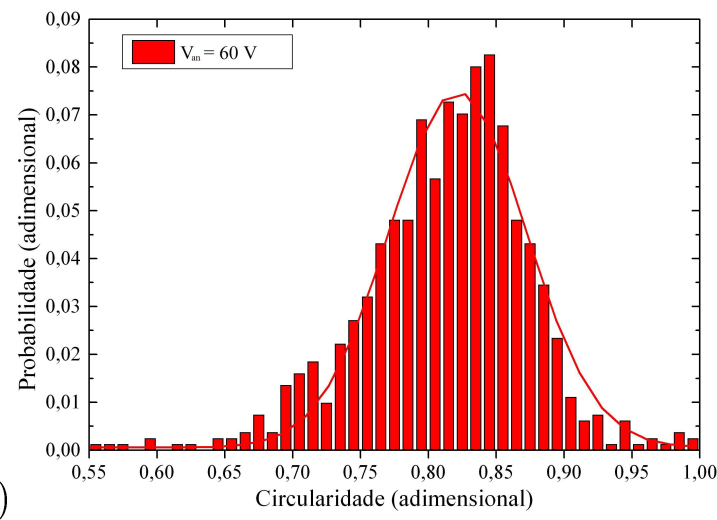

Figura 3.16: Distribuição de probabilidade do diâmetro dos poros (a, c, e, g) e da circularidade dos poros $(\mathrm{b}, \mathrm{d}, \mathrm{f}, \mathrm{h})$ para várias amostras anodizadas a $3^{\circ} \mathrm{C}$, em $(\mathrm{COOH})_{2}$ a $0,3 \mathrm{~mol} / \mathrm{L}$, durante 1 hora $\left(1^{\mathrm{a}}\right) / 40$ minutos $\left(2^{\mathrm{a}}\right)$, em ordem crescente de voltagem de anodização: $15 \mathrm{~V}(\mathrm{a}-\mathrm{b}), 30 \mathrm{~V}$ (c-d), $40 \mathrm{~V}$ (e-f) e $60 \mathrm{~V}$ (g-h). 


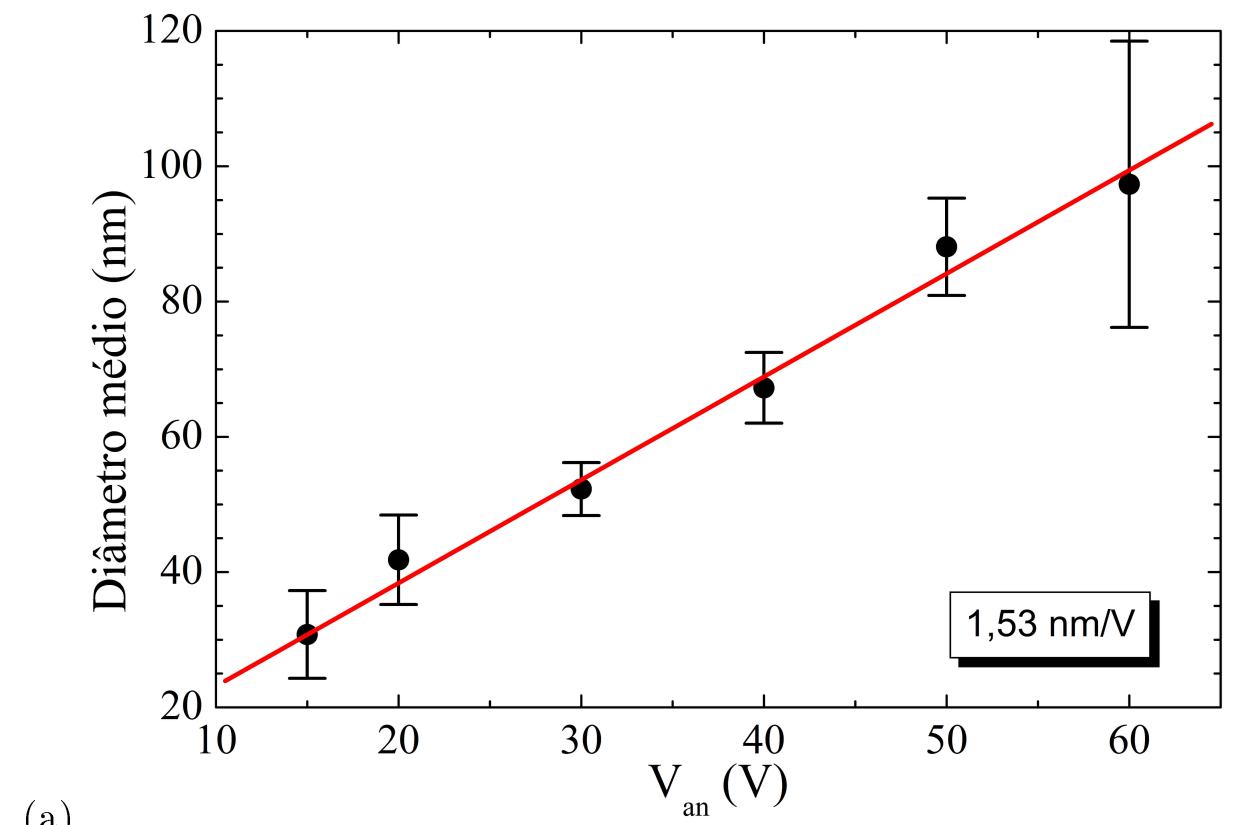

(a)

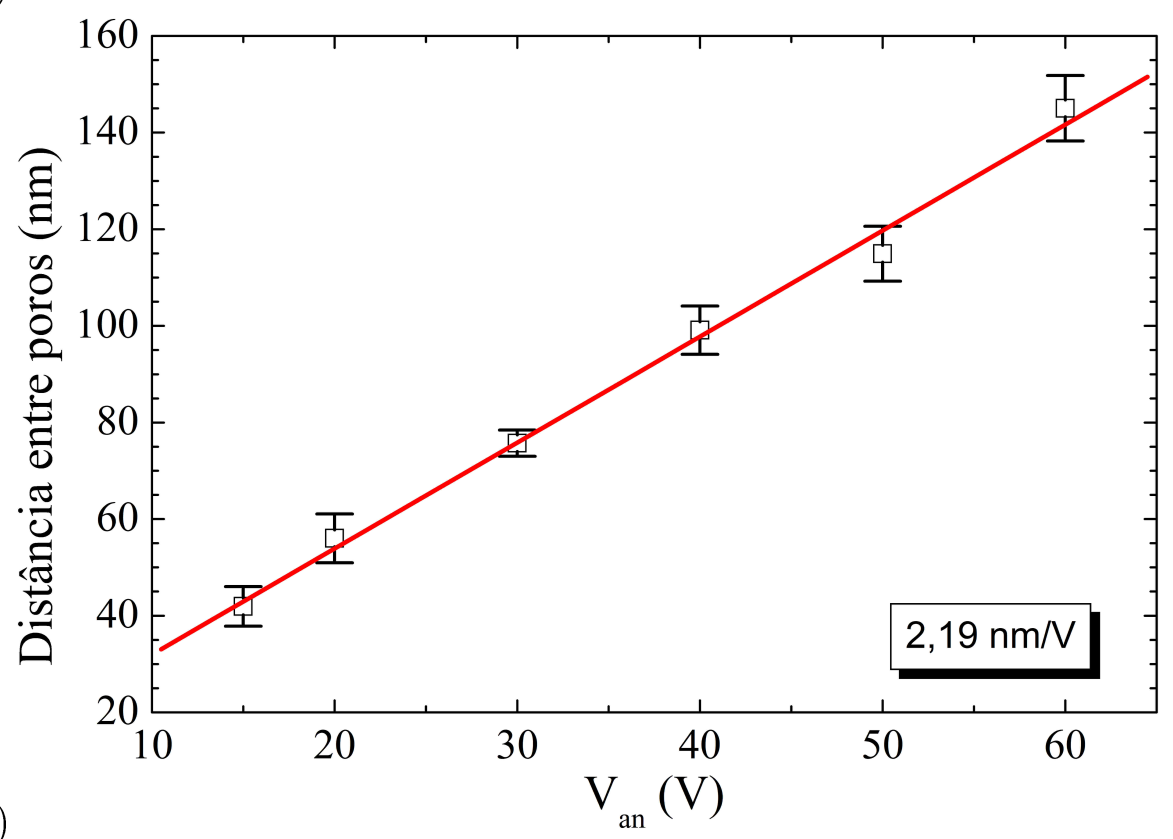

Figura 3.17: (a) Diâmetro médio e (b) distância média entre poros em função da tensão aplicada durante a anodização. Ambos mostram uma evidente dependência linear com $V_{a n}$, de acordo com a literatura [42]. Taxas de crescimento calculadas foram de $1,53 \mathrm{~nm} / \mathrm{V}$ para $\langle D\rangle$ e 2,19 $\mathrm{nm} / \mathrm{V}$ para $\left\langle d_{\text {int }}\right\rangle$. 


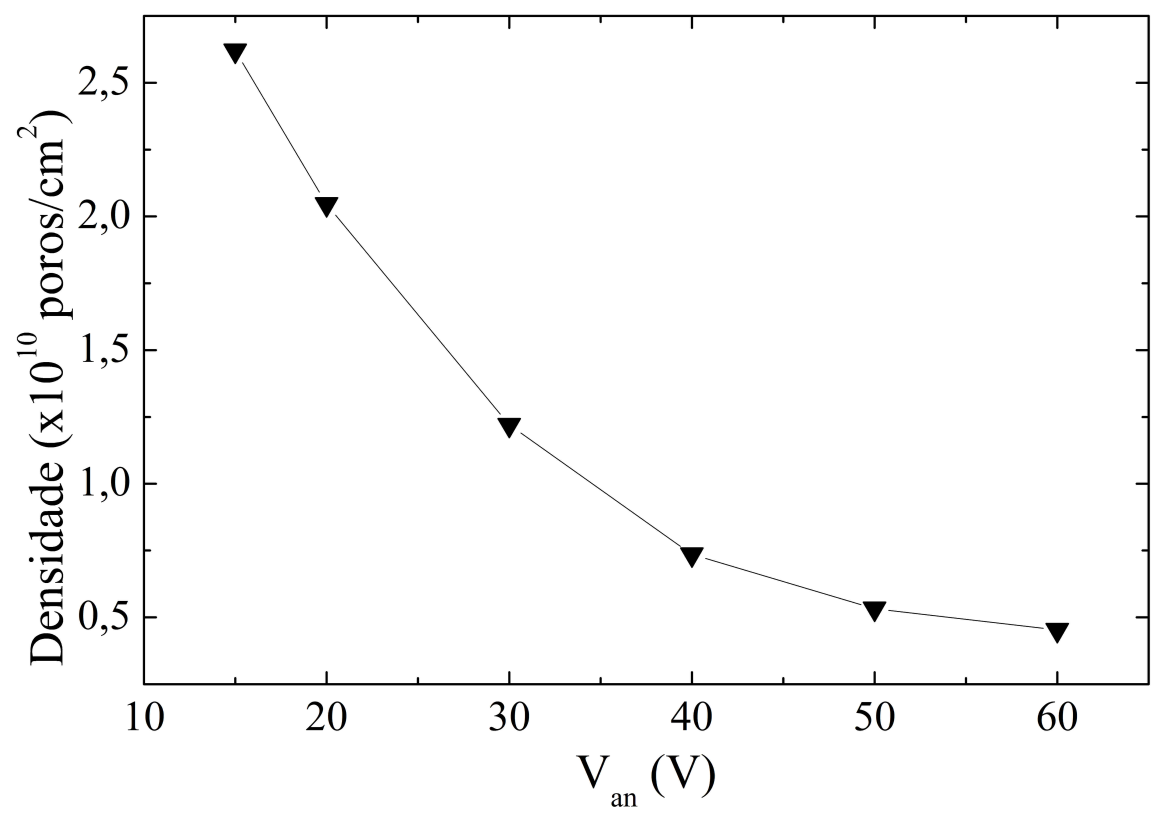

(a)

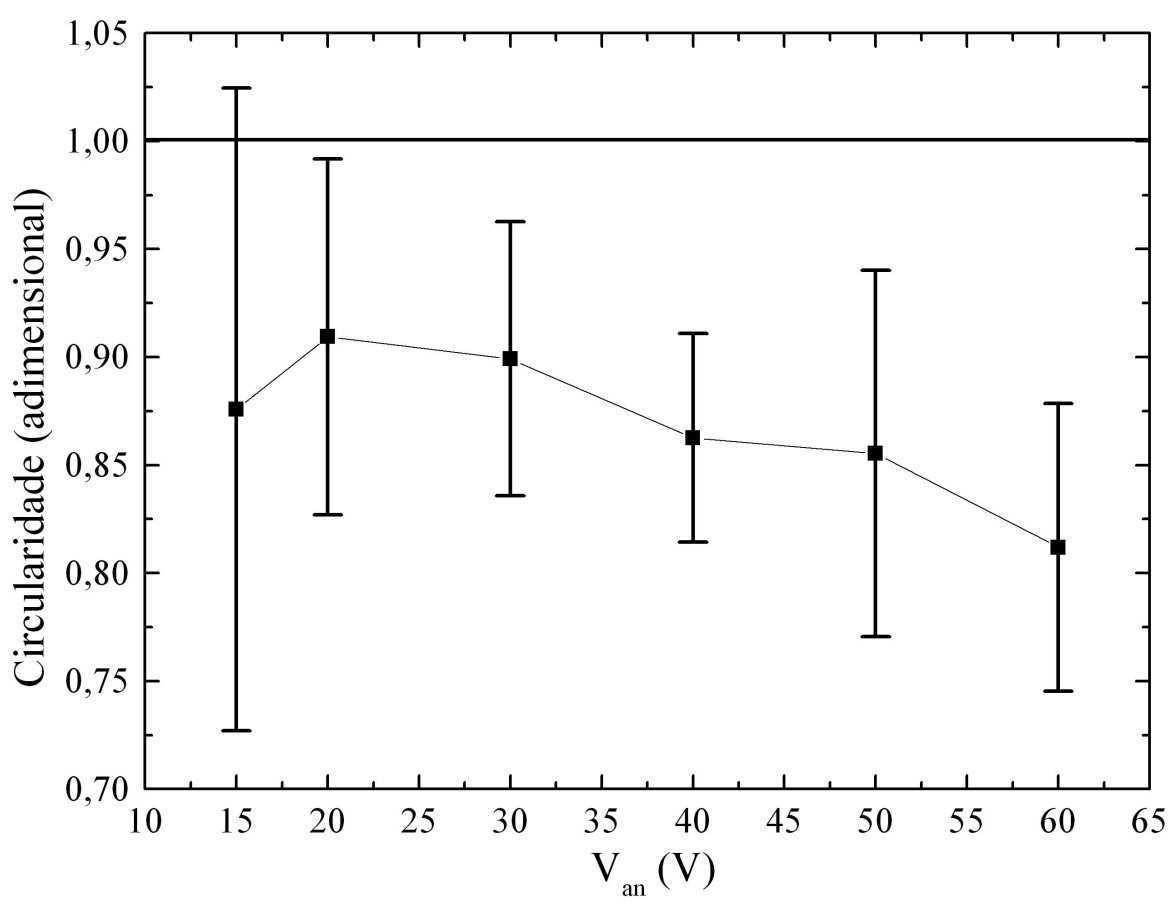

Figura 3.18: (a) Densidade superficial e (b) circularidade média dos poros em função da tensão aplicada durante a anodização. Os poros exibiram alta circularidade, acima de 0,8. A densidade exibe uma dependência com $V_{a n}^{-2}$, em acordo com a literatura [42]. 
de 0,75, o desvio-padrão é grande. Em particular, a queda do valor médio e a grande incerteza da circularidade da amostra $43-1\left(V_{a n}=15 \mathrm{~V}\right)$ se deve ao perfil do respectivo histograma [figura 3.16(b)]. Se considerarmos apenas a população mais significativa de poros, percebemos que a circularidade média seria em torno de 0,95. A circularidade dos poros influencia fortemente nos modos de inversão dos nanofios, pois constituem defeitos morfológcos dos fios, que desestabilizam modos de inversão típicos de estruturas de geometria ideal, como a inversão por vórtices (curling) e por dobramento (buckling) [43]. Defeitos morfológicos tendem a funcionar como nucleadores ou aprisionadores de paredes de domínios e vórtices [43].

Com isso, realizamos as primeiras eletrodeposições em modo de para valores de potencial indicados pelas voltametrias. O resultado observado foi uma deposição excessiva e desordenada de Ni sobre os eletrodos. Resolvemos, então, utilizar o método de eletrodeposição em potencial alternado (com forma de onda senoidal) por ser mais eficiente em amostras com alta resistividade, como foi ressaltado anteriormente [18]. Até esta etapa utilizamos o potenciostato recém adquirido. A partir daqui, ele passou a apresentar problemas de comunicação com o computador através de uma porta USB, impossibilitando qualquer medida ou controle das etapas eletroquímicas.

Para resolver este problema, utilizamos uma fonte DC comum durante a anodização em dois passos e uma fonte geradora de ondas acoplado a um amplificador de tensão durante a eletrodeposição AC, numa configuração de dois eletrodos. Nesta configuração, a caracterização por voltametria cíclica não é válida, pois os valores de potencial medidos durante a voltametria referem-se ao eletrodo de referência, numa configuração de três eletrodos. Além disso, utilizamos um multímetro digital com uma porta óptica e um software para aquisição de dados para o monitoramento da corrente elétrica, mas ele só tinha estabilidade no tempo de medida nas etapas em tensão dc, de modo que não foi possível monitorar a corrente durante as eletrodeposições.

Enfim, realizamos séries de eletrodeposições ac com diferentes valores de tensão de pico, freqüência e duração, variando entre 15 e $30 \mathrm{~V}$, entre 50 e $300 \mathrm{~Hz}$ e entre 2 e 60 minutos, respectivamente. Observamos que a deposição é possível em todas as freqüências utilizadas, apesar de em alguns casos ser excessiva e/ou pouco reprodutível. Os melhores resultados (mais reprodutíveis) foram obtidos para anodizações em voltagens abaixo de 
$40 \mathrm{~V}$ e eletrodeposições em tensões acima de $20 \mathrm{~V}$ ac, em torno de $100 \mathrm{~Hz}$, com durações em torno de 2 minutos.

Então, após testar diferentes condições de eletrodeposição, estabelecemos um procedimento padrão e escolhemos um conjunto de amostras para um estudo mais sistemático. Utilizamos em todas as eletrodeposições os seguintes parâmetros: solução de $0,1 \mathrm{~mol} / \mathrm{L}$ de $\mathrm{NiSO}_{4} \cdot 6 \mathrm{H}_{2} \mathrm{O}+45 \mathrm{~g} / \mathrm{L}$ de $\mathrm{H}_{3} \mathrm{BO}_{3}$, temperatura de $50^{\circ} \mathrm{C}, 25 \mathrm{~V}$ pico a pico, a $100 \mathrm{~Hz}$, por 2 minutos. O conjunto de amostras estudado está detalhado na tabela 3.1.

\begin{tabular}{c|c|c|c|c} 
Amostra & $V_{a n}(\mathrm{~V})$ & $\langle D\rangle(\mathrm{nm})$ & $d_{\text {int }}(\mathrm{nm})$ & Densidade $\left(\times 10^{10} \mathrm{~cm}^{-2}\right)$ \\
\hline $43-1$ & 15 & 31 & 42 & 2,62 \\
$44-1$ & 18 & 38 & 50 & 2,28 \\
$41-1$ & 20 & 42 & 62 & 2,05 \\
$42-1$ & 25 & 48 & 65 & 1,64 \\
$45-1$ & 30 & 52 & 76 & 1,22 \\
& 40 & 67 & 100 & 0,75 \\
& 50 & 88 & 115 & 0,55 \\
& 60 & 98 & 145 & 0,45
\end{tabular}

Tabela 3.1: Parâmetros morfológicos dos arranjos de nanoporos em lâminas de $\mathrm{Al}_{2} \mathrm{O}_{3}$ anodizadas e utilizadas para eletrodeposição de Ni e Co.

Em suma, os arranjos de nanoporos de melhor qualidade, ou seja, aqueles com maior ordenamento hexagonal da rede de poros, com maiores grãos superficiais, pequenos diâmetros e alta circularidade dos poros, alta densidade, com poros retos, paralelos e sem falhas foram obtidos para valores intermediários de tensão e concentração de $(\mathrm{COOH})_{2}$, respectivamente, nas faixas de 15 a $40 \mathrm{~V}$ e de 0,3 a $0,5 \mathrm{~mol} / \mathrm{L}$. Já um baixo grau de empacotamento não depende simplesmente da tensão de anodização, mas deve satisfazer uma combinação de outros fatores, como tipo de eletrólito e $\mathrm{pH}[42]$. A baixa temperatura (abaixo de $5^{\circ} \mathrm{C}$ ) e longas durações das anodizações também são condições importantes para garantir a boa qualidade das redes de nanoporos para posterior eletrodeposição.

\subsubsection{Difratometria de Raios X}

Após as eletrodeposições, as amostras foram caracterizadas através de difração de raios-X (XRD), no Laboratório de Cristalografia do Departamento de Física Aplicada do IFUSP. As amostras foram irradiadas sobre porta-amostras de vidro, num difratômetro Rigaku Ultima $^{T M}$ III, com geometria $\theta-2 \theta$. Utilizamos uma fonte de radiação $\mathrm{Cu}-\mathrm{K}_{\alpha}$, com 
$\lambda=1,5418 \AA$, ddp de $40 \mathrm{kV}$ e corrente de filamento de $30 \mathrm{~mA}$, em varredura $\theta-\theta$. Varremos o ângulo de espalhamento em intervalos de $0,05^{\circ}$, no modo de contagens por segundo (cps). Em torno dos picos prováveis do Ni e Co, fizemos uma varredura mais lenta, a fim de obter uma boa estatística de contagem. Como o Co pode estabilizar em duas fases diferentes ( $h c p$ ou $f c c$ ), as faixas de varredura para o Co abrangem picos das duas fases. Detalhes da varredura e tempos de exposição em torno dos possíveis picos de difração são encontrados na tabela 3.2 .

\begin{tabular}{c|c|c} 
Amostra & Intervalo & Tempo de exposição (s) \\
\hline $\mathrm{Ni}$ & $35^{\circ}$ a $43^{\circ}$ & 10 \\
& $43^{\circ}$ a $47^{\circ}$ & 50 \\
& $47^{\circ}$ a $50^{\circ}$ & 10 \\
& $50^{\circ}$ a $54^{\circ}$ & 50 \\
$54^{\circ}$ a $74,5^{\circ}$ & 10 \\
& $74,5^{\circ}$ a $79,5^{\circ}$ & 50 \\
& $79,5^{\circ}$ a $90,5^{\circ}$ & 10 \\
& $90,5^{\circ}$ a $96,5^{\circ}$ & 50 \\
& $96,5^{\circ}$ a $97^{\circ}$ & 10 \\
\hline Co & $44^{\circ}$ a $56^{\circ}$ & 40 \\
& $72^{\circ}$ a $102^{\circ}$ & 40
\end{tabular}

Tabela 3.2: Parâmetros de varredura da difratometria de raios X para amostras de nanofios de $\mathrm{Ni}$ e Co.

Primeiramente, realizamos uma difratometria apenas do substrato de $\mathrm{Al}_{2} \mathrm{O}_{3} / \mathrm{Al}$. Este difratograma, mostrado na figura 3.19, apresentou intensos picos de Al, mas nenhum pico de $\mathrm{Al}_{2} \mathrm{O}_{3}$, sugerindo que este material é majoritariamente amorfo. Observamos também uma mudança de textura do $\mathrm{Al}$ entre as amostras a partir da mudança no perfil de intensidade dos picos. Isto pode ser devido ao procedimento de annealing durante a etapa de pré-tratamento, antes da anodização. Os difratogramas das amostras eletrodepositadas (figuras 3.20 e 3.21) exibiram os mesmos picos típicos de Al, com intensidades variáveis conforme a textura, bem como picos típicos de Ni fcc de baixa intensidade. Isso se deve ao pequeno volume de Ni depositado nas amostras em comparação ao volume do substrato. Esperamos que o pico (111) do Ni seja o mais intenso, dado a sua estrutura fcc. Porém, em nenhuma das amostras ele foi observado por coincidir com o intenso pico (200) do Al.

No caso das amostras de Co, a situação é ainda mais crítica. Apenas duas amostras 


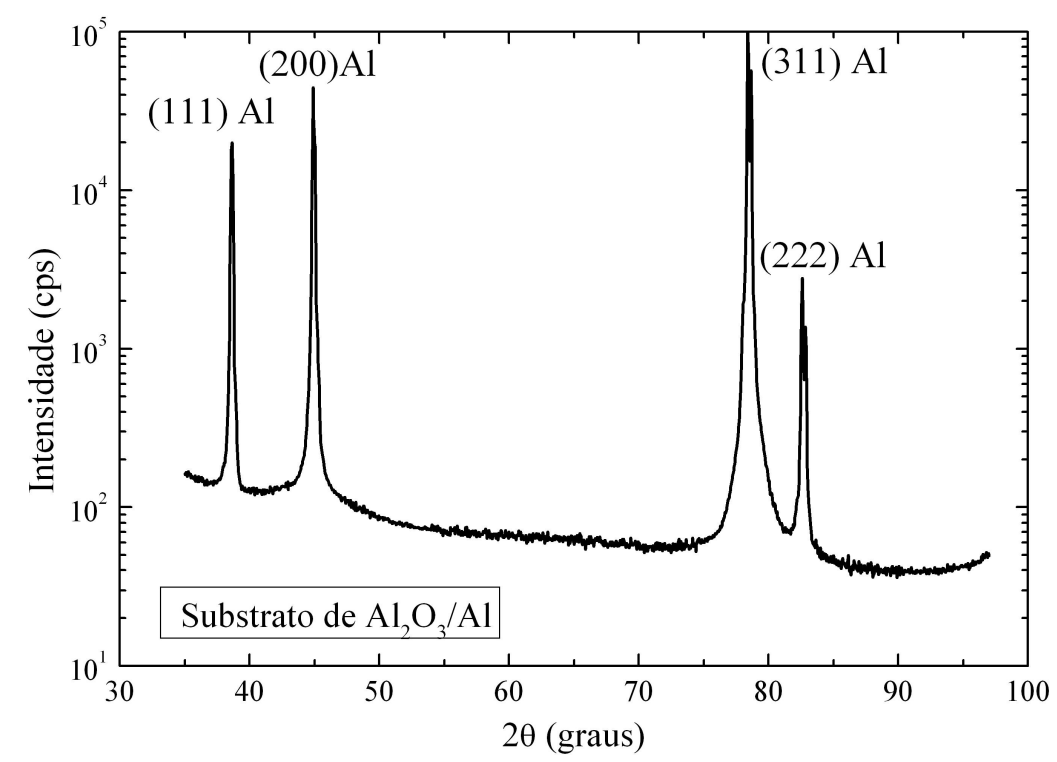

Figura 3.19: Difratogramas de raios $\mathrm{X}$ do substrato de $\mathrm{Al}_{2} \mathrm{O}_{3} / \mathrm{Al}$ utilizado nas amostras.

revelaram traços de Co, muito embora os nanofios estivessem presentes em todas elas, como foi comprovado pelas medidas magnéticas (seção 3.3). Devido à pequena quantidade de material depositado nas amostras de Co, apenas um único pico foi detectado [associado à reflexão no plano (110)], porém com uma intensidade muito baixa. A presença de um único pico sugere também uma possível texturização ao longo dessa direção. Isso impossibilitou uma análise quantitativa detalhada. Os resultados para amostras de Co anodizadas em três diferentes voltagens (portanto, com três diferentes diâmetros médios) são mostrados na figura 3.22. Nessas amostras, a quantidade de material depositado na superfície foi claramente menor do que nas amostras de Ni. Se o preenchimento dos poros não é completo (até a superfície), o sinal do Co fica muito atenuado pelo grande volume de $\mathrm{Al}$ na amostra. O pico de Co observado localiza-se em $2 \theta=76^{\circ}$. Sabe-se que duas fases cristalinas de Co pode-se formar em nanofios crescidos por eletrodeposição: uma $f c c$, outra $h c p$. As condições de estabilidade dessas fases ainda são discutidos na literatura. Comparando os difratogramas previstos para $\mathrm{Co}(f c c)$ e $\mathrm{Co}(h c p)$, percebe-se a existência de um pico em $2 \theta=76^{\circ}$ em ambas as fases, associados a diferentes planos de reflexão. Este pico pode corresponder à reflexão $\mathrm{Co}(110)$ da fase $h c p$ ou à reflexão $\mathrm{Co}(220)$ da fase fcc. Porém, a intensidade dos picos observados impossibilita a realização de uma análise quantitativa confiável e, conseqüentemente, a determinação da fase presente nos nanofios de Co e seus parâmetros microestruturais. No entanto, as medidas magnéticas mostradas 


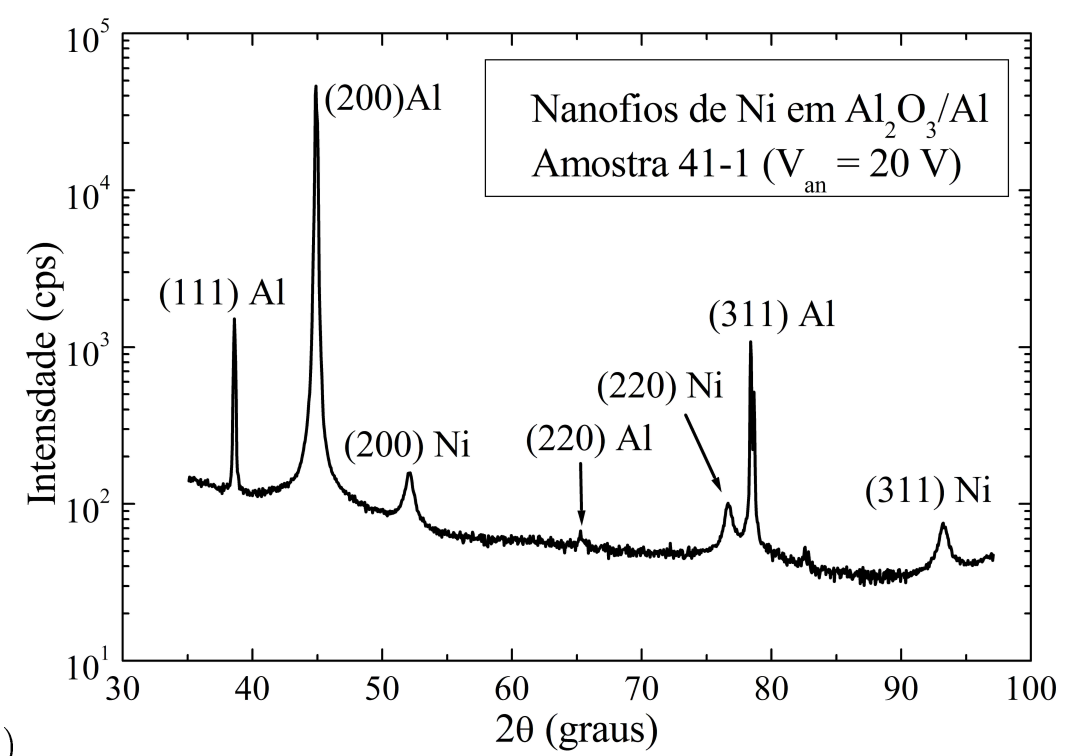

(a)

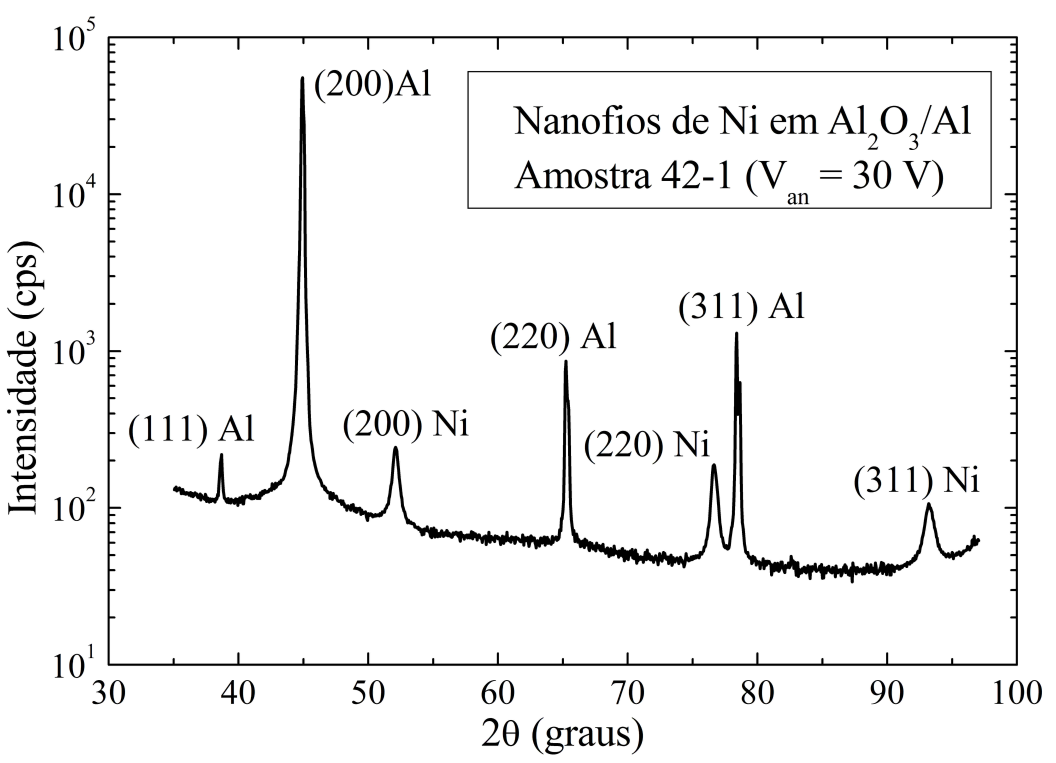

Figura 3.20: Difratogramas de raios X de nanofios de Ni referentes às amostras(a) 41-1 ( $V_{a n}=20$ $\mathrm{V})$ e (b) $42-1\left(V_{a n}=30 \mathrm{~V}\right)$. 


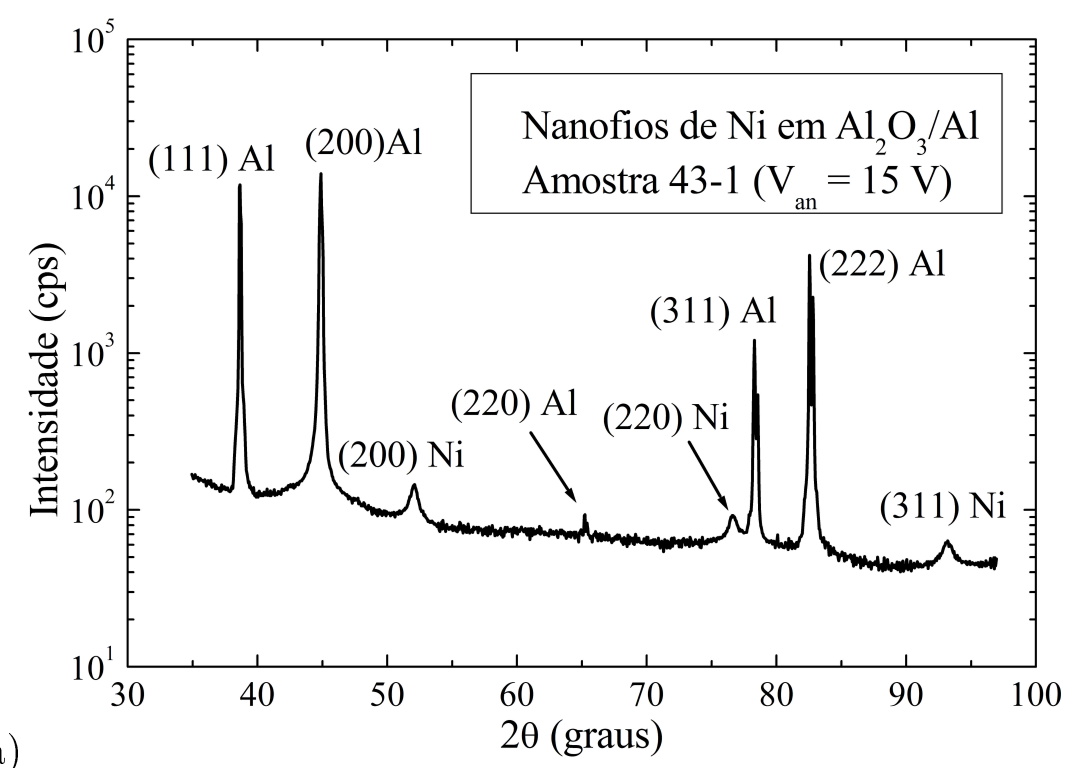

(a)

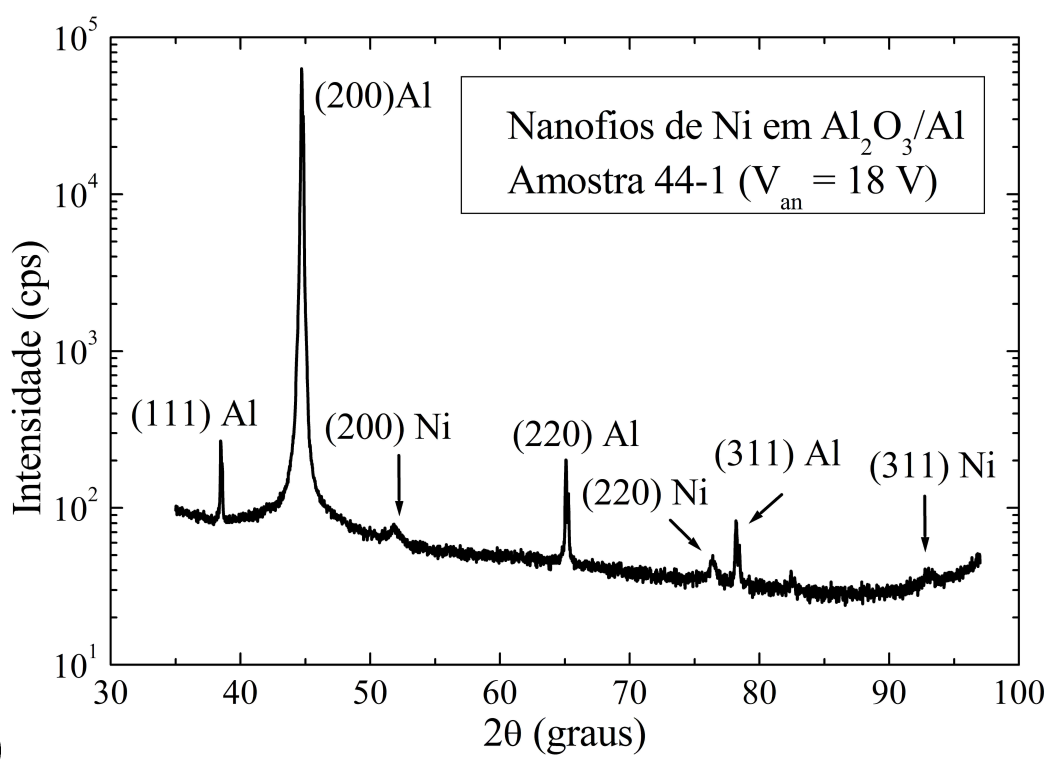

Figura 3.21: Difratogramas de raios $\mathrm{X}$ de nanofios de Ni referentes às amostras (a) 43-1 ( $V_{a n}=$ $15 \mathrm{~V})$ e (b) $44-1\left(V_{a n}=18 \mathrm{~V}\right)$. 


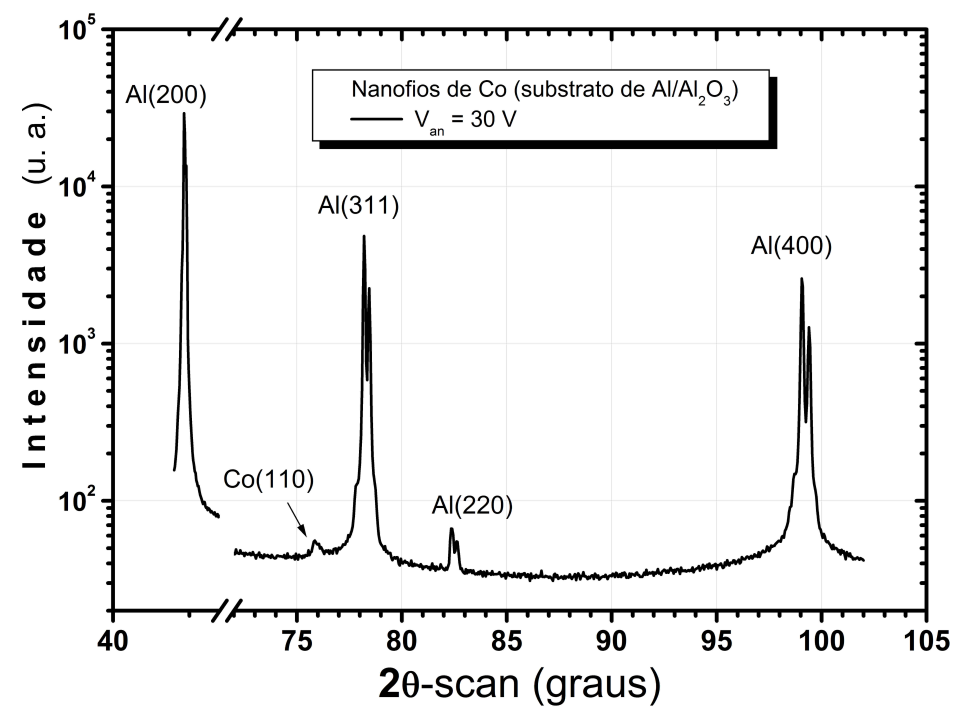

(a)

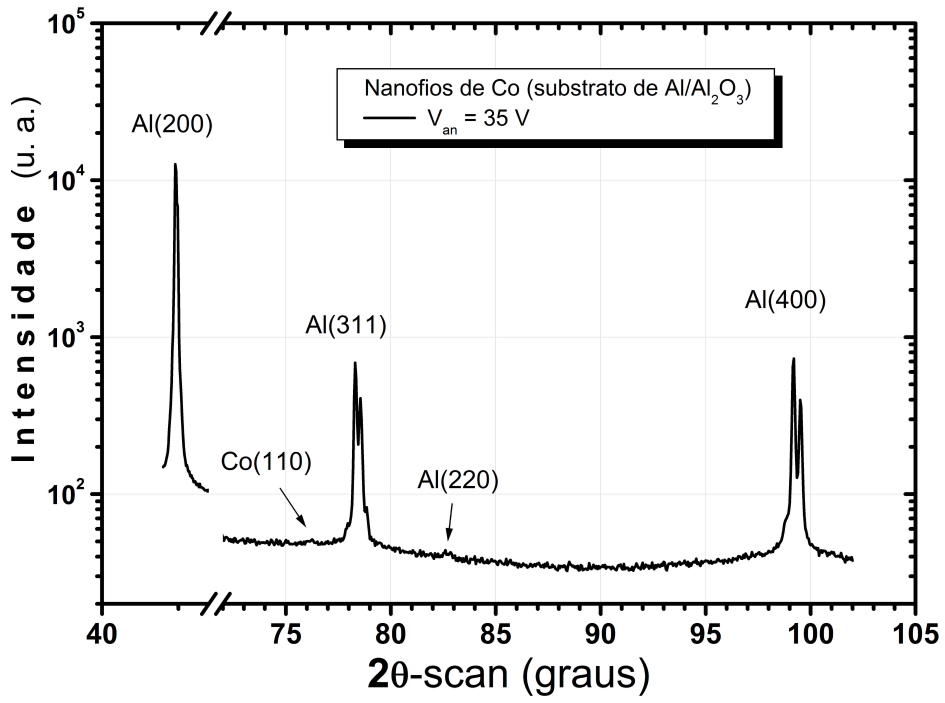

(b)

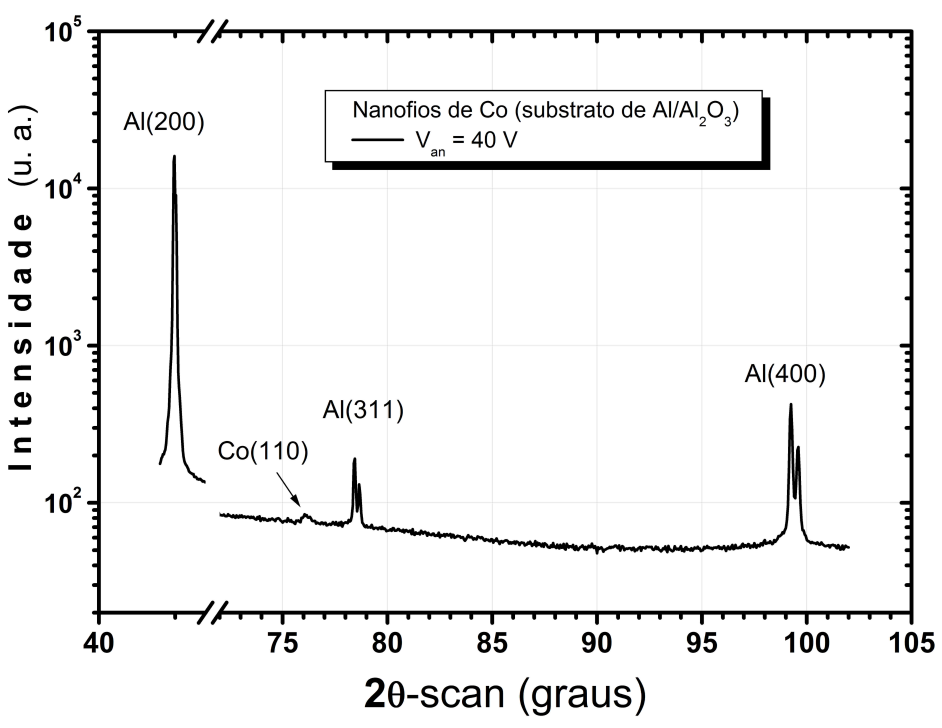

Figura 3.22: Difratogramas de amostras de nanofios de Co anodizadas a (a) $30 \mathrm{~V}$, (b) $35 \mathrm{~V}$ e (c) $40 \mathrm{~V}$. Apenas duas delas apresentaram fracos traços de Co. O pico $\mathrm{Co}(110)$ observado está presente tanto no difratograma da fase $h c p$ quanto no da $f c c$ do Co. Uma análise quantitativa confiável não é possível nesse caso devido à baixa intensidade dos picos. 
na seção 3.3 confirmam a formação de fios de Co nos poros.

A partir da análise dos difratogramas, é possível calcular o tamanho médio dos grãos cristalinos de Ni e Co para cada direção cristalográfica $\left(D_{h k l}\right)$. Isso é feito através do ajuste de cada pico do Ni por uma curva lorentziana e medindo sua largura à meia altura $\left(B_{h k l}\right)$. Daí, calculamos $D_{h k l}$ a partir da fórmula Scherrer,

$$
D_{h k l}=\frac{k \lambda}{\beta_{h k l} \cos \theta_{h k l}},
$$

onde $\lambda$ é o comprimento de onda da radiação incidente, $k$ é uma constante adimensional (que vale 0,89 neste trabalho), $\theta_{h k l}$ é o ângulo do feixe difratado na direção $[h k l]$ e $\beta_{h k l}$ é a largura à meia altura do pico, descontada a divergência do feixe, que foi de $0,1^{\circ}$, ou seja,

$$
\beta_{h k l}=\sqrt{B_{h k l}^{2}-(0,1)^{2}}
$$

Na figura 3.23, representamos o tamanho de grão de Ni em função do diâmetro médio dos fios. Os grãos de Ni têm tamanhos médios entre 17 e 24 nm ao longo da direção [220]. Entretanto, não podemos afirmar que esta seja a direção preferencial de crescimento, uma vez que o pico (111) do Ni não pôde ser observado. Por outro lado, observamos no gráfico uma tendência de crescimento do tamanho de grão à medida que o diâmetro dos poros aumenta. Isso indica que a geometria dos poros regula o tamanho de grão de Ni durante a eletrodeposição. Da mesma forma, estimamos para os nanofios de Co um tamanho de grão da ordem de $4 \mathrm{~nm}$ ao longo da direção (110), para a amostra anodizada a $30 \mathrm{~V}$.

\begin{tabular}{c|cccc}
\hline$V_{a n}(\mathrm{~V})$ & 15 & 18 & 20 & 30 \\
$\langle D\rangle(\mathrm{nm})$ & 31 & 38 & 42 & 52 \\
\hline$d_{g r}^{N i}(\mathrm{~nm})$ & 16,9 & 21,2 & 17,2 & 19,8 \\
$d_{g r}^{C o}(\mathrm{~nm})$ & - & - & - & 4,3 \\
\hline$d_{g r} / l_{e x}(\mathrm{Ni})$ & 2,1 & 2,6 & 2,1 & 2,4 \\
$d_{g r} / l_{e x}(\mathrm{Co})$ & - & - & - & 0,85 \\
\hline
\end{tabular}

Tabela 3.3: Valores típicos da razão $d_{g r} / l_{e x}$ e diâmetros médios $\langle D\rangle$ das amostras de nanofios de Ni e Co em função da tensão de anodização. 


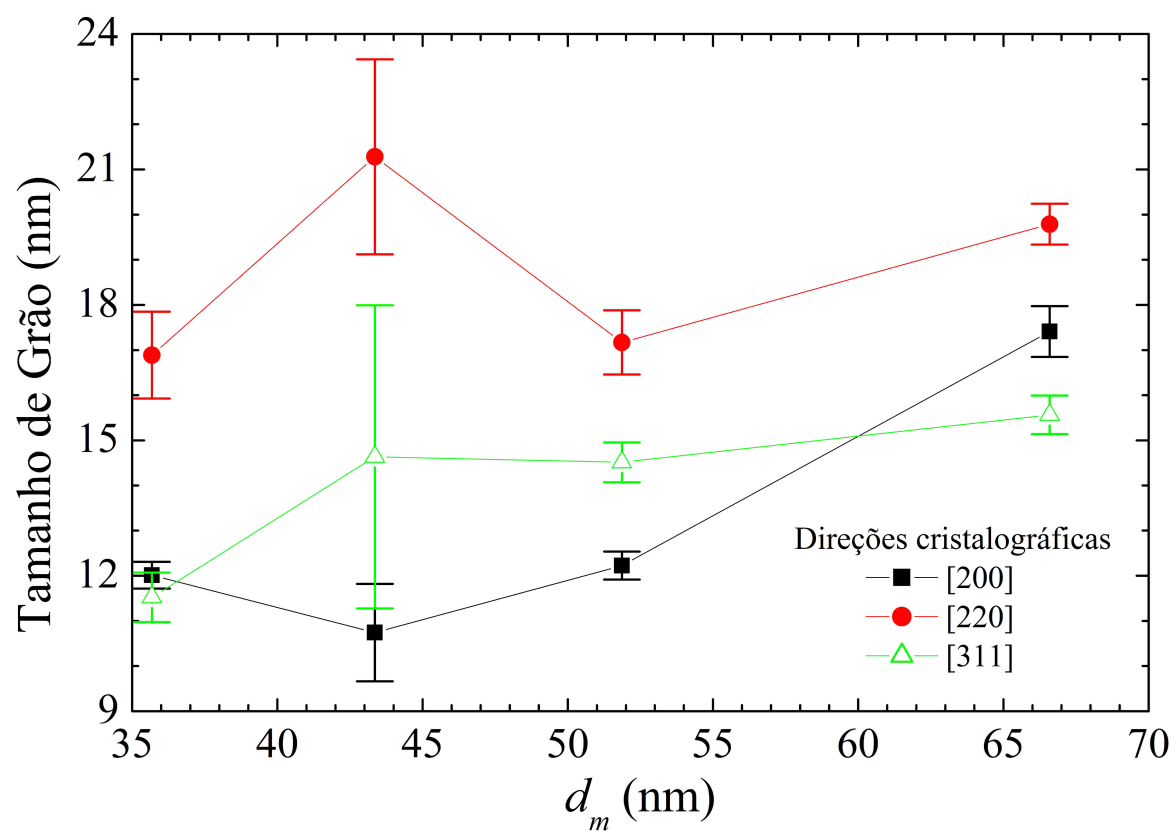

Figura 3.23: Tamanho médio de grão cristalino de Ni em cada direção cristalográfica em função do diâmetro médio dos fios.

Conhecendo os valores do comprimento de coerência $l_{e x}$ de $\mathrm{Ni}(8,2 \mathrm{~nm})$ e Co $(2,9 \mathrm{~nm})$ (dados na tabela 2.2, à página 32) e os tamanhos de grão $d_{g r}$ de cada amostra, podemos calcular os valores típicos da razão $d_{g r} / l_{e x}$ das nossas amostras de nanofios em função da voltagem de anodização. Os resultados encontram-se na tabela 3.3. Nossas amostras de nanofios apresentam razões de aspecto entre 50 e 200. Comparando esses valores da tabela 3.3 com o diagrama de fases da figura 2.16, podemos dizer que os nanofios de Co encontram-se na fase de vórtice ou multidomínio, segundo a modelagem magnética da referência [50], uma vez que eles apresentam uma alta razão $D / l_{e x}$, com grãos muito pequenos $\left(d_{g r} / l_{e x}<1\right)$ e altas razões de aspecto. Já os nanofios de Ni têm seu menor diâmetro médio $\left(\langle D\rangle=3,8 l_{e x}\right)$ sobre o limiar da transição entre os estados uniforme e de vórtice. Mas as demais amostras de Ni também se encontram no regime de multidomínio. Esses resultados têm importantes implicações nas propriedades magnéticas de nanofios Ni e Co, que serão discutidas com detalhe na seção 3.2.

\subsection{Caracterização Magnética}

Os resultados de XRD indicaram que os nanofios de Ni são policristalinos, de estrutura $f c c$, com tamanho de grão entre 17 e $24 \mathrm{~nm}$. Essa faixa se encontra abaixo dos diâmetros 
médios dos poros, mas acima do comprimento de coerência do Ni, que é de $8,2 \mathrm{~nm}$ (tabela 2.2). Os nanofios de Co têm tamanho da ordem de $4 \mathrm{~nm}$, o que corresponde a $0,85 l_{e x}$ - são formados por grãos magnéticos monodomínio, alguns possivelmente também superparamagnéticos. Nesta faixa de tamanho de grão, o material é dito nanocristalino, praticamente formando um meio particulado fino, quase contínuo. No caso dos nanofios de Ni, seus grãos atravessam o limiar entre dois regimes micromagnéticos: o de partículas magnéticas mono- e multidomínio. Sua policristalinidade causa numa distribuição aleatória dos eixos de anisotropia das partículas, resultando numa fraca influência da anisotropia magnetocristalina na estabilização do estado monodomínio do nanofio e seu comportamento é determinado pelo acoplamento com partículas vizinhas por interação de troca (exchangecoupling) e pela anisotropia de forma do sistema. A existência de paredes de domínio no material está associada a defeitos entre os contornos de grão, podendo nuclear modos não-uniformes de inversão da magnetização, como vórtices ou movimento de paredes de domínio.

Fios magnéticos com alta razão de aspecto apresentam forte anisotropia de forma na direção do seu eixo. Isso significa que o campo coercivo nessa direção é maior do que na direção perpendicular ao eixo. Além disso, as propriedades magnéticas macroscópicas típicas do material volumoso, como coercividade e remanência, podem ser bem diferentes daquelas do mesmo material em dimensões nanoscópicas. Portanto, para confirmar se há formação de nanofios magnéticos com essas propriedades, é necessário realizar curvas de magnetização, pois a coercividade nas direções paralela e perpendicular aos nanofios depende fortemente das anisotropias induzidas pela geometria do sistema. A detecção dessas características magnéticas confirmariam uma deposição satisfatória do Ni no interior dos poros.

\subsubsection{Curvas de Magnetização}

Realizamos, então, ciclos de histerese de várias amostras, a $300 \mathrm{~K}$, no SQUID do nosso departamento. As medidas foram feitas nas direções perpendicular e paralela à superfície da amostra e apresentaram sinais de uma forte anisotropia de forma na direção perpendicular à superfície, ou seja, paralela ao eixo dos nanofios. As amostras eram segmentos quadrados de $5 \times 5 \mathrm{~mm}$. Na figura 3.24, exibimos ciclos de histerese da amostra 43- 


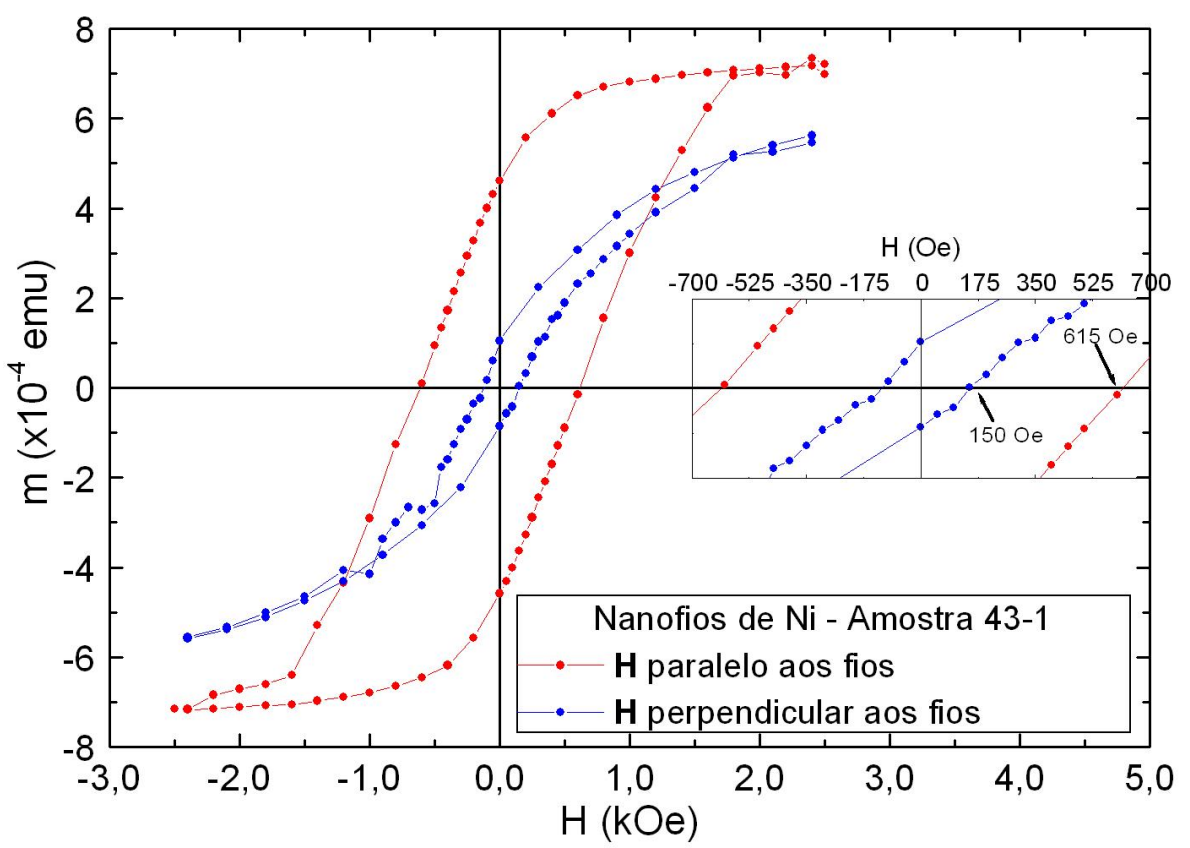

Figura 3.24: Ciclos de histerese da amostra 43-1 de nanofios de Ni, realizados em SQUID, a 300 $\mathrm{K}$, com campo aplicado nas direções paralela (em vermelho) e perpendicular (azul) ao eixo dos nanofios.

$1\left[6^{\circ} \mathrm{C},(\mathrm{COOH})_{2}\right.$ a $0,3 \mathrm{~mol} / \mathrm{L}, 15 \mathrm{~V}$ dc, $\left.1 \mathrm{~h}\left(1^{\mathrm{a}}\right) / 40 \mathrm{~min} .\left(2^{\mathrm{a}}\right)\right]$, eletrodepositada na solução-padrão de $\mathrm{Ni}\left(\mathrm{NiSO}_{4} \cdot 6 \mathrm{H}_{2} \mathrm{O}\right.$ a $0,1 \mathrm{~mol} / \mathrm{L}+\mathrm{H}_{3} \mathrm{BO}_{3}$ a $\left.45 \mathrm{~g} / \mathrm{L}\right)$, a $25 \mathrm{~V}$ ac, $100 \mathrm{~Hz}$, $60^{\circ} \mathrm{C}$, por 2 minutos.

Estes ciclos de histerese indicam fortemente a presença de nanofios de Ni na estrutura porosa, pois apresentam uma grande diferença entre os campos coercivos nas direções paralela $\left(H_{C}^{\|} \approx 150\right.$ Oe) e perpendicular $\left(H_{C}^{\perp} \approx 615\right.$ Oe $)$ à superfície e uma forte componente desmagnetizante (inclinação da curva para longe do eixo vertical e dificuldade de se atingir a saturação). Além disso, ambas as coercividades são muito mais altas do que se observaria em $\mathrm{Ni}$ volumoso $\left(H_{C} \approx 50 \mathrm{Oe}\right)$. A remanência também é bem mais alta na direção perpendicular do que na paralela.

\subsubsection{Análise FORC}

Por ser um mapa completo da resposta magnética do sistema, o diagrama FORC fornece informações sobre as interações magnetostáticas predominantes no sistema, assim como a curva $\Delta M$. Para o cálculo das distribuições FORC, recorremos a métodos computacionais. A princípio, tentamos desenvolver um algoritmo em Linguagem C. Os primeiros 


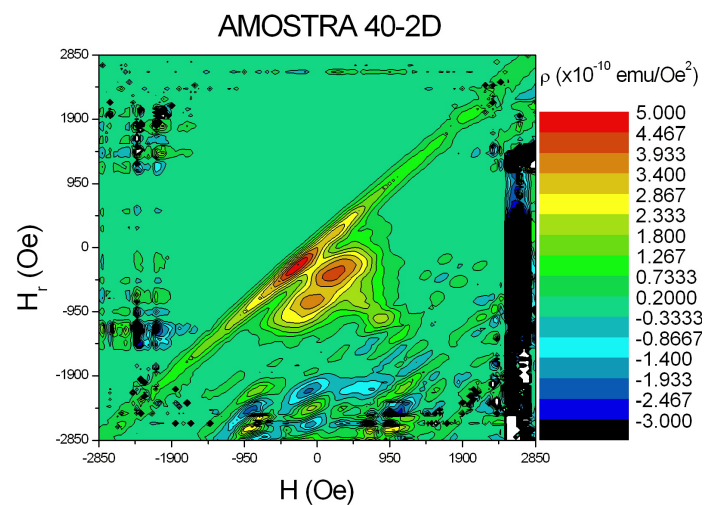

(a)

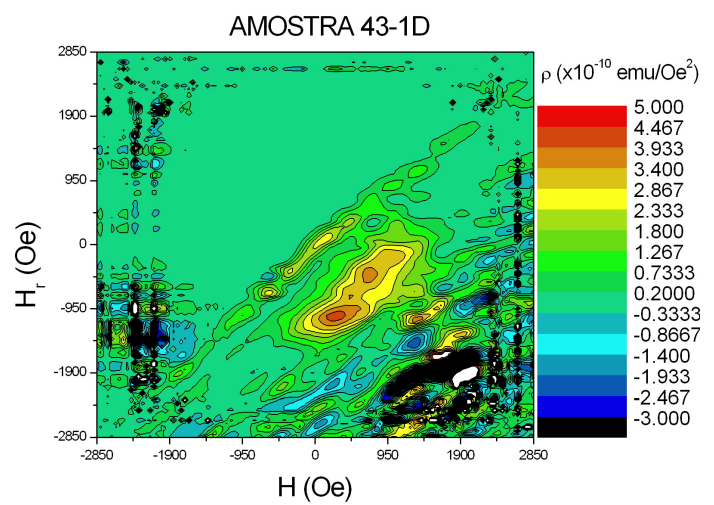

(b)

Figura 3.25: Diagramas FORC das amostras de nanofios de Ni (a) 40-2 ( $\left.V_{a n}=30 \mathrm{~V}\right)$ e (b) 43-1 $\left(V_{a n}=15 \mathrm{~V}\right)$, preparadas nas mesmas condições $\left[3^{\circ} \mathrm{C},(\mathrm{COOH})_{2}\right.$ a $0,3 \mathrm{~mol} / \mathrm{L}, 1$ hora $\left(1^{\underline{a}}\right) / 40$ minutos $\left(2^{\underline{a}}\right)$; eletrodeposição $\left.\mathrm{AC} \operatorname{com} f=100 \mathrm{~Hz}\right]$.

resultados obtidos são mostrados nas figuras 3.25(a) e 3.25(b) para as amostras 40-2 e $43-1$, anodizadas a $30 \mathrm{~V}$ e $15 \mathrm{~V}$, respectivamente $\left[3^{\circ} \mathrm{C}, 15 \mathrm{~V} \mathrm{dc},(\mathrm{COOH})_{2}\right.$ a $0,3 \mathrm{~mol} / \mathrm{L}$, 1 hora $\left(1^{\mathrm{a}}\right) / 40$ minutos $\left(2^{\underline{a}}\right)$; eletrodeposição ac com $\left.f=100 \mathrm{~Hz}\right]$.

Apesar de o programa gerar fortes flutuações numéricas (fortes picos que vão a fundo da escala de cores nos diagramas da fig. 3.25), os diagramas FORC apresentaram características típicas para estes sistemas (na região próximo ao centro dos diagramas). O diagrama FORC da amostra 40-2 [figura 3.25(a)] foi o que apresentou melhores resultados obtidos pelo programa desenvolvido em C. Nele observamos uma largo pico ao longo de $H_{r}=H\left(H_{c}=0\right)$, centrado em valores negativos de $H_{r}\left(H_{b}<0\right)$, ou seja, na porção inicial de cada FORC. Nessa região, o campo aplicado é invertido de sentido, causando a inversão brusca de partículas que estão mais suscetíveis, isto é, partículas menores, com baixos campos de inversão e/ou superparamagnéticas. Por isso, esse pico é freqüentemente associado a componentes reversíveis da magnetização [91].

Observamos também dois fortes picos para valores de campo próximos à coercividade do material e para $H_{r}<0$. Num sistema de partículas não interagentes, esperamos a existência de um único pico [55, 61, 92]. À medida que o sistema passa a interagir, gradualmente o pico principal tende a se elongar na direção diagonal $\left(H_{r}=H\right)$, até que se desdobra em dois ou mais picos. A existência de dois picos, portanto, indica que o sistema é fortemente interagente [55, 61, 92, 94]. A assimetria observada na posição desses picos para $H_{r}<0$ indica a predominância de interações desmagnetizantes no 
sistema, provavelmente de origem dipolar - devido ao efeito desmagnetizante de forma e interação dipolar inter-fios.

Um pequeno pico pode ser observado para valores mais altos de $H\left(H_{r}=-H \approx-950\right.$ Oe). Esse pico corresponde a modos de inversão nucleados a altos campos, majoritariamente irreversíveis. Podemos observar ainda regiões onde $\rho<0$, que podem estar associados a efeitos desmagnetizantes ou de viscosidade magnética para baixos campos e a modos de inversão irreversíveis, para campos mas altos. A figura 3.25(b) apresenta características semelhantes, apesar de menos visíveis devido à qualidade dos resultados. As regiões pretas e brancas nos gráficos, assim como valores de $\rho \neq 0$ na região $H_{r}>H$, que é experimentalmente inacessível, correspondem a flutuações numéricas e não representam nenhum comportamento físico do sistema.

Para fazer a analogia da distribuição FORC com uma distribuição de partículas monodomínios, é preciso construir esses gráficos em função dos eixos $\left\{H_{c}, H_{b}\right\}$. Para isso, desenvolvemos o algoritmo descrito na seção 2.1.6 em MatLab, que é uma linguagem de alto nível, melhor adaptada para se operar com matrizes. Nesta linguagem, o algoritmo desenvolvido (ver apêndice A) é bem mais simples do que o anterior e apresenta resultados melhores, com menos flutuações e maior confiabilidade. Além disso, a manipulação da distribuição entre os diferentes sistemas de coordenadas $\left(\left\{H_{r}, H\right\} \rightleftharpoons\left\{H_{c}, H_{b}\right\}\right)$ e outras formas de representação mostrou-se bem mais simples.

\subsection{Resultados e Discussão}

Os resultados obtidos para as amostras de nanofios de Ni são mostrados nas figuras 3.26 a 3.29. Nelas vemos as FORCs medidas (a) e suas respectivas distribuições FORC (b). Os diagramas FORC exibiram as mesmas estruturas de "dois ramos" (two-branch) e o pico reversível em $H_{c}=0$ observadas por Pike et al. [55] em um arranjo de nanofios de Ni. Também observamos o desdobramento do pico principal, como demonstrado por Dumas et al. [61] em nanopartículas de Fe e Muxworthy et al. [92] a partir de modelos micromagnéticos. Neste mesmo trabalho, os autores demonstram que o desdobramento do pico principal está diretamente associado ao grau de interação entre as entidades magnéticas do sistema. Nessas figuras também fica claro que o desdobramento do pico 
principal ocorre ao longo de $H_{b}$, tendendo a formar dois picos verticalmente adjacentes [61].

Em geral, os picos mais proeminentes ocorrem para valores de $H_{c}$ em torno da coercividade do material, como esperado, mas toda a distribuição é deslocada para $H_{b}<0$. Uma vez que nossas amostras não exibiram exchange-bias e nem a presença de óxido de níquel, esta assimetria é entendida como o efeito de interações dipolares entre fios vizinhos, que atuam como um campo médio desmagnetizante sobre cada fio [30]. Os arranjos de nanofios têm alta densidade superficial, nos quais os fios têm alta razão de aspecto $(>50)$. Assim, cada fio comporta-se como um dipolo magnético, cujas linhas de campo na superfície tendem a fechar nas extremidades dos fios vizinhos [24]. Assim, cada fio está sujeito a um campo de interação local, efetivo, desmagnetizante $\left(\left\langle H_{b}\right\rangle<0\right)$.

Podemos observar também um largo pico secundário em torno de $H_{c}=0$. Este pico é bem claro nas amostras $41-1\left(V_{a n}=20 \mathrm{~V},\langle D\rangle=42 \mathrm{~nm}\right)$ e $42-1\left(V_{a n}=30 \mathrm{~V},\langle D\rangle=48 \mathrm{~nm}\right)$ [figuras 3.28(b) e 3.29(b)]. Na interpretação estatística, essa região do diagrama representa partículas com baixos campos de inversão. Assim, essas partículas são predominantemente reversíveis, pois alinham-se com o campo facilmente. Por isso, este pico é chamado de "pico reversível" [55, 91]. Nas amostras com menores diâmetros médios, 43-1 ( $V_{a n}=15 \mathrm{~V}$, $\langle D\rangle=31 \mathrm{~nm})$ e $44-1\left(V_{a n}=18 \mathrm{~V},\langle D\rangle=38 \mathrm{~nm}\right)$, o pico reversível é bem menos definido [figuras 3.26(b) e 3.27(b)], indicando uma menor componente reversível da magnetização nessas amostras.

Como o campo de inversão de uma partícula magnética é determinado por seu volume, então a dependência de $\rho \operatorname{com} H_{c}$ está diretamente associada a uma distribuição de volumes das partículas. Em geral, ambas distribuições exibem um perfil tipo lognormal. Porém, a existência de regiões em que $\rho<0$ indicam que $\rho\left(H_{c}, H_{b}\right)$ não é univocamente determinada pela distribuição $P\left(H_{c}, H_{b}\right)$, mas dependem também do campo aplicado e do estado de magnetização, ou seja, da história magnética do sistema [30, 55, 91, 92]. Por outro lado, o perfil de $\rho\left(H_{c}, H_{b}\right)$ em função de $H_{b}$ revela o caráter das interações magnéticas. Entretanto, essa abordagem é inspirada no modelo fenomenológico de Preisach, no qual as diferentes interações presentes no sistema estão incorporadas nos parâmetros $H_{c}$ e $H_{b}$ de modo que não podem ser distinguidas [27, 28]. É provável que haja alguma correlação entre esses parâmetros. Evidências disso são as principais distinções 


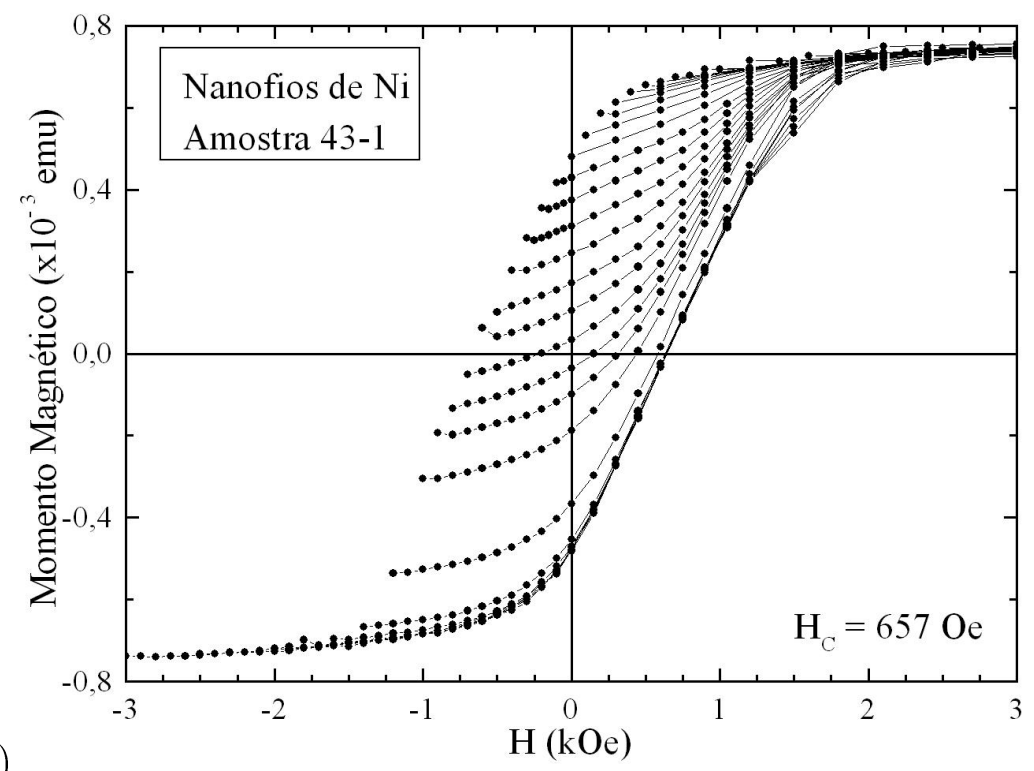

(a)

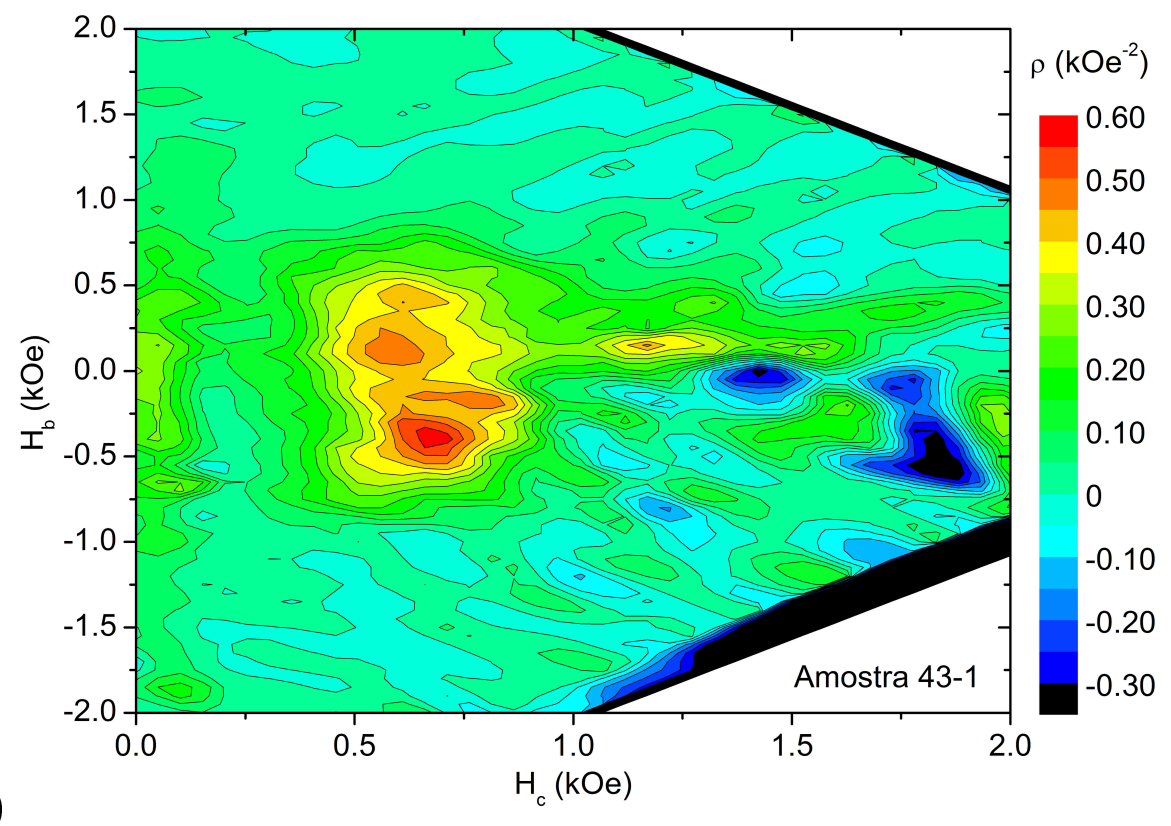

(b)

Figura 3.26: FORCs experimentais (a) e diagrama FORC (b) da amostra de nanofios de Ni anodizada a $V_{a n}=15 \mathrm{~V}, \operatorname{com}\langle D\rangle=31 \mathrm{~nm}$. 


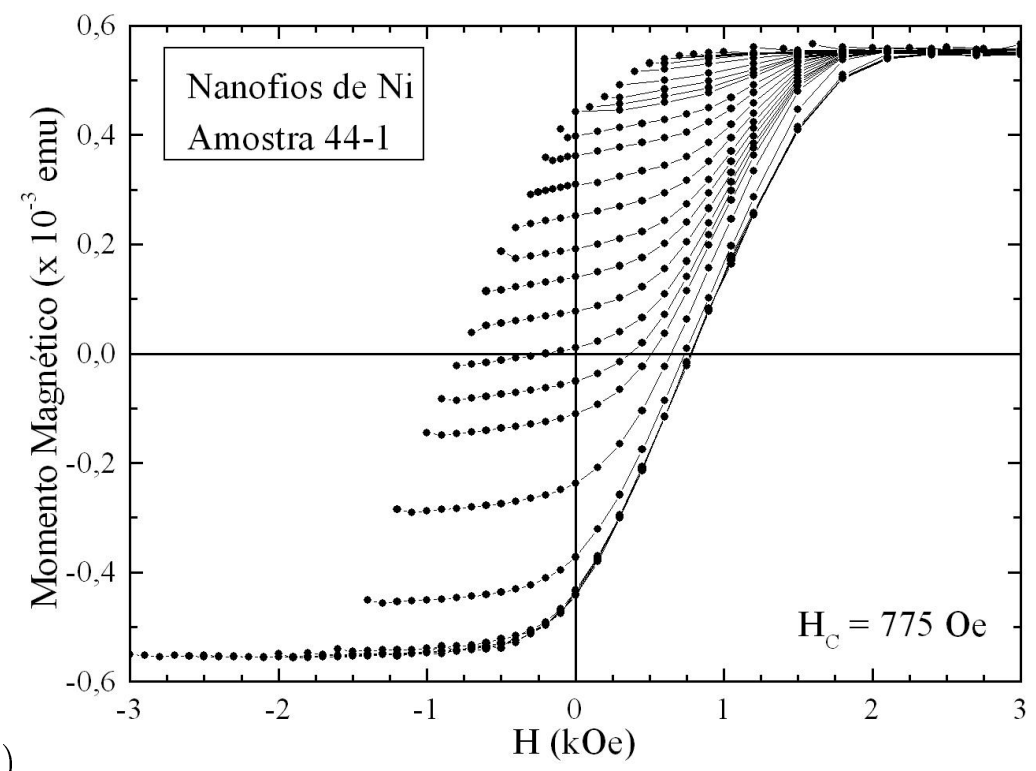

(a)

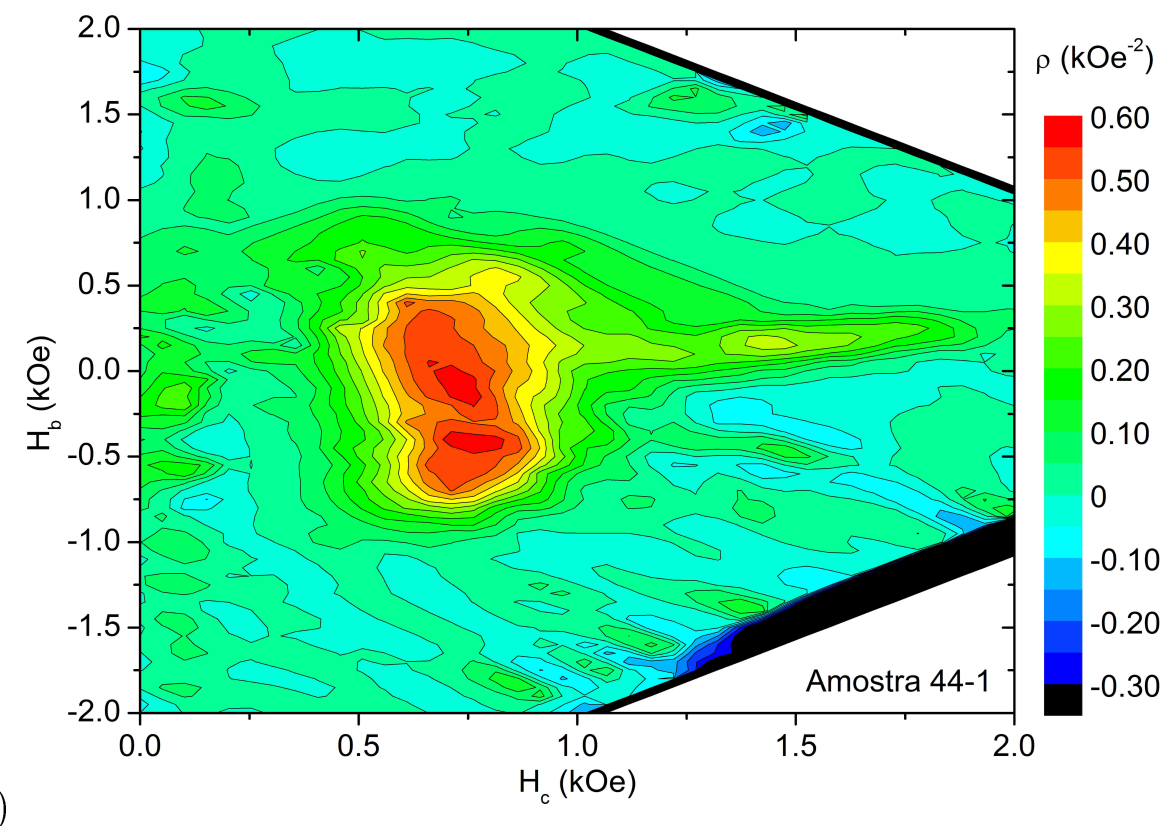

(b)

Figura 3.27: FORCs experimentais (a) e diagrama FORC (b) da amostra de nanofios de Ni anodizada a $V_{a n}=18 \mathrm{~V}, \operatorname{com}\langle D\rangle=38 \mathrm{~nm}$. 


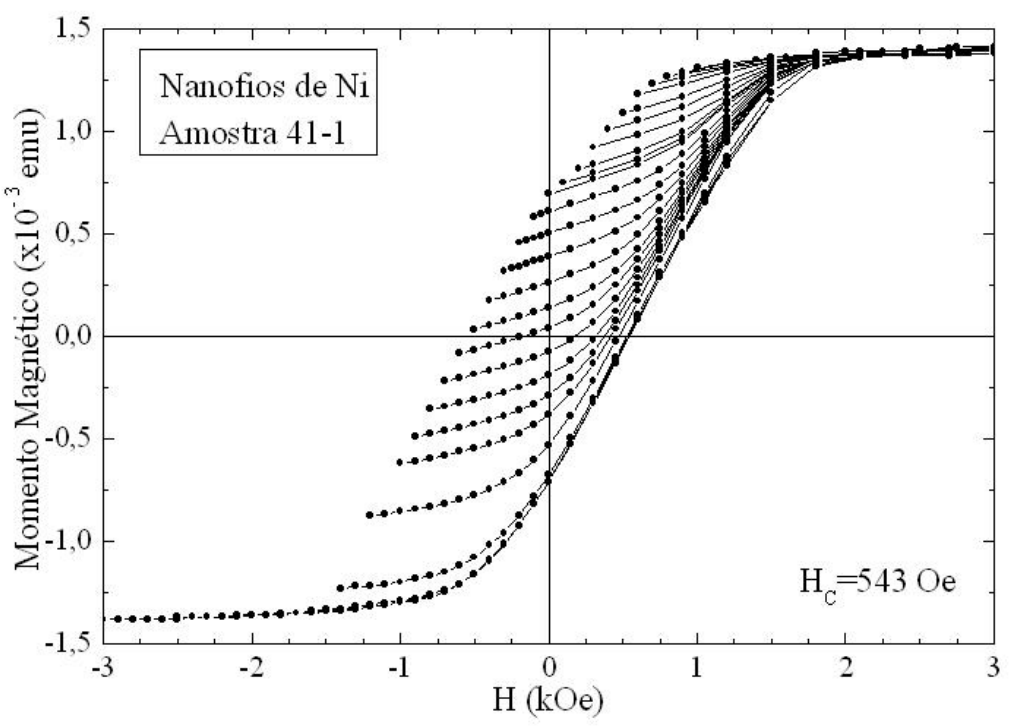

(a)

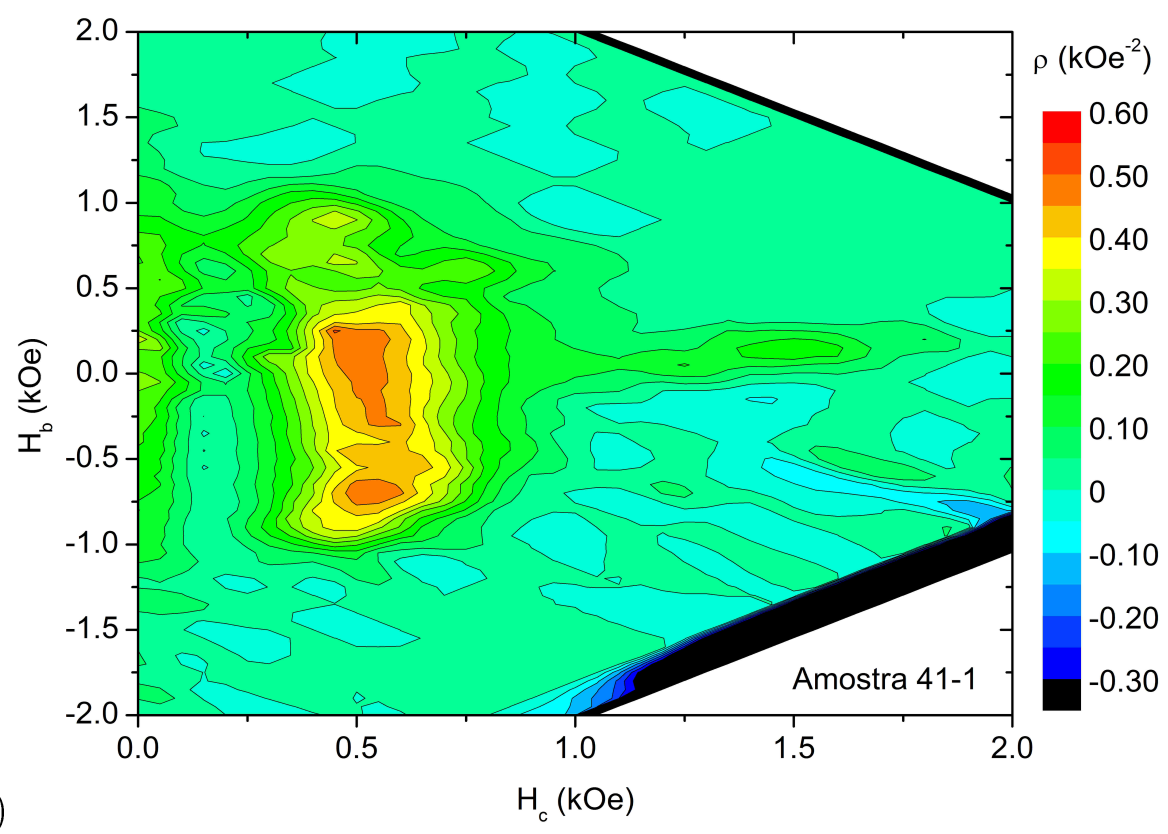

Figura 3.28: FORCs (a) e diagrama FORC (b) da amostra de nanofios de Ni anodizada a $V_{a n}=20 V, \operatorname{com}\langle D\rangle=42 \mathrm{~nm}$. 


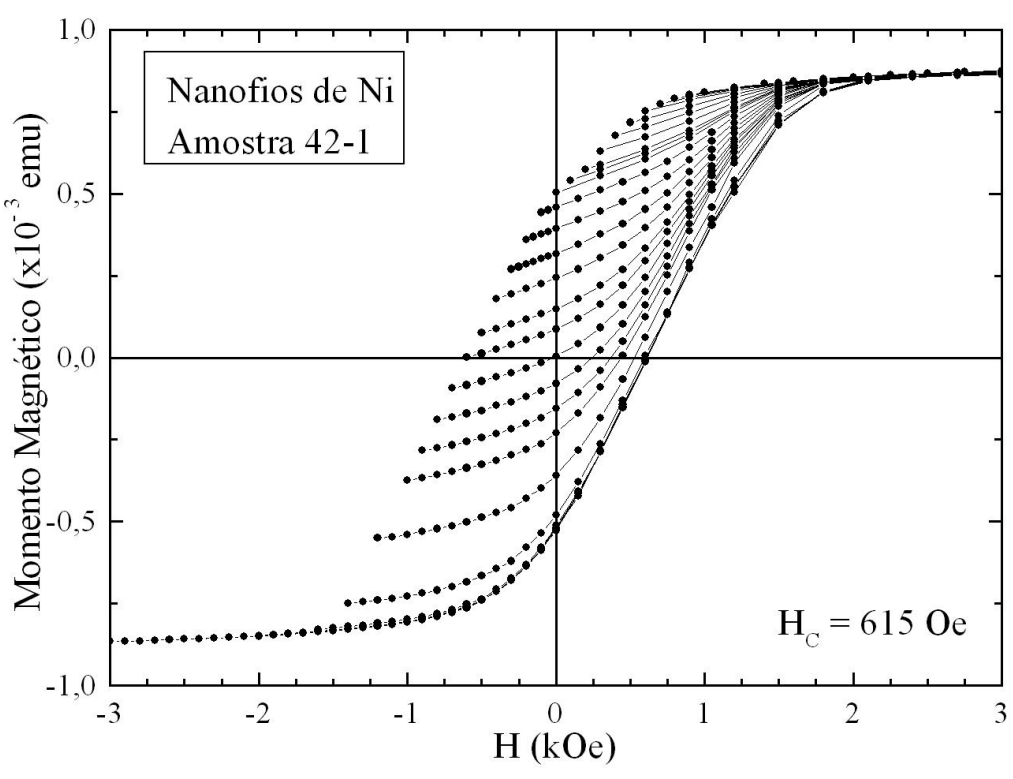

(a)

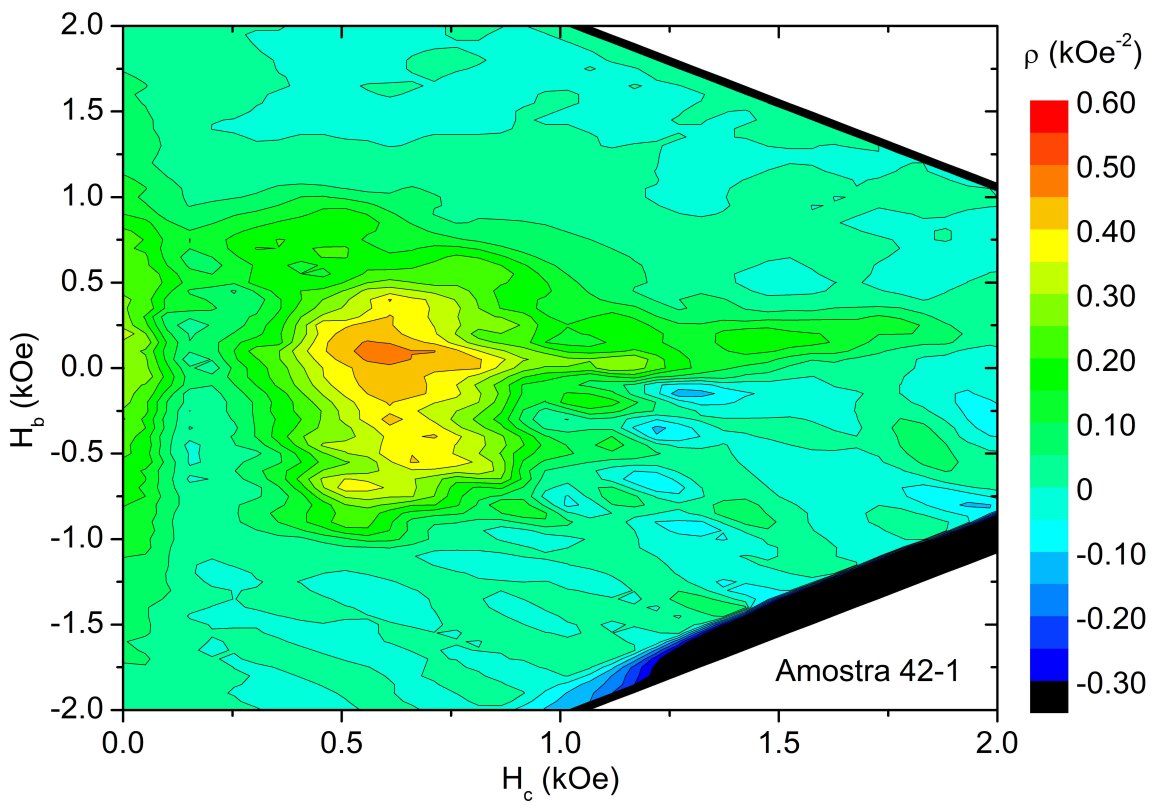

(b)

Figura 3.29: FORCs (a) e diagrama FORC (b) da amostra de nanofios de Ni anodizada a $V_{a n}=30 \mathrm{~V}, \operatorname{com}\langle D\rangle=48 \mathrm{~nm}$. 
entre $\rho\left(H_{c}, H_{b}\right)$ e a distribuição de Preisach, como as regiões de $\rho<0$. Há ainda uma tendência da distribuição se deslocar para $H_{b}=0$, para altos valores de $H_{c}$, formando uma "cauda" nessa região, como se partículas fortemente bloqueadas não sentissem nenhum campo de interação local. Assim sendo, o que essa abordagem permite é distinguir o caráter magnetizante ou desmagnetizante efetivo das interações.

Para verificar essas características, construímos as projeções de $\rho\left(H_{c}, H_{b}\right)$ sobre os eixos $H_{c}=0$ e $H_{b}=0$ nas figuras 3.30(a e b), respectivamente. Na figura 3.30(a), vemos a distribuição de campos de interação para o pico reversível de cada amostra. Vemos que esses picos são levemente assimétricos em torno de $H_{b}=0$, sendo a amostra 44-1 $\left(V_{a n}=18 \mathrm{~V}\right)$ visivelmente a mais assimétricade todas, com o pico principal em torno de 750 Oe e claramente desdobrado. Esta característica é associada a uma forte componente irreversível devido a eventos de inversão sob forte influência (interação) da vizinhança [55, 61, 91, 92, 94]. Alguns autores explicam a assimetria desse pico como um acoplamento entre as componentes reversíveis e irreversíveis da magnetização [29, 55, 91], manifestando-se inclusive nas curvas $M_{r e v}\left(M_{i r r}\right)$ de maneira inédita [29, 93]. Os valores negativos de $\rho$ nesse regime estão associados à viscosidade magnética presente quando o campo aplicado é invertido. Nesse caso, a susceptibilidade magnética diferencial é negativa no início de algumas FORCs.

Na figura 3.30(b), vemos a distribuição de campos de inversão para $H_{b}=0$. A proporção entre o pico reversível e o pico principal (predominantemente irreversível) representa a relação entre as componentes reversíveis e irreversíveis em cada amostra. Esses picos podem ainda representar duas populações de partículas: uma distribuição normal de pequenas partículas tipo Stoner-Wohlfarth (reversíveis) e outra log-normal de partículas bloqueadas (pinned), tipicamente irreversíveis. As amostras $41-1\left(V_{a n}=20 \mathrm{~V}\right)$ e 42-1 $\left(V_{a n}=30 \mathrm{~V}\right)$ têm os maiores diâmetros médios e poros menos circulares, o que pode favorecer a nucleação de modos de inversão não-uniformes, como formação de vórtices ao longo do fio (curling). Este modo de inversão é caracterizado por altas comonentes reversíveis de magnetização e o acoplamento entre as componentes reversíveis e irreversíveis [29], principalmente para campos mais altos que o campo de inversão do material. Como podemos observar nos gráficos da figura 3.30, estas amostras são as mais reversíveis e mais assimétricas para $H_{c}=0$. Isto pode ser uma evidência deste modo de inversão de 


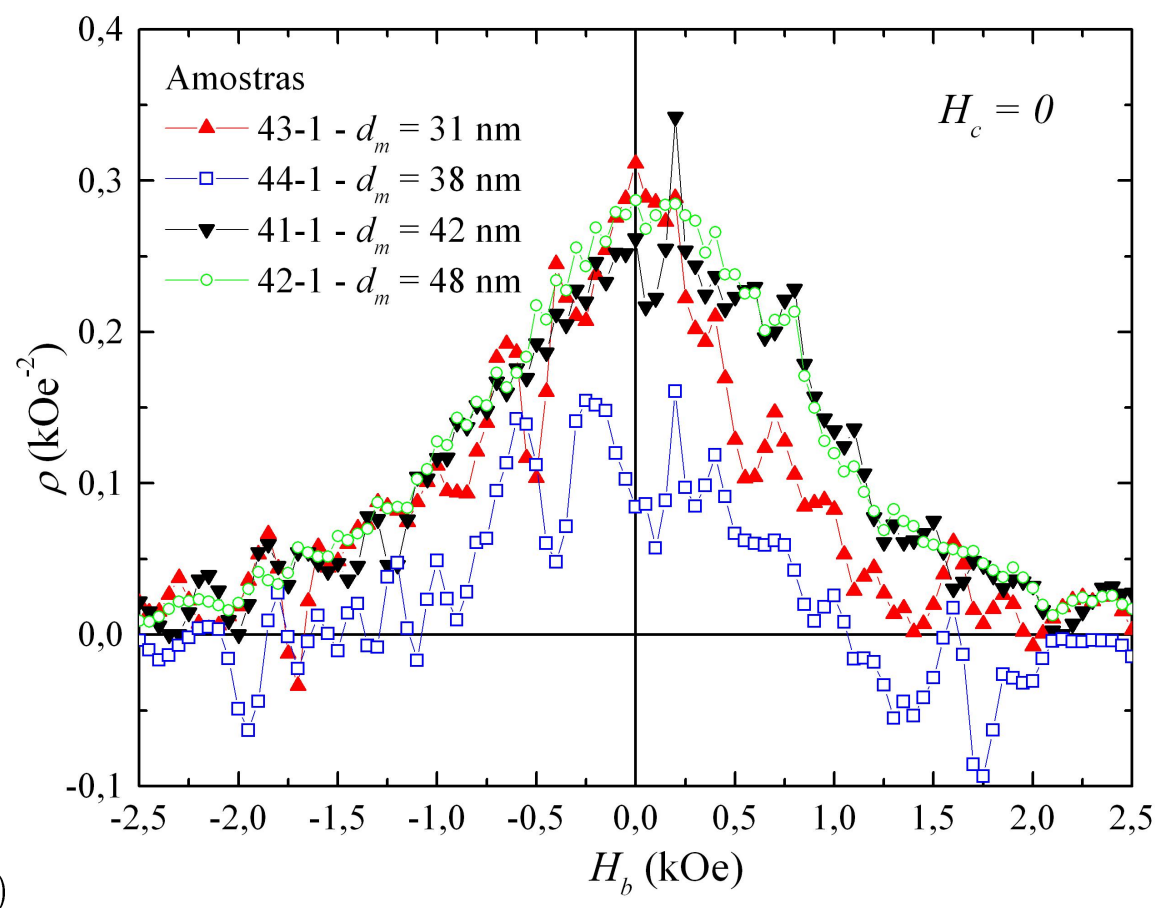

(a)

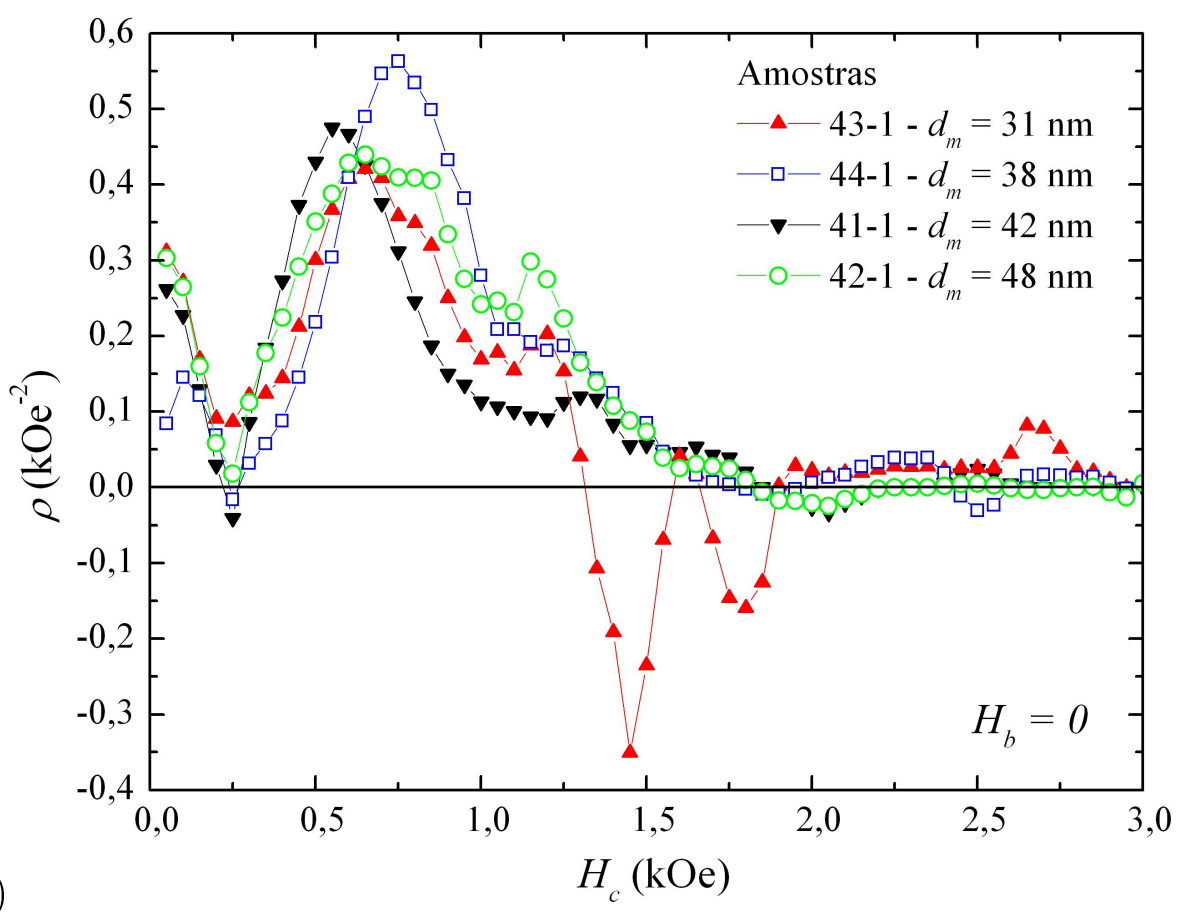

Figura 3.30: Perfil da distribuição FORC das amostras 43-1 $\left(V_{a n}=15 \mathrm{~V}\right)$ a $42-1\left(V_{a n}=30 \mathrm{~V}\right)$ para (a) $H_{c}=0$ e (b) $H_{b}=0$. 
magnetização [24, 61] nesses sistemas.

Na figura 3.31(a), mostramos o perfil do máximo absoluto das distribuições FORC em função de $H_{b}$. Para cada amostra, o máximo ocorre em diferentes valores de $H_{c}$, todos em torno da coercividade do material. A assimetria da distribuição para $H_{b}<0$ é mais forte nessa região. Entretanto, vários autores [61, 92, 94] indicam que a largura a meia altura (FWHM) vertical (ao longo de $\left.H_{b}\right)$ de $\rho\left(H_{c}, H_{b}\right)$ pode ser vista como uma medida do campo de interação local $H_{\text {int }}$ num sistema [30, 61, 92]. Então, medimos a posição e a largura do pico principal de cada diagrama FORC e representamos seus comportamentos em função do diâmetro médio, juntamente com a coercividade de cada material, na figura $3.31(b)$.

Podemos ver que o pico principal é sempre negativo, mas tende a zero à medida que o diâmetro médio aumenta. Em outras palavras, o campo médio desmagnetizante diminui à medida que a distância entre os nanofios aumenta, trazendo o pico para o centro do diagrama. Isso também foi observado por Stancu et al. [95] em amostras que transitam de um comportamento tipo monodomínio para um comporamento tipo multidomínio, ou seja, em função do aumento dos grãos cristalinos, como ocorre com os nanofios de Ni. Além disso, à medida que a posição do pico tende a zero (i.e., o campo médio diminui em módulo), a coercividade diminui. Como é de se esperar, a diminuição do campo desmagnetizante tende a facilitar o processo de magnetização. Além disso, à medida que o diâmetro dos fios aumenta, a razão de aspecto dos fios diminui, diminuindo também a magnitude da anisotropia de forma. Assim, esperamos um comportamento semelhante para o campo desmagnetizante intrínseco dos nanofios.

A largura do pico aparentemente tende a aumentar com o diâmetro médio. Entretanto, como a largura do pico está relacionada ao campo de interação local (em cada grão magnético), esperamos que o $H_{\text {int }}$ dependa mais fortemente da morfologia (anisotropias magneto-cristalina, de forma, etc.) e da interação do grão magnético com sua vizinhança (exchange coupling) do que do diâmetro do fio. Assim, $H_{\text {int }}$ deve depender diretamente do tamanho de grão, que por sua vez cresce com o diâmetro dos poros (figura 3.23). Então, à medida que os grãos cristalinos crescem, observamos um aumento da largura do pico, indicando que o campo de interação local é proporcional ao volume de material magnético na vizinhança. Portanto, o acoplamento de troca entre as partículas deve se 


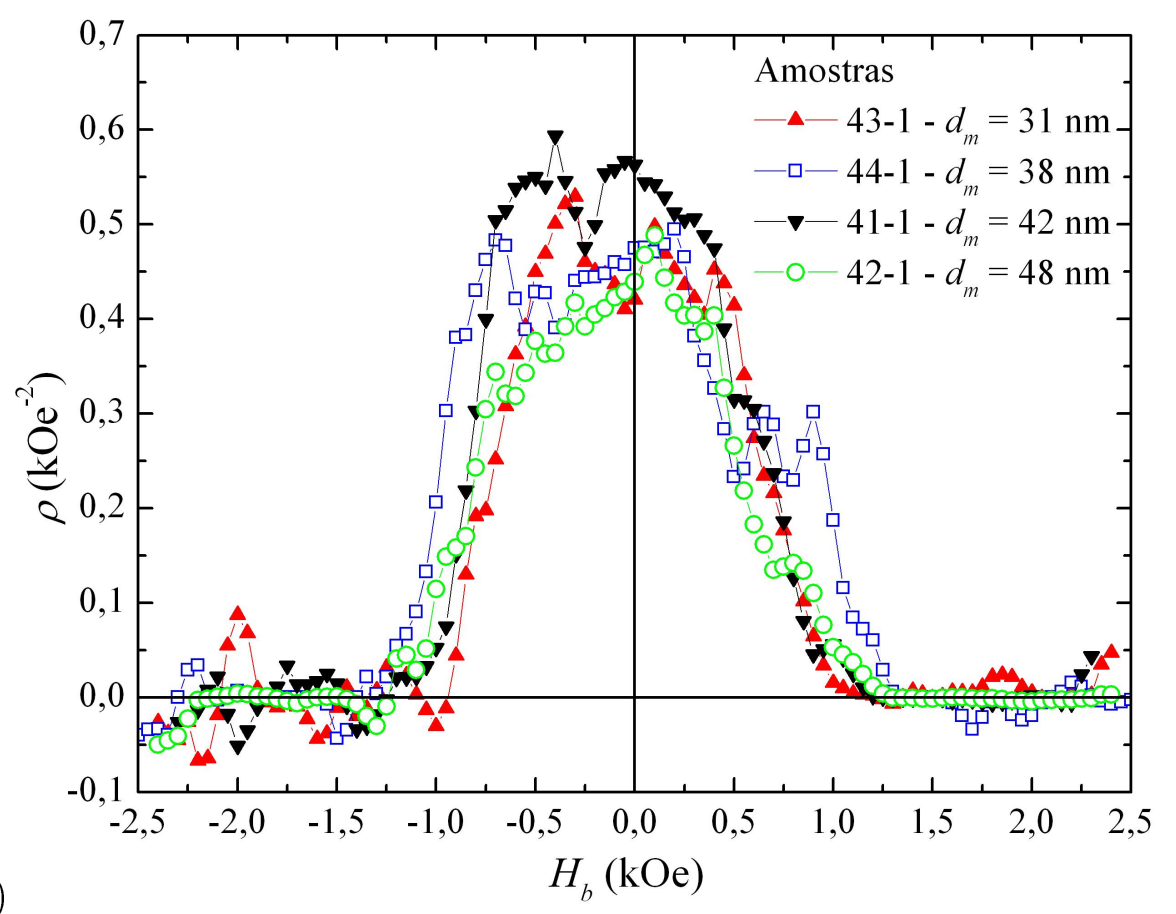

(a)

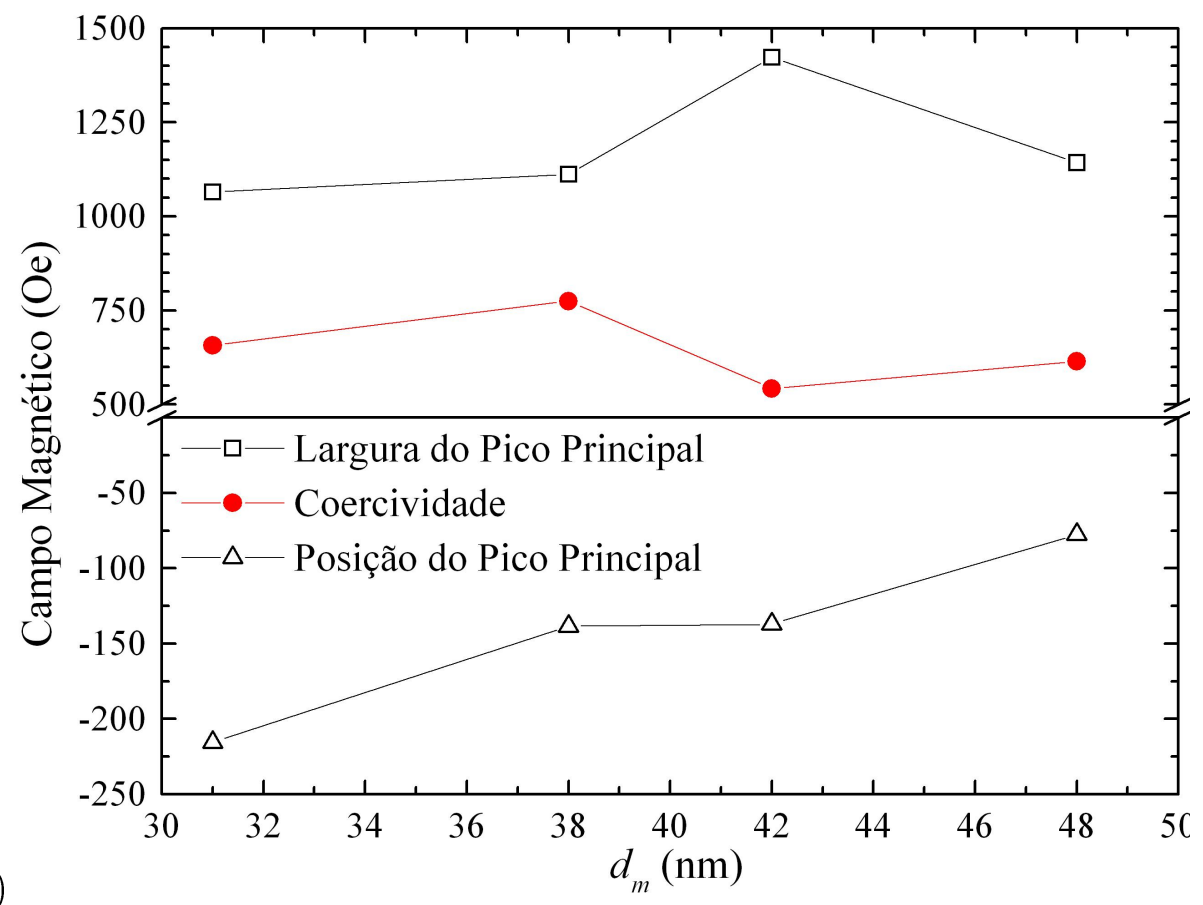

Figura 3.31: (a) Pico principal da distribuição FORC de cada uma das amostras para $H_{c}$ fixo e (b) comportamento da coercividade, da posição e da largura do pico principal de cada amostra em função do diâmetro médio. 
tornar mais forte à medida que o diâmetro dos fios crescem. Como esta é uma interação magnetizante, cooperativa, ela tende a contrabalancear a ação do campo dipolar entre fios. Portanto, há pelo menos dois efeitos competitivos presentes na fenomenologia de nanofios magnéticos: o acoplamento de troca cooperativo intra-fio, que tende a manter a magnetização do sistema; e a interação dipolar inter-fio, que tende a desmagnetizar o sistema. Esses efeitos certamente influenciam no modo de inversão da magnetização e nas propriedades magnéticas macroscópicas desses sistemas [45].

Uma outra representação dos resultados que o programa permite obter é a mostrada nas figuras 3.32 a 3.35. Nesta representação, mapeamos a distribuição FORC diretamente sobre o ciclo de histerese do material. Isso torna evidente onde estão presentes as contribuições reversíveis e irreversíveis durante o processo de inversão de magnetização, como a presença da viscosidade magnética ao longo da "margem esquerda" da histerese e a processos fortemente irreversíveis ao longo da "margem direita". Além disso, tendências mais sutis saltam aos olhos nesta representação, como por exemplo, à medida que o diâmetro médio das amostras aumenta (figs. $3.32 \rightarrow 3.35$ ), o máximo absoluto da distribuição "migra" do quarto quadrante para o primeiro quadrante, ao longo de uma diagonal que acompanha a inclinação natural da histerese. Isso significa que para nanofios mais largos os principais processos irreversíveis de inversão ocorrem a campos mais altos. Há também um comportamento transiente (figs. 3.33 e 3.34 ) em que os dois picos (no $1^{\circ}$ e no $4^{\circ}$ quadrantes) estão presentes.

Nas figuras 3.36 a 3.42, vemos os resultados das medidas de FORCs e seus respectivos diagramas FORC em nanofios de Co, em função do ângulo $\theta$ entre a direção do campo magnético aplicado e o eixo de anisotropia das amostras (perpendicular à superfície). Estas medidas foram realizadas no VSM do LMM-DFMT, a temperatura ambiente, com campo de saturação $H_{\max }=20 \mathrm{kOe}$. Os arranjos de nanofios de Co exibiram altas coercividades, entre 630 Oe $\left(\theta=90^{\circ}\right)$ e 1780 Oe $\left(\theta=0^{\circ}\right)$. A variação da forma das histereses com o ângulo $\theta$ atesta claramente a formação de nanofios com forte anisotropia perpendicular de forma. Os diagramas FORC, por sua vez, mostraram-se um tanto diferentes daqueles obtidos para as amostras de Ni: a forma de "dois-ramos" da distribuição, típica de arranjos de nanofios [55], aparece mais difusa no caso do Co, embora ainda reconhecível. Isso pode ser efeito do valor mais alto de $n_{v i z}=3$ utilizado no cálculo das distribuições 


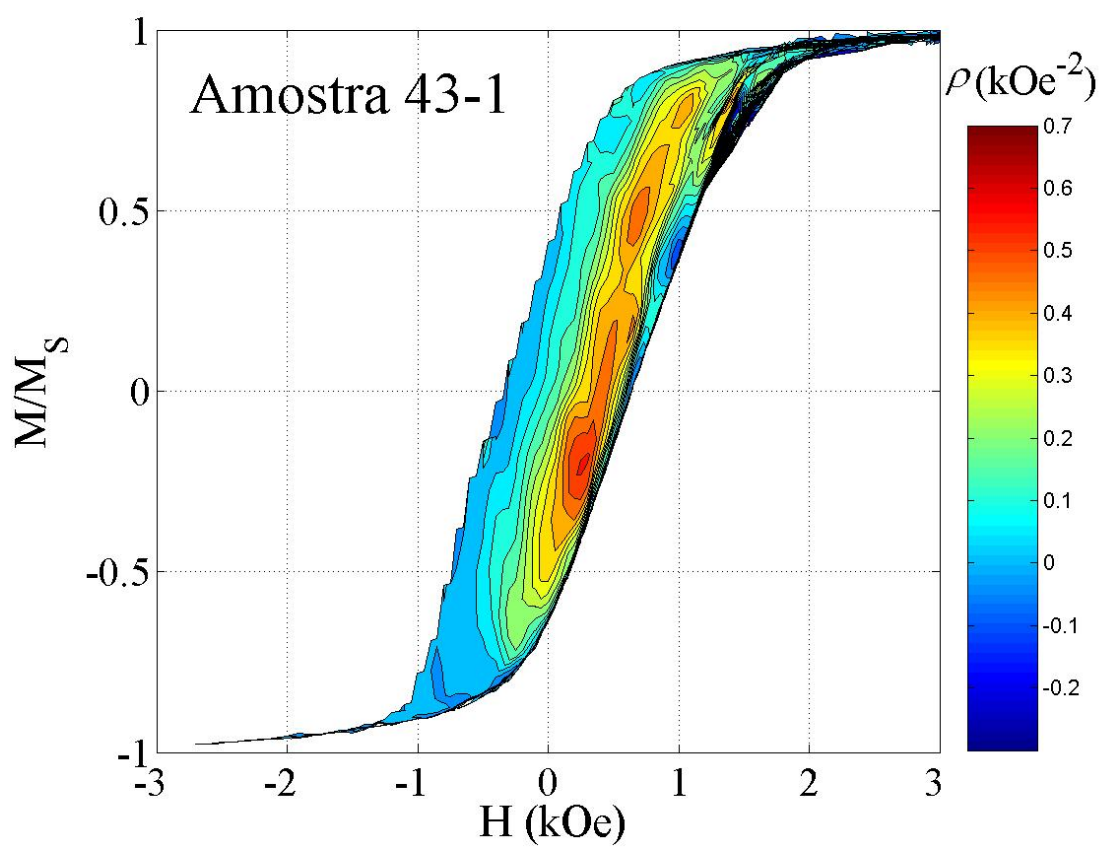

Figura 3.32: Distribuição FORC da amostra de nanofios de Ni 43-1 ( $V_{a n}=15 \mathrm{~V}$ de nanofios de $\mathrm{Ni},\langle D\rangle=31 \mathrm{~nm})$ representada sobre a própria histerese.

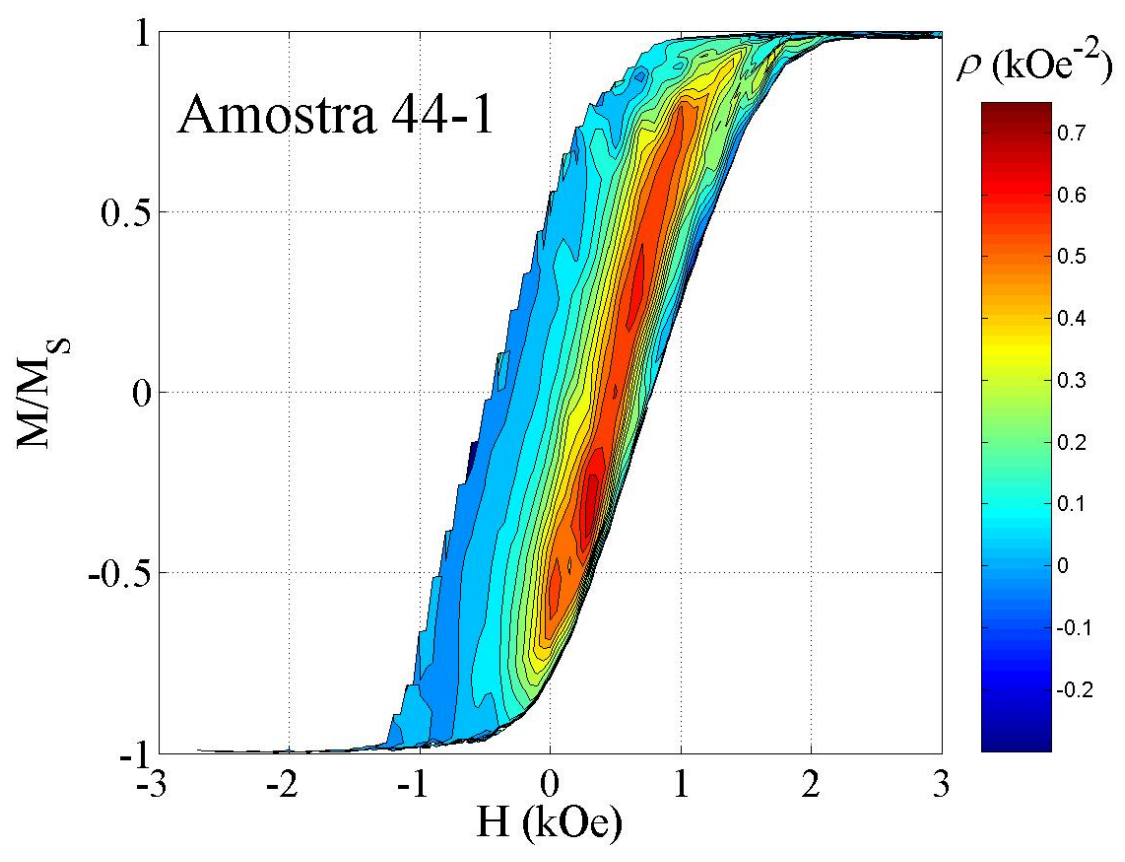

Figura 3.33: Distribuição FORC da amostra de nanofios de Ni 44-1 ( $V_{a n}=18 \mathrm{~V}$ de nanofios de $\mathrm{Ni},\langle D\rangle=38 \mathrm{~nm})$ representada sobre a própria histerese. 


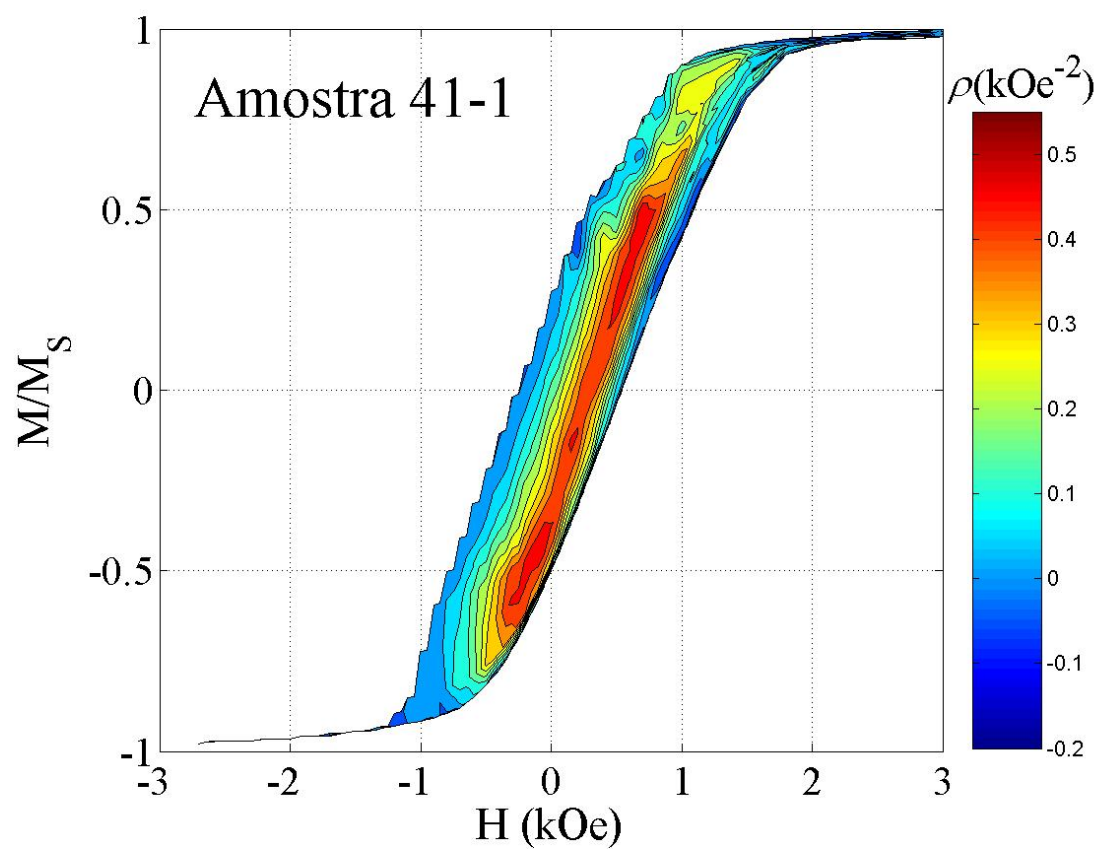

Figura 3.34: Distribuição FORC da amostra de nanofios de Ni 41-1 $\left(V_{a n}=20 \mathrm{~V}\right.$ de nanofios de $\mathrm{Ni},\langle D\rangle=42 \mathrm{~nm}$ ) representada sobre a própria histerese.

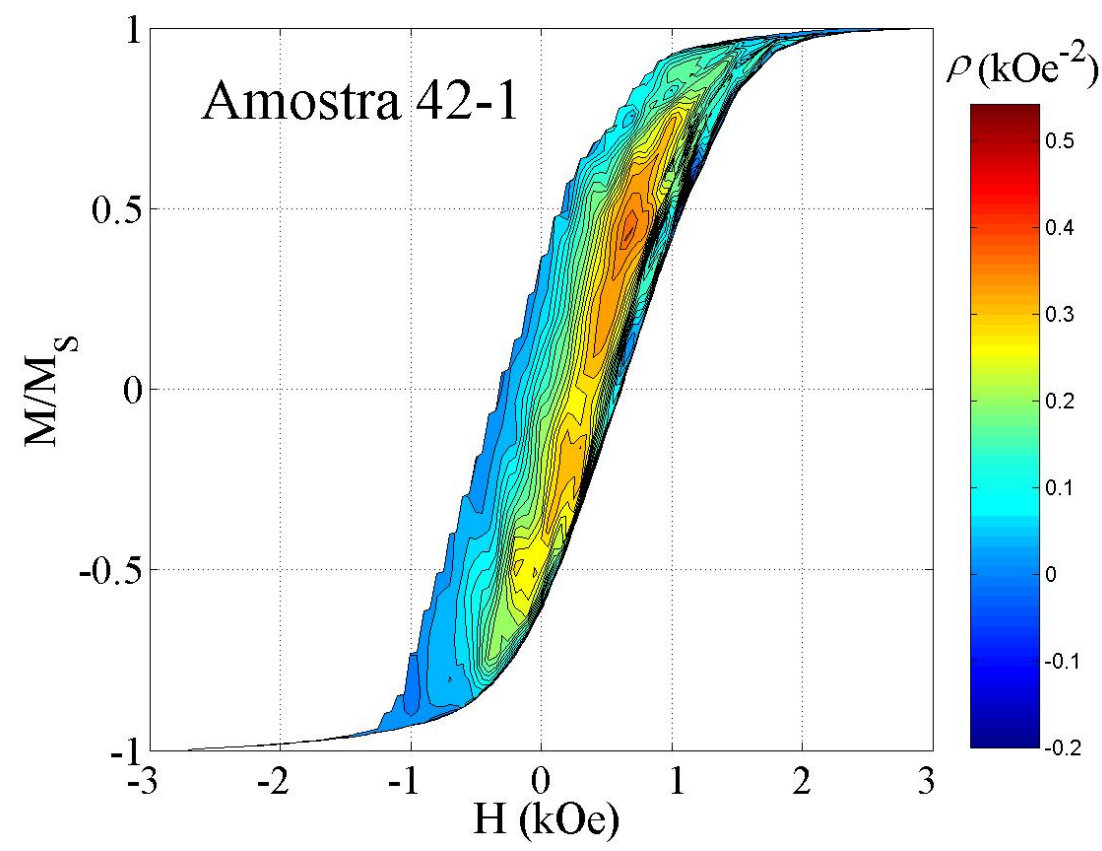

Figura 3.35: Distribuição FORC da amostra de nanofios de Ni $42-1$ ( $V_{a n}=30 \mathrm{~V}$ de nanofios de $\mathrm{Ni},\langle D\rangle=48 \mathrm{~nm})$ representada sobre a própria histerese. 


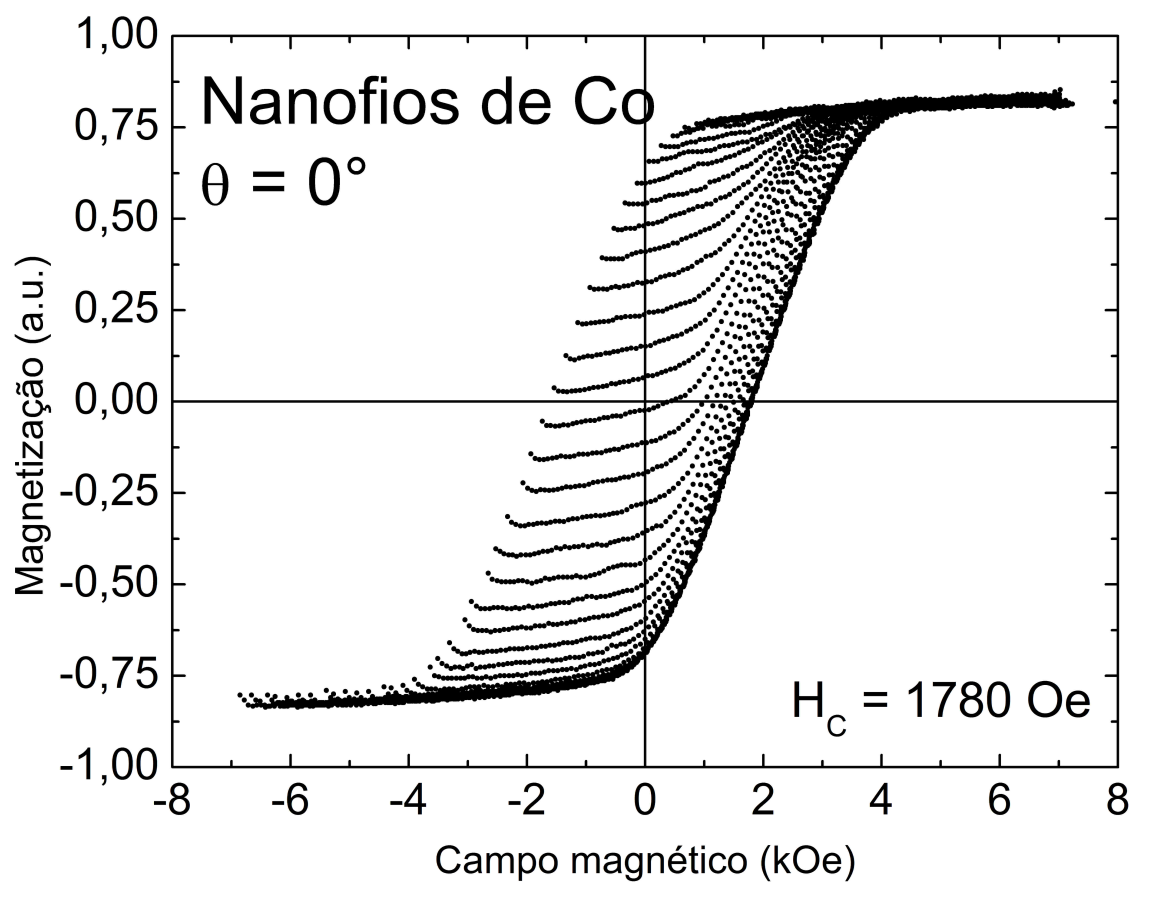

(a)

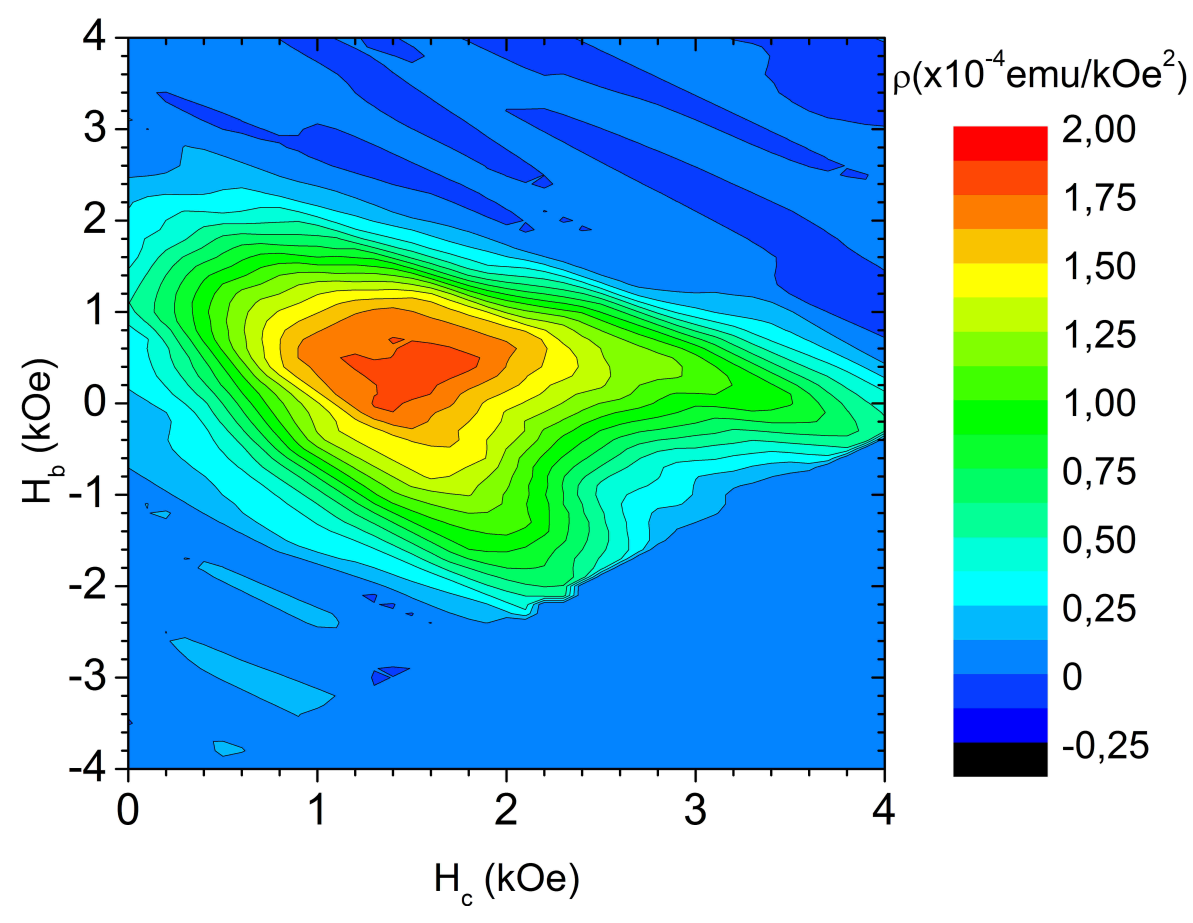

Figura 3.36: FORCs (a) e correspondentes diagramas FORC (b) de uma amostra de nanofios de Co $\left[5^{\circ} \mathrm{C},(\mathrm{COOH})_{2}\right.$, a $0,3 \mathrm{~mol} / \mathrm{L}, V_{a n}=25 \mathrm{~V}, 4$ horas $\left(1^{\mathrm{a}}\right) / 1$ hora $\left.\left(2^{-}\right)\right]$, para campo magnético aplicado num ângulo $\theta=0^{\circ}$ em relação à normal à superfície. 


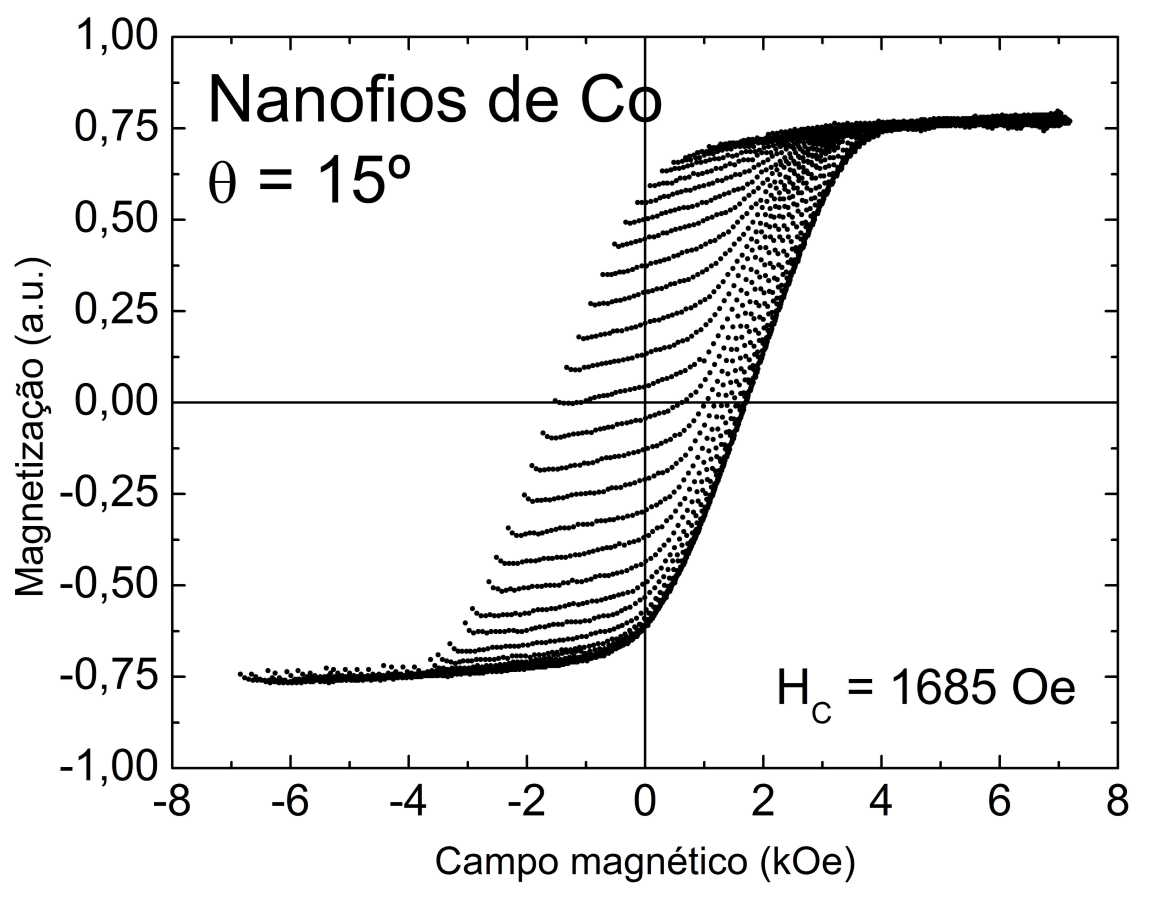

(a)

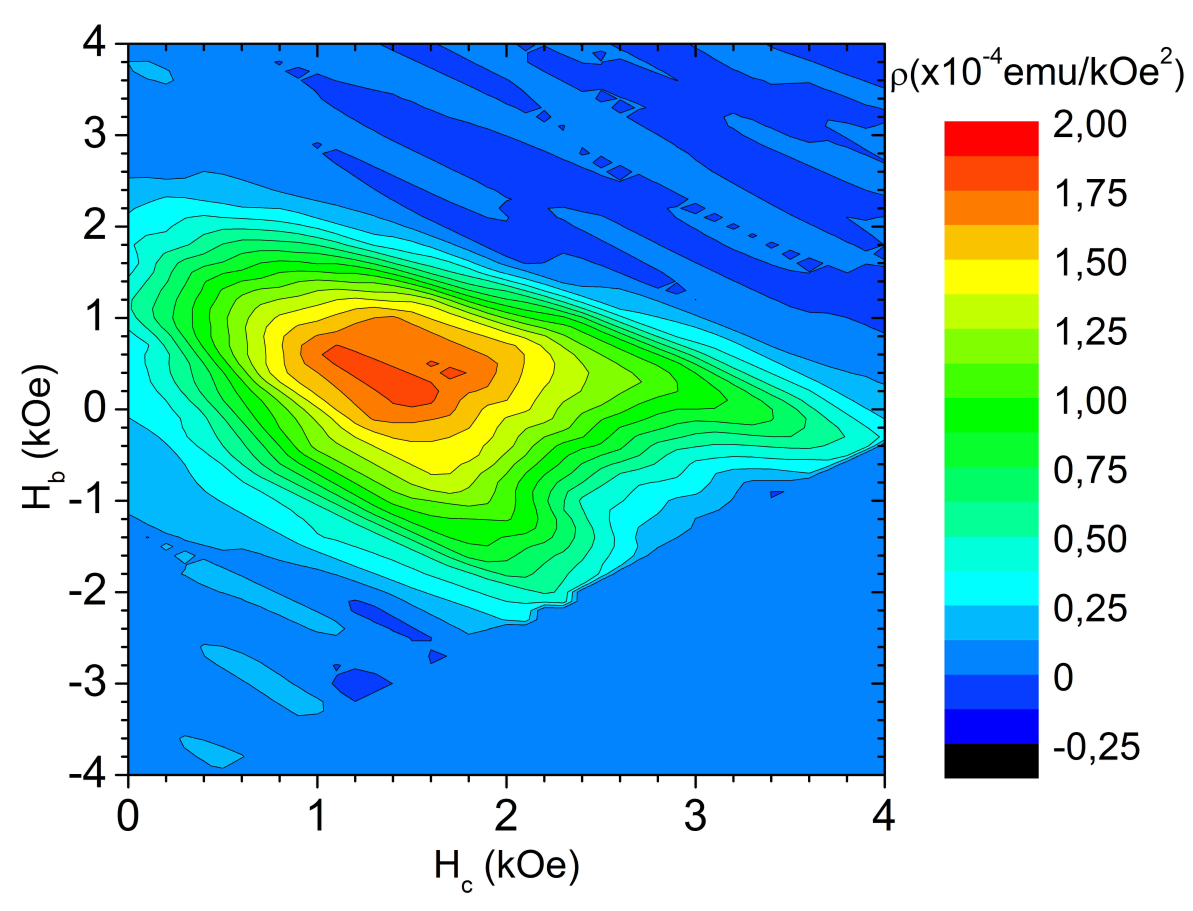

Figura 3.37: FORCs (a) e correspondentes diagramas FORC (b) de uma amostra de nanofios de Co $\left[5^{\circ} \mathrm{C},(\mathrm{COOH})_{2}\right.$, a $0,3 \mathrm{~mol} / \mathrm{L}, V_{a n}=25 \mathrm{~V}, 4$ horas $\left(1^{\mathrm{a}}\right) / 1$ hora $\left.\left(2^{-}\right)\right]$, para campo magnético aplicado num ângulo $\theta=15^{\circ}$ em relação à normal à superfície. 


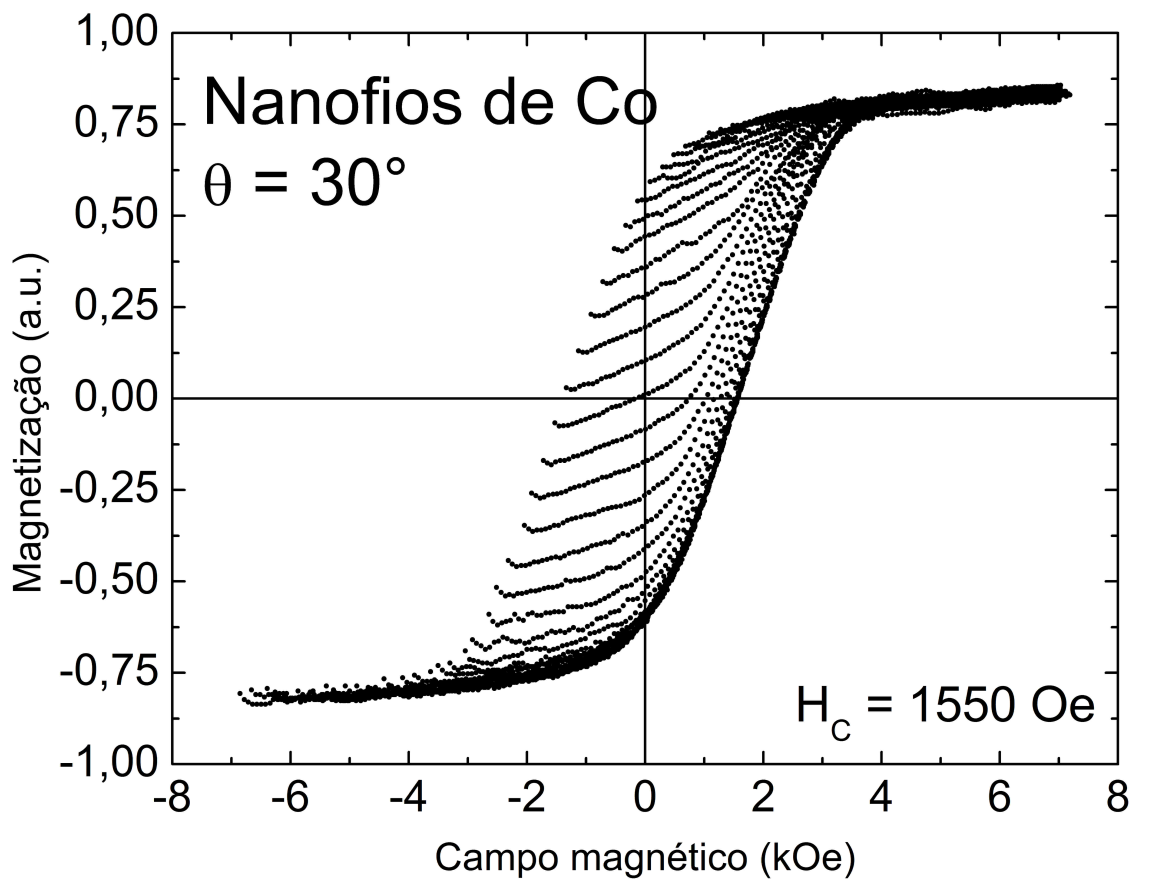

(a)

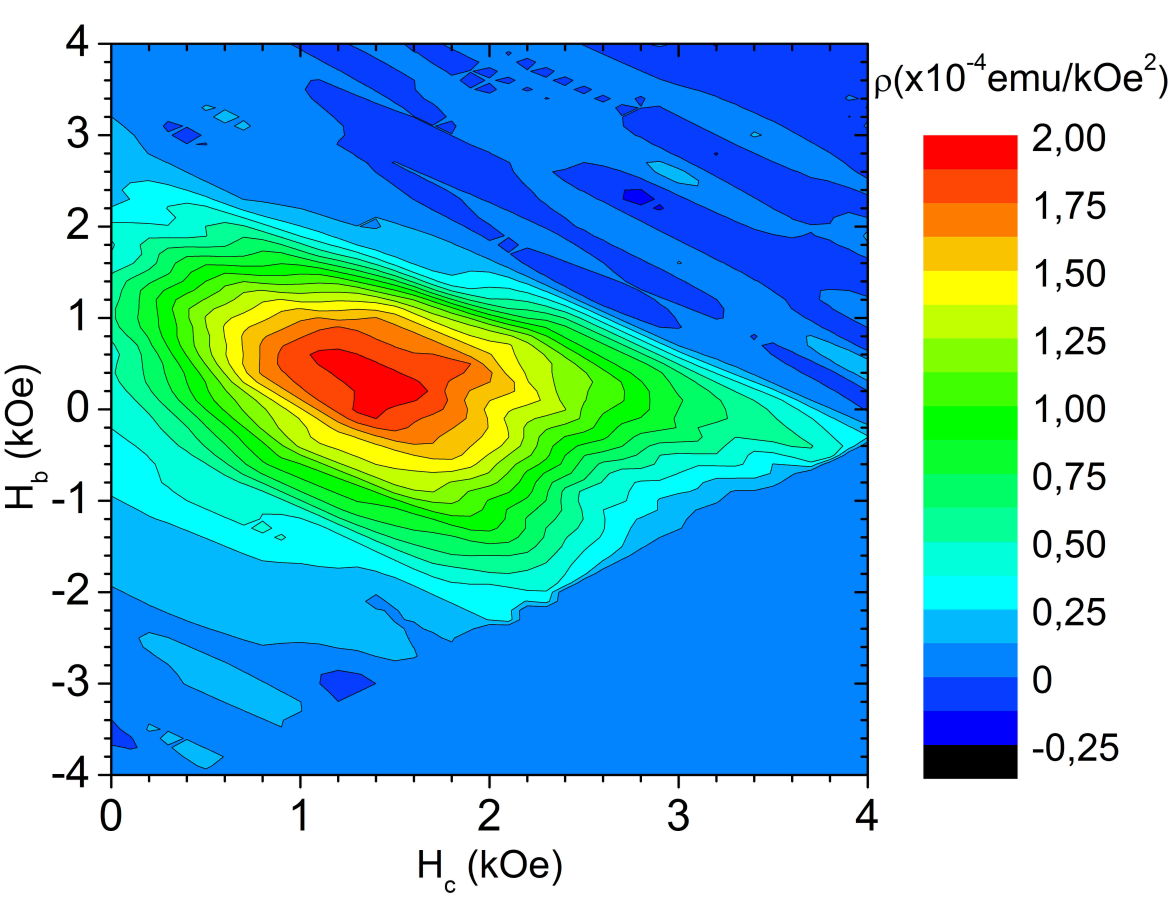

Figura 3.38: FORCs (a) e correspondentes diagramas FORC (b) de uma amostra de nanofios de Co $\left[5^{\circ} \mathrm{C},(\mathrm{COOH})_{2}\right.$, a $0,3 \mathrm{~mol} / \mathrm{L}, V_{a n}=25 \mathrm{~V}, 4$ horas $\left(1^{\mathrm{a}}\right) / 1$ hora $\left.\left(2^{-}\right)\right]$, para campo magnético aplicado num ângulo $\theta=30^{\circ}$ em relação à normal à superfície. 


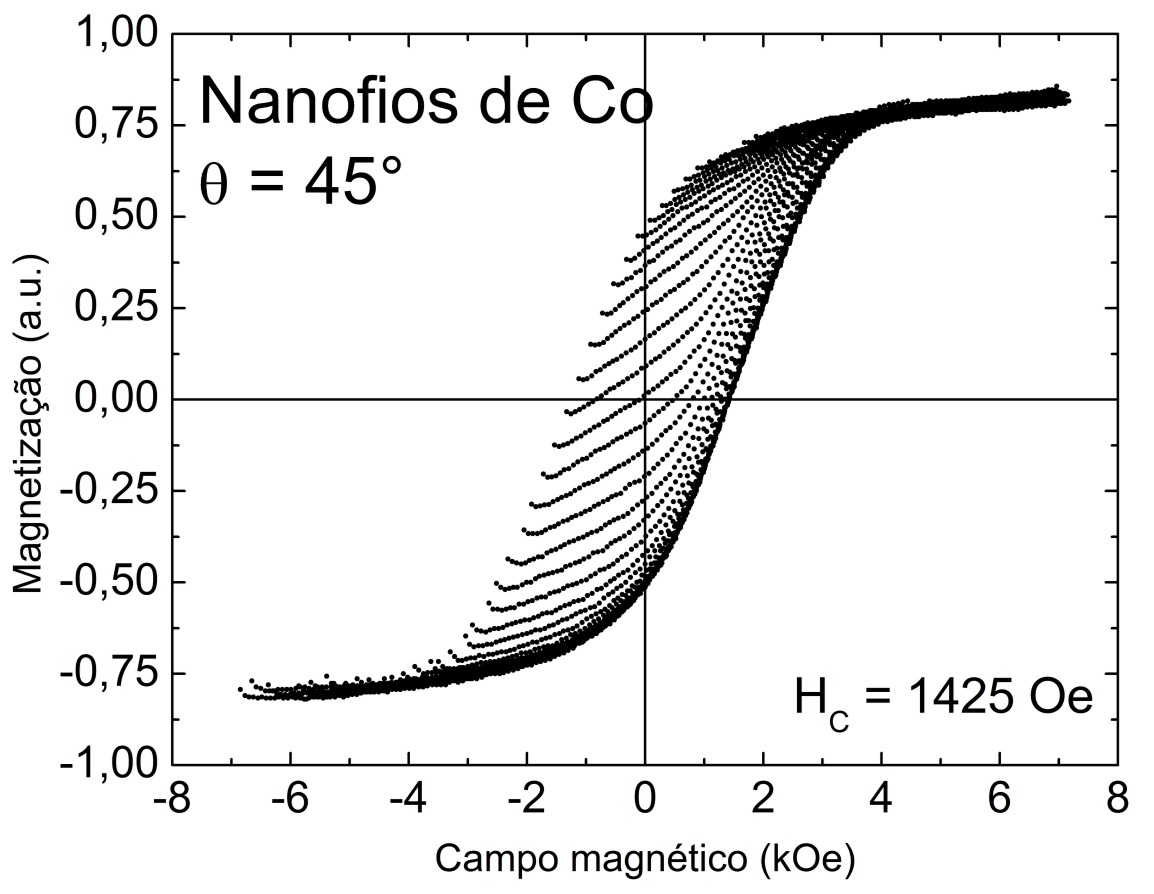

(a)

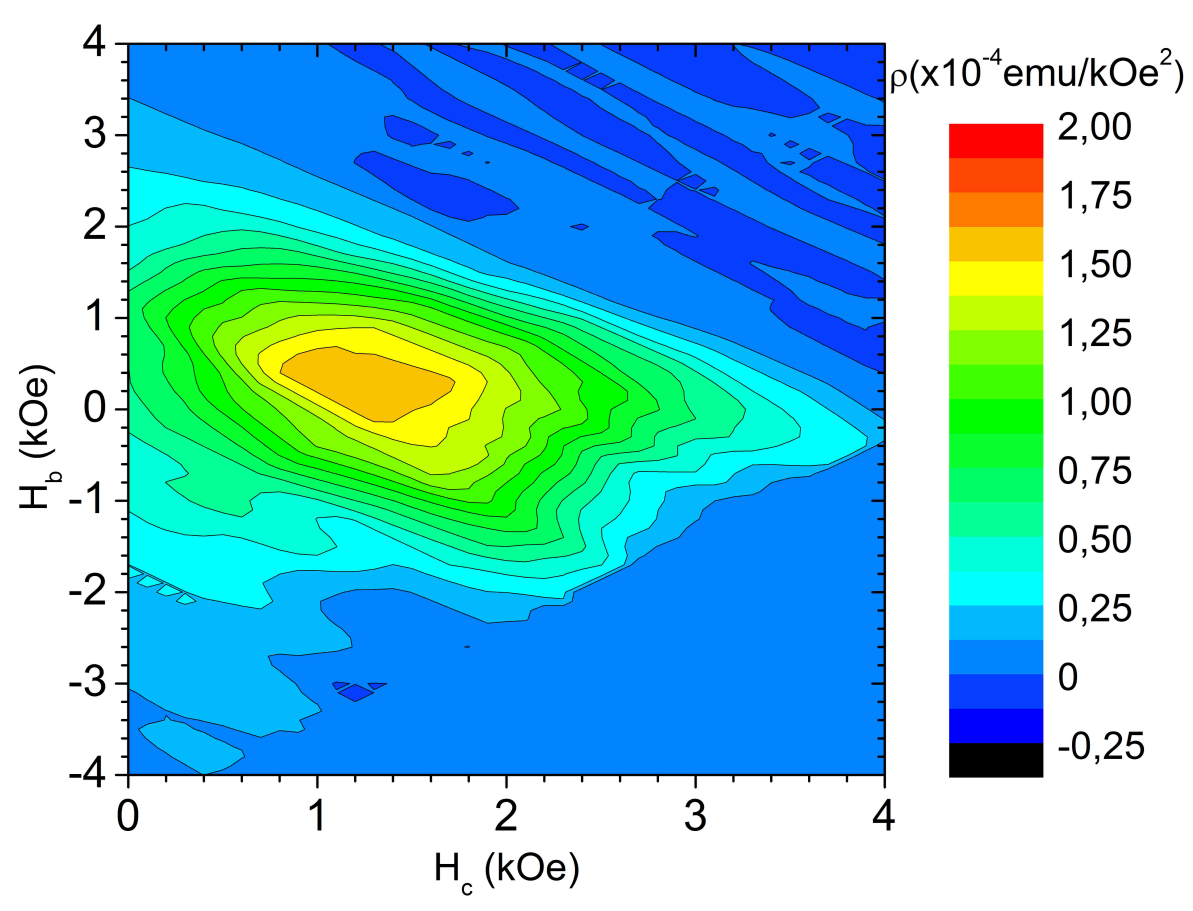

Figura 3.39: FORCs (a) e correspondentes diagramas FORC (b) de uma amostra de nanofios de Co $\left[5^{\circ} \mathrm{C},(\mathrm{COOH})_{2}\right.$, a $0,3 \mathrm{~mol} / \mathrm{L}, V_{a n}=25 \mathrm{~V}, 4$ horas $\left(1^{\mathrm{a}}\right) / 1$ hora $\left.\left(2^{-}\right)\right]$, para campo magnético aplicado num ângulo $\theta=45^{\circ}$ em relação à normal à superfície. 


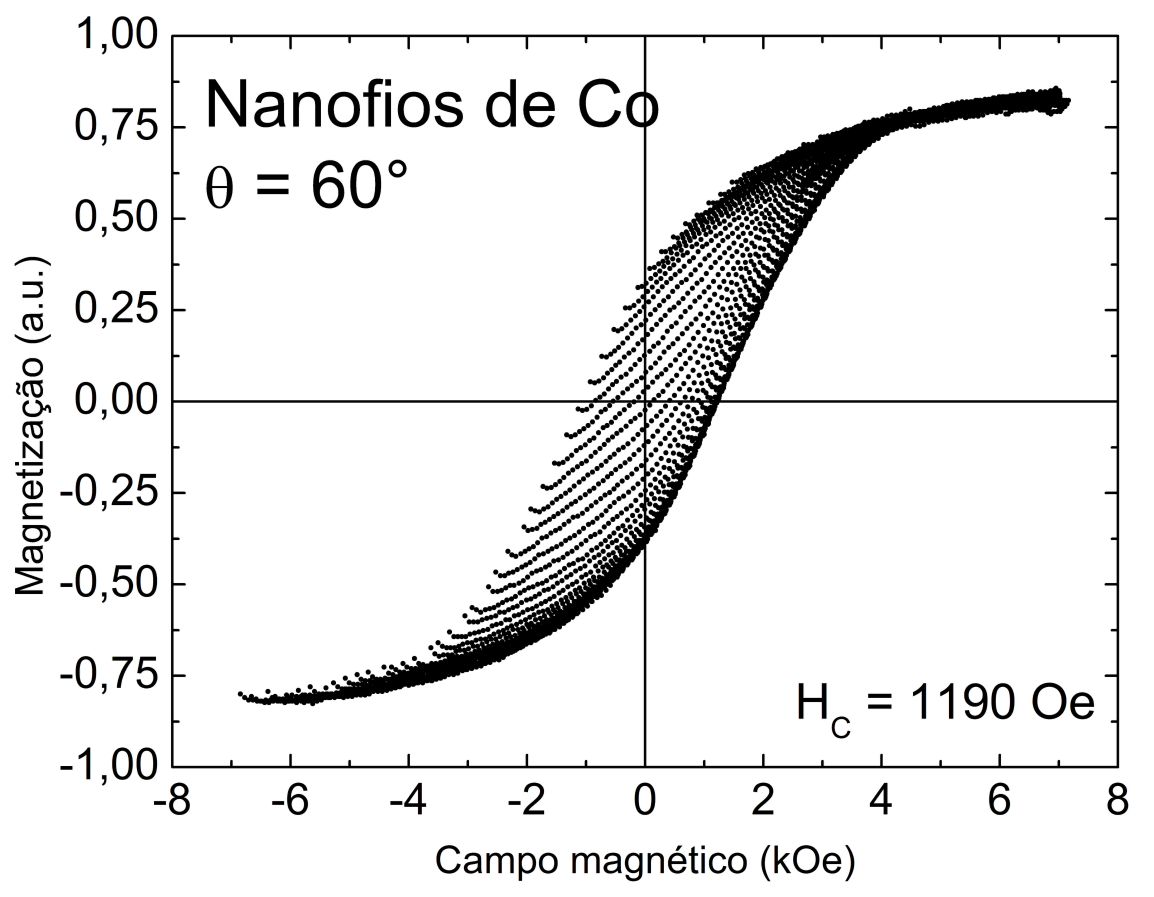

(a)

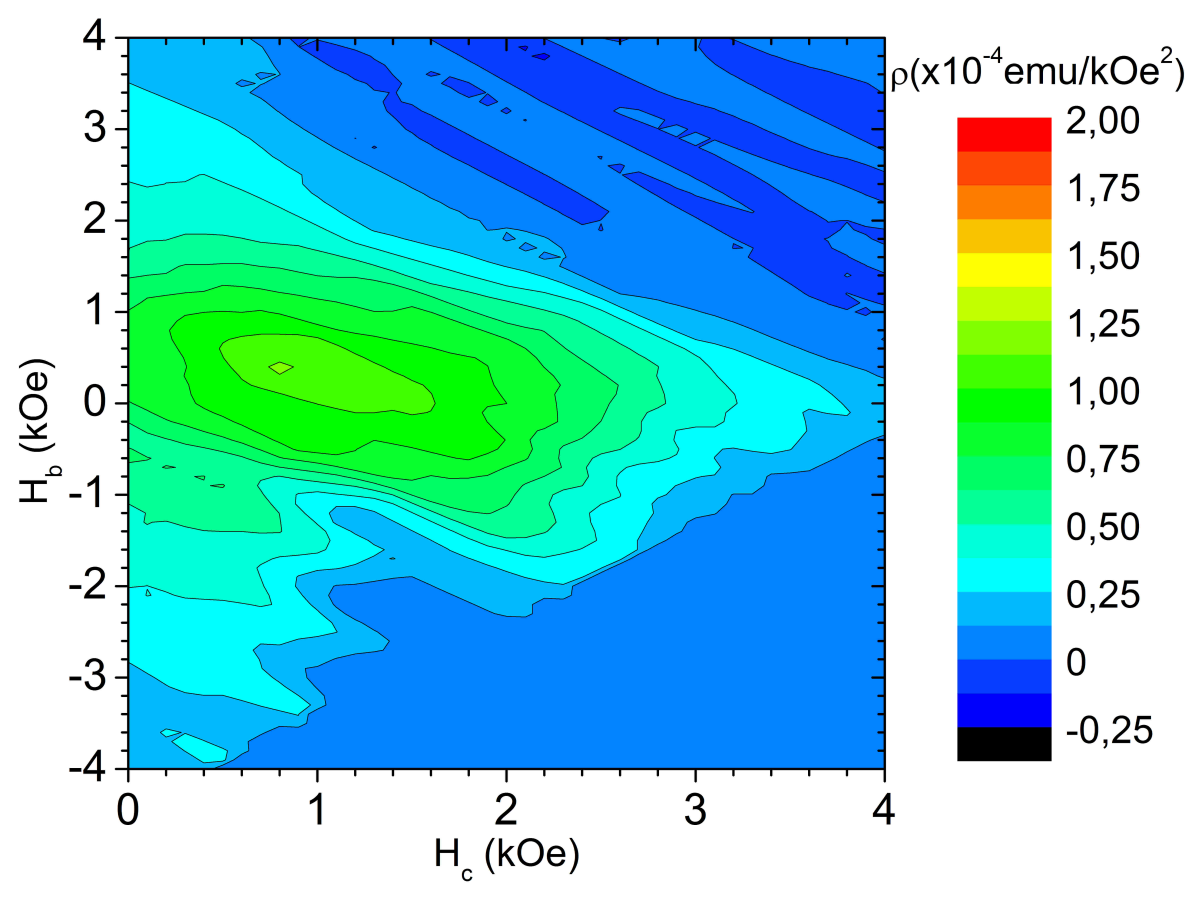

Figura 3.40: FORCs (a) e correspondentes diagramas FORC (b) de uma amostra de nanofios de Co $\left[5^{\circ} \mathrm{C},(\mathrm{COOH})_{2}\right.$, a $0,3 \mathrm{~mol} / \mathrm{L}, V_{a n}=25 \mathrm{~V}, 4$ horas $\left(1^{\mathrm{a}}\right) / 1$ hora $\left.\left(2^{-}\right)\right]$, para campo magnético aplicado num ângulo $\theta=60^{\circ}$ em relação à normal à superfície. 


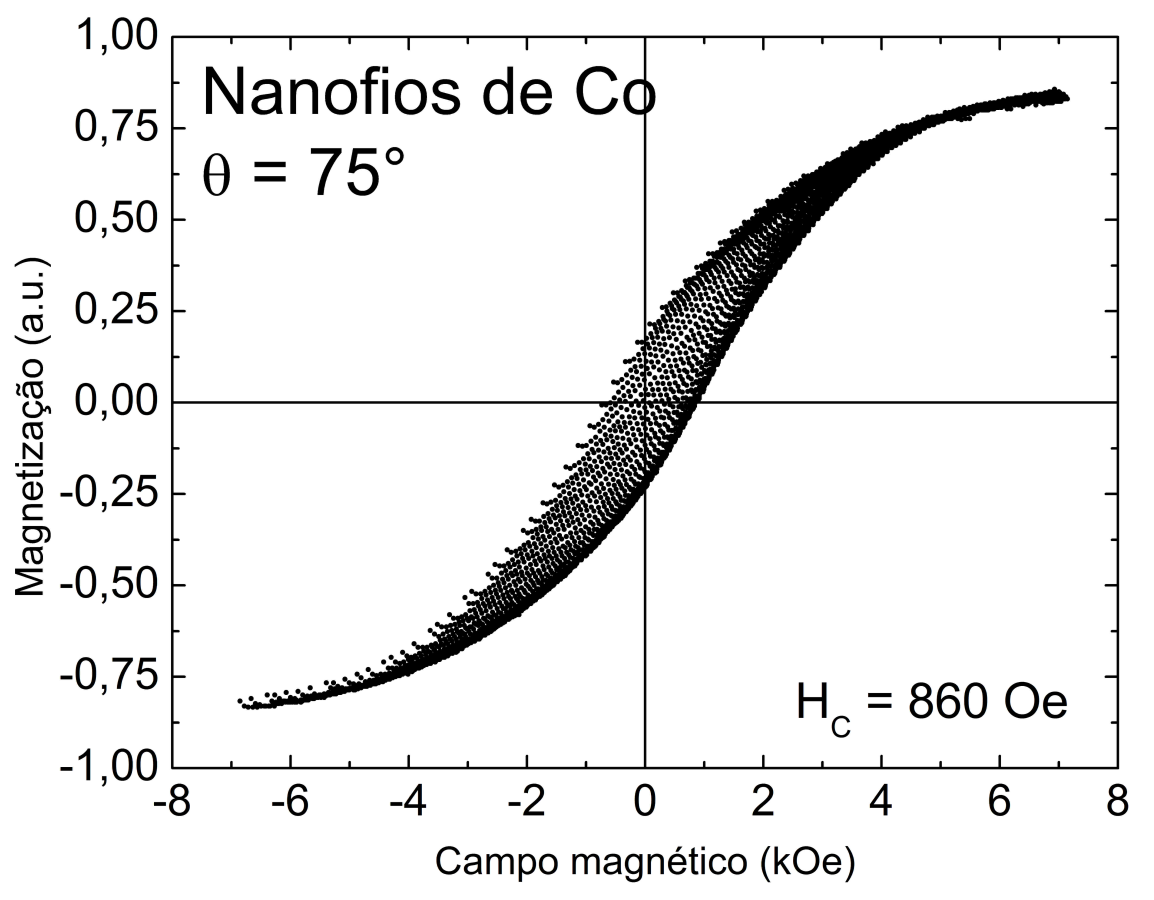

(a)

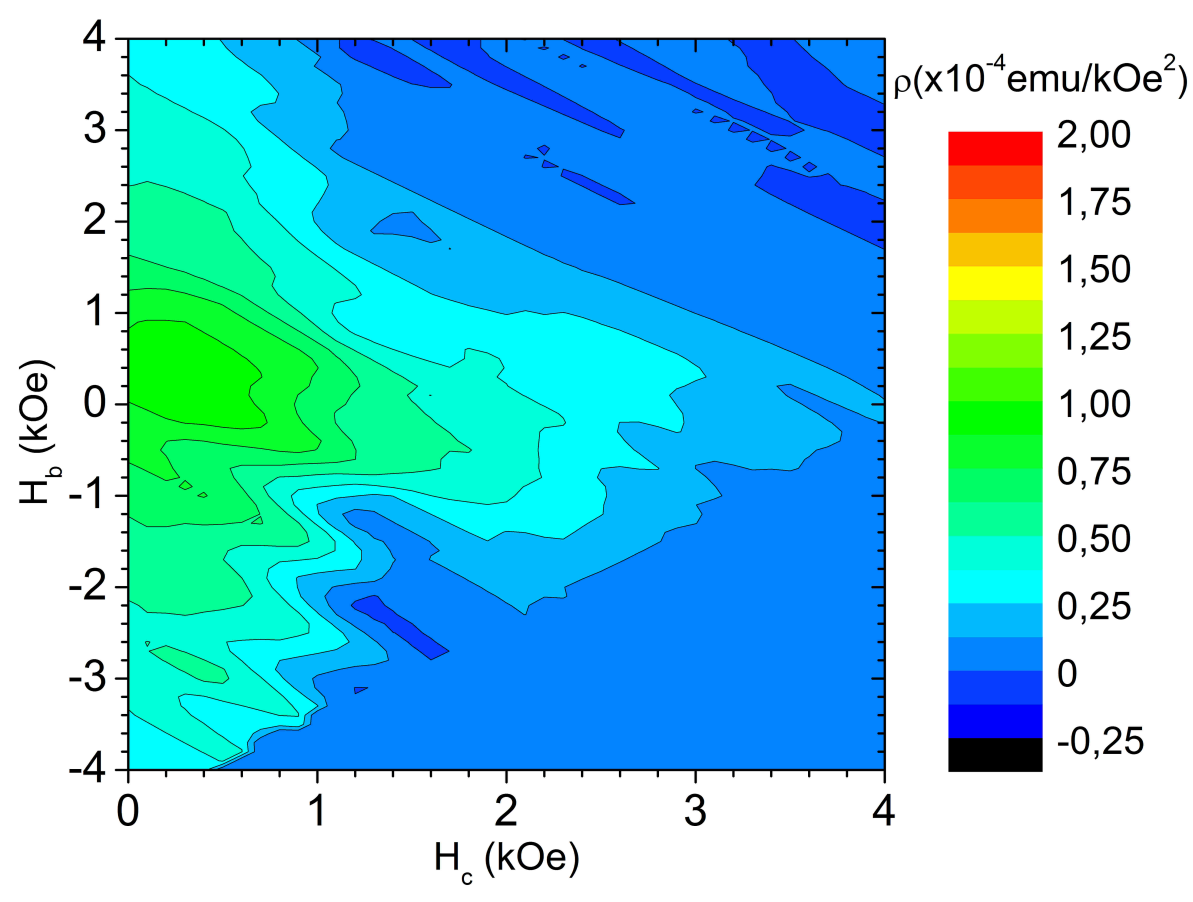

Figura 3.41: FORCs (a) e correspondentes diagramas FORC (b) de uma amostra de nanofios de Co $\left[5^{\circ} \mathrm{C},(\mathrm{COOH})_{2}\right.$, a $0,3 \mathrm{~mol} / \mathrm{L}, V_{a n}=25 \mathrm{~V}, 4$ horas $\left(1^{\mathrm{a}}\right) / 1$ hora $\left.\left(2^{-}\right)\right]$, para campo magnético aplicado num ângulo $\theta=75^{\circ}$ em relação à normal à superfície. 


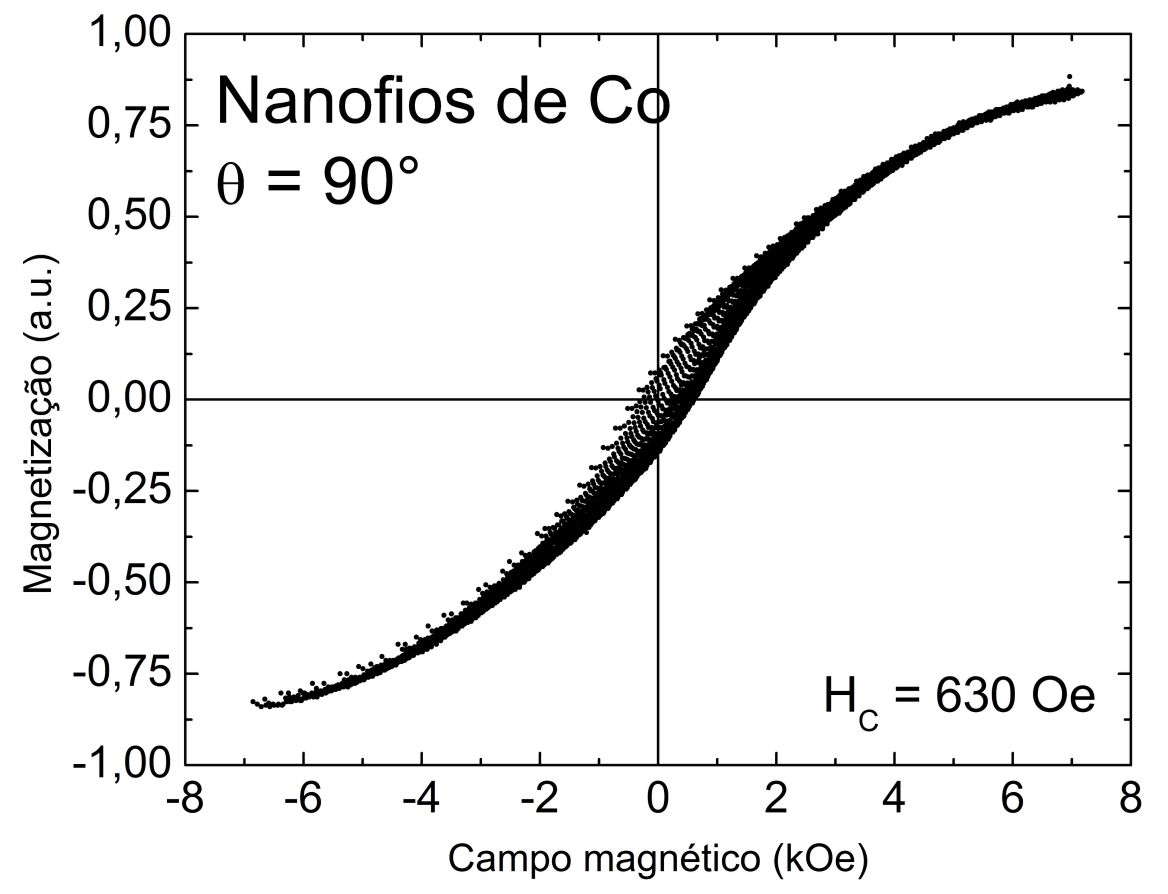

(a)

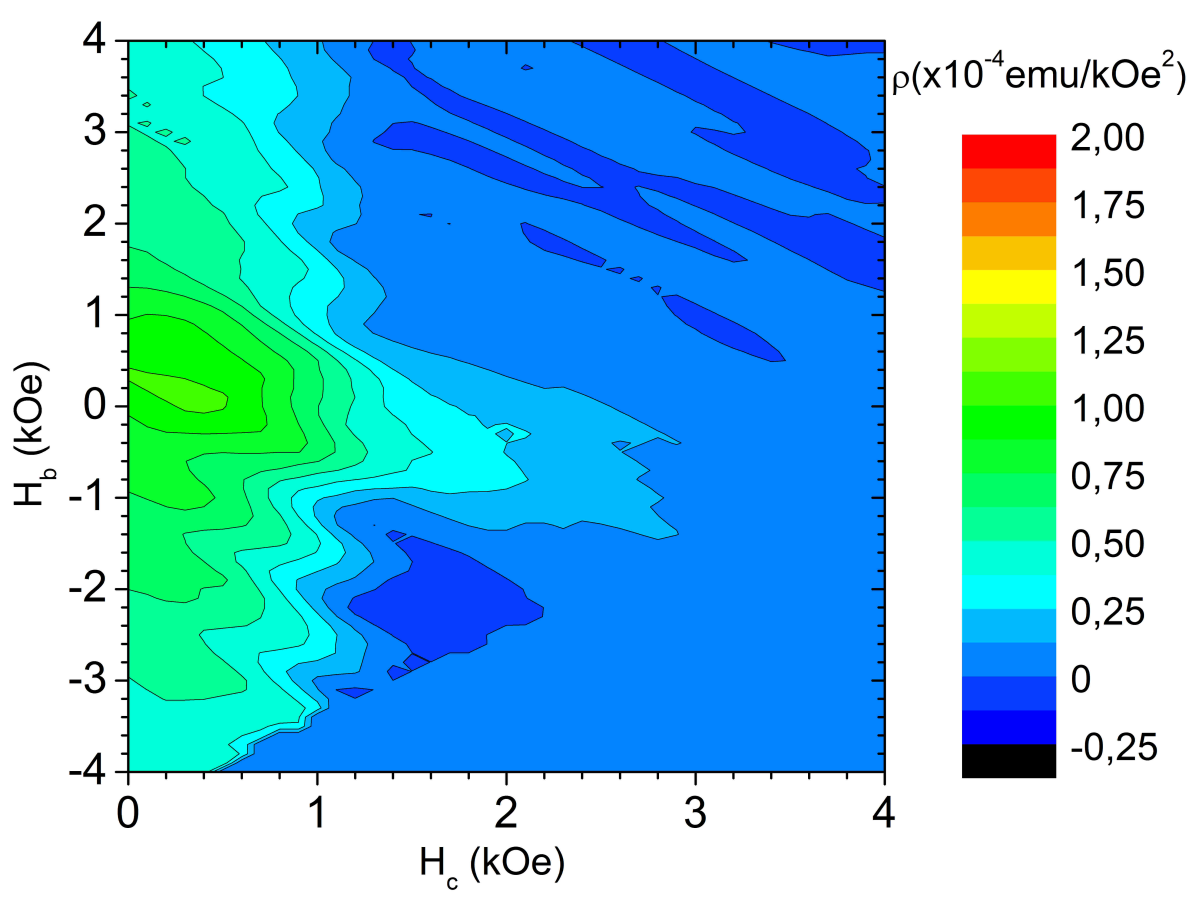

Figura 3.42: FORCs (a) e correspondentes diagramas FORC (b) de uma amostra de nanofios de Co $\left[5^{\circ} \mathrm{C},(\mathrm{COOH})_{2}\right.$, a $0,3 \mathrm{~mol} / \mathrm{L}, V_{a n}=25 \mathrm{~V}, 4$ horas $\left(1^{\mathrm{a}}\right) / 1$ hora $\left.\left(2^{-}\right)\right]$, para campo magnético aplicado num ângulo $\theta=90^{\circ}$ em relação à normal à superfície. 
FORC das amostras de Co, causando uma maior suavização da distribuição. Ainda assim, há uma marcante assimetria para baixo, indicando o mesmo caráter de campo médio desmagnetizante observado nos nanofios de Ni. Os máximos absolutos das distribuições encontram-se no lado $H_{b}>0$, mas muito próximos da origem $H_{b}=0$. Os diagramas para $\theta<45^{\circ}$ quase não exibem componentes reversíveis - $\rho$ é praticamente nulo em $H_{c}=0$. Mas à medida que $\theta$ aumenta, há um crescimento das componentes reversíveis em detrimento das irreversíveis: o pico principal tende a $H_{c}=0$, acompanhando a diminuição da coercividade, enquanto a distribuição cresce como um todo ao longo de $H_{c}=0$. Esse padrão se mantém evidente até $\theta=60^{\circ}$, com poucas mudanças. Mas, para $\theta=75^{\circ}$ (fig. 3.41), o diagrama FORC apresenta uma clara mudança, uma forma completamente diferente dos anteriores. A partir daí, a distribuição passa a mudar rapidamente em função de $\theta$, tendendo a uma distribuição mais reversível e alargada ao longo de $H_{c}=0$, sem um pico irreversível bem definido. Isto significa que o sistema está num estado metaestável. A remoção do campo aplicado causaria a inversão quase total do sistema, resultando numa baixa remanência. Curiosamente, este comportamento e sua assinatura nos diagramas FORC estão de acordo com as observações de Henry et al. em nanofios de Co, por MFM [43] e com sua discussão (ver seção 2.1.3) a respeito do ângulo limite $90^{\circ}-\epsilon<\theta<90^{\circ}+\epsilon$ para formação de um estado remanente multidomínio ao longo dos fios. Nossos resultados confirmam a existência de um ângulo crítico $\epsilon \approx 15^{\circ}$ em torno da direção perpendicular aos fios (eixo duro), que marca uma transição do estado remanente entre uma fase monodomínio e outra caracterizada por um conjunto de domínios magnéticos ao longo dos fios. Na análise FORC, essa transição é marcada pela clara mudança da assinatura das interações magnetostáticas nos diagramas. A distribuição FORC para $\theta=90^{\circ}$ (fig. 3.42) é o caso limite, seu diagrama FORC se assemelha ao de um sistema de partículas reversíveis e não-interagentes, como num paramagneto, cuja principal contribuição magnetizante é o próprio campo aplicado. Nessa situação, o campo é aplicado ao longo do eixo duro de anisotropia. Conseqüentemente, o sistema apresenta baixa saturação, baixa coercividade e um forte campo desmagnetizante - resultando numa histerese inclinada e em forma de "S".

Nas figuras 3.43, mostramos o perfil da distribuição FORC ao longo de (a) $H_{c}=0$ ("pico reversível") e (b) $H_{b}=0$. Observamos um claro aumento gradativo das compo- 
nentes reversíveis da magnetização em 3.43(a), à medida que o ângulo do campo aplicado tende ao eixo duro. Em 3.43(b), observamos a queda do pico irreversível à medida que $\theta$ aumenta, ao mesmo tempo que o pico reversível surge ao longo de $H_{c}=0$. Esse comportamento dos picos demostra o acoplamento entre as componentes reversível e irreversível da magnetização.
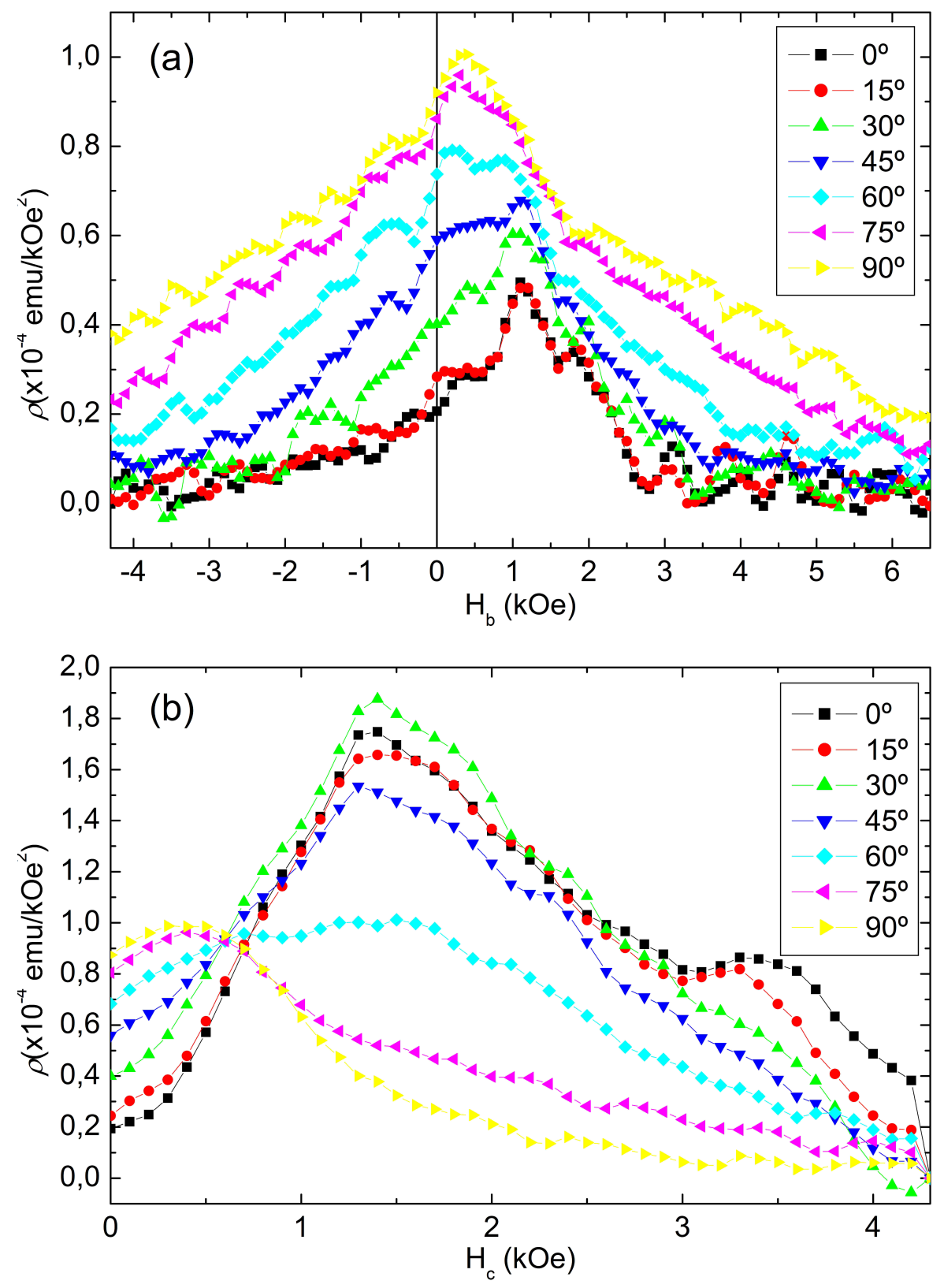

Figura 3.43: Perfil da distribuição FORC da amostra de nanofios de Co para (a) $H_{c}=0$ e (b) $H_{b}=0$.

Os resultados, portanto, revelaram uma forte dependência das propriedades estruturais 
dos arranjos de nanofios com os parâmetros de anodização. Em particular, um crescimento linear do diâmetro (de 30 a $95 \mathrm{~nm}$ ) e da distância entre poros (de 40 a $145 \mathrm{~nm}$ ) com a voltagem de anodização é observado, em bom acordo com a literatura [14, 15, 16, 17, $24,31,34,90,42,66]$. A densidade e a circularidade dos nanofios decrescem com o aumento da voltagem de anodização, com valores entre $10^{9}$ e $10^{10} \mathrm{~cm}^{-2}$ e acima de 0,75 , respectivamente. Os resultados sugerem, ainda, que a competição entre os efeitos de cada parâmetro de anodização leva a diferentes regimes de crescimento (ordenado ou desordenado) dos poros e, eventualmente, a regimes de otimização da estrutura obtida [34].

Os resultados de XRD revelaram uma estrutura amorfa para a $\mathrm{Al}_{2} \mathrm{O}_{3}$ e uma estrutura $f c c$, policristalina para o Ni, com tamanhos de grão variando entre 9 e $24 \mathrm{~nm}$. Foi observado um crescimento linear do tamanho de grão de Ni com o diâmetro médio dos fios, mostrando que a geometria dos poros regula a microestrutura do nanofio e, portanto, é determinante de suas propriedades micromagnéticas. Nessa faixa de tamanhos, os grãos cristalinos de Ni são partículas monodomínio, pois a largura de parede de domínio para Ni é maior que $100 \mathrm{~nm}$ [24]. Portanto, podemos afirmar que os nanofios são formados por aglomerados de partículas magnéticas monodomínio, acopladas por interação de troca (exchange-coupling), com seus eixos de anisotropia magneto-cristalina orientados aleatoriamente em todas as direções e sujeitos a uma forte anisotropia de forma na direção perpendicular à superfície (paralela ao eixo dos nanofios) [24].

A partir dos ciclos de histerese medidos, foi observada uma forte anisotropia de forma na direção perpendicular à superfície das amostras. Houve um crescimento da coercividade e da remanência em comparação com amostras volumosas de Ni. As coercividades observadas variaram entre 500 e 800 Oe e a remanência sempre $M_{R}>0,5 M_{S}$. A análise dos diagramas FORC construídos indicam um caráter fortemente desmagnetizante das interações do sistema e um crescimento das componentes reversíveis da magnetização com o aumento do diâmetro dos nanofios. Além disso, a assimetria do pico reversível em relação a $H_{b}$ sugere que há um acoplamento entre as componentes reversíveis e irreversíveis da magnetização [91], pois à medida que se desmagnetiza o material (i.e., à medida que $H_{r}$ diminui), o sistema cria estados de magnetização que favorecem o surgimento de componentes reversíveis [29], ou seja, $\rho\left(H_{c}=0, H_{b}\right) \neq \rho\left(H_{c}=0,-H_{b}\right)$. Em geral, modos 
não-uniformes de inversão de magnetização apresentam tais características. Desta forma, e dada as características estruturais e micromagnéticas desses sistemas, é possível que haja a nucleação de modos não-uniformes de inversão de magnetização, como a formação de vórtices (curling) ao longo dos fios [24, 25, 66]. Este modo favorece a formação de grandes componentes reversíveis da magnetização e corrobora a dependência entre a magnetização reversível e a irreversível [29, 91].

Estimativas do campo médio dipolar e do campo de interação local foram feitas a partir da posição e da largura a meia altura vertical do pico principal de cada distribuição FORC. Foi observado que o campo dipolar médio (desmagnetizante) diminui com o aumento da distância entre poros (entre -215 e -50 Oe) e que $H_{\text {int }}$ variou entre 900 e 1500 Oe e cresce (em módulo) em função do diâmetro médio dos nanofios. Isso indica uma mudança de regime do comportamento magnético do arranjo de nanofios em função de suas propriedades estruturais devido à competição entre efeitos intra-fios magnetizantes (anisotropia de forma, exchange-coupling) e inter-fios desmagnetizantes (interação dipolar).

Os "mapas" FORC obtidos para as amostras de Ni e Co, quando comparados com os resultados das grandezas micromagnéticas $\left(D / l_{e x}\right.$, tabela 3.3), morfológicas (razão de aspecto $r$ ) e microestruturais (tamanho de grão), bem como com resultados da literatura $[43,50]$, confirmam o estado multidomínio dos nanofios de Co e a saída dos nanofios de Ni do limiar entre os estados uniforme e multidomínio. Em particular, esses comportamentos imprimiram fortes assinaturas nos diagramas FORC. Os diagramas FORC de Ni representados sobre a histerese (figs. 3.32 a 3.35) mostraram uma clara migração do pico irreversível do $4^{\circ}$ para o $1^{\circ}$ quadrante, à medida que o diâmetro aumentava, tendendo a favorecer o estado multidomínio. Já os diagramas FORC de Co revelaram uma sensível mudança para campos aplicados entre $75^{\circ}$ e $90^{\circ}$ em relação ao eixo-fácil, confirmando seu caráter remanente multidomínio. Baseados na extensa literatura sobre a análise FORC e nanofios magnéticos [24, 61, 91, 92, 94], concluímos que as amostras estudadas de arranjos de nanofios de Ni são dominadas por interações desmagnetizantes e seu processo de magnetização ocorre majoritariamente por modos não-uniformes, como curling ou movimento de paredes de domínio ao longo dos fios. Nossos resultados corroboram resultados anteriores de análise de curvas $\Delta M$ em nanofios de Fe [29]. As sensíveis mudanças 
observadas nos diagramas FORC em função do diâmetro dos fios e da direção de apliação do campo magnético demonstram aspectos do comportamento magnético do sistema que permanecem inacessíveis nos ciclos de histerese. Outras abordagens, como a modelagem micromagnética desses sistemas, podem trazer informações complementares sobre o mecanismo de inversão de magnetização e a contribuição de cada interação magnética para o comportamento macroscópico do sistema. 


\section{CAPÍTULO 4}

\section{Excitações de Superfície em Filmes Finos de $\mathrm{O}-\mathrm{Fe} / \mathrm{W}(001)$}

Neste capítulo, estudamos a dinâmica de spins na superfície de filmes de Fe com 30 monocamadas (ML) de espessura, depositados num monocristal de W(001) e exposto a 5 langmuirs (L) de $\mathrm{O}_{2}$. Esse estudo foi realizado utilizando-se a técnica de espectroscopia por perda de energia de elétrons spin-polarizados (SPEELS), um método sensível à dependência em spin de excitações elementares e modos vibracionais de adsorvatos em superfícies. Todo o estudo foi realizado in situ, numa câmara em regime de ultra alto vácuo (UHV).

\subsection{Sistema de Ultra-Alto Vácuo (UHV)}

Os experimentos foram realizados numa câmara de ultra-alto vácuo (UHV), com toda a caracterização estrutural e magnética realizadas in situ. O sistema de UHV consiste em três subcâmaras interconectadas por válvulas, nas quais a pressão é mantida abaixo de $10^{-10}$ mbar, através de diferentes tipos de bombas de vácuo, trabalhando em arranjos paralelo e/ou em série. Um braço manipulador é responsável pela transferência da amostra de uma câmara a outra e de seu movimento em três eixos perpendiculares e rotação.

Um esquema do sistema UHV utilizado pode ser visto nas figuras 4.1(a) (em perspectiva) e 4.1(b) (seção longitudinal). A câmara principal (em azul, na figura), onde se realiza o experimento de SPEELS, é cilíndrica, com o eixo ao longo do manipulador da amostra. Ao lado desta, encontra-se a câmara de preparação do cátodo (em verde), onde o fotocátodo de GaAsP é passivado por $\mathrm{Cs}_{\text {e }} \mathrm{O}_{2}$ logo antes do experimento. A câmara 
de análise (em vermelho) é onde as amostras são preparadas e caracterizadas estrutural e magneticamente antes de serem submetidas à SPEELS. Esta câmara também se encontra ao longo do eixo do manipulador, que é o eixo principal do sistema (eixo $z$ ).

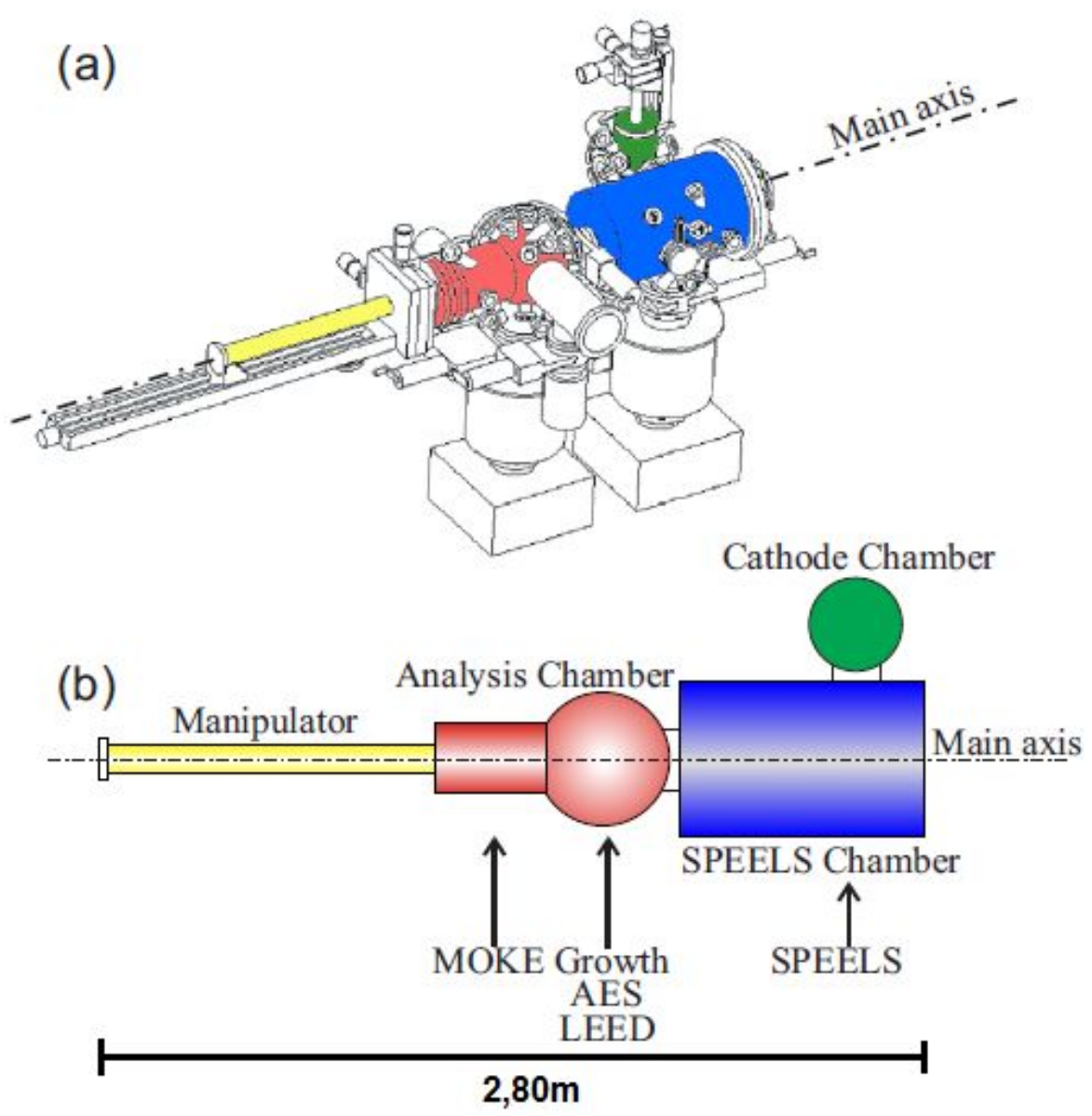

Figura 4.1: (a) Vista em perspectiva da câmara UHV utilizada neste trabalho. (b) Esquema pictórico da seção longitudinal da câmara e suas subpartes: o manipulador da amostra (em amarelo, ao longo do eixo principal do sistema), a câmara de análise (em vermelho), onde a amostra é preparada e analizada, a câmara de SPEELS (em azul) e a câmara de preparação do cátodo de GaAsP (em verde). Durante o experimento de SPEELS, o cátodo é transferido para a câmara de SPEELS. As diversas técnicas experimentais utilizadas neste trabalho estão discriminadas na figura. (Obtido da ref. [85])

A faixa de pressão de trabalho é de $10^{-7}$ a $10^{-11}$ mbar na câmara de análise, dependendo da aplicação, e sempre melhor que $6 \times 10^{-11}$ mbar na câmara de SPEELS. Quatro diferentes tipos de bombas de vácuo são utilizadas para manter a condição de UHV nas câmaras, sendo cada uma adequada a um diferente regime de pressão. A bomba mecânica trabalha na faixa da pressão atmosférica a $10^{-2}$ mbar. Ela serve para manter uma baixa pressão $\left(10^{-1}\right.$ a $10^{-2}$ mbar) num reservatório com grande volume, acoplado às subcâmaras 
- o pré-vácuo. Este pré-vácuo serve de saída para as bombas turbomoleculares e atua como um sistema de segurança para o sistema UHV, no caso de quebra do ultra-alto vácuo interno. Entre o pré-vácuo e o UHV, as bombas turbomoleculares trabalham na faixa de $10^{-2}$ a $10^{-9}$ mbar e são responsáveis por remover moléculas pesadas, como $\mathrm{N}_{2}$, $\mathrm{O}_{2}, \mathrm{CO}, \mathrm{CO}_{2}, \mathrm{H}_{2} \mathrm{O}$, entre outras. Em paralelo às bombas turbomoleculares, operam bombas iônicas, que trabalham na faixa de $10^{-7}$ a $10^{-11}$ mbar. Nas câmaras de análise e de SPEELS, há ainda uma armadilha criogênica, responsável por resfriar o sistema à temperatura do $\mathrm{N}_{2}$ líquido, condensando moléculas em sua superfície e reduzindo a pressão interna rapidamente.

Na câmara de análise, encontram-se a maioria das técnicas de preparação e caracterização dos filmes finos. Os filmes são preparados por epitaxia por feixe molecular (MBE),

à temperatura ambiente. A caracterização estrutural e morfológica é feita por difração de elétrons de baixas energias (LEED) e o monitoramento da pureza da superfície, por espectroscopia de elétrons Auger (AES). Na câmara há ainda uma bobina magnética, capaz de aplicar campos magnéticos de até 400 Oe (ao longo do eixo z), e um sistema de magnetometria por efeito Kerr magneto-óptico (MOKE), em configuração longitudinal. A câmara possui também um espectrômetro quadrupolar de massa (QMS), para monitoramento da atmosfera interna e para experimentos de dessorção térmica, a partir de um sistema de bombardeamento de elétrons montado sob o substrato de W.

\subsection{Preparação e Caracterização de Filmes de O-Fe/W(001)}

Os filmes de $\mathrm{O}-\mathrm{Fe} / \mathrm{W}(001)$ foram preparados por MBE, à temperatura ambiente. O substrato é uma lâmina retangular de W monocristalino, orientado na direção [001], com dimensões de $5 \mathrm{~mm}$ de largura por $8 \mathrm{~mm}$ de comprimento (direção z do manipulador) e 0,3 mm de espessura. Primeiramente, a lâmina é sujeita a um procedimento de limpeza por tratamento térmico, que consiste em ciclos de bombardeamento de elétrons a alta e baixa potência alternadamente - flashing -, em diferentes condições de atmosfera. O substrato atinge temperaturas de $1200 \mathrm{~K}$ no ciclo de baixa potência e $2200 \mathrm{~K}$ no ciclo de alta potência. O procedimento em detalhe é o seguinte [117]: 
1. 2 flashes de alta potência (HPF; $1,1 \mathrm{kV} / 160 \mathrm{~mA} / 176 \mathrm{~W}$, por $10 \mathrm{~s})$, em vácuo melhor que $3 \times 10^{-10}$ mbar, para eliminar qualquer resquício de material depositado sobre o substrato. Devido à alta temperatura atingida, o carbono intersticial presente no volume do substrato é segregado na superfície, contaminando-a com excesso de carbono, o que é indesejável;

2. 8 a 10 ciclos de flashes de baixa potência (LPF; $1,1 \mathrm{kV} / 40 \mathrm{~mA} / 44 \mathrm{~W}$, por $15 \mathrm{~s}$, em intervalos de $60 \mathrm{~s}$ ), em atmosfera de $\mathrm{O}_{2}$, com pressão parcial de $5 \times 10^{-8}$ mbar. Nesta etapa, o $\mathrm{O}_{2}$ admitido à câmara é adsorvido à superfície do substrato, onde reage com o carbono segregado, formando $\mathrm{CO}$ e $\mathrm{CO}_{2}$. Ao atingir $1200 \mathrm{~K}$, essas espécies são dessorvidas e eliminadas.

3. 1 ciclo de HPF, nas mesmas condições do primeiro, para remover óxidos de W e o próprio oxigênio atômico, que só são removidos a temperaturas tão altas quanto 2200 K. [120].

Este último ciclo resulta, entretanto, na segregação do carbono intersticial. Porém, após seguidas repetições do procedimento acima, a contaminação por C segregado torna-se desprezível.

Após este procedimento, espera-se obter um substrato epitaxial totalmente limpo de impurezas (adsorvatos) como átomos de $\mathrm{H}, \mathrm{C}, \mathrm{N}, \mathrm{O}$ ou moléculas tais como $\mathrm{CO}, \mathrm{CO}_{2}$, $\mathrm{NO}, \mathrm{O}_{2}, \mathrm{WO}, \mathrm{WO}_{2}, \mathrm{H}_{2} \mathrm{O}$, dentre outras. Padrões de LEED e espectros de AES foram obtidos após esta etapa e demonstraram uma boa qualidade do substrato, como visto respectivamente nas figuras 4.2 e 4.4 (curva em preto). A figura 4.2 mostra padrões de LEED da superfície de W(001) para feixes de elétrons com energias (a) $96 \mathrm{eV}$, (b) $113 \mathrm{eV}$ e (c) $160 \mathrm{eV}$. Nelas, observamos um padrão claro de uma superfície (001) de uma estrutura $b c c$, sem superestruturas ou reconstruções. Espectros de AES obtidos subseqüentemente (curva preta na figura 4.4(a)) também comprovam a pureza química da superfície, a menos de um pequeno pico típico de carbono segregado, que não pode ser evitado devido à última etapa do procedimento de limpeza, que consiste num HPF.

Em seguida, espera-se o substrato retornar à temperatura ambiente, na qual é realizada a deposição, e a recuperação da pressão de base na câmara ao nível de $3 \times 10^{-11}$ mbar. Nessas condições, é depositada uma carga de $200 \mu \mathrm{C}$ de Fe por MBE, a $990 \mathrm{~V}$ de tensão, 11 


\section{$96 \mathrm{eV}$}

(a)

\section{$113 \mathrm{eV}$}

(b)

\section{$160 \mathrm{eV}$}

(c)

Figura 4.2: Padrões de LEED do substrato de W(001), após ciclos de flash de baixa e alta potência, para elétrons com energias de (a) 96, (b) 113 e (c) $160 \mathrm{eV}$. 
mA de emissão e $80 \mathrm{nA}$ de fluxo. De acordo com a calibração realizada no laboratório com $\mathrm{Fe} / \mathrm{W}(110)$ [121, 122], isso corresponde a um filme de Fe(001) com 30 ML de espessura.

\subsubsection{Estrutura e Morfologia}

Com esta espessura, a superfície do filme de Fe já se encontra relaxada e longe do contato com o substrato. De fato, o espectro de AES visto na figura 4.4(a) (curva vermelha) mostra fortes picos de Fe, sem sinais de W e nem do C segregado. Logo em seguida, realizamos um annealing por $30 \mathrm{~s}$, a $500 \mathrm{~K}$ e admitimos $\mathrm{O}_{2}$ à câmara, a uma pressão parcial de $3,3 \times 10^{-8}$ mbar, por $200 \mathrm{~s}$. Isso corresponde a uma exposição de $5 \mathrm{~L}$ (1 langmuir $=1,0 \times 10^{-6}$ torr $\left.\cdot \mathrm{s}=1,33 \times 10^{-6} \mathrm{mbar} \cdot \mathrm{s}\right)$. Por fim, um novo annealing nas mesmas condições é realizado, para estabilizar o oxigênio que foi adsorvido e novamente foi realizado AES. O espectro, mostrado na figura 4.4(a) (curva azul), revelou claramente a cobertura da superfície de Fe por uma camada de oxigênio: aparece um forte pico de O, acompanhado de uma pequena queda de intensidade dos picos de Fe.

Na figura 4.3(a), vemos o padrão de difração de elétrons de 30 ML Fe/W(001) (antes da exposição a $\mathrm{O}_{2}$ e sem annealing), com feixe de energia $120 \mathrm{eV}$. Nele se observa um padrão muito difuso de uma superestrutura desordenada de $(1 \times 1)$ bcc-Fe $(001)$, como confirmado pela literatura $[118,119]$. A subseqüente exposição a $5 \mathrm{~L}$ de $\mathrm{O}_{2}$ cria uma nova camada de aproximadamente $1 \mathrm{ML}$ de $\mathrm{O}$ sobre a superfície de $\mathrm{Fe}(001)$, que leva a um padrão de difração mais difuso (desordenado) ainda, mostrada na figura 4.3(b), obtido a $120 \mathrm{eV}$. Ao se realizar um annealing na amostra, elimina-se o excesso de átomos de O em sítios instáveis, remanescendo apenas os adsorvatos mais quimicamente estáveis, tornando a superfície mais regular e ordenada. A figura 4.3(c) comprova a boa qualidade da superfície e seu caráter pseudomórfico após o annealing e a clara reconstrução p $(1 \times 1) \mathrm{O}-$ $\mathrm{Fe} / \mathrm{W}(001)$.

Esta reconstrução $\mathrm{p}(1 \times 1)$ observada sugere que os átomos de $\mathrm{O}$ repousam sobre os sítios vazios entre dois átomos de Fe, formando uma estrutura semelhante à do $\mathrm{FeO}$ cristalino [118], como mostra a figura 4.7(a). De fato, tanto estudos experimentais quanto modelos dinâmicos [118] de LEED indicam que esta é a configuração mais estável para este sistema, a baixas exposições de $\mathrm{O}_{2}$, e que a superfície de $\mathrm{O}-\mathrm{Fe} / \mathrm{W}(001)$ exibe propriedades elásticas e eletrônicas de uma superfície de FeO [118, 123]. Por se tratar de uma superfície 
$120 \mathrm{eV}$

(a)

$120 \mathrm{eV}$

(b)

$90 \mathrm{eV}$

(c)

Figura 4.3: Padrões de LEED de (a) $30 \mathrm{ML} \mathrm{Fe/W(001),} \mathrm{a} 120 \mathrm{eV}$, (b) a mesma amostra, após exposição a $5 \mathrm{~L} \mathrm{O}_{2}$, a $120 \mathrm{eV}$ e $($ c) a clara reconstrução $\mathrm{p}(1 \times 1) \mathrm{O}-\mathrm{Fe} / \mathrm{W}(001)$, a $90 \mathrm{eV}$, após annealing. 

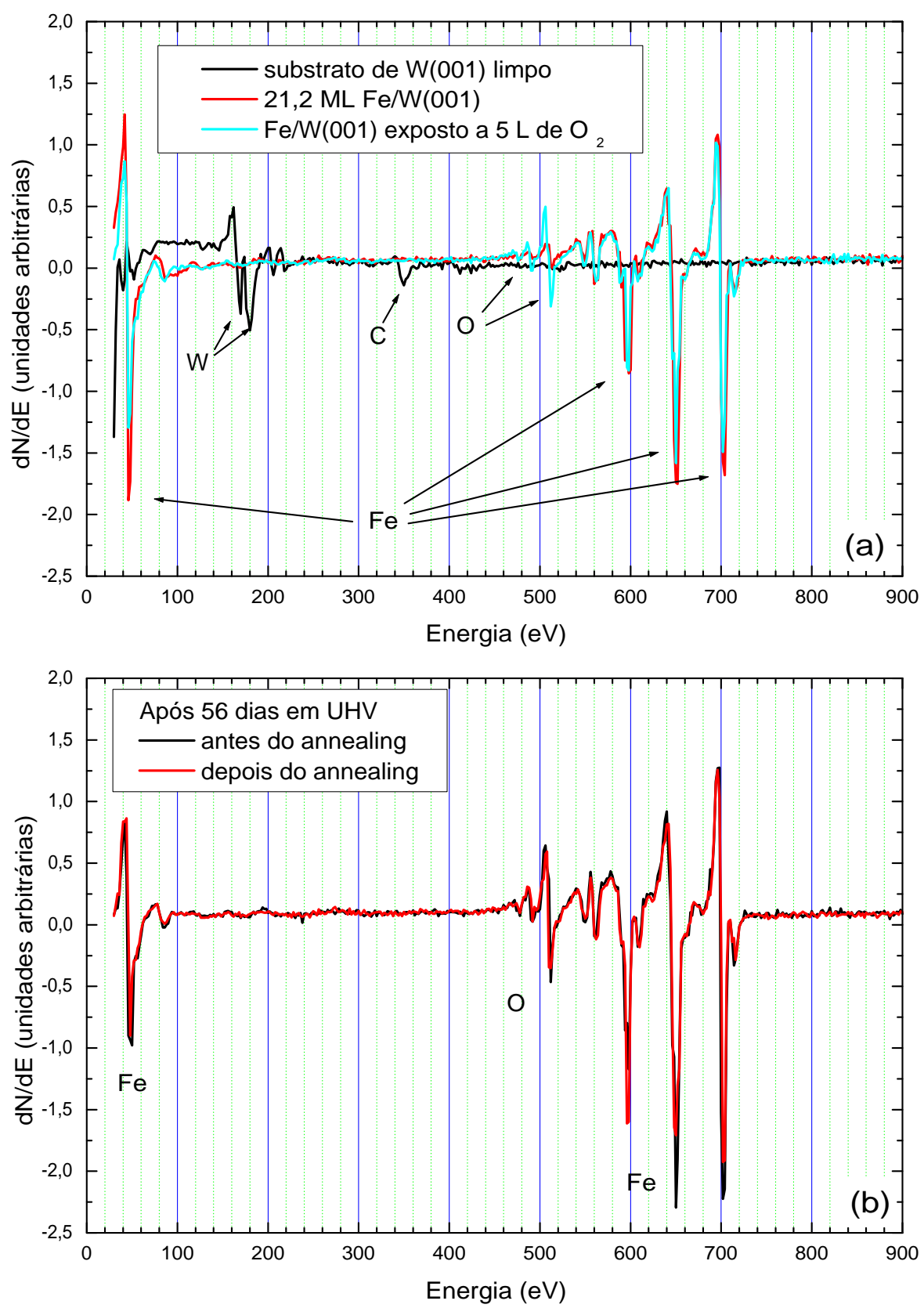

Figura 4.4: (a) Espectros de AES em diferentes etapas da preparação da amostra de $30 \mathrm{ML}$ $\mathrm{O}-\mathrm{Fe} / \mathrm{W}(001)$ : somente o substrato de W(001), após o flash (curva preta); após a deposição de 30 ML Fe (curva vermelha); e após exposição a $5 \mathrm{~L}$ de $\mathrm{O}_{2}$ (curva azul). (b) Espectros de AES para a mesma amostra, 56 dias após sua preparação, exposta à atmosfera residual da câmara UHV (em preto), ( $p_{\text {base }} \approx 4 \times 10^{-10} \mathrm{mbar}$, e logo após um annealing de $30 \mathrm{~s}$ a $500 \mathrm{~K}$ (em vermelho). A coincidência entre as curvas prova a boa estabilidade da amostra. 
de caráter metálico reduzido pela presença do oxigênio, espera-se uma alta estabilidade química contra impurezas e adsorvatos. Para testar essa hipótese, deixamos a amostra exposta à atmosfera do sistema de UHV por longos períodos, sem nenhum tratamento de limpeza. Os gases residuais na câmara podem eventualmente conter traços de CO, $\mathrm{CO}_{2}, \mathrm{H}_{2} \mathrm{O}, \mathrm{H}_{2}, \mathrm{~N}_{2}, \mathrm{O}_{2}$, dentre outros. Após 56 dias nessas condições, realizamos AES na amostra antes e depois de um annealing de $30 \mathrm{~s}$. Os resultados são mostrados na figura 4.4(b). Em ambos espectros não há quaisquer sinais de outros elementos senão $\mathrm{O}$ e Fe. Isso mostra que, além da qualidade estrutural demonstrada pelo LEED, essa superfície é de alta estabilidade química, o que a torna particularmente interessante para aplicações tecnológicas.

A maioria dos experimentos de SPEELS foram realizados em amostras mais espessas, para garantir uma menor influência do substrato sobre a qualidade da superfície. Mas para comprovar que a estrutura da superfície não sofre mais influência da espessura da camada, mostramos na figura 4.5 uma série de padrões de LEED obtidos de 46,7 ML O-Fe/W(001), para elétrons com energias de (a) 88, (b) 113, (c) 170, (d) 187, (e) 253 e (f) $277 \mathrm{eV}$. Todas comprovam a reconstrução $\mathrm{p}(1 \times 1)$ bcc $(001)$ observada. Além disso, analisamos a homogeneidade da deposição sobre toda a área do substrato a partir de espectros de AES ao longo do eixo maior da amostra (ao longo do manipulador). Os resultados são mostrados na figura $4.5(\mathrm{~g})$ e revelam uma marcante coincidência, tanto nas posições quanto nas intensidades, dos picos de $\mathrm{Fe}$ e $\mathrm{O}$, em diferentes posições da amostra, no centro (curva vermelha) e nas extremidades (curvas preta e azul).

\subsubsection{Magnetismo}

Os filmes de $\mathrm{O}-\mathrm{Fe} / \mathrm{W}(001)$ com $30 \mathrm{ML}$ de espessura foram magneticamente caracterizados por magnetometria MOKE à temperatura ambiente, em geometria longitudinal, com campo magnético aplicado ao longo da direção [010] da rede cristalina. Como calibração da magnetização de saturação em função da espessura do filme de Fe, foram considerados os mesmos parâmetros utilizados em trabalhos anteriores em filmes de $\mathrm{Fe}(110)$ [84, 85], que reproduz dados da literatura em filmes de Fe/W [121], devidamente adaptados para uma superfície (001). Os filmes exibiram uma resposta típica de um monodomínio ferromagnético, com eixo-fácil ao longo da direção do campo aplicado, como mostra a figura 
$88 \mathrm{eV}$

(a)

$170 \mathrm{eV}$

(c)

\section{$253 \mathrm{eV}$}

(e)

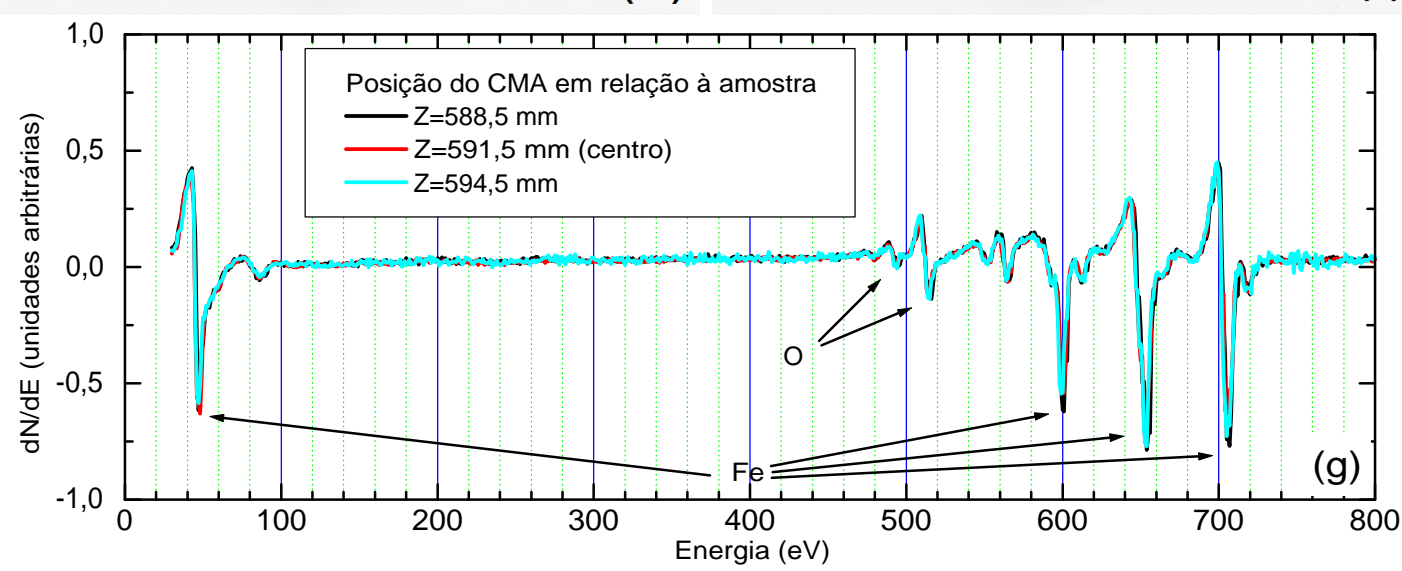

(b)

\section{$187 \mathrm{eV}$}

(d)

$277 \mathrm{eV}$

Figura 4.5: Padrões de LEED de 46,7 ML O-Fe/W(001) para elétrons com energias de (a) 88, (b) 113, (c) 170, (d) 187, (e) 253 e (f) 277 eV. (g) Espectros de AES em diferentes posições da amostra ao longo do eixo do manipulador, mostrando a homogeneidade da superfície da amostra. 
4.6. Campos de até 2400 Oe foram aplicados para saturá-los $\left(M_{S} \approx 510 \mu \mathrm{rad}\right)$. Coercividades típicas observadas são extremamente baixas, da ordem de 8 Oe (ver detalhe da figura 4.6), com remanências tão altas quanto $M_{R}=M_{S}$. Foi observado também um suave aumento da coercividade após a exposição da superfície de $\mathrm{Fe}$ a $5 \mathrm{~L}$ de $\mathrm{O}_{2}$ e subseqüente annealing, mas nenhuma alteração significativa de $M_{S}$.

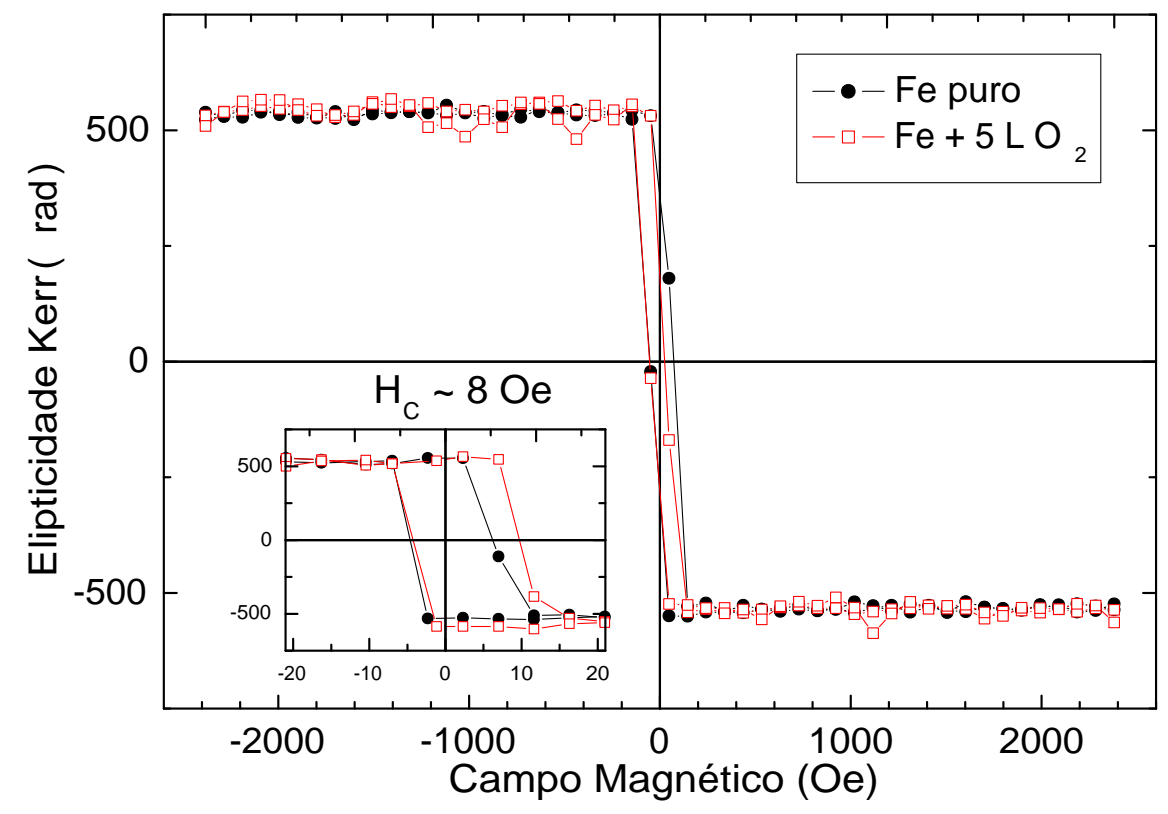

Figura 4.6: Curva de histerese de $30 \mathrm{ML} \mathrm{O}-\mathrm{Fe} / \mathrm{W}(001)$ a temperatura ambiente. Para garantir a saturação da amostra, campos magnéticos de até 2400 Oe foram aplicados. No detalhe, curvas de histerese realizadas com incremento menor, a fim de se determinar a coercividade com melhor precisão.

Portanto, os filmes de 30 ML O-Fe/W(001) são ferromagnéticos à temperatura ambiente, saturados na direção [010], no plano da superfície. Os experimentos de SPEELS foram realizados nessas amostras, com o plano de espalhamento ao longo da direção [100], perpendicular à direção da magnetização. Deste modo, quaisquer excitações causadas pelo espalhamento de elétrons propagam-se ao longo do eixo [100], que corresponde à direção $\bar{\Gamma} \bar{X}$ da zona de Brillouin de superfície (SBZ), perpendicular à magnetização. Esta situação está esquematizada na figura 4.7(b). Assim, o spin dos elétrons incidentes podem ser paralelos ou anti-paralelos aos spins dos elétrons majoritários da amostra. E, como a amostra se encontra saturada, a criação (elétron perde energia) de excitações elementares tipo spin-flip (mágnons e excitações de Stoner) só é permitida se o elétron incidente transferir um momento angular tal que cause a diminuição do momento magnético da 

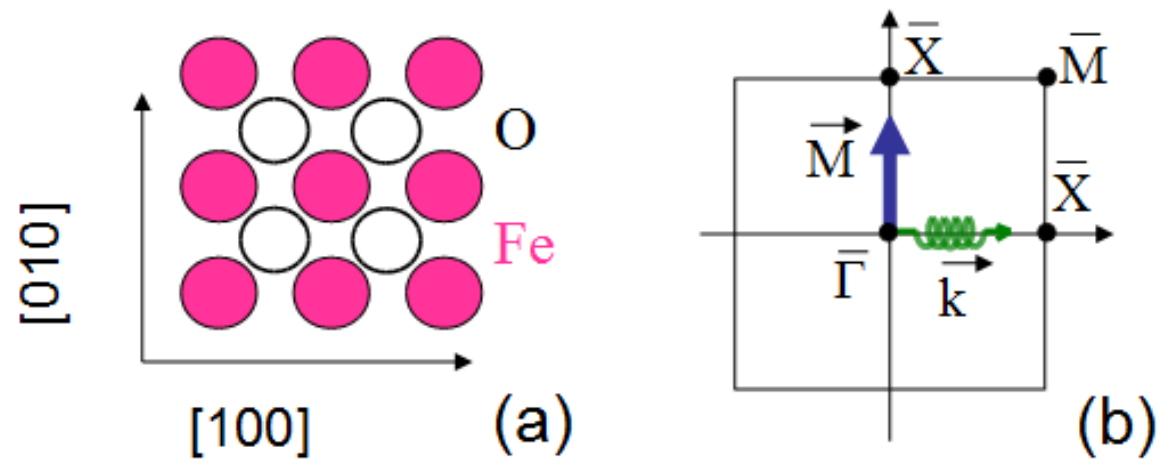

Figura 4.7: Esquema pictórico da (a) estrutura cristalina da superfície de 30 ML O-Fe/W(001), com os átomos de $\mathrm{O}$ ocupando os sítios vazios da rede $b c c$ do $\mathrm{Fe}(001)$, e (b) sua respectiva zona de Brillouin de superfície, com seus pontos de alta simetria e as direções da magnetização remanente (azul) e da direção de propagação das excitações elementares excitadas (verde).

amostra de -1 eћ, ou seja, somente elétrons com spins minoritários. O inverso se aplica para a aniquilação (elétron ganha energia) de excitações: apenas elétrons majoritários podem excitá-las, ganhando energia no processo e aumentando o momento magnético da amostra de +1 eћ.

\subsection{Resultados e Discussão}

Medidas de SPEELS foram realizadas à temperatura ambiente, com magnetização saturada ao longo da direção [010] e com plano de espalhamento paralelo à direção [100] da superfície (perpendicular à magnetização), em geometria especular $\left(\theta_{i}=\theta_{f}\right)$ e nãoespecular $\left(\theta_{i} \neq \theta_{f}\right)$, com um ângulo de espalhamento fixo $\theta_{0}=\theta_{i}+\theta_{f}=80^{\circ}$. Em ambos os casos, os espectros parciais $\left(I_{\uparrow}\right.$ e $\left.I_{\downarrow}\right)$ são fortemente dominados pelo pico elástico em torno da origem, resultante dos elétrons espalhados sem perda de energia. Exemplos típicos de espectros nessas duas geometrias são mostrados na figura 4.8. Em geometria especular [fig. 4.8(a)], a refletividade dos elétrons espalhados elasticamente é extremamente alta e o pico elástico domina o espectro. As intensidades dos picos inelásticos são abaixo de $1 \%$ da intensidade do pico elástico. A assimetria observada (no detalhe) é alta (cerca de -60\%) e constante em todo o espectro, ou seja, não sofre influência de excitações inelásticas. Isso é uma indicação de que a superfície ferromagnética funciona como um polarizador de spin para elétrons espalhados especularmente. Isto estabelece uma correlação entre excitações elásticas e inelásticas em geometria especular: a assimetria observada é devido 
ao caráter ferromagnético da superfície e influencia igualmente todos os eventos (elásticos e inelásticos) através da forte interação de troca na superfície [78, 79]. Essas propriedades da superfície, somadas à qualidade e estabilidade estrutural e magnética, a tornam viável para aplicação como sensor de um analizador spin de elétrons de alta eficiência, capaz de identificar a polarização de spin de elétrons incidentes [124, 119, 125, 126]. Dois fortes picos inelásticos não-spin-flip são identificados, um em $E_{l o s s}=33 \mathrm{meV}$ e outro em $E_{\text {loss }}=53 \mathrm{meV}$. Ambos são também observados longo de toda a direção $\bar{\Gamma} \bar{X}$ da SBZ, variando-se o vetor de onda no plano. O pico inelástico mais intenso é sempre aquele observado em $E_{\text {loss }}=53 \mathrm{meV}$. Discutimos suas origens e naturezas mais adiante.

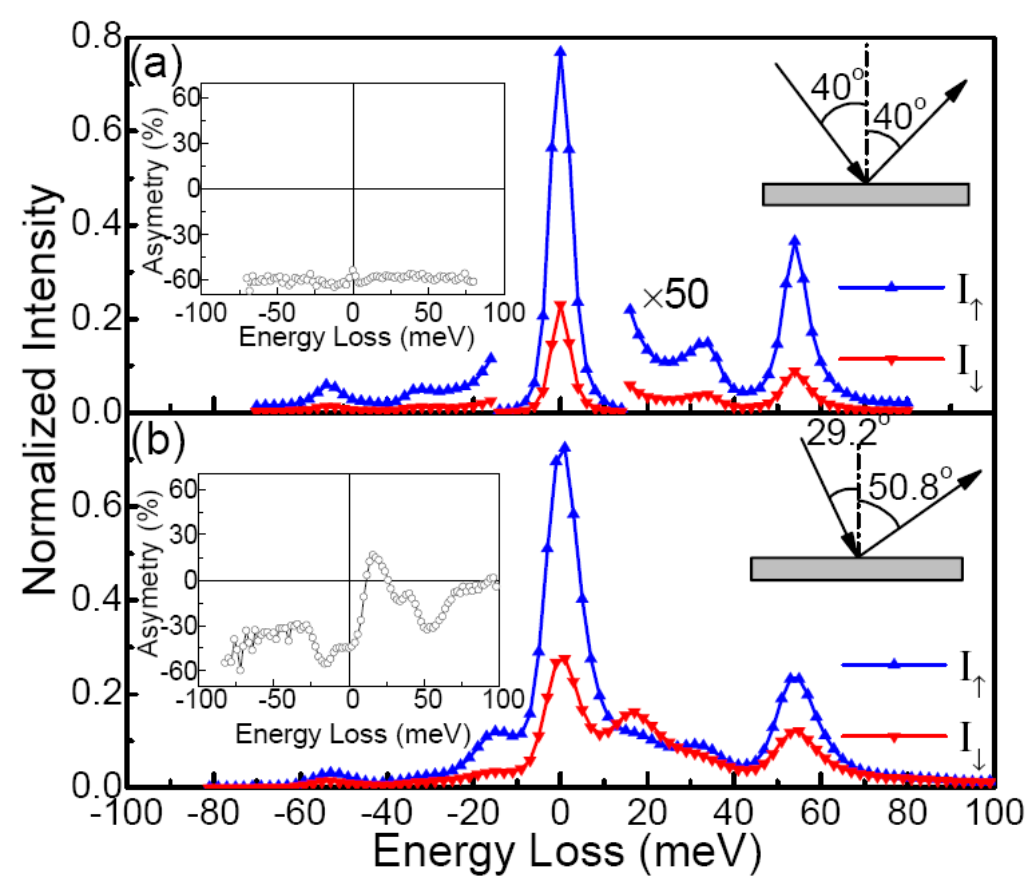

Figura 4.8: Espectros de SPEELS de 30 ML O-Fe/W(001) em geometrias (a) especular e (b) não-especular. Os vetores de onda no plano são respectivamente 0 e $0,3 \AA^{-1}$. As assimetrias de spin são mostradas nos detalhes. A energia dos elétrons incidentes é de $4,1 \mathrm{eV}$, com resolução (FWHM) de $6 \mathrm{meV}$.

Já em geometria não-especular [fig. 4.8(b)], o pico quasi-elástico é bem menos intenso e os picos inelásticos correspondem a até $25 \%$ da intensidade daquele. Com isso, a assimetria passa a exibir uma forte dependência com a perda de energia dos elétrons espalhados, em função da natureza magnética das excitações, principalmente na faixa entre $-20 \mathrm{meV}$ e $+20 \mathrm{meV}$. Nessa faixa de energia, observa-se picos eqüidistantes (à origem) e de sinais opostos em torno de $\pm 16 \mathrm{meV}$ na assimetria. Ao contrário dos picos não-spin-flip men- 
cionados anteriormente, que exibem a mesma assimetria nos regimes de perda e ganho de energia, esta excitação spin-flip exibe uma assimetria positiva de aproximadamente $+16 \%$ no regime de perda e uma negativa de aproximadamente $-55 \%$ no regime de ganho. Essa clara "inversão" da assimetria de spin indica a ocorrência de uma excitação tipo spin-flip por meio do mecanismo de espalhamento por troca de elétrons, como já foi explicado na seção 2.2.2. Os dois picos não-spin-flip observados anteriormente em geometria especular (33 meV e $53 \mathrm{meV}$ ) são observados também aqui.
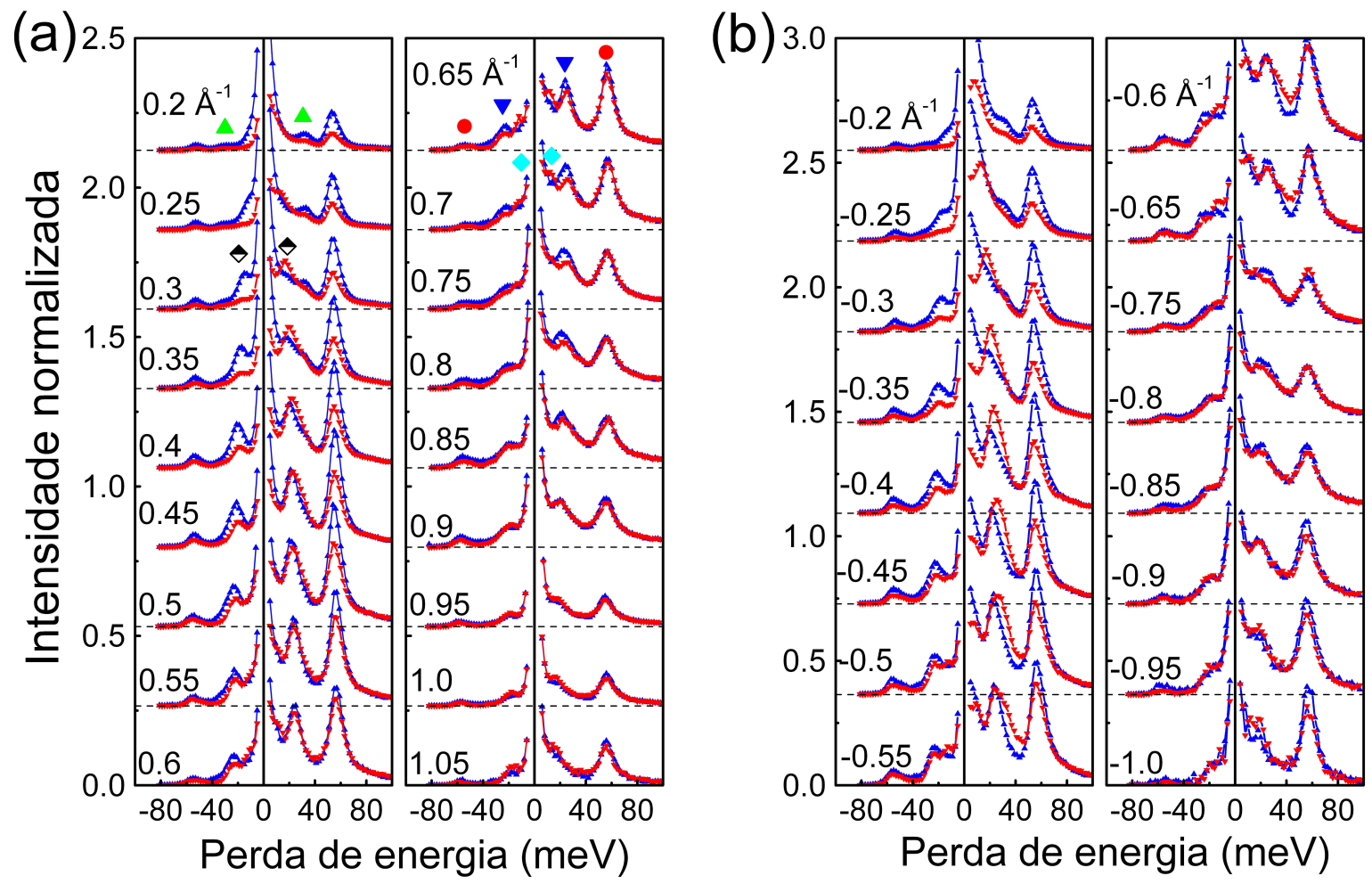

Figura 4.9: Espectros de SPEELS de $30 \mathrm{ML}$ O-Fe/W(001) para os ramos (a) positivo e (b) negativo de vetores de onda paralelos à superfície, ao longo de toda a SBZ, na direção $\bar{\Gamma} \bar{X}$. As diferentes excitações estão marcadas com diferentes símbolos. Os losangos em preto e branco representam as excitações spin-flip, que são atribuídas a mágnons (ondas de spin) de grandes vetores de onda. Os demais símbolos representam as excitações não-spin-flip, detalhadas no texto. A energia dos elétrons incidentes é de $4 \mathrm{eV}$, com resolução (FWHM) de $6 \mathrm{meV}$, para $\Delta K<0,7 \AA^{-1}$, e $8 \mathrm{eV}$, com FWHM $11 \mathrm{meV}$, para $\Delta K>0,7 \AA^{-1}$.

Mudando-se gradativamente o ângulo de incidência do feixe primário, variamos o momento linear transferido à amostra ao longo da direção [100], paralelamente à superfície. Assim, obtivemos espectros de SPEELS para um extenso conjunto de pontos da SBZ ao 
longo da direção $\bar{\Gamma} \bar{X}$, com vetores de onda variando de 0,2 a $1,1 \AA^{-1}$, que é o limite da SBZ para esta superfície. Os resultados para o conjunto positivo de vetores de onda encontram-se na figura 4.9(a). Resultados semelhantes foram obtidos para o ramo negativo [4.9(b)]. Na figura 4.9(a), vemos em destaque (símbolos) os picos spin-flip (losango em preto e branco) e não-spin-flip (demais símbolos), dois dos quais (círculo vermelho e triângulo verde) já mencionados acima. À medida que variamos o vetor de onda paralelo ao plano, distinguimos outros picos (triângulo azul-escuro e losango azul-claro), na faixa de energia entre 7 e $25 \mathrm{meV}$, que parecem mais claros conforme a geometria do espalhamento muda [por exemplo, o pico em azul-claro é bem mais evidente para vetores de onda negativos - ver fig. 4.9(b)] $]^{1}$. Estes dois últimos, ao contrário dos anteriores, exibem uma clara dispersão, típica de modos elásticos coletivos do material, como veremos a seguir.

A partir da determinação da posição dos picos inelásticos nestes espectros, construímos a relação de dispersão das excitações de superfície observadas em $30 \mathrm{ML}$ O-Fe/W(001). Na figura 4.10, usamos os mesmos símbolos da figura 4.9 para identificar as curvas de dispersão de cada pico inelástico. Para confirmar as propriedades de simetria do sistema, a precisão do equipamento e a ausência de artefatos experimentais, construímos quatro ramos para cada excitação, correspondentes aos picos observados em cada um dos regimes de energia (ganho e perda) e de direção de propagação da excitação (vetores de onda positivos e negativos). As curvas são bastante simétricas, dentro da resolução do aparelho, como esperado. Passamos a discutir a partir daqui a natureza das excitações observadas, começando pelas excitações tipo spin-flip. Estas exibem uma forte dispersão entre 16 e $40 \mathrm{meV}$, à medida que o vetor de onda varia de 0,2 a $0,7 \AA^{-1}$. Porém, ao mesmo tempo, os picos tornam-se cada vez mais largos, para maiores vetores de onda (fig. 4.9). A forte dispersão observada é típica de um ramo acústico de ondas de spin. Porém, no limite de $\Delta K \rightarrow 0$ (centro da SBZ) parece não ir a zero como um autêntico ramo acústico, mas convergir para um valor não nulo em $\Delta K=0$. Isto significa a existência de um modo magnetostático (de comprimento de onda infinito), que corresponde à visão clássica da

\footnotetext{
${ }^{1}$ Ocorre uma modulação das intensidades dos picos inelásticos em função da geometria do espalhamento (em particular, em função de $\theta_{i}$ e $\theta_{0}$ ) devido ao fenômeno da estrutura fina do padrão de LEED, já discutido na seção 2.2.1. Isso pode dificultar ou facilitar a identificação de alguns picos inelásticos mais sutis e até mesmo a definição de uma margem de erro experimental para a determinação da posição de um dado pico.
} 


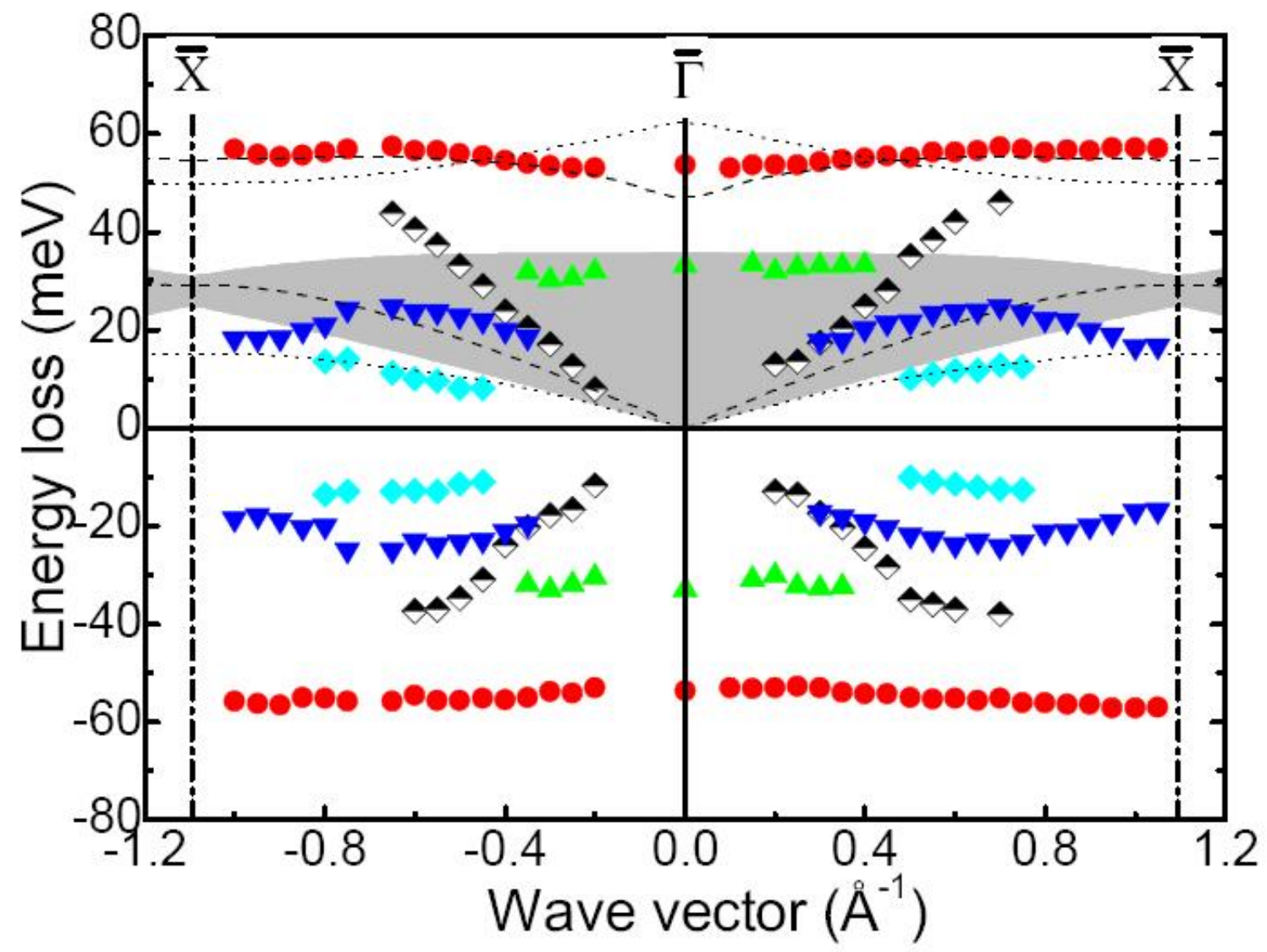

Figura 4.10: Dispersão das excitações inelásticas de superfície observadas em 30 ML O$\mathrm{Fe} / \mathrm{W}(001)$ ao longo da direção [010] do cristal ( $\bar{\Gamma} \bar{X}$ da SBZ). Os losangos em preto e branco correspondem às excitações tipo spin-flip (ondas de spin), enquanto todas as outras são nãospin-flip. Os círculos vermelhos correspondem ao modo óptico de vibração dos átomos de O. Os triângulos verdes correspondem a modos ressonantes induzidos no volume do filme de $\mathrm{Fe}$, mas com alguma amplitude na superfície. Os triângulos azúis correspondem ao modo óptico dos fônons de superfície em $\mathrm{FeO}$, no qual os átomos de $\mathrm{Fe}$ e $\mathrm{O}$ vibram em oposição de fase. Os losangos azúis-claros correspondem ao modo transversal acústico de superfície do Fe (modo de Rayleigh). Esse último modo apresenta um ótimo acordo com resultados de fônons de superfície obtidos por espalhamento de átomos de He numa superfície oxidada de $2 \mathrm{ML} \mathrm{Fe/MgO(001)} \mathrm{[112],}$ muito semelhante à estudada neste trabalho. As linhas tracejadas e pontilhadas são obtidas do modelo e correspondem a diferentes polarizações (longitudinal e transversal, respectivamente) dos modos calculados. A zona hachurada corresponde à banda de volume da camada de $\mathrm{Fe}$ subjacente. 
precessão da magnetização remanente do material em torno da posição de equilíbrio determinada pelo eixo de anisotropia magnética. Para $\Delta K>0,7 \AA^{-1}$, os picos spinflip tornam-se muito difusos, impossibilitando sua precisa determinação. Isto está de acordo com estudos anteriores em superfícies de Co [68, 83] e Fe [84, 85] e se deve ao decaimento das ondas de spin em excitações de Stoner, no limite de grandes vetores de onda. Neste limite, a dispersão de ondas de spin penetra no continuum das excitações de Stoner, quebrando a coerência das ondas de spin - entendidas como estados coerentes de mágnons -, que decaem em estados excitados de elétrons isolados [127]. Isto evidencia o caráter tipicamente itinerante do magnetismo desses sistemas.

O magnetismo de metais de transição deve-se essencialmente aos elétrons dos níveis eletrônicos 3d, que formam bandas de elétrons quase livres, com bastante mobilidade no metal. Estes elétrons interagem não apenas com os núcleos atômicos localizados nos sítios da rede, mas também entre si, via repulsão coulombiana e interação de troca. Desta forma, os elétrons 3d apresentam um comportamento que, ora parece o de elétrons localizados - como nos casos das excitações de spin de baixas energias e do calor específico a baixas temperaturas, bem descritas pelo modelo de Heisenberg e pela lei $T^{\frac{3}{2}}$ de Bloch -, ora o de elétrons itinerantes - como nos casos da ocorrência de valores não-inteiros de momentos magnéticos atômicos, das excitações de Stoner em altas energias e do modelo de Hubbard [127]. Para pequenos vetores de onda (longos comprimentos de onda), as excitações são de baixas energias e os autoestados de elétrons únicos na banda de condução são coerentes, resultando na visão clássica de "ondas de spins" localizados, descritas pelo modelo de Heisenberg [127]). Mas no limite de altas energias, a superposição (overlap) dos subníveis 3d e 4s e a interação entre elétrons nesses níveis degenerados tornam o caráter itinerante mais evidente e o modelo de Heisenberg - spins localizados nos sítios da rede - perde sua validade $[84,131]$.

Agora, discutimos a origem dos picos não-spin-flip observados, a partir de resultados de modelos da literatura [128, 129], e sua corroboração por estudos experimentais anteriores $[112,118]$. O modelo desenvolvido por aqueles autores se baseia na combinação da teoria de Born-von Karman de vibrações elásticas de redes cristalinas [130] para a camada de Fe subjacente [128] com um modelo de íon-rígido para a superfície de FeO [129]. O modelo considera apenas interações de curto alcance (até primeiros vizinhos), descritas através 
de uma matriz de constantes de força atribuída a cada um do vizinhos de um dado átomo no cristal. Essas matrizes são introduzidas na equação de movimento dos átomos da rede e utilizadas para determinar as energias dos fônons,

$$
m \ddot{\epsilon}_{i}=\sum_{j, l} \phi_{i j}^{(l)} \epsilon_{j}^{(l)}
$$

onde $m$ é a massa de um dado átomo da rede, $\epsilon_{i}$ é o deslocamento do átomo na direção $i$, $\phi_{i j}^{(l)}$ é a matriz de constantes de forças entre o átomo na origem e o vizinho $l$. Ela pode ser entendida como a força na direção $i$ sobre o átomo na origem devido a um deslocamento do vizinho $l$ na direção $j$. As equações são resolvidas via método de mínimos quadrados.

A adaptação desse modelo ao nosso sistema foi desenvolvida pelo colega Dr. Yu Zhang e colaboradores do Instituto Max Planck de Física de Microestruturas, em Halle, e nos indica uma possível interpretação dos nossos resultados. No modelo, uma rede cristalina é composta por dois diferentes átomos: Fe e O. O sistema consiste em 29 camadas atômicas de Fe (uma única célula unitária por camada), com uma monocamada de FeO em cima. Apenas interações entre primeiros vizinhos são consideradas entre átomos da superfície e os da camada de Fe logo abaixo. Além disso, o acoplamento entre um átomo de $\mathrm{O}$ da superfície e um de Fe do volume é considerado igual ao acoplamento O-Fe da superfície. Todos os outros parâmetros são considerados iguais aos do Fe intrínseco, obtidos da referência [129].

Cada átomo $n$ da rede desloca-se de $\mathbf{u}_{\mathbf{n}}$ de sua posição de equilíbrio. A energia potencial do sistema, numa aproximação adiabática, é dada por

$$
U=U_{0}+\frac{1}{2} \sum_{\mathbf{n}, \mathbf{n}^{\prime}, \alpha, \beta} \mathbf{D}_{\mathbf{n}, \mathbf{n}^{\prime}}^{\alpha \beta} \mathbf{u}_{\mathbf{n}}^{\alpha} \mathbf{u}_{\mathbf{n}^{\prime}}^{\beta}
$$

onde $U_{0}$ é uma constante, $\alpha$ e $\beta$ são coordenadas cartesianas, $\mathbf{D}_{\mathbf{n}, \mathbf{n}^{\prime}}^{\alpha \beta}$ é a "matriz dinâmica" do sistema. A equação do movimento para os átomos nos sítios da rede cristalina sob a ação do potencial acima é escrita da forma

$$
m_{n} \ddot{\mathbf{u}}_{\mathbf{n}}{ }^{\alpha}=-\frac{\partial U}{\partial \ddot{\mathbf{u}}_{\mathbf{n}}{ }^{\alpha}}=-\sum_{\mathbf{n}^{\prime}, \beta} \mathbf{D}_{\mathbf{n}, \mathbf{n}^{\prime}}^{\alpha \beta} \mathbf{u}_{\mathbf{n}^{\prime}}^{\beta}
$$


e é resolvida para funções harmônicas do tipo $\mathbf{u}_{\mathbf{n}}^{\alpha} \propto \exp \left\{-i \vec{k} \cdot \overrightarrow{r_{n}}+\omega t\right\}$ para cada átomo da supercélula que representa o sistema. Para construir essa supercélula e calcular a matriz de forças dos átomos com seus vizinhos, é necessário utilizar um método ab initio. A matriz de forças é dada por

$$
\Phi_{\mathbf{n}, \mathbf{l} ; \mathbf{n}^{\prime}, \mathbf{l}^{\prime}}^{\alpha \beta}=-\frac{\mathbf{F}_{\mathbf{n}, \mathbf{l}}^{\alpha}}{\mathbf{u}_{\mathbf{n}^{\prime}, \mathbf{l}^{\prime}}^{\beta}}
$$

onde o índice $l$ denota células individuais da supercélula. Combinando as equações acima com a solução harmônica, obtém-se a seguinte expressão para a matrix dinâmica:

$$
\mathbf{D}_{\mathbf{n}, \mathbf{n}^{\prime}}^{\alpha \beta}(\vec{k})=\frac{1}{\sqrt{m_{n} m_{n^{\prime}}}} \sum_{l^{\prime}} \boldsymbol{\Phi}_{\mathbf{n}, \mathbf{0} ; \mathbf{n}^{\prime}, \mathbf{l}^{\prime}}^{\alpha \beta} \exp \left\{-i \vec{k} \cdot\left(\vec{r}_{n^{\prime}, l^{\prime}}-\vec{r}_{n, 0}\right)\right\}
$$

Substituindo o resultado acima na equação do movimento, obtém-se a equação de autovalores dos fônons

$$
\omega^{2} \mathbf{e}_{\nu}(\tilde{\mathbf{k}})=\mathbf{D}(-\tilde{\mathbf{k}}) \mathbf{e}_{\nu}(\tilde{\mathbf{k}})
$$

onde $\omega$ é a freqüência dos fônons e $\mathbf{e}_{\nu}(\tilde{\mathbf{k}})$ são os autovetores dos modos. Com isso pode-se obter toda a estrutura de bandas de fônons do sistema, inclusive com a amplitude dos modos em função de sua localização espacial (distância em relação á superfície). Isso nos permite comparar com os resultados experimentais, identificá-los e interpretá-los.

Como já foi dito, o ramo em torno de $53 \mathrm{meV}$ (círculos vermelhos) exibe uma dispersão muito fraca e um caráter claramente óptico - converge para um valor não nulo quando $\Delta K \rightarrow 0$. A fraca dispersão é uma característica de modos vibracionais de adsorvatos na superfície. O modelo prevê dois ramos ópticos nessa região: um longitudinal (linha tracejada), outro transversal (linha pontilhada), mas a distinção experimental não é clara, podendo até haver uma mistura de modos. Entretanto, as regras de seleção de espalhamento inelástico de elétrons [98] confirmam o caráter transversal da excitação em $53 \mathrm{meV}$. Além disso, estudos prévios de EELS [118] em FeO confirmam que esse ramo corresponde ao modo vibracional perpendicular da ligação O-Fe [129]. O modelo também prevê uma banda de fônons de volume na camada de Fe subjacente, representada pela área hachurada.

O pico em $33 \mathrm{meV}$ (triângulos verdes) também exibe uma dispersão típica de um ramo óptico de fônons localizados na superfície. Porém ele coexiste com a banda de volume de 
fônons (área hachurada) [129]. O modelo indica que este não é um modo de superfície genuíno, mas um modo de superfície hibridizado com modos de volume, existindo também em camadas abaixo da superfície; ou ainda um modo ressonante, que é um modo com características de fônons de volume de Fe, mas com grandes amplitudes na superfície de Feo [98].

Os picos denotados por losangos azúis-claros constituem o modo tranversal acústico de fônons de superfície em FeO (ondas de Rayleigh). Ele tangencia o limite inferior da banda de volume do Fe e concorda perfeitamente com os resultados de dispersão de fônons de superfície da referência [112], obtidos por espalhamento de átomos de He em superfícies de $2 \mathrm{ML} \mathrm{O}-\mathrm{Fe} / \mathrm{MgO}(001)$, muito semelhante ao sistema estudado aqui.

A curva em triângulos azúis-escuros é muito curiosa: esses picos só puderam ser claramente distintos para vetores de onda acima de $0,3 \AA^{-1}$, numa curta faixa de 16 a $25 \mathrm{meV}$, que corresponde à região da banda de volume da camada de Fe subjacente [128]. Além disso, sua dispersão é caracterizada por um máximo em $0,7 \AA^{-1}$, donde passa a decair fortemente, para fora da banda de volume, tendendo a coincidir com o modo transversal acústico no limite da SBZ. O modelo prevê um ramo longitudinal acústico localizado na camada mais externa de Fe, nesta faixa de energia, superposto à banda de volume. Mas, na camada de $\mathrm{O}$, a polarização muda para um modo transversal. Devido à simplicidade do modelo, a possibilidade de hibridização entre os modos de superfície e de volume não é levada em conta. Com isso, nem a tendência descendente observada nesse ramo pode ser prevista, nem seu caráter (ressonante ou hibridizado) pode ser confirmado. Para isso, é necessário um modelo que considere um acoplamento mais realista entre os átomos da superfície e do volume.

Portanto, a partir de uma modelagem ab initio e apoiados em resultados da literatura, fomos capazes de identificar satisfatoriamente os diversos ramos não-spin-flip observados nos espectros de SPEELS. As particularidades de cada ramo foram discutidas e interpretadas na caracterização dos modos vibracionais presentes na superfície de O-Fe/W(001) via SPEELS, de maneira inédita, assim como a primeira medida da dispersão de ondas de spin de superfície com grandes vetores de onda (próximo ao limite da SBZ). Mostramos que nesse limite os mágnons sofrem forte interação com as excitações de Stoner, que são pares elétron-buraco com spins opostos, acoplados em torno da energia de Fermi. 


\section{CAPÍTULO 5}

\section{Conclusões e Perspectivas}

Neste trabalho, estudamos as interações magnetostáticas e os mecanismos de inversão da magnetização de arranjos auto-organizados de nanofios de Ni e Co com alta anisotropia de forma, através de um novo método de caracterização magnética, a análise FORC. Os arranjos de nanofios de Ni exibiram altas coercividades (entre 540 e 750 Oe) e altas remanências $\left(\geq 0,5 M_{S}\right)$. Determinamos a microestrutura dos arranjos de nanofios através de MEV, AFM/MFM e XRD. Os arranjos exibem alta densidade de fios paralelos entre si e perpendiculares à superfície, com comprimentos cerca de 50 a 200 vezes maiores que seus diâmetros. Os nanofios de Ni são policristalinos, com grãos variando de 17 a $24 \mathrm{~nm}$. Grãos cristalinos de Ni são menores que o diâmetro médio dos fios, porém maiores que seu comprimento de coerência (que é em torno de $8 \mathrm{~nm}$ para o Ni) e sem uma orientação cristalina preferencial. Este é, portanto, um típico sistema micromagnético, composto de partículas monodomínio, com eixos de anisotropia distribuídos aleatoriamente no espaço [24], acoplados entre si via interação de troca. Os nanofios de Co exibiram coercividades ainda maiores, entre 630 e 1800 Oe e uma alta anisotropia de forma, orientada ao longo do fio.

A análise dos parâmetros micromagnéticos e microestruturais obtidos dos experimentos a partir de resultados de modelagem micromagnética da literatura [43, 50] mostraram que os nanofios de Ni encontram-se no limiar de transição entre um estado remanente uniforme e um estado de multidomínio ou vórtice, enquanto os nanofios de Co encontram-se no regime de multidomínio ou vórtices. A alta razão de aspecto dos fios induz uma forte anisotropia de forma ao longo do nanofio, favorecendo a tendência magnetizante ao longo do fio, bem como a formação de pólos magnéticos descompensados nas extremidades dos 
fios, gerando um campo desmagnetizante proporcional a $-\vec{M}$ no interior. Por outro lado, a disposição paralela e a alta densidade de fios favorecem uma interação dipolar desmagnetizante entre os fios. Portanto, há uma série de contribuições intra-fios e inter-fios, que competem entre si, favorecendo a redução do campo de inversão local e o surgimento de modos não-uniformes de inversão da magnetização (tais como curling, buckling, etc.).

A análise FORC confirmou a predominância de efeitos desmagnetizantes em todas as amostras analisadas, em acordo com resultados da literatura [55, 57]. Em particular, estudamos a influência do diâmetro médio dos fios nos diagramas FORC dos nanofios de Ni e a influência da direção do campo magnético aplicado sobre os diagramas FORC dos nanofios de Co. Em ambos os casos, observamos um perfil assimétrico típico das distribuições FORC de arranjos de nanofios [55]. Esse perfil, invariável com as particularidades das amostras, parece ter origem em características gerais do sistema, como a anisotropia de forma e a interação dipolar desmagnetizante: um suave pico ao longo de $H_{c}=0$, associado às componentes reversíveis da magnetização; um pico irreversível principal, em torno de $H_{c}=H_{C}$, bastante largo ou às vezes desdobrado em dois; e uma "cauda" para grandes valores de $H_{c}$. Outras tendências gerais observadas são: a predominância da distribuição FORC na região de $H_{b}<0$, que é associada a um comportamento tipo campo médio [55] de caráter desmagnetizante do sistema [29, 55, 57]. Um resultado interessante foi uma clara migração do máximo absoluto da distribuição para $H_{b} \rightarrow 0$ à medida que o diâmetro dos fios aumenta, favorecendo componentes reversíveis de magnetização, típicas de modos não-uniformes de inversão. Quando dispostas sobre a histerese, o máximo absoluto das distribuições FORC migrou do $4^{\circ}$ para o $1^{\circ}$ quadrante da histerese. Observamos que os nanofios de Ni têm tamanhos de grãos e diâmetros dos fios numa região limiar entre um estado uniforme e outro de vórtice ou multidomínio. Acreditamos que essas mudanças dos diagramas FORC à medida que o diâmetro dos fios aumenta são a assinatura dessa transição que os nanofios de Ni sofrem. Demonstramos ainda o acoplamento entre as componentes reversíveis e irreversíves da magnetização [29] e sua relação com o surgimento de modos não-uniformes de inversão. Particularmemte, observamos o aumento das componentes reversíveis e concomitante diminuição de mecanismos irreversíveis à medida que o volume dos fios cresce, favorecendo modos não-uniformes de inversão. 
Os diagramas FORC obtidos para os arranjos de nanofios de Co exibiram alguma semelhança com aqueles obtidos para os nanofios de Ni, como a forma de "dois ramos" da distribuição e a assimetria para $H_{b}<0$, mas com o máximo principal na região $H_{b}>0$. A influência da direção do campo magnético aplicado nos diagramas FORC indicam uma forte predominância das componentes irreversíveis da magnetização e da forma típica do diagrama FORC para ângulos menores que $75^{\circ}$ em relação ao eixo fácil. A partir desse valor, ocorre um rápido crescimento das componentes reversíveis em detrimento das irreversíveis e uma visível mudança do comportamento do diagrama. Acreditamos que esse valor é muito próximo do ângulo limite para a ativação de um estado remanente multidomínio, caracterizado por domínios magnéticos opostos ao longo do fio, que ocorre para pequenos ângulos em torno da direção do eixo duro $\theta=90^{\circ} \pm \epsilon$. Estimamos o valor de $\epsilon=15^{\circ}$ a partir da análise FORC e da mudança da assinatura das interações magnéticas no diagrama FORC em função do ângulo $\theta$., em pleno acordo com a literatura [43]. Para $\theta=90^{\circ}$, o diagrama FORC aparenta ser o de uma amostra quase totalmente reversível. Esses resultados mostram de maneira evidente o efeito desmagnetizante da forte anisotropia de forma sobre o perfil da distribuição FORC, ao se afastar da direção de fácil magnetização, e, conseqüentemente, sobre o processo de magnetização dos nanofios.

Enfim, demonstramos que a análise FORC é capaz de revelar informações micromagnéticas que não são diretamente acessíveis num ciclo de histerese convencional e pode ser uma ferramenta poderosa de caracterização magnética, especialmente quando associada a técnicas de caracterização microestrutural e à modelagem micromagnética. Isto reside no fato de que, durante a medida de um grande conjunto de FORCs, o sistema visita (virtualmente) todos os microestados magnéticos acessíveis. Possíveis interessantes estudos seriam: (1) a influência da temperatura no diagrama FORC desses sistemas, em toda a faixa de temperatura, desde a temperatura ambiente até $T \rightarrow 0 \mathrm{~K}$; (2) estudar a influência do crescimento do grão de Co sobre os diagramas FORC, a partir de um tratamento térmico das amostras de Co; e (3) a tentativa de se excitar modos magnéticos coletivos confinados nos nanofios através de alguma técnica de medidas magnéticas dinâmicas.

Estudamos também o comportamento dinâmico magnético e elástico de filmes finos de O-Fe/W(001) através de SPEELS, a única técnica conhecida hoje em dia capaz de detectar excitações elementares de superfície ao longo de toda a SBZ, i.e., no limite de 
grandes vetores de onda. Comprovamos através de LEED, AES e MOKE a boa qualidade estrutural e magnética da superfície, estudamos o espectro de SPEELS em geometria de espalhamento especular, mostramos a alta polarização de spin dessa superfície, sua estabilidade e a independência da assimetria de spin com espalhamentos ineásticos, o que dá a essa superfície um alto potencial para aplicações tecnológicas em spintrônica ou polarização de elétrons ou ainda espalhamentos dependentes de spin. Estudamos também o espalhamento inelástico de elétrons em geometria não-especular, identificamos os picos inelásticos tipo spin-flip e não-spin-flip e apresentamos, de maneira inédita, o espectro de mágnons e fônons de superfície em $\mathrm{O}-\mathrm{Fe} / \mathrm{W}(001)$, no limite de grandes vetores de onda, medidos por SPEELS. Interpretamos os espectros segundo resultados conhecidos da literatura em INS e espalhamento de átomos de He [112, 128, 129], bem como à luz de modelos teóricos bem estabelecidos, como a teoria de Born-von Karman das vibrações elásticas [128, 129, 130] e da recente literatura de filmes finos magnéticos estudados por SPEELS [83, 84, 85, 127, 131]. Discutimos também que, embora nos dê uma idéia semi-clássica de excitações elementares coletivas - ondas de spin -, o modelo de Heisenberg não representa a interpretação mais adequada para a dinâmica de spins em sistemas magnéticos itinerantes, como superfícies metálicas. Por exemplo, ele não leva em conta a existência de excitações spin-flip de pares de elétrons - as excitações de Stoner -, que são importantes no limite de altas energias, próximas ao limite da SBZ. Nessa região, as ondas de spin interferem com as excitações de elétrons nas bandas de energia, próximos ao nível de Fermi. Além disso, o modelo de Heisenberg também não leva em consideração a ocorrência de modos mistos de mágnons-fônons, que podem estar presentes nesse sistema $[86,87,88]$. Possíveis evidências seriam a detecção de dois ramos na dispersão (um spin-flip, outro não-spin-flip), que não se cruzam, acompanhado de um forte decaimento dos dois modos na região em que os ramos se aproximam. Nesse caso, ocorreria uma modulação da largura dos picos de mágnons e fônons para vetores de onda próximos à região de cruzamento (cross-over) dos ramos. Uma outra interessante proposta de estudo seria a deposição de uma camada de Fe sobre a superfície de FeO, de modo que a camada mais externa se acoplaria à camada de Fe subjacente por meio do mecanismo de superexchange, uma vez que há uma camada de átomos de $\mathrm{O}$ entre as duas de Fe. Esse mecanismo favorece um forte acomplamento antiferromagnético entre as duas 
camadas de Fe, de modo que as ondas de spin de superfície nesse caso podem trazer este caráter antiferromagnético em sua dispersão.

A detecção de tais modos é, em princípio, possível através de SPEELS, mas o estado de arte da técnica ainda não permite uma determinação precisa (em energia) dos ramos de mágnon próximos ao continuum de Stoner. Possíveis melhorias instrumentais seriam: (1) a construção de espectrômetros de elétrons que permitam feixes de intensidades razoáveis, com resoluções $\leq 1 \mathrm{meV}$, e (2) a utilização de um analizador de spins na saída do espectrômetro, de modo a se obter as quatro intensidades parciais spin-flip e não-spin-flip separadamente. Nessas condições, a revisitação desse sistema poderia revelar a interação mágnon-fônon e/ou ondas de spin antiferromagnéticas, em especial a baixas temperaturas. 


\section{Apêndice A}

\section{Algoritmo Desenvolvido para o Cálculo da Distribuição FORC}

Abaixo transcrevemos o algoritmo desenvolvido em MatLab. Ele consiste em duas partes: um arquivo-fonte principal desenvolvido por mim (abaixo) e de uma sub-rotina (sg_forc.m), definida na referência [54], para o cálculo do filtro de convolução de SavitzkyGolay (em seguida).

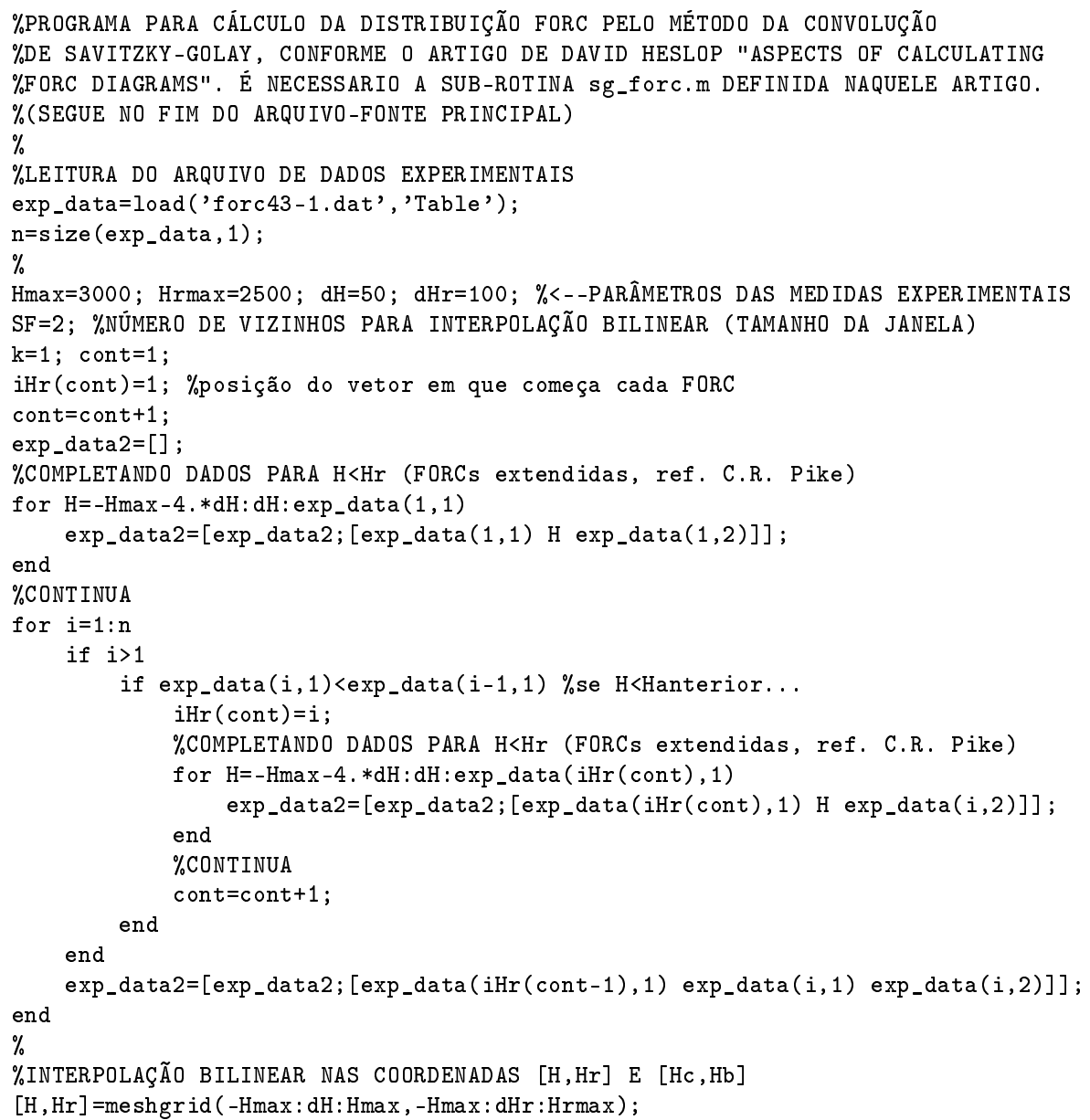




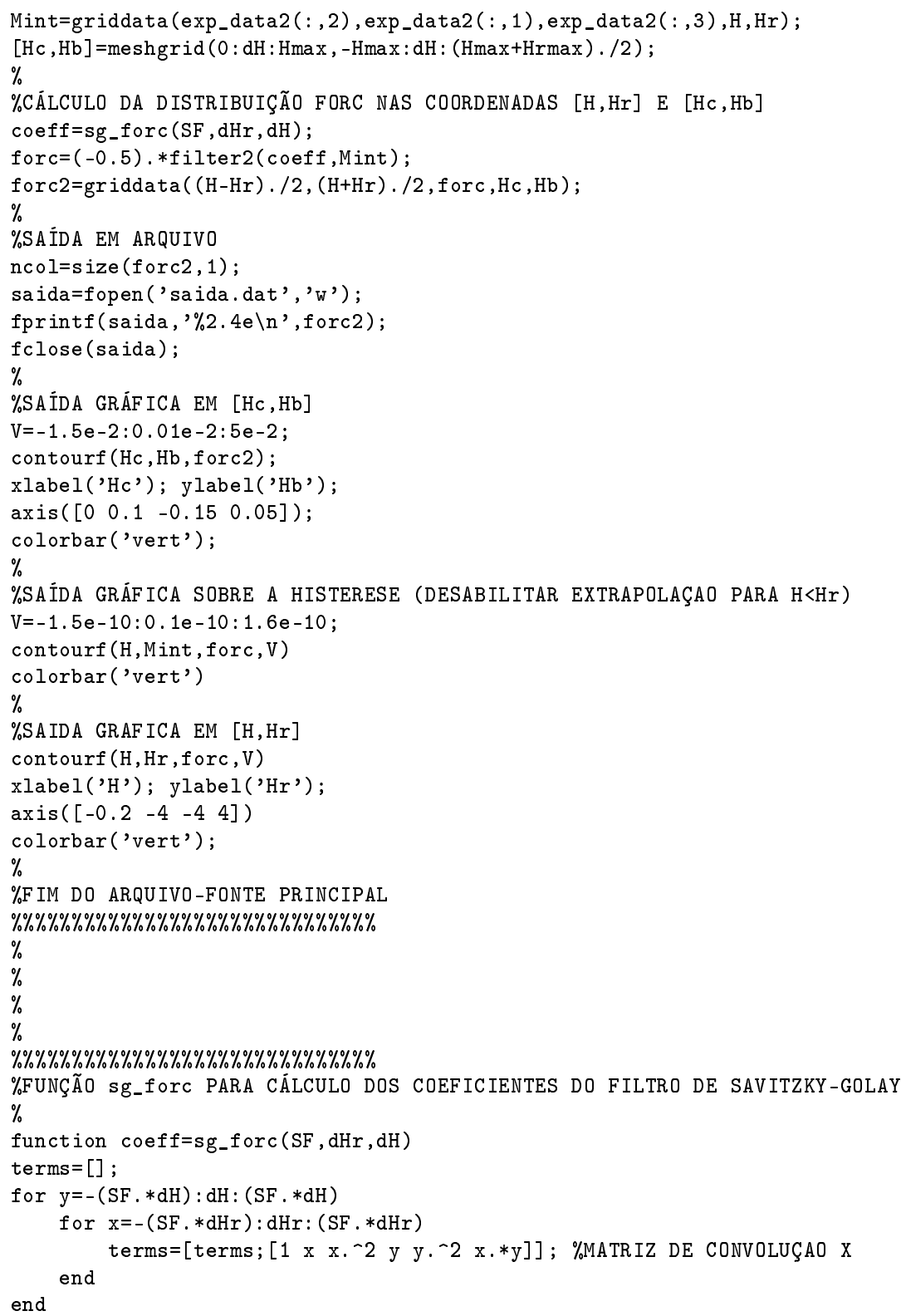




\section{Apêndice B}

\section{Lista de Publicações}

Nas páginas seguintes, encontram-se os anversos das publicações realizadas durante o período do Doutorado, em ordem cronológica. 


\title{
Characterizing magnetic interactions in Ni nanowires by FORC analysis
}

\author{
T.R.F. Peixoto, D.R. Cornejo*
}

Instituto de Física, Universidade de São Paulo, 05508-900 São Paulo, SP, Brazil

Available online 21 February 2008

\section{Abstract}

Polycrystalline Ni nanowires with different diameters were electrodeposited in nanoporous anodized alumina membranes. First-Order Reversal Curves (FORCs) were measured and FORC distributions were calculated. They clearly showed an asymmetric behavior with a strong maximum at negative interaction fields, evidencing the dominant demagnetizing interactions which depend on the geometry of the nanowires.

(C) 2008 Elsevier B.V. All rights reserved.

PACS: $75.60 . \mathrm{Ej} ; 75.60 . \mathrm{Jk} ; 75.75 .+\mathrm{a}$

Keywords: Magnetic nanowire; FORC; Demagnetization process; Electrodeposition

\section{Introduction}

Self-organized arrays of ferromagnetic nanowires show potential feasibility for applications in perpendicular magnetic recording media and high-sensitivity magnetic sensors [1], and are well suited for both experimental and theoretical study of magnetism at nanoscale [1-4]. These systems can be easily synthesized through the method of two-step anodization [5] and subsequent chemical electrodeposition $[2,3]$.

One phenomenological approach that has been topic of renewed interest in magnetic systems is the First-Order Reversal Curves (FORC) analysis [6-11]. FORCs can be experimentally obtained as follows: (a) first, one has to saturate the sample with a field $H_{\max }$; (b) then, set the field $H$ to a return value $H_{\mathrm{r}}<H_{\mathrm{max}}$; (c) then, increase $H$ back to $H_{\max }$, measuring the magnetization; and (d) and repeat steps (b) and (c) for decreasing values of $H_{\mathrm{r}}$, while $H_{\mathrm{r}} \geqslant-H_{\max }$

The FORC distribution is, then, defined by $\rho\left(H_{\mathrm{r}}, H\right) \equiv$ $-0.5\left\{\partial^{2} M\left(H_{\mathrm{r}}, H\right) / \partial H_{\mathrm{r}} \partial H\right\}$ and performed on the dataset of the measured FORCs. The FORC diagram is a contour plot of $\rho$ on a $45^{\circ}$ rotated coordinate system $\left\{H_{\mathrm{c}}=\right.$ $\left.\left(H-H_{\mathrm{r}}\right) / 2, \quad H_{\mathrm{b}}=\left(H+H_{\mathrm{r}}\right) / 2\right\}$. In these coordinates,

\footnotetext{
${ }^{*}$ Corresponding author. Tel.: + 551130916885 ; fax: + 551130916984 . E-mail address: cornejo@if.usp.br (D.R. Cornejo).
}

0304-8853/\$ - see front matter (C) 2008 Elsevier B.V. All rights reserved. doi:10.1016/j.jmmm.2008.02.060 $\rho$ can be compared to the statistical distribution of particles from the Preisach model [12], which describes the fieldinduced reversal of an ensemble of single-domain particles.

Thus, the FORC diagram provides a detailed characterization of the hysteretic response of a system because it evidences dominant magnetic interactions, magnetic aftereffects and the annihilation of memory during the demagnetization process.

In this work, a set of samples of Ni nanowires grown in the nanoporous anodized alumina membranes were magnetically characterized by FORC analysis.

\section{Experimental details}

Thin $(0.2 \mathrm{~mm}) \mathrm{Al}$ foils with $99.997 \%$ purity were pretreated in vacuum at $600{ }^{\circ} \mathrm{C}$ for $2 \mathrm{~h}$; washed in acetone; electropolished in a $\mathrm{H}_{2} \mathrm{SO}_{4}+\mathrm{H}_{3} \mathrm{PO}_{4}+\mathrm{H}_{2} \mathrm{O}$ solution; etched in a $3 \mathrm{M} \mathrm{NaOH}$ solution and rinsed in deionized water. Later, the foils were anodized in a constant voltage cell containing an aqueous solution of $0.3 \mathrm{M}$ oxalic acid $\left(\mathrm{H}_{2} \mathrm{C}_{2} \mathrm{O}_{4}\right)$, at $4{ }^{\circ} \mathrm{C}$, using a graphite electrode as cathode. The first anodization was carried out for $1 \mathrm{~h}$ and the second for $40 \mathrm{~min}$. Several samples were prepared with anodization voltage $V_{\text {an }}$ varying between 15 and $30 \mathrm{~V}$. The electrodepositions were carried out in a solution of $0.1 \mathrm{M}$ $\mathrm{NiSO}_{4} \cdot 6 \mathrm{H}_{2} \mathrm{O}+45 \mathrm{~g} / \mathrm{LH}_{3} \mathrm{BO}_{3}$, at $55^{\circ} \mathrm{C}$, for $2 \mathrm{~min}$, under $20 \mathrm{~V}$, at $100 \mathrm{~Hz}$. 


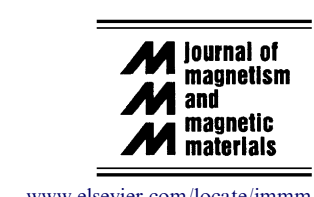

www.elsevier.com/locate/jmmm

\title{
Reversible and irreversible magnetization components behavior in $\mathrm{Ni}$ nanowires
}

\author{
C. Rocha, T.R.F. Peixoto, D.R. Cornejo*
}

Instituto de Fisica, Universidade de São Paulo, 05508-900 São Paulo, SP, Brazil

Available online 21 February 2008

\begin{abstract}
Polycrystalline $\mathrm{Ni}$ nanowires were electrodeposited in nanoporous anodized alumina membranes with mean diameter of approximately $42 \mathrm{~nm}$. Their magnetic properties were studied at $300 \mathrm{~K}$, by measurements of recoil curves from demagnetized state and also from saturated state. $M_{\mathrm{rev}}$ and $M_{\mathrm{irr}}$ components were obtained and $M_{\mathrm{rev}}\left(M_{\mathrm{irr}}\right)_{H}$ curves were constructed from the experimental data. These curves showed a behavior that suggests a non-uniform reversal mode influenced by the presence of dipolar interactions in the system. A qualitative approach to this behavior is obtained using a Stoner-Wohlfarth model modified by a mean field term and local interaction fields.
\end{abstract}

(C) 2008 Elsevier B.V. All rights reserved.

PACS: 75.60.Ej; 75.60.Jk; 75.75. + a

Keywords: Ni nanowire; Magnetization reversal; Irreversible magnetization; Magnetic interaction

\section{Introduction}

Recently, patterned nanowire structures have been intensively studied due to their potential application in high-density recording media and microelectromechanical systems [1]. One simple method to obtain self-organized arrays of nanowires is using anodized alumina membranes (AAMs) as templates [2]. These templates can be homogeneously filled with magnetic elements such as $\mathrm{Ni}$ by means of a well-controlled electrodeposition process.

The magnetization process in these materials offers interesting challenges, since the interplay between the different anisotropies favors soft magnetic material like $\mathrm{Ni}$ to display coercivities comparable to hard magnetic materials.

To study mechanisms of magnetization reversal, it is common to separate the total magnetization $M$ into reversible $\left(M_{\text {rev }}\right)$ and irreversible $\left(M_{\text {irr }}\right)$ components. $M_{\text {irr }}$ can be experimentally probed by measuring remanence curves from the demagnetized state (i.e., the isothermal

${ }^{*}$ Corresponding author. Tel.: +551130916885 ; fax: + 551130916984 E-mail address: cornejo@if.usp.br (D.R. Cornejo). remanence, $\left.M_{\mathrm{irr}}=M_{\mathrm{r}}\left(H_{\mathrm{p}}\right)\right)$ and from the saturated state (obtaining the demagnetization remanence, $M_{\mathrm{irr}}=M_{\mathrm{d}}\left(H_{\mathrm{p}}\right)$ ), for a set of return fields $H_{\mathrm{p}}$. Thus, $M_{\text {rev }}\left(H_{\mathrm{p}}, H\right)$ of any state of magnetization is immediately defined as $M_{\text {rev }}=M-M_{\text {irr }}$. By using a suitable set of first-order reversal curves, it is possible to build, for several values of the magnetic internal field $H, M_{\text {rev }}\left(M_{\text {irr }}\right)_{H}$ curves. The behavior of these curves gives an indicative of the magnetization reversal mode of the material [3]. For systems that reverse by coherent rotation, $M_{\text {rev }}\left(M_{\text {irr }}\right)_{H}$ curves are linear, with negative slope. On the other hand, in systems whose reversal mechanism is domain wall unpinning or nucleation of inverse domains, these curves are parabolic, exhibiting a minimum during demagnetization process.

In a previous work [4], a new form of $M_{\text {rev }}\left(M_{\text {irr }}\right)_{H}$ curves was reported in $\mathrm{Fe}$ nanowires. In this work, we report a similar behavior of these curves for Ni nanowire arrays and a qualitative approach of this behavior by means of computational modeling. We generated numerical firstorder recoil curves through an interacting Stoner-Wohlfarth model and obtained $M_{\mathrm{rev}}\left(M_{\mathrm{irr}}\right)_{H}$ by the same way as the experimental curves. This model is based in one originally developed by Crew $[5,6]$ and it takes into 


\section{Referências Bibliográficas}

[1] J. J. Sakurai e S. F. Tuan, Modern Quantum Mechanics - Revised Edition, AddisonWesley Publishing Co., Nova York, EUA, 1994.

[2] T. R. F. Peixoto, Dissertação de Mestrado, Universidade Federal do Rio Grande do Norte, Natal, Brasil, 2005.

[3] M. N. Baibich, J. M. Broto, A. Fert, F. N. Vandau, F. Petroff, P. Eitenne, G. Creuzet, A. Friederich e J. Chazelas, Physical Review Letters, 61, p. 2472, 1988.

[4] G. Binasch, P. Grünberg, F. Saurenbach e W. Zinn, Physical Review B, 39, p. 4828-4830, 1989.

[5] H. Lüth, Surfaces and Interfaces of Solid Materials, $3^{\text {a }}$ edição, Springer-Verlag, Berlim, Alemanha, p. 37-50, 1995.

[6] W. H. Meiklejohn e C. P. Bean, Physical Review, 105, p. 904, 1957.

[7] M. Jullière, Physics Letters A, 54, p. 225, 1975.

[8] E. Grochowski e R. D. Halem, IBM Systems Journal, 42, p. 228, 2003.

[9] P. S. Peercy, Nature, 406, p. 1023-1026, 2000.

[10] M. Knobel, Revista Brasileira de Ensino de Física, 22, p. 387, 2000.

[11] V. Skumryev, S. Stoyanov, Y. Zhang, G. Hadjipanayis, D. Givord e J. Nogués, Nature, 423, p. 850, 2003.

[12] G. A. Prinz, Physics Today, 48, p. 46, 1995.

[13] J. W. Diggle, T.C. Downie e C. W. Goulding, Chemical Review, 69, p. 365, 1969. 
[14] H. Masuda e K. Fukuda, Science, 268, p. 1466, 1995.

[15] H. Masuda e M. Satoh, Japanese Journal of Applied Physics, 35, p. L126, 1996.

[16] H. Masuda, H. Yamada, M. Satoh, H. Asoh, M. Nakao e T. Tamamura, Applied Physics Letters, 71, p. 2770, 1997.

[17] G. Sauer, G. Brehm, S. Schneider, K. Nielsch, R. B. Wehrspohn, J. Choi, H. Hofmeister e U. Gösele, Journal of Applied Physics, 91, p. 3243, 2002.

[18] A. J. Yin, J. Li, A. J. Bennett e M. Xu, Applied Physics Letters, 79, p. 1039, 2001.

[19] H. L. Seet, X. P. Li, Z. J. Zhao, L. C. Wong, H. M. Zheng e K. S. Lee, Journal of Magnetism and Magnetic Materials, 302, p. 113, 2006.

[20] M. J. Zheng, L. D. Zhang, G. H. Li e W. Z. Shen, Chemical Physics Letters, 363, p. $123,2002$.

[21] G. Schmid, Journal of Materials Chemistry, 12, p. 1231, 2002.

[22] T. Ohgai, X. Hoffer, A. Fábián, L. Gravier e J. P. Ansermet, Journal of Materials Chemistry, 13, p. 2530, 2003.

[23] J. Qin, J. Nogués, M. Mikhaylova, A. Roig, J. S. Muñoz e M. Muhammed, Chemical Materials, 17, p. 1829, 2005.

[24] D. J. Sellmyer, M. Zheng e R. Skomski, Journal of Physics: Condensed Matter, 13, p. R433, 2001.

[25] P. M. Paulus, F. Luis, M. Kröll, G. Schmid e L. J. de Jongh, Journal of Magnetism and Magnetic Materials, 224, p. 180, 2001.

[26] C. G. Wu, H. L. Lin e N. L. Shau, Journal of Solid State Eletrochemistry, 10, p. $198,2006$.

[27] I. D. Mayergoyz, IEEE Transactions on Magnetics, MAG-22(5), p. 603-608, 1986.

[28] I. D. Mayergoyz, Mathematical Models of Hysteresis, Springer-Verlag, Nova York, EUA, 1991. 
[29] D. R. Cornejo e E. Padrón-Hernández, Journal of Magnetism and Magnetic Materials, 316, p. e48, 2007.

[30] C. R. Pike, A. P. Roberts e K. L. Verosub, Journal of Applied Physics, 85, p. 6660, 1999.

[31] M. Vázquez, M. Hernández-Vélez, K. Pirota, A. Asenjo, D. Navas, J. Velázquez, P. Vargas e C. Ramos, European Physical Journal B, 40, p. 489, 2004.

[32] Z. J. Li e K. L. Huang, Journal of the Brazilian Chemical Society, 18, p. 406-409, 2007.

[33] J. C. O’Sullivan e G. C. Wood, Proceedings of the Royal Society of London A, 317, p. 511-543, 1970.

[34] O. Jessensky, F. Müller e U. Gösele, Applied Physics Letters, 72, p. 1173, 1998.

[35] Z. Wu, C. Richter e L. Menon, Journal of Electrochemical Society, 154, p. E8-E12, 2007.

[36] F. Li, L. Zhang e R. M. Metzger, Chemical Materials, 10, p. 2470, 1998.

[37] R. M. Metzger, V. V. Konovalov, M. Sun, T, Xu, G. Zangari, B. Xu, M. Benakli e W. D. Doyle, IEEE Transactions on Magnetics, 36, p. 30, 2000.

[38] Y. Zhao, M. Chen, Y. Zhang, T. Xu e W. Liu, Materials Letters, 59, p. 40, 2005.

[39] M. Vázquez, M. Hernández-Vélez, A. Asenjo, D. Navas, K. Pirota, V. Prida, O. Sánchez e J. L. Baldonedo, Physica B, 384, p. 36-40, 2006.

[40] E. A. Ticianelli e E. R. Gonzalez, Eletroquímica, 2a edição, Edusp, p. 20-31, 2005.

[41] E. P. Hernández, Tese de Doutorado, Departamento de Física, Universidade Federal de Pernambuco, Recife, Brasil, 2009.

[42] K. Nielsch, J. Choi, K. Schwirn, R. B. Wehrspohn e U. Gösele, Nano Letters, 2, p. $677,2002$. 
[43] Y. Henry, A. Iovan, J. M. George e L. Piraux, Physical Review B, 66, p. 184430, 2002.

[44] R. Skomski, H. Zeng, M. Zheng e D. J. Sellmyer, Physical Review B, 62, p. 3900$3904,2000$.

[45] L. P. Carignan, C. Lacroix, A. Ouimet, M. Ciureanu, A. Yelom e D. Ménard, Journal of Applied Physics, 102, p. 23905, 2007.

[46] L. D. Landau e E. Lifshitz, Physikalische Zeitschrift der Sowjetunion, 8, p. 153169, 1935.

[47] W. F. Brown, Micromagnetics, Wiley, Nova York, EUA, 1963.

[48] R. C. O’Handley, Modern Magnetic Materials - Principles and Applications, John Wiley \& Sons Inc., Nova York, EUA, 2000.

[49] E. D. Torre, Physica B, 343, p. 1-9, 2004.

[50] C. A. Ross, M. Hwang, M. Shima, J. Y. Cheng, M. Farhoud, T. A. Savas, H. I. Smith, W. Scwarzacher, F. M. Ross, M. Redjdal e F. B. Humphrey, Physical Review B, 65, 144417, 2002.

[51] E. P. Wohlfarth, Journal of Applied Physics, 29, p. 595, (1958).

[52] J. Geshev e M. Mikhov, Journal of Magnetism and Magnetic Materials, 104-107, p. 1569-1570, 1992.

[53] J. Geshev, M. Mikhov e J. E. Schmidt, Journal of Applied Physics, 85, p. 7321-7327, 1999.

[54] D. Heslop e A. R. Muxworthy, Journal of Magnetism and Magnetic Materials, 288, p. $155,2005$.

[55] C. R. Pike, C. A. Ross, R. T. Scalettar e G. Zimanyi, Physical Review B, 71, p. $134407,2005$. 
[56] M. Vázquez, K. Nielsch, P. Vargas, J, Velázquez, D. Navas, K. Pirota, M. Hernández-Vélez, E. Vogel, J. Cartes, R. B. Wehrspohn e U. Gösele, Physica B, 343, p. 395-402, 2004.

[57] A. Stancu, C. R. Pike, L. Stoleriu, P. Postolache e D. Cimpoesu, Journal of Applied Physics, 93, p. 6620-6622, 2003.

[58] A. P. Roberts, C. R. Pike e K. L. Verosub, Journal of Geophysical Research, 105, p.28461-28475, 2000.

[59] G. Acton, Q. Z. Yin, K. L. Verosub, L. Jovane, A. Roth, B. Jacobsen e D. S. Ebel, Journal of Geophysical Research, 112, p. B03S90, 2007.

[60] H. G. Katzgraber, F. Pázmándi, C. R. Pike, K. Liu, R. T. Scalettar, K. L. Verosub e G. T. Zimányi, Physical Review Letters, 89, p. 257202, 2002.

[61] R. K Dumas, C. P. Li, I. V. Roshchin, I. K. Schuller e K. Liu, Physical Review B, 75, p. $134405,2007$.

[62] G. Bertotti, Hysteresis in Magnetism for Physicists, Material Scientists and Engineers, Academic Press, San Diego, EUA, 1998.

[63] P. G. Bercoff, M. I. Oliva, E. Borclone e H. R. Bertorello, Physica B, 320, p. 291-293, 2002.

[64] M. de Wulf, L. Vandevelde, J. Maes, L. Dupre e J. Melkebeek, IEEE Transactions on Magnetics, 36, p. 3141-3443, 2000.

[65] A. Savitzky e M.J.E. Golay, Analytical Chemistry, 36, p. 1627, 1964.

[66] K. Nielsch, R. B. Wehrspohn, J. Barthel, J. Kirschner, S. F. Fischer, H. Kronmüller, T. Schweinböck, D. Weiss e U. Gösele, Journal of Magnetic and Magnetic Materials, 249, p. 234, 2002.

[67] M. Plihal, D. L. Mills e J. Kirschner, Physical Review Letters, 82, 2579, 1999.

[68] R. Vollmer, M. Etzkorn, P. S. Anil Kumar, H. Ibach e J. Kirschner, Physical Review Letters, 91, p. 147201, 2003. 
[69] H. Ibach, D. Bruchmann, R. Vollmer, M. Etzkorn, P. S. Anil Kumar e J. Kirschner, Review Scientific Instruments, 74, p. 4089, 2003.

[70] H.A. Mook, Spin Waves and Magnetic Excitations, vol. 1, vol.1, editado por A. S. Borovik-Romanov e S. K. Sinha), p. 425-477, Elsevier, Amsterdã, Holanda, 1988.

[71] A. Schreyer, T. Schmitte, R. Siebrecht, P. Bödeker, H. Zabel, S. H. Lee, R. W. Erwin, C. F. Majkrzak, J. Kwo e M. Hong, Journal of Applied Physics, 87, p. 5443, 2000 .

[72] P.A. Grünberg, Progress on Surface Science, 18, p. 1-58, 1985.

[73] B. Hillebrands, Brillouin light scattering from layered magnetic structures, in Topics in Applied Physics, 75, p. 174-289, Springer, Berlim, Alemanha, 2000.

[74] J. F. Cochran, in Ultrathin Magnetic Structures II, editado por B. Heinrich e J. A. C. Bland, Springer-Verlag, Berlim, Alemanha, p. 222-257, 1994.

[75] B. Heinrich, in Ultrathin Magnetic Structures II, editado por B. Heinrich e J. A. C. Bland, Springer-Verlag, Berlim, Alemanha, p. 195-222, 1994.

[76] T. Balashov, A. F. Takács, W. Wulfhekel e J. Kirschner, Physical Review Letters, 97, p. 187201, 2006.

[77] J. Kirschner, Physical Review Letters, 55, p. 973-976, 1985.

[78] J. Kirschner, Polarized Electrons at Surfaces, Springer, Berlim, Alemanha, 1985.

[79] R. Feder, Polarized Electrons in Surface Physics, World Scientific, Cingapura, 1985.

[80] H. Hopster, R. Raue e R. Clauberg, Physical Review Letters, 53, p. 695, 1984.

[81] J. Kirschner, D. Rebenstorff e H. Ibach, Physical Review Letters, 53, p. 698, 1984.

[82] D. Venus e J. Kirschner, Physical Review B, 37, p. 2199, 1988.

[83] M. Etzkorn, Tese de Doutorado, Martin-Luther-Universität, Halle-Wittenberg, Alemanha, 2005. 
[84] W. X. Tang, Y. Zhang, I. Tudosa, J. Prokop, M. Etzkorn e J. Kirschner, Physical Review Letters, 99, p. 87202, 2007.

[85] Y. Zhang, Tese de Doutorado, Martin-Luther Universität, Halle-Wittenberg, Alemanha, 2009.

[86] C. Kittel, Physical Review, 110, p. 836-841, 1958.

[87] S. C. Guerreiro e S. M. Rezende, Revista Brasileira de Física, 1, p. 207-232, 1971.

[88] S. M. Rezende, D. W. Hone e R. M. Toussaint, Physical Review B, 29, p. 16381646, 1984 .

[89] S. M. Rezende, Materiais e Dispositivos Eletrônicos, $2^{\mathrm{a}}$ edição, Ed. Livraria da Física, São Paulo, Brasil, p. 22-23, 2004.

[90] L. Ba e W. S. Li, Journal of Physics D: Applied Physics, 33, p. 2527, 2000.

[91] C. R. Pike, Physical Review B, 68, p. 104424, 2003.

[92] A. R. Muxworthy, D. Heslop e W. Williams, Geophysical Journal International, 158, p. $888,2004$.

[93] C. Rocha, T. R. F. Peixoto e D. R. Cornejo, Journal of Magnetism and Magnetic Materials, 320, p. e275-e278, 2008.

[94] J. E. Davies, J. Wu, C. Leighton e K. Liu, Physical Review B, 72, p. 134419, 2005.

[95] F. Wehland, A. Stancu, P; Rochette, M. J. Dekkers e E. Appel, Physics of the Earth an Planetary Interiors, 153, p. 181, 2005.

[96] J. A. C. Bland, B. Heinrich et al., Ultrathin Magnetic Structures I, Springer-Verlag, Berlim, Alemanha, capítulo 5, p. 177-303, 1994.

[97] C. M. C. Castilho, V. B. Nascimento, E. A. Soares, A. S. C. Esperidião, F. B. Mota e V. E. de Carvalho, Revista Brasileira do Ensino de Física, 27, p. 527-543, 2005.

[98] H. Ibach, Physics of Surfaces and Interfaces, Springer-Verlag, Berlim, Alemanha, 2006. 
[99] W. J. M. de Jonge, P. J. H. Bloemen e F. J. A. den Broeder, in Ultrathin Magnetic Structures I, editado por J. A. C. Bland e B. Heinrich, Springer-Verlag, Berlim, Alemanha, p. 77-78, 1994.

[100] S. D. Bader e J. L. Erskine, in Ultrathin Magnetic Structures II, editado por J. A. C. Bland e B. Heinrich, Springer-Verlag, Berlim, Alemanha, p. 297-305, 1994.

[101] Adriana P. B. Tufaile, Tese de Doutorado, Instituto de Física, Universidade de São Paulo, São Paulo, Brasil, p. 21-38, 2001.

[102] J. O. Jones e P. J. Jennings, Surface Science Reports 9, p. 165-196, 1988.

[103] D. A. Muller, T. Sorsch et al., Nature, 399, 758-761, 1999.

[104] B. Diaconescu, K. Pohl et al., Nature, 448, 57-59, 2007.

[105] S. J. Park e R. E. Palmer, Physical Review Letters, 102, 216805, 2009.

[106] Y. M. Wang e C. Wöll, Surface Science, 603, p. 1589-1599, 2009.

[107] S. Ladas, R. Imbihl e G. Ertl, Surface Science, 280, p. 14-22, 1993.

[108] H. Dietrich, K. Jacobi e G. Ertl, Journal of Chemical Physics, 106, p. 9313-9319, 1997 e Surface Science, 377-379, p. 308-312, 1997.

[109] Ş. C. Bădescu, K. Jacobi et al., Physical Review B, 68, 205401, 2003.

[110] H. Hopster, in Ultrathin Magnetic Structures I, editado por J. A. C. Bland e B. Heinrich, Springer-Verlag, Berlim, Alemanha, p. 123-152, 1994.

[111] P. M. Echenique e J. B. Pendry, Journal of Physics C: Solid State Physics, 11, p. 2065-2075, 1978.

[112] G. Fahsold, M. S. Hammond, J. Kirschner e J. W. Krewer and R. Feder, Solid State Communications, 84, p. 541-544, 1992.

[113] A. B. Schmidt, M. Pickel, T. Allmers, M. Budke, J. Braun, M. Weinelt e M. Donath, Journal of Physics D: Applied Physics, 41, p. 164003, 2008. 
[114] M. Donath, C. Math, M. Pickel, A. B. Schmidt e M. Weinelt, Surface Science, 601, p. 5701-5706, 2007.

[115] L. Petaccia, L. Grill, M. Zangrando e S. Modesti, Physical Review Letters, 82, p. 386389, 1999.

[116] P. Drescher, H. G. Andresen et al., Applied Physics A, 63, p. 203-206, 1996.

[117] Kh. Zakeri, T. R. F. Peixoto, Y. Zhang, J. Prokop e J. Kirschner, Surface Science, 604, p. L1-L3, 2010.

[118] J.-P. Lu, M. R. Albert, S. L. Bernasek e D. J. Dwyer, Surface Science, 215, p. 348-362, 1989 e referências aí contidas; J.-P. Lu, M. R. Albert, C. C. Chang e S. L. Bernasek, Surface Science, 227, p. 317, 1990.

[119] R. Bertacco e F. Ciccacci, Physical Review B, 59, p. 4207, 1999; R. Bertacco, D. Onofrio, F. Ciccacci, Review of Scientific Instruments, 70, p. 3572, 1999.

[120] Y. G. Ptushinskii e B. A. Chuikov, Surface Science, 6, p. 42, 1967; Surface Science, 7, p. 90, 1967; Fizika Tverdogo Tela, 10, p. 772, 1968; N. P. Vas'ko, Y. G. Ptushinskii e B. A. Chuikov, Surface Science, 14, p. 448, 1969.

[121] H. J. Elmers, Int. J. Mod. Phys. B, 9, p. 3115-3180, 1995; M. Pratzer et al., Physical Review Letters, 87, p. 127201, 2001; M. Pratzer and H. J. Elmers, Physical Review B, 67, p. 094416, 2003; U. Gradmann, G. Liu , H. J. Elmers, and M. Przybylski, Hyperfine Interactions, 57, p. 1845, 1990; H. J. Elmers, J. Hauschild, and U. Gradmann, Journal of Magnetism and Magnetic Materials, 221, p. 219, 2000; M. Przybylski and U. Gradmann, Physical Review Letters, 59, 1152, 1987; S. Stankov et al., Physical Review Letters, 99, p. 185501, 2007.

[122] Y. Zhang, P. Buczek, L. Sandratskii, W. X. Tang, J. Prokop, I. Tudosa, T. R. F. Peixoto, Kh. Zakeri e J. Kirschner, Physical Review B, 81, p. 94438, 2010.

[123] M. Getzlaff, J. Bansmann e G. Schönhense, Frenesius' Journal of Analytical Chemistry, 353, p. 743-747, 1995.

[124] D. Tillmann, R. Thiel e E. Kisker, Z. Phys. B: Condensed Matter, 77, p. 1, 1989. 
[125] R. Jungblut, Ch. Roth, F. U. Hillebrecht, E. Kisker, Surface Science, 269/270, p. $615,1992$.

[126] A. Winkelmann, D. Hartung, H. Engelhard, C. T. Chiang e J. Kirschner, Review of Scientific Instruments, 79, p. 83303, 2008.

[127] S. W. Lovesey, Theory of Neutron Scattering from Condensed Matter, Oxford University Press, Nova York, Estados Unidos, p. 56-101, 2003.

[128] V. J. Minkiewicz, G. Shirane e R. Nathans, Physical Review, 162, p. 528, 1967.

[129] G. Kugel, C. Carabatos, B. Hennion, B. Prevot, A. Revcolevschi e D. Tocchetti, Physical Review B, 16, p. 378, 1977.

[130] M. Born e K. Huang, Dynamical Theory of Crystal Lattices, Oxford University Press, New York, Estados Unidos, 1954.

[131] A. T. Costa, R. B. Muniz e D. L. Mills, Physical Review B, 70, p. 54406, 2004.

[132] H. Chiriac, N. Lupu, L. Stoleriu, P. Postolache e A. Stancu, Journal of Magnetism and Magnetic Materials, 316, p. 177, 2007. 


\section{Índice Remissivo}

Éxciton, 54, 66

Buckling, 159

Curling, 119, 159

Exchange-bias, 9

Superexchange, 161

Acoplamento de troca, 32, 36

Adsorvato, 62, 65, 138

AES (Auger Electron Spectroscopy), 58, 63, 140,161

AFM (Atomic Force Microscopy), 23, 77, $93,95,158$

AGM (Alternating Gradient Magnetic), 9

Amortecimento, 66

Analisador

com campo de retardo (RFA), 61

de espelho cilíndrico (CMA), 63

Anisotropia

cúbica, 42

constante de, 30, 32

de forma, 7-9, 23, 26-28, 31, 34, 110, $121,123,135,158-160$

efetiva, $7,23,36,38$

eixo de, 23, 27, 30, 110, 123, 154, 158

energia de, 30

local, 32 magnética, 29, 154

magneto-cristalina, 26-30, 44, 110, 135

perpendicular, 8, 95

uniaxial, $26,31,38$

Anodização, 10

em dois passos, 10

Aproximação adiabática, 155

Aproximação de Born, 61

Armadilha criogênica, 140

Artefato, 70

Assimetria de spin, 69

Auger

efeito, 63

elétron, 63

espectroscopia, 63

Banho eletrolítico, 10

Barkhausen

saltos tipo, 44

BBZ (Bulk Brillouin Zone), 4

Birrefringência circular, 64

Bloch, lei de, 154

BLS (Brillouin Light Scattering), 56, 67

Bomba

iônica, 140

mecânica, 139 
turbomolecular, 140

Born-von Karman

teoria de, 154, 161

Bragg

lei de, 61

plano de, 4

Célula

de efusão (MBE), 58

eletrolítica, 10, 14, 16-18

Camada

tipo barreira, 10

Campo

de inversão, 119

médio, 159

Catálise, 65

Channeltron, 73

Ciência de superfícies, 65

Ciclos internos, 39

CMA (Cylindrical Mirror Analyzer), 63

Coerência

comprimento de, 29, 32, 36, 109, 110

Componente da magnetização

irreversível, 119

reversível, 119

Comprimento

de coerência, 158

de penetração, 72

Comprimento de coerência, 32

Comutador de fase, 64

Condutância, 16

Convolução, 70 filtro de, 52

Curie

temperatura de, 30

Curling, 37, 136

Curva I-V (LEED), 62

Deslocamento

linhas de, 60

redes de, 60

Detector

de spin, 69

Difração de elétrons de baixas energias

$$
\text { (LEED), } 60
$$

Dispersão, 67, 157

Domínio

magnético, 25

parede de, 26

Domínios magnéticos, 31

EELS (Electron Energy Loss Spectroscopy), $56,65,156$

Efeito Kerr magneto-óptico (MOKE), 64

longitudinal, 64

polar, 64

transversal, 64

Eletrólise, 17

Eletrodeposição, 15

$\mathrm{AC}, 20,23,27$

Eletrodo

contra-, 10

de referência, 17, 19, 95

de trabalho, 10, 17 
Energia

ganho de, 66

magnetostática, 36

perda de, 66

Epitaxia por feixe molecular (MBE), 57

Equação

de Landau-Lifshitz, 33

Ertl, Gerhard, 65

Espalhamento

de luz Brillouin (BLS), 56

inelástico de nêutrons, 55

múltiplo, 61

simples, 61

Espectrômetro

analizador, 69

Espectroscopia

de elétrons Auger (AES), 63

de

tunela-

mento de elétrons spin-polarizados (SP-STS), 56

por perda de energia de elétrons spinpolarizados, 3

por perda de energia de elétrons spinpolarizados (SPEELS), 66, 138

Estrutura fina (LEED), 61

Evolução de hidrogênio, 13

Excitações

de Stoner, 56, 66, 69, 148, 154, 161

elementares, 54, 138

Fônon, 4, 54, 55, 66, 68, 161

Feixe de átomos, 58

de íons, 58

de elétrons, 60, 63, 66

eletrônico, 69

luminoso, 64, 65

molecular, 140

primário, 61, 62, 66

Fermi

nível de, 65, 72, 161

Filme

ultrafino, 67

FMR (Ferromagnetic Resonance), 56, 67, 68

FORC

análise, 3, 4, 6, 9, 43, 46, 53, 111, 133

diagrama, 4, 45, 46, 49, 111-113, 121, 123, 133, 135

distribuição, 45, 47, 49, 52, 53, 111, 113, 121, 123, 133, 136

FORC (First-Order Reversal Curve), 4, 9, 39, 40, 43, 45, 46, 49, 77, 112, 113, $119,136,158-160$

Grão

contorno de, 32, 33, 110

cristalino, 22, 23, 26, 28, 32, 38, 108, 121, 135

magnético, 110, 121

monodomínio, 23, 110

multidomínio, 23

superficial, 90, 102 
tamanho de, 22, 23, 26, 28, 32, 46, 108110, 121, 135, 136

Heisenberg, modelo de, 154, 161

Henkel

curvas de, 46

Heteroestrutura, 6

Hibridização, 55

HREELS (High Resolution Electron Energy Loss Spectroscopy), 65

INS (Inelastic Neutron Scattering), 55, 161

Interação

de troca, 70, 135, 154, 158

desmagnetizante, 159

dipolar, 48, 159

mágnon-fônon, 57

spin-órbita, 70

Zeeman, 36

Interdifusão, 58

Interferômetro

de Fabry-Pérot, 68

Interpolação, 50

Inversão

da magnetização, 43

temporal, 64

Ising

modelo de, 46

Junção-túnel magnética, 55

Kink, 60

Landau-Lifshitz equação de, 36

Laue

lei de, 61

LEED (Low Energy Electron Diffraction), $60,63,65,140,161$

Lei

de Kryder, 7

de Moore, 7

Livre caminho médio, 60, 63, 65

Mágnon, 4, 54-56, 66-70, 148, 151, 154, 157, 161, 162

-fônon, 161, 162

Magnetometria, 9

MBE (Molecular Beam Epitaxy), 57, 58, 140,141

MET (Microscopia Eletrônica de Transmissão), 23

MEV (Microscopia Eletrônica de Varredura), 23, 158

MFM (Magnetic Force Microscopy), 23, 77, 93, 158

MFM (Magnetic force Microscopy), 25, 93

Microscopia

de força atômica (AFM), 23, 77, 93

de força magnética (MFM), 23, 77, 93

eletrônica de transmissão (MET), 23

eletrônica de varredura (MEV), 23, 77

Modelagem micromagnética, 29, 46

Modo

de crescimento de filmes, 58, 59

Frank-van der Merve, 59 
Stransky-Krastanov, 59, 60

Vollmer-Weber, 59

de inversão da magnetização, 45, 119, 121, 123, 159

não-uniforme, 110, 119, 136

magnetostático, 152

misto (mágnon-fônon), 161

ressonante de fônons, 157

Modos magnetostáticos, 67

Modos vibracionais, 65, 138

MOKE (Magneto-Optic Kerr Effect), 64, 65, 140, 146, 161

Monodomínio, 34, 135, 158

Monte Carlo

simulação de, 46

Multicamada, 67

Multidomínio, 34

Nanociência, 2

Nanoestruturas, 34

Nanotecnologia, 2

Nobel

prêmio, 65

Nucleação, 119

Onda

eletromagnética, 55

onda

função de, 64

Ondas

de Rayleigh, 157

Paleomagnetismo, 46
Parâmetro de rede, 56

Permissividade elétrica

tensor, 64

$\mathrm{pH}, 10,15,16,22,102$

Plásmon, 66

Plano de incidência, 64

Poláriton, 54

Polarização, 64, 69

$$
\sigma^{+}, 73
$$

$\sigma^{-}, 73$

catódica, 17

circular (da luz), 64

de spin, 64, 66, 68, 73

eixo de, 73

Policristalino, 26-28, 34, 46, 109, 135, 158

Potencial de redução, 17

Pré-vácuo, 140

Preisach

distribuição de, 119

modelo de, 9, 43, 46, 77

Quantização

direção de, 66, 68

Quasipartículas, 66, 68

RAMAC, 7

Razão de aspecto, 34, 77, 158

Reconstrução, 60, 62

Regra de seleção, 70

Relaxação, 60

Remanência

desmagnetizante ou recuperada, 40 
magnetizante ou isotérmica, 39

Ressonância ferromagnética (FMR), 56

RFA (Retarding Field Analyzer), 61, 63

RHEED (Reflection High Energy Electron Diffraction, 58

Rotação coerente, 36

Savitzky-Golay

método de convolução de, 52

SBZ (Surface Brillouin Zone), 4, 56, 66, 148, 150-152, 157, 160

Secção de choque de espalhamento, 68, 70

Simetria

quebra de, 36,55

Solubilidade, 10

SP-STS (Spin-Polarized Scanning Tunneling Spectroscopy), 56

SPEELS (Spin-Polarized Electron Energy Loss Spectroscopy), 3, 4, 55-57, 6668, 73, 74, 138-140, 146, 148, 149, 151, 157, 160-162

Spin, 1

momento angular de, 1, 2 ondas de, 4, 5, 55-57, 66, 67, 69, 151, $152,154,157,161,162$

válvula de, 55

Spintrônica, 2

SQUID (Superconducting Quantum Interference Device), 9, 40, 53, 77, 110

Stoner-Wohlfarth sistema de, 40, 46

Super-rede, 62, 67
Superestrutura, 62

Teoria

cinemática (LEED), 61 dinâmica (LEED), 61

Terraço, 60

Transição de fase, 37

UHV (Ultra-High Vacuum), 4, 57, 63, 138140, 146

Vácuo criogênico, 140 ultra alto (UHV), 138

Vórtice, 34

Vidro de spin, 46

Voltametria cíclica, 17

Voltamograma, 18

VSM (Vibrating Sample Magnetometer), 9, $53,77,123$

Wood notação de, 62

XRD (X-Ray Diffraction), 77, 158

\section{Zeeman} efeito, 33

Zona de Brillouin, 56, 67 de superfície, 4, 56 